\title{
SINGLE-SITE SALEN AND SALAN ALUMINUM \\ COMPLEXES FOR THE STEREOSELECTIVE \\ POLYMERIZATION OF LACTIDES
}

\author{
PROEFSCHRIFT \\ ter verkrijging van \\ de graad van doctor aan de Universiteit Twente, \\ op gezag van de rector magnificus, \\ prof. dr. H. Brinksma, \\ volgens besluit van het College voor Promoties \\ in het openbaar te verdedigen \\ op donderdag 3 september 2009 om 13.15 uur
}

door

\section{Hongzhi Du}

geboren op 15 september 1981

te Maanshan, China 
Dit proefschrift is goedgekeurd door:

Promotor: prof. dr. J. Feijen

Promotor: prof. dr. X. Chen

Assistent promotor: dr. P.J. Dijkstra 
dedicated to all the people who love and support me! 
This research described in this thesis was financially supported by the CAS-KNAW joint training Ph.D. program (06PhD09).

Single-Site Salen and Salan Aluminum Complexes for the Stereoselective Polymerization of Lactides.

Ph.D. Thesis with references; summary in English and Dutch.

University of Twente, Enschede, the Netherlands

ISBN 978-90-365-2862-7

Copyright (C) 2009 Hongzhi Du

All rights reserved.

Printed by Ipskamp Drukkers B.V., Enschede, the Netherlands, 2009 


\section{Contents}

Chapter 1 General Introduction 1

Chapter 2 Catalysts for Stereoselective Ring-Opening 7

Polymerization of Lactides

$\begin{array}{ll}\text { Chapter } 3 & \text { Synthesis and Characterization of Achiral } \\ \text { Bis(salicylidene) Schiff Base Aluminum Compounds }\end{array}$

Chapter 4 rac-Lactide Polymerization using Achiral

Chapter 5 Stereoselective Polymerization of Lactides using Bis(pyrrolidene) Schiff Base Aluminum Complexes

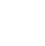




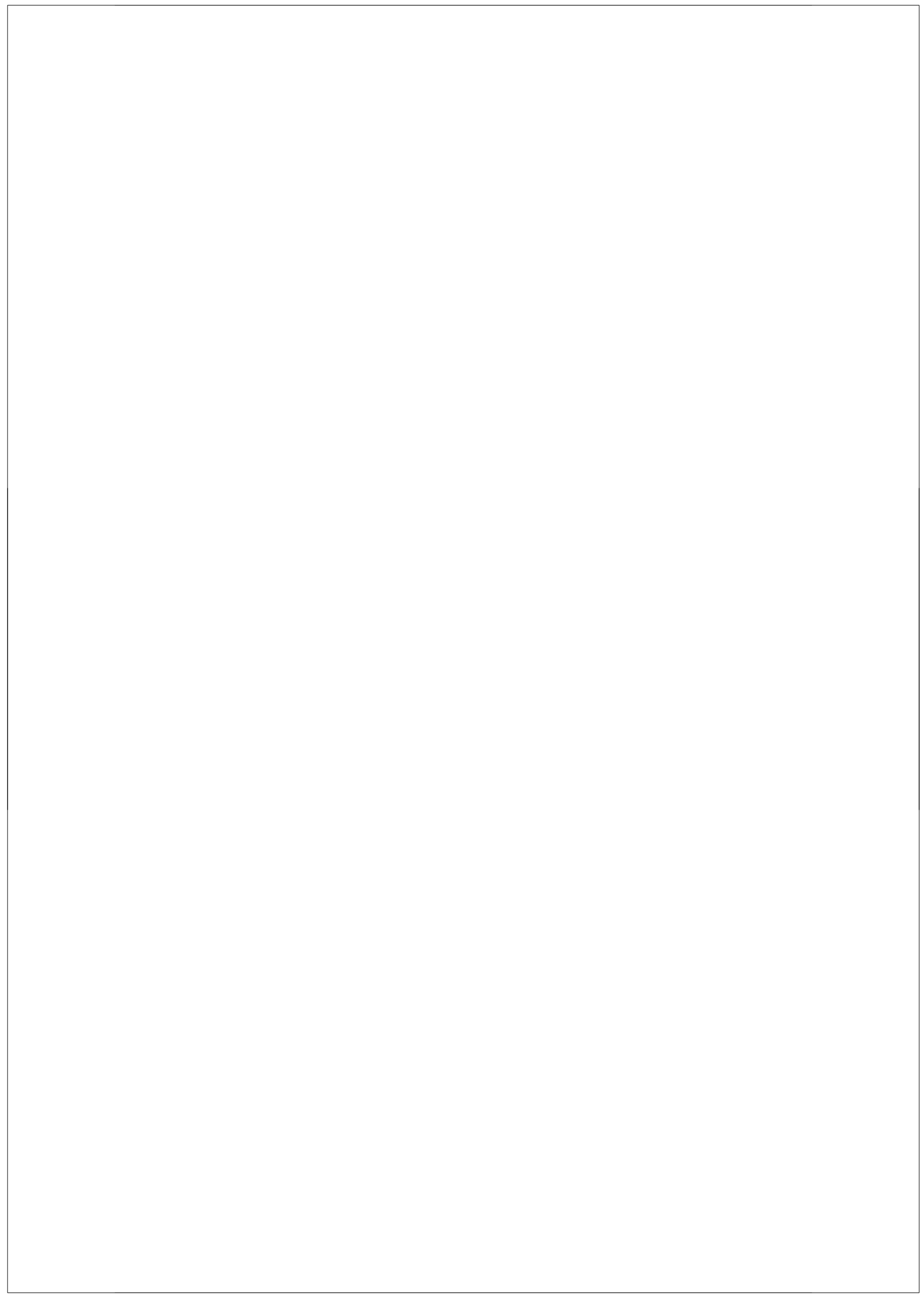




\section{1}

\section{General Introduction}

\section{Stereochemistry of Poly(lactide)s}

Poly(lactic acid) (PLA) is the most well known biodegradable and biocompatible material among the aliphatic polyesters nowadays explored for biomedical, pharmaceutical and environmental applications. ${ }^{1}$ Poly(lactic acid)s are generally synthesized by the ring-opening polymerization (ROP) of lactide (LA), the cyclic dimer of lactic acid. Due to the presence of two chiral centers in the lactide monomer, different lactide stereoisomers are distinguished, namely $(S, S)$-LA (L-LA), $(R, R)$-LA (D-LA), and $(R, S)$-LA (meso-LA). The stereochemistry of the monomeric units in the polymer chains plays an important role in the mechanical, physical and degradation properties of PLA materials. Highly stereoregular $(S, S)$-PLA and $(R, R)$-PLA are crystalline polymers, with a high melting temperature and good mechanical strength. ${ }^{2}$ Atactic PLA's with a random placement of $S$ - and $R$-LA units in the polymer chains are amorphous and brittle materials. Due to the crystallinity of stereoregular PLAs these materials slowly degrade in a physiological environment, whereas atactic PLA materials degrade much faster. ${ }^{3}$

\section{History and Perspectives}

The synthesis of stereoregular PLA materials starting from a racemic mixture of $(S, S)$ and $(R, R)$-LA, referred to as rac-LA, can be traced back to 1996 by the pioneering studies of Spassky and coworkers. ${ }^{4}$ They showed that an enantiomeric pure Schiff base aluminum alkoxide catalyst-initiator preferably polymerized $(S, S)$-LA over $(R, R)$-LA from $r a c$-LA, leading to an isotactic type PLA material with a gradient of $S$ - and $R$ - LA units in the polymer chains. 
Since then, many research groups have explored the field of stereoselective polymerization of lactide, and many single-site metal catalyst-initiators have been developed and exploited to produce stereoregular PLA's. Three metal catalyst-initiator systems have been demonstrated to exhibit unique stereocontrol in lactide polymerization. Schiff base catalyst-initiator systems based on a five-coordinated central aluminum atom were studied most intensively. These systems afforded the synthesis of highly isotactic PLA from rac-LA and highly syndiotactic PLA from meso-LA. A second system is based on $\beta$-diiminate catalyst-initiators having a central zinc atom. These exhibit an excellent syndiotactic control in rac-LA polymerization. A third system is the group of amine bis(phenolate) catalyst-initiators which are based on rare earth metal atoms. It was discovered that these systems have a unique heterotactic control in rac-LA polymerization. So far, highly isotactic PLA materials with tacticities up to 0.98 were prepared by Nomura and coworkers, ${ }^{5}$ a highly syndiotactic PLA with a tacticity up to 0.96 was synthesized by Coates and coworkers, ${ }^{6}$ and a highly heterotactic material with a tacticity of 0.99 was reported by Cui and coworkers. $^{7}$

Although much progress has been made in the preparation of highly stereoregular PLA materials, there are still three items to be further investigated: (1) highly stereoselective initiators that can be applied in lactide polymerization at high temperatures to meet the requirements of industrial production; (2) catalyst-initiators that combine a high stereoselectivity and a high activity, which could furnish PLA materials with a high tacticity and, a controlled molecular weight after a relatively short reaction time; (3) the mechanism of the stereoselective polymerization of lactide still is not fully understood and should be further investigated to design optimized novel catalyst-initiators in the future.

\section{Survey of the Thesis}

The research described in this thesis is focused on the design and application of five-coordinated, single-site aluminum catalyst-initiator systems for the controlled and 
stereoselective ROP of lactides. So far, achiral and chiral bis(salicylidene) Schiff base aluminum catalyst-initiators have been reported to afford stereoregular, especially isotactic PLA materials. However, there are no studies which have demonstrated a clear relationship between the molecular structure of the catalyst and its polymerization behavior. In this respect, the first chapters of this thesis are related to the synthesis and characterization of a series of achiral bis(salicylidene) Schiff base aluminum complexes having different substitutent's at the phenolate rings, as well as diimine bridges with different lengths and rigidity. Of great interest is the relationship between the structure of these complexes and their catalytic behavior toward rac-LA polymerization. ${ }^{8}$ This allows the design of novel aluminum initiators that have high activity and/or high stereoselectivity.

To expand our studies on achiral Schiff base aluminum initiators, novel five-coordinated aluminum complexes stabilized by an achiral bis(pyrrolidene) Schiff base ligand framework were prepared. ${ }^{9}$ Compared to the traditional substituted-salicylaldehyde Schiff base aluminum catalysts, these catalysts have a tetradentate $N, N, N, N$-coordination mode, and thus, a different complex geometry. These catalysts provide a controlled polymerization as well as stereocontrol in the solution polymerization of lactide and turned out to be the most active among the aluminum alkoxide initiator systems.

Finally, the third theme of this thesis is concerned with novel five-coordinated chiral salan aluminum ethyls which were developed based on our previous work on Jacobsen Schiff base aluminum isopropoxides. ${ }^{10}$ It was shown that each of the salan aluminum systems contains two species with different configurations due to different wrapping modes of the chiral salan ligands in the aluminum ethyl complexes. In the presence of 2-propanol as an initiator, these chiral salan aluminum ethyls are active catalyst in lactide polymerization. The polymerization data including detailed kinetics and microstructural analysis of the resultant polymers supplied firm evidence that lactide polymerization with these systems may take place via an enantiomorphic site-control mechanism as well as a chain-end-control mechanism. Novel four-coordinated, bis(triphenylsilanoxy) aluminum structures were also prepared but turned out to be not 
active in lactide polymerization.

\section{Outline of this Thesis:}

Chapter 2 gives an overview of recent advances in the design of organometallic single-site catalysts for the stereoselective ROP of rac- and meso-LA.

In Chapter 3 the synthesis and molecular structures of a series of achiral bis(salicylidene) Schiff base aluminum ethyls and isopropoxides are described. These aluminum complexes have an $N, N, O, O$-tetradentate bis(salicylidene) Schiff base ligand framework. X-ray diffraction analysis of single crystals and ${ }^{1} \mathrm{H}$ NMR experiments of the aluminum complexes in solution were performed to study the presence of monomeric and dimeric forms of these catalyst-initiators.

The activity and the stereoselectivity of a series of in situ-formed aluminum isopropoxides, comprising the $\mathrm{N}, \mathrm{N}, \mathrm{O}, \mathrm{O}$-tetradentate bis(salicylidene) Schiff base ligand framework as described above, toward the ROP of rac-lactide are described in Chapter 4. The effect of substituents on the phenolic rings and the rigidity of the diimine bridge on the rate of the polymerization as well as the tacticity of the polymers isolated was studied.

In chapter $\mathbf{5}$ we describe a series of aluminum ethyls and isopropoxides based upon a bis(pyrrolidene) Schiff base ligand framework. NMR studies were performed to elucidate the structure of the complexes in solution. The aluminum ethyls were used as catalysts in the presence of 2-propanol as an initiator in rac- and meso-LA polymerization in toluene to test their activities and stereoselectivities.

Chapter 6 is directed to the synthesis and molecular structure determination of a series of chiral salan aluminum ethyls. These chiral salan aluminum ethyls were applied in the ROP of rac- and meso-LA. The polymerization kinetics and stereoselectivity in relation to the catalyst structure are reported. 


\section{REFERENCES AND NOTES}

[1] Lenz, R. W. Adv. Polym. Sci., 1993, 107, 1.

[2] Krouse, S. A.; Schrock, R. R.; Cohen, R. E. Macromolecules 1987, 20, 904-906.

[3] Belbella, A.; Vauthier, C.; Fessi, H.; Devissaguet, J. P.; Puisieux, F. Int. J. Pharm., 1996, 129, 95-102.

[4] Spassky, N.; Wisniewski, M.; Pluta, C.; LeBorgne, A. Macromol. Chem. Phys. 1996, 197, 2627-2637.

[5] Nomura, N.; Ishii, R.; Yamamoto, Y.; Kondo, T. Chem. Eur. J., 2007, 13, 4433-4451.

[6] Ovitt, T. M.; Coates, G. W.; J. Am. Chem. Soc. 2002, 124, 1316-1326.

[7] Liu, X.; Shang, X.; Tang, T.; Hu, N.; Pei, F.; Cui, D.; Chen, X.; Jing, X. Organometallics 2007, 26, 2747-2757.

[8] Du, H.; Pang, X.; Yu, H.; Zhuang, X.; Chen, X.; Cui, D.; Wang, X.; Jing, X. Macromolecules 2007, 40, 1904-1913.

[9] Du, H.; Velders, A. H.; Dijkstra, P. J.; Zhong, Z.; Chen, X.; Feijen, J. Macromolecules 2009, 42, 1058-1066.

[10] Du, H.; Velders, A. H.; Dijkstra, P. J.; Sun, J.; Zhong, Z.; Chen, X.; Feijen, J. in press Chem. Eur. J.. 


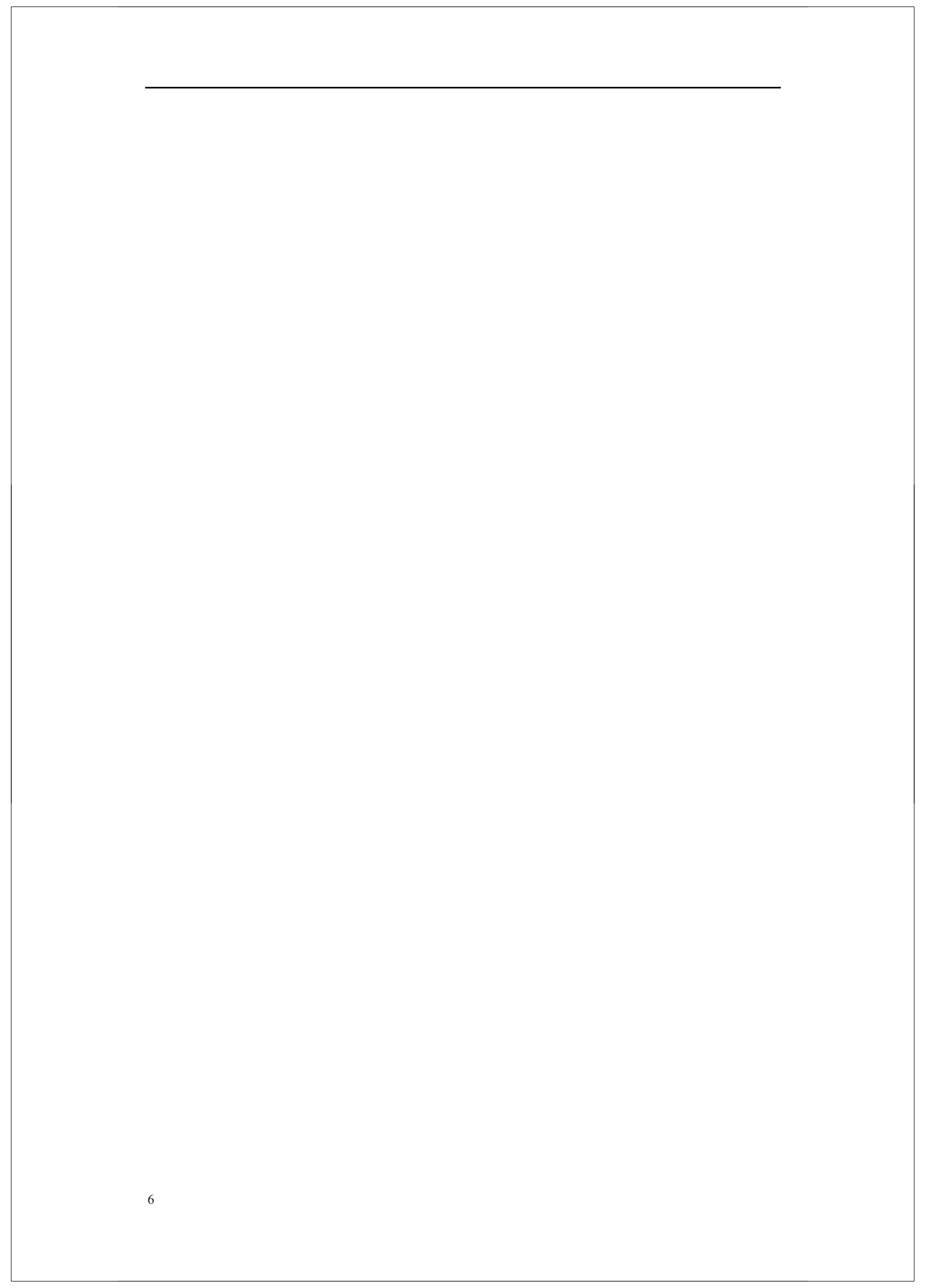




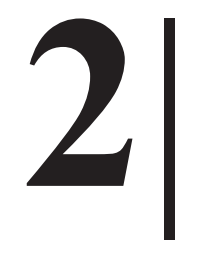

\section{Catalysts for Stereoselective Ring-Opening Polymerization of Lactides}

\section{Introduction}

Polymeric materials derived from petrochemical feedstocks are widely used nowadays. However, these petrochemical resources will arguably be consumed in the near future. Thus, there is an urgent need to develop new polymeric materials using renewable resources. The production and utilization of biodegradable aliphatic polyesters, such as poly(lactic acid)s (PLAs), have been developed recently to meet this requirement. The most straightforward methods to prepare PLAs are (1) the polycondensation of lactic acid and (2) the ring-opening polymerization (ROP) of lactide. It seems that polycondensation of lactic acid is the commercially most attractive route to prepare PLAs. However, condensation polymerization to form PLAs is hampered by the typical limitations of step polymerization, like the difficulty in obtaining polymers with sufficiently high molecular weights. Since esterification reactions are equilibrium processes in a condensation polymerization, it is necessary to drive the polymerization by the removal of water to achieve high degrees of polymerization. The ROP of lactide circumvents this disadvantage and is the method nowadays used to prepare PLAs.

\section{Ring-Opening Polymerization of Lactide}

Lactide, which is a cyclic dimer of lactic acid, is produced by the thermal degradation of poly(lactic acid) oligomers. A catalyst is required for the ROP of lactide. Different metal complexes can be applied in the ROP of lactide. Depending on the catalyst used, different mechanisms are involved, such as a cationic, ${ }^{1-4}$ anionic, $^{5-8}$ or coordination-insertion mechanism. ${ }^{9}$ It is very difficult to obtain PLA materials with 
high molecular weights by using metal complexes which act via a cationic mechanism in the ROP of lactide. ${ }^{10}$ Moreover, the ROP of lactide following an anionic mechanism usually leads to problems in controlling the molecular weight and molecular weight distribution of the PLA product, which is mainly caused by side reactions such as epimerization, chain termination, and inter-/intra-molecular transesterification reactions. ${ }^{11}$ Therefore, the study of metal complexes that catalyze lactide polymerization via a coordination-insertion mechanism has become an important topic.

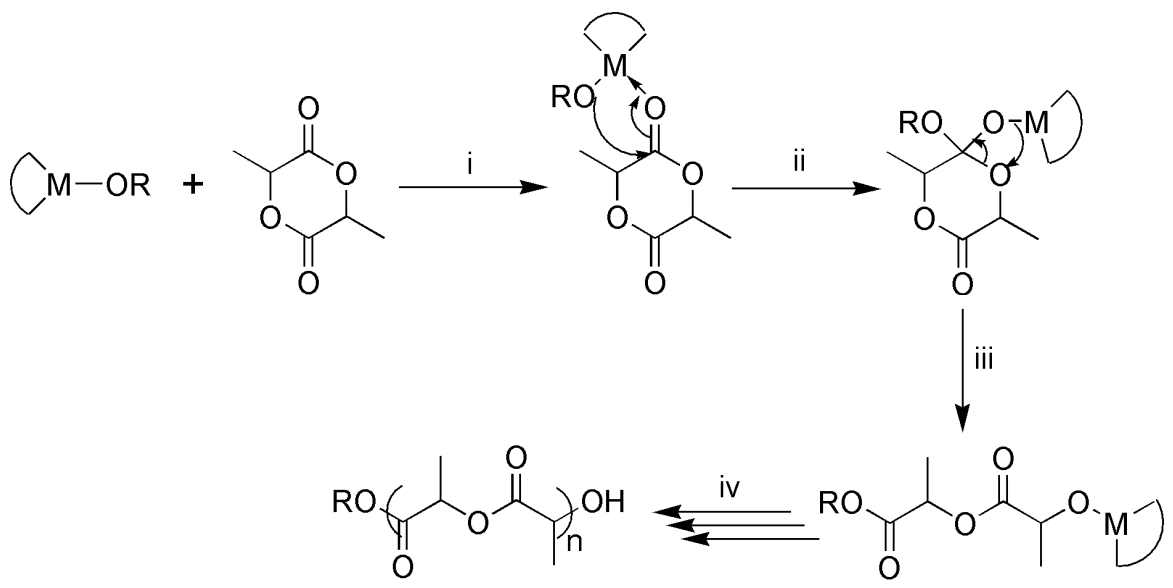

Figure 2.1 Proposed mechanism of a coordination-insertion mechanism in the ROP of lactide.

Metal alkoxides are known to catalyze the ROP of lactide via a coordination-insertion mechanism, which involves four steps as depicted in Figure 2.1 (i) coordination of the lactide monomer to the Lewis-acid metal center, (ii) the lactide monomer inserts into one of the metal-alkoxide bonds via nucleophilic addition, (iii) ring-opening of the lactide monomer via acyl-oxygen cleavage, (iv) continuous insertion of lactide monomers. Finally termination of the polymerization reaction by hydrolysis of the active propagation chain is performed before isolation of the PLA material. 


\title{
Multivalent Metal Alkoxides
}

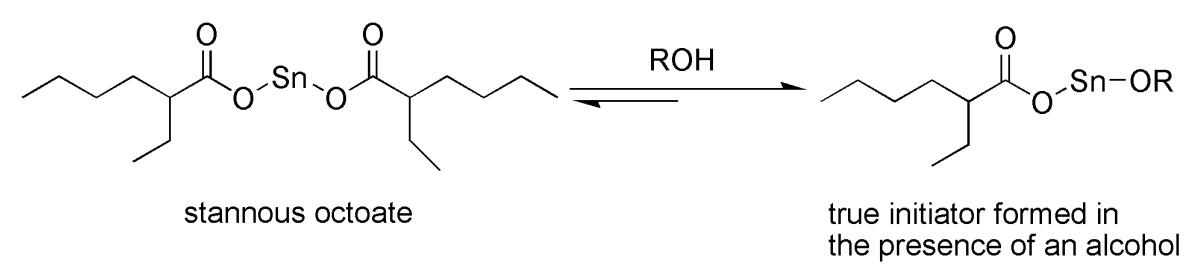

Figure 2.2 Structures for the true initiator of $\mathrm{Sn}(\mathrm{Oct})_{2}$ formed in the presence of protic reagents.

The most widely used catalyst for the industrial production of PLA materials is undoubtedly tin(II) bis(2-ethylhexanoate), usually referred to as tin(II)octanoate or $\mathrm{Sn}(\mathrm{Oct})_{2}$. The mechanism of the ROP of lactones and lactides catalyzed by $\mathrm{Sn}(\mathrm{Oct})_{2}$ has been a research subject for many years. Now it is generally accepted that protic reagents such as alcohols, or even impurities such as lactic acid present in the monomer may act as co-initiators ${ }^{12-14}$ (Figure 2.2). Tin(II) alkoxides will be generated from the reaction between $\mathrm{Sn}(\mathrm{Oct})_{2}$ and the protic reagents in the initiation step, and act as the true active species to initiate the ROP of lactides.

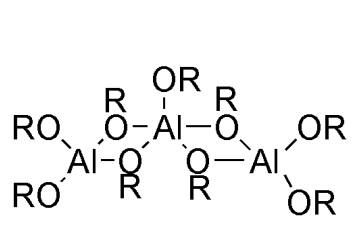

$\mathrm{A}_{3}$

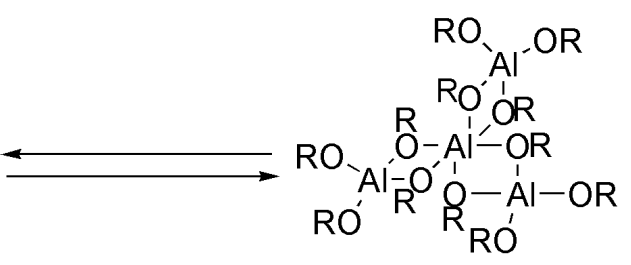

$\mathrm{A}_{4}$

$$
\mathrm{R}=\mathrm{CH}\left(\mathrm{CH}_{3}\right)_{2}
$$

Figure 2.3 Equilibrium between the tetramer and trimer of $\mathrm{Al}\left(\mathrm{O}^{\mathrm{i}} \mathrm{Pr}\right)_{3}$.

\begin{abstract}
Aluminum alkoxides have also been proven to be efficient initiator/catalysts for the ROP of lactide. ${ }^{15-17}$ The aluminum isopropoxide, $\mathrm{Al}\left(\mathrm{O}^{\mathrm{i}} \mathrm{Pr}\right)_{3}$, turned out to be remarkably less active than $\mathrm{Sn}(\mathrm{Oct})_{2}$. Moreover, an induction period of a few minutes is observed when applying $\mathrm{Al}\left(\mathrm{O}^{\mathrm{i}} \mathrm{Pr}\right)_{3}$ as an initiator in lactide polymerization. This feature was attributed to the presence of an equilibrium between the tetramer $\left(\mathrm{A}_{4}\right)$ and
\end{abstract}


the trimer $\left(\mathrm{A}_{3}\right)$ (Figure 2.3), of which $\mathrm{A}_{3}$ was demonstrated to be more reactive than $\mathrm{A}_{4}{ }^{18}$

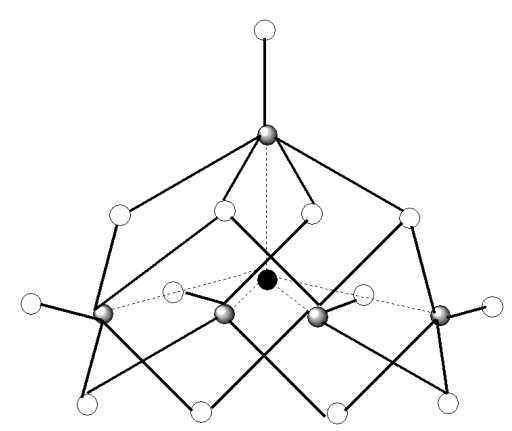

Figure 2.4 Core structure of $\mathrm{Fe}_{5}(\mu-\mathrm{O})(\mathrm{OEt})_{13}$ or $\mathrm{Y}_{5}(\mu-\mathrm{O})\left(\mathrm{O}^{\mathrm{i}} \mathrm{Pr}\right)_{13}$. Metal atoms are presented by grey circles and oxygen atoms by white circles. The black circle in the center represents the $\mu-5$ oxygen atom connecting to all the metal atoms. All other atoms are left out for clarity.

Homoleptic metal alkoxide clusters were also studied in lactide polymerization. Feijen and coworkers ${ }^{19}$ have reported that $\mathrm{Y}_{5}(\mu-\mathrm{O})\left(\mathrm{O}^{\mathrm{i}} \mathrm{Pr}\right)_{13}$, with a core structure shown in Figure 2.4, has a remarkable activity in $(S, S)$-LA polymerization, and a non-linear relationship between the apparent propagation rate and the cluster concentration is present, which is an indication that the propagating chains aggregate in the solution. Tolman and coworkers ${ }^{20}$ reported that $\mathrm{Fe}_{5}(\mu-\mathrm{O})(\mathrm{OEt})_{13}$, having an analogous cluster structure, displayed very high rates and excellent molecular weight control in lactide polymerization.

Although these metal alkoxides were proven to be efficient catalyst-initiators for the ROP of lactide, control of molecular weight is sometimes complicated by the clustered form of the active species. Molecular weight distributions will be broadened when more than one growing chain is connected to one metallic center. For these reasons, well-defined single-site catalysts have been designed and exploited in lactide polymerization. 


\section{Single-Site Metal Catalysts for Stereoselective Polymerization of Lactide}

The last two decades have witnessed a tremendous development of single-site metal catalysts in the synthesis of polyolefins ${ }^{21}$ and polyesters. These single-site catalysts have a general formula of $L_{\mathrm{n}} \mathrm{MR}$, where $\mathrm{M}$ is a central metal atom surrounded by an ancillary ligand $\mathrm{Ln}$. The steric and electronic properties of the ligand adjust the bonding of the metal center to the ligand, and therefore, influence the activity and stereoselectivity of the catalyst. $\mathrm{R}$ is the initiating group, which also affects the polymerization activity of the complexes. It is possible, by employing appropriate combinations of $L_{\mathrm{n}}$ with $\mathrm{M}$ and $\mathrm{R}$, to generate efficient catalysts which can precisely control the polymerization rate, molecular weight, molecular weight distribution, comonomer incorporation, and even polymer stereochemistry in lactide polymerization. Spassky and coworkers $^{22}$ were the first to discover that ( $R$-SalBinap)AlOMe induced a highly stereocontrolled polymerization of rac-LA, to form isotactic and crystalline PLAs with a higher melting temperature $\left(T_{\mathrm{m}}\right)$ than that of optically pure $(S, S)$-PLA or $(R, R)$-PLA. Since that time it was demonstrated that, single-site metal alkoxides supported by various kinds of auxiliary ligand frameworks have unique advantages in carrying out well-controlled and in certain cases stereoselective polymerization of lactides.

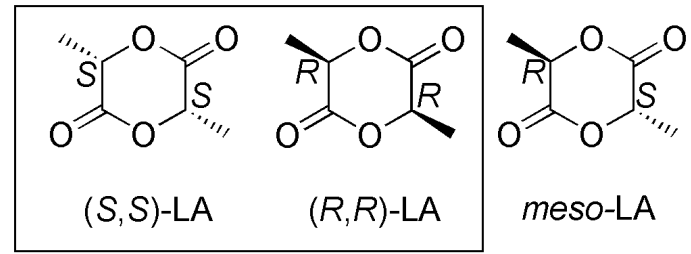

$1: 1$ mixture is named rac-LA

Figure 2.5 Structures of lactide stereo-isomers.

Because there are two stereogenic centers in one lactide molecule, different stereo-isomers of lactide are distinguished, $(S, S)$-LA, $(R, R)$-LA, and meso-LA (Figure 2.5). An equivalent mixture of $(S, S)$-LA and $(R, R)$-LA is referred to as rac-LA. The 
alignment of $R$ and $S$ stereogenic centers in different modes along the polymer chain

(Figure 2.6) determines the mechanical and physical properties of the PLA materials.<smiles>CC(C)OC(=O)OC1COC2(C)CC(C1)O2</smiles>

Isotactic<smiles>CCOC(=O)COC(=O)C(C)OC(=O)C(C)OC(=O)C(C)OC(=O)OC(C)C</smiles>

Heterotactic

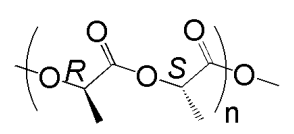

Syndiotactic Isotactic stereoblock

Figure 2.6 Structures of stereoregular PLA materials.

Stereoregular PLA materials can be prepared from rac- or meso-LA by using a variety of single-site metal complexes, which function via two different mechanisms (i) a chain-end-control mechanism, where the configuration of the next inserted monomer in rac-LA polymerization or the cleavage site of the monomer in meso-LA polymerization is determined by the stereogenic center in the last repeating unit along the propagating chain. If the stereogenic center in the last unit favors a meso-enchainment, isotactic PLA is obtained from rac-LA and heterotactic PLA will be obtained by using meso-LA. However, if the stereogenic center in the last unit favors a racemic-enchainment, hetereotactic PLA will be obtained from rac-LA and syndiotactic PLA from meso-LA; (ii) an enantiomorphic site-control mechanism, where the configuration of the inserted monomer in rac-LA polymerization or the cleavage site of the monomer in meso-LA polymerization is determined by the configuration of the surrounding ligand. Thus, in the lactide polymerization following an enantiomorphic site control mechanism, only isotactic or syndiotactic PLA can be obtained from $r a c$ - or meso-LA, respectively. 


\section{Formation of Isotactic/Stereoblock PLAs from rac-LA.}

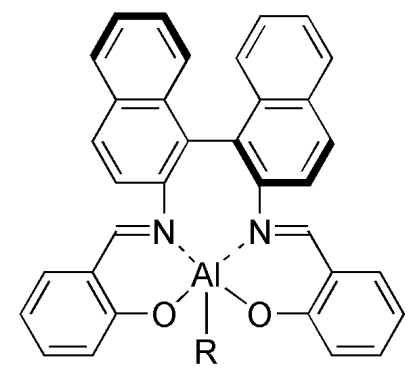

$\mathrm{R}=\mathrm{OMe}, \mathbf{1} ; \mathrm{O}^{\mathrm{P}} \mathrm{Pr}, \mathbf{2}$

The most important breakthrough in the field of stereoselective polymerization of lactide was made by Spassky and co-workers. ${ }^{22}$ They discovered that in a rac-LA polymerization carried out at $70{ }^{\circ} \mathrm{C}$ initiated by the enantiomerically pure Schiff base aluminum methoxide $(R, R)-\mathbf{1}$, the polymerization rate of $(R, R)$-LA is 19 times higher than that of $(S, S)$-LA. A living polymerization occurred as shown by the narrow molecular weight distributions of the polymers obtained. At conversions less than $50 \%$, the polymer microstructure was predominantly isotactic, in this case (R)-PLA. At conversions higher than $60 \%$, only $(S, S)$-LA remained. The reaction reached $100 \%$ conversion very slowly due to the fact that the polymerization rate of $(S, S)$-LA is much lower than that of $(R, R)$-LA. The resulting PLA had a tapered stereoblock microstructure, in which the stereoblock distribution was changing from all $(R, R)$-units to all (S,S)-units over the polymer chain (Figure 2.7). This material exhibited a $T_{\mathrm{m}}$ of $187^{\circ} \mathrm{C}$, higher than that of the enantiopure isotactic $(S)$-PLA or $(R)$-PLA, which have $T_{\mathrm{m}} \mathrm{S}$ in between 170 and $180^{\circ} \mathrm{C}$.

\section{- $(R R R R R R R R)(S S)(R R R R R R)(S S S S)(R R R R)(S S S S S S)(R R)(S S S S S S S S)$ -}

Figure 2.7 Schematic structure of tapered isotactic PLA.

Coates and coworkers ${ }^{23,24}$ discovered the presence of a bimetallic side product when preparing 1. In order to eliminate the formation of this bimetallic side product, they 
prepared compound $\mathbf{2}$ with an isopropoxide group connected to the central aluminum. They reported that the polymerization of $r a c$-LA using $r a c-2$ at $70{ }^{\circ} \mathrm{C}$ gave a stereoblock PLA material with a $T_{\mathrm{m}}$ of $179{ }^{\circ} \mathrm{C}$. Inspecting the methine region of the homonuclear decoupled ${ }^{1} \mathrm{H}$ NMR spectrum of the resulting polymer revealed that the PLA is not a stereocomplex formed between enantiomerically pure strands of isotactic $(S, S)$-PLA and $(R, R)$-PLA previously reported by Baker. ${ }^{25}$ Instead, the true structure of the resulting PLA is a stereoblock copolymer.

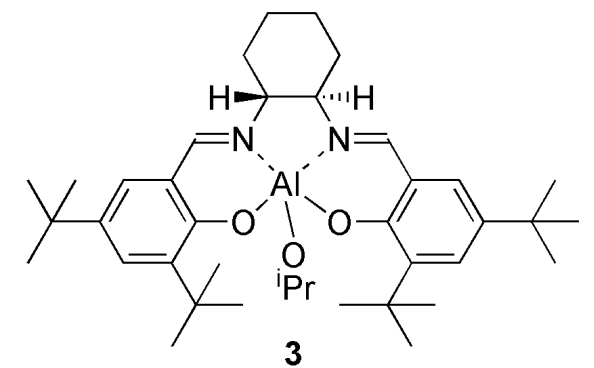

Schiff base aluminum isopropoxides $(R, R)-\mathbf{3}$ and rac-3 prepared from the commercially available Jacobsen ligand were reported by Feijen and co-workers. ${ }^{26,27}$ It was demonstrated that $(R, R)-\mathbf{3}$ has a moderate activity in rac-LA polymerization. Unlike $(R, R)-1$ which exhibits a 20:1 preference for the polymerization of $(R, R)$-LA over $(S, S)$-LA $\left(k_{\mathrm{RR}} / k_{\mathrm{SS}}=20\right),(R, R)-3$ has a strong preference for the polymerization of $(S, S)$-LA $\left(k_{\mathrm{SS}} / k_{\mathrm{RR}}=14\right) . R a c-3$ initiated and catalyzed the polymerization of $r a c$-LA to form a stereoblock PLA material with a $P_{\mathrm{i}}$ value of 0.93 at $85 \%$ conversion of $\mathrm{rac}$-LA. Notably, this excellent stereocontrol was still maintained even in a bulk polymerization. At $130{ }^{\circ} \mathrm{C}$, the poly $(r a c-L A)$ prepared by using $r a c-3$ has a $P_{\mathrm{i}}$ value of 0.88 . So far, this is the first time that a highly isotactic PLA is obtained under bulk polymerization conditions from rac-LA. Chisholm et al. ${ }^{28,29}$ have recently re-examined the rac-LA polymerization using $(R, R)-\mathbf{3}$, revealing a combined influence of some factors on the stereoselectivity of the complex, which are the chirality of the complex, the initiating group, and the nature of the polymerization solvent. Thus, it is problematic to ascribe the high stereoselectivity of $(R, R)-3$ either completely to a chain-end-control or to an enantiomorphic site-control mechanism. 


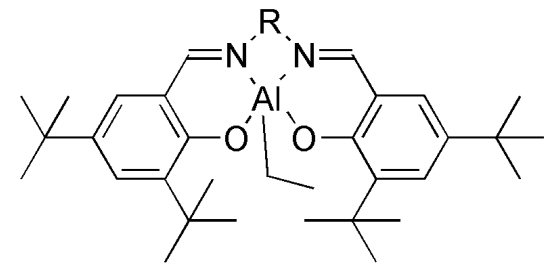

$\mathrm{R}=\left(\mathrm{CH}_{2}\right)_{2}, \mathbf{4} ;\left(\mathrm{CH}_{2}\right)_{3}, \mathbf{5}$.

Many achiral Schiff base aluminum alkyls were proven to be efficient stereoselective catalysts for lactide polymerization in the presence of an alcohol as initiator. Nomura and coworkers ${ }^{30}$ reported on the stereoselective polymerization of rac-LA by in-situ formed aluminum alkoxides from the the achiral Schiff base aluminum ethyls $\mathbf{4}$ and $\mathbf{5}$ with bulky tert-butyl groups at the ortho and para positions of the phenol group. In the presence of benzyl alcohol as an initiator, complexes $\mathbf{4}$ and $\mathbf{5}$ catalyzed rac-LA polymerization via a chain-end-control mechanism. Complex $\mathbf{5}$ with a propylene diimine bridge furnished PLA materials with an isotacticity $\left(P_{\mathrm{m}}=0.91\right)$ higher than that of PLA obtained with complex 4 comprising of an ethylene diimine bridge. DFT(B3LYP/6-31G*) calculations of the most stable conformation of complex 5 revealed that the propylene diimine bridge is more flexible than the ethylene diimine bridge. The more flexible propylene diimine bridge in complex $\mathbf{5}$ may allow an easy adaptation for the lactide with a specific configuration, which will increase the difference in transition state energy between lactides with different configurations, leading to an enhanced isoselectivity of $\mathbf{5}$ in rac-LA polymerization.

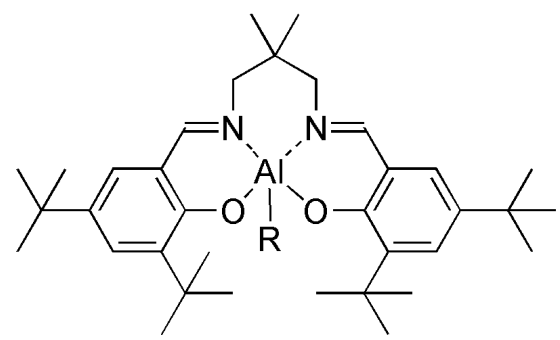

$\mathrm{R}=\mathrm{Et}, \mathbf{6} ; \mathrm{O} \mathrm{Pr}, 7$. 


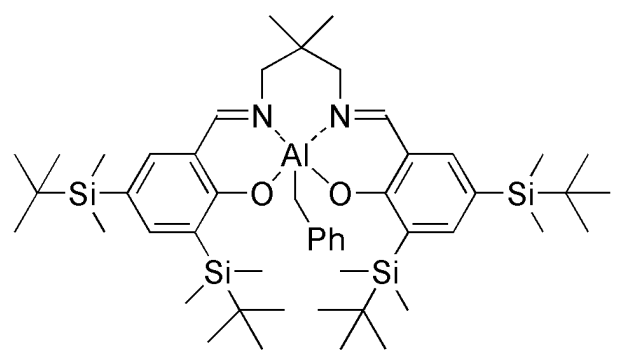

8

In 2003, Chen and coworkers ${ }^{31}$ reported on the complex 6/2-propanol as a catalyst/initiator system in rac-LA polymerization. In the presence of 2-propanol, complex 6 has a high isoselectivity in the polymerization of rac-LA generating a stereoblock PLA with a $P_{\mathrm{m}}$ value of 0.90 . Thermal analysis revealed that this stereoblock PLA has a $T_{\mathrm{m}}$ of $201{ }^{\circ} \mathrm{C}$. Kinetic data indicated that the rac-LA polymerization using complex 6/2-propanol is first-order, both in monomer and catalyst. Subsequently, the aluminum isopropoxide 7 was synthesized by the reaction between 6 and 2-propanol. ${ }^{32}$ Complex 7 was structurally determined to be monomeric with a five-coordinated central aluminum both in the solid and solution state. Polymerization data revealed that complex 7 gave the same isoselectivity and polymerization rate constant as that of 6/2-propanol, indicating that $\mathbf{7}$ is the true active species that initiates the lactide polymerization when using 6/2-propanol as a catalyst/initiator system. Further polymerizations carried out by the group of Nomura ${ }^{33}$ illustrated that compound 7 maintains a high isoselectivity in bulk polymerization of rac-LA. At $130{ }^{\circ} \mathrm{C}$, the obtained PLA showed a high $T_{\mathrm{m}}$ of $169^{\circ} \mathrm{C}$ with a $P_{\mathrm{m}}$ value of 0.84. At $150{ }^{\circ} \mathrm{C}$, the polymerization furnished PLA materials with a $P_{\mathrm{m}}$ value of 0.82 and a $T_{\mathrm{m}}$ of $158^{\circ} \mathrm{C}$. As the polymerization temperature increased to $180{ }^{\circ} \mathrm{C}$, the $P_{\mathrm{m}}$ and $T_{\mathrm{m}}$ values of the resultant PLA decreased to 0.80 and $155^{\circ} \mathrm{C}$, respectively. In 2007, Nomura et al have reported on a Schiff base aluminum complex 8 with flexible but bulky ${ }^{t} \mathrm{BuMe}_{2} \mathrm{Si}$ substituents at the ortho and para positions of the phenol groups. This catalyst induced stereoblock PLA formation from rac-LA with a $P_{\mathrm{m}}$ value of 0.98 and a $T_{\mathrm{m}}$ of $210{ }^{\circ} \mathrm{C} .{ }^{34} \mathrm{Up}$ to now, this is the highest isotactic stereoblock PLA material which has been prepared using an achiral catalyst/initiator system in rac-LA polymerization. 


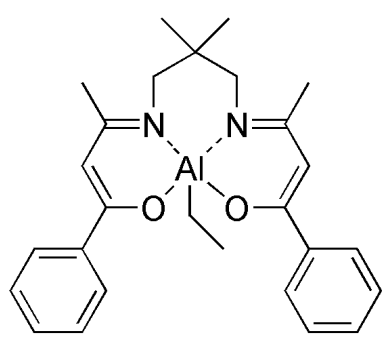

9

Schiff base aluminum catalysts which have been traditionally applied in lactide polymerizations are based on a bis(salicylidene) Schiff base ligand framework. Chen and co-workers ${ }^{35,36}$ reported the synthesis of a series of tetradentate enolic Schiff base aluminum ethyl complexes and their application as catalysts in rac-LA polymerization. Systematic research revealed that modifications on the auxiliary ligand exerted a dramatic influence on their catalytic performance, including activity and stereoselectivity. Lengthening the ethylene diimine bridge to a propylene diimine bridge and the presence of electron-withdrawing substituents at the 5-position in the diketone skeleton both resulted in a remarkable enhancement of stereoselectivity and polymerization rate. In the presence of 2-propanol as an initiator, complex 9 polymerized $r a c$-LA to form isotactic enriched PLA materials with a $P_{\mathrm{m}}$ of 0.78 .

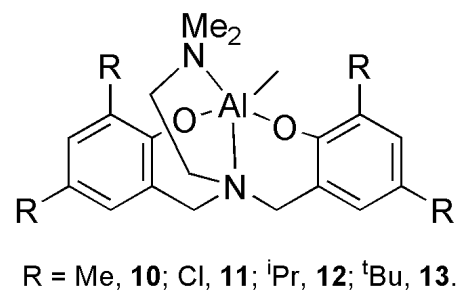

A family of aluminum methyl complexes supported by tetradentate aminophenoxide ligands have been prepared by Gibson et al. ${ }^{37}$ and exploited for the ROP of rac-LA. It was found that the catalytic behavior of these complexes is highly dependent on the substituents at the ortho and para positions of the phenol group. Complexes $\mathbf{1 0}$ and $\mathbf{1 2}$ 
with methyl and isopropyl groups at the ortho and para positions of the phenol group furnished isotactic-biased PLA materials with $P_{\mathrm{m}}$ values of 0.73 and 0.65 , respectively. However, complex 13 with tert-butyl substituents at the ortho and para positions of the phenol group led to a slight heterotactic polymerization of rac-LA, affording PLA material with a $P_{\mathrm{r}}$ value of 0.57 . Complex 11 with chlorine substituents at the ortho and para positions of the phenol group only gave an atactic material from rac-LA.

\section{Formation of Heterotactic PLAs from rac-LA}

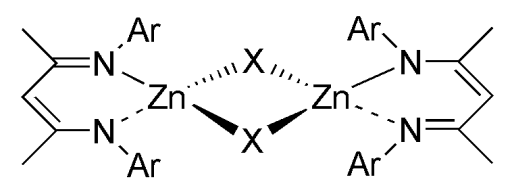

$\mathrm{Ar}=2,6-\mathrm{Pr}_{2} \mathrm{C}_{6} \mathrm{H}_{3}, \mathrm{X}=\mathrm{O} \mathrm{O} \mathrm{Pr}, \mathbf{1 4}$

$\mathrm{Ar}=2,6-\mathrm{Pr}_{2} \mathrm{C}_{6} \mathrm{H}_{3}, \mathrm{X}=\mathrm{OAc}$ lactate, 15 ;

$\mathrm{Ar}=2,6-\mathrm{Pr}_{2} \mathrm{C}_{6} \mathrm{H}_{3}, \mathrm{X}=\mathrm{O} \mathrm{OPr}$ and

$\mathrm{Ar}=2,6-\mathrm{Et}_{2} \mathrm{C}_{6} \mathrm{H}_{3}, \mathrm{X}=\mathrm{O} \mathrm{O} \mathrm{Pr}$ are also prepared for comparison with 14

The most notable feature for $\beta$-diketiminate zinc or magnesium complexes is that they furnish highly hetereotactic PLAs in rac-LA polymerization. Coates et al. ${ }^{38,39}$ reported the synthesis and characterization of the zinc isopropoxide $\mathbf{1 4}$ and zinc methyl lactate 15. Structural characterization revealed that both compounds are dimeric in the solid as well as in solution. Polymerization data indicated that they are both efficient initiators for lactide polymerization, producing PLAs with predictable molecular weights and narrow molecular weight distributions. Notably, complex $\mathbf{1 4}$ initiated the stereoselective ROP of rac-LA via a chain-end-control mechanism, yielding highly heterotactic microstructures with a $P_{\mathrm{r}}$ value up to 0.90 at room temperature and 0.94 at $0{ }^{\circ} \mathrm{C}$. 


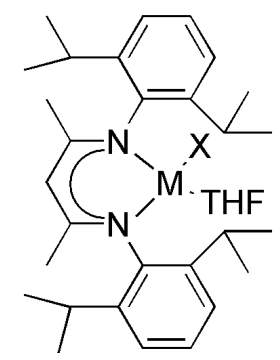

$M=Z n, X=O \mathrm{OSPh}_{3}, \mathbf{1 6}$
$M=M g, X=\mathrm{N}^{\mathrm{i} P r_{2},} \quad \mathbf{1 7}$
$M=\mathrm{Mg}, X=\mathrm{O}^{\mathrm{t}} \mathrm{Bu}$,

The monomeric zinc triphenylsilanoxide complex $\mathbf{1 6}$ supported by a $\beta$-diketiminate ligand ${ }^{40}$ with a THF molecule coordinated to the central zinc atom was shown to have the same heteroselectivity toward rac-LA in THF as that of the dinuclear zinc complex 14 in $\mathrm{CH}_{2} \mathrm{Cl}_{2}$. Although the magnesium complexes $\mathbf{1 7}$ and $\mathbf{1 8}$ as reported by Chisholm et al. ${ }^{41,42}$ do not show stereoselectivity toward $\mathrm{rac}$-LA either in $\mathrm{CH}_{2} \mathrm{Cl}_{2}$ or benzene, they have a similar heteroselectivity in THF as complex 14. It seems that the coordinated THF molecule to the central metal atom plays an important role in enhancing the heteroselectivity of the $\beta$-diketiminate zinc or magnesium complexes.

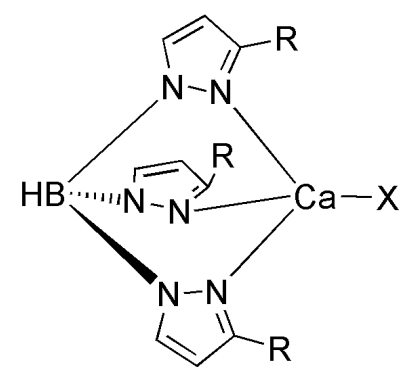

$$
\begin{aligned}
& R={ }^{\mathrm{t}} \mathrm{Bu}, \mathrm{X}=\mathrm{N}\left(\mathrm{SiMe}_{3}\right)_{3}, 19, \\
& \mathrm{R}={ }^{\mathrm{i}} \mathrm{Pr}, \mathrm{X}=\mathrm{OC}_{6} \mathrm{H}_{3}-2,6-\mathrm{Pr}, 20, \\
& \mathrm{R}={ }^{\mathrm{t}} \mathrm{Bu}, \mathrm{X}=\mathrm{OC}_{6} \mathrm{H}_{3}-2,6-{ }^{\mathrm{i}} \mathrm{Pr}, 21 .
\end{aligned}
$$

Chisholm and coworkers ${ }^{43}$ have used trispindazolyl(Tp)-hydroborate ligands to coordinate calcium to form efficient initiators for lactide polymerization. The calcium amide complex 19 with bulky tert-butyl substituents on the Tp ligand was reacted with 
200 equiv of $r a c$-LA in THF. In all cases, polymerizations of rac-LA were very rapid, 90\% conversion within 5 min was achieved. Complex 20 with the less bulky $i$-propyl substituents on the Tp ligand revealed an extremely rapid rac-LA polymerization, achieving 90\% conversion in less than $1 \mathrm{~min}$. Moreover, under the protection of the bulky tert-butyl substituent on the Tp ligand, complex 21 furnished a heterotactic PLA material from $r a c-$ LA with a $P_{\mathrm{r}}$ value of 0.90 .

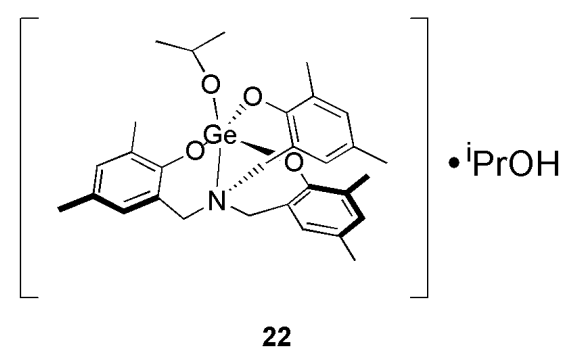

A new germanium alkoxide 22 supported by a $C_{3}$-symmetric amine(trisphenolate) ligand was recently reported by Davidson et al. ${ }^{44}$ This compound has been applied in the bulk polymerization of $\mathrm{rac}$-LA at $130{ }^{\circ} \mathrm{C}$. Analysis of the microstructure of the isolated polymers revealed a strong heterotactic bias $\left(P_{\mathrm{r}}=0.78-0.82\right)$. So far, this is the first example of a highly heteroselective polymerization of rac-LA under solvent-free conditions at a relatively high temperature.

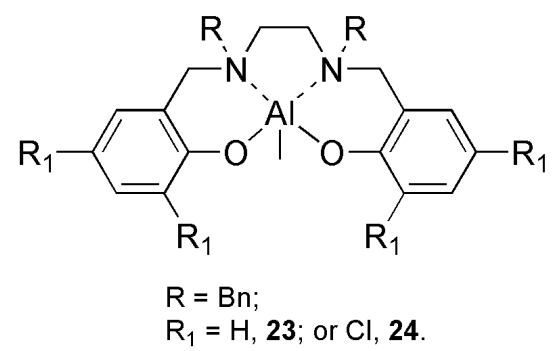

It must be emphasized that Gibson and coworkers ${ }^{45}$ have found an interesting remarkable stereocontrol of achiral aminophenoxide aluminum methyl complexes in the polymerization of rac-LA. In the presence of benzyl alcohol as an initiator, these 
complexes catalyzed rac-LA polymerizations in a well-controlled and living manner, affording highly isotactic PLA materials with a $P_{\mathrm{m}}$ value of 0.88 by using $\mathbf{2 3}$, and highly heterotactic PLAs with a $P_{\mathrm{r}}$ value of 0.96 by using 24. So far, this is the first time that aluminum complexes have been found to furnish a highly heterotactic PLA, and the first time that a dramatic switch in tacticity of the resulting PLA has been observed upon changing the substituent pattern at the ortho and para positions of the phenol group in the complexes. Preliminary kinetic data indicated that the rac-LA polymerizations catalyzed by these complexes were both first-order in monomer and catalyst.

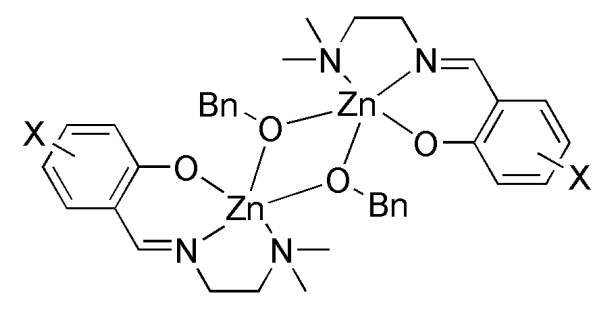

$X=2,4-{ }^{-} \mathrm{Bu}, 25$.

Lin and coworkers ${ }^{46}$ synthesized a series of dinuclear zinc complexes supported by a $\mathrm{N}, \mathrm{N}, \mathrm{O}$-tridentate Schiff base ligand framework. Polymerization data indicated that the reactivities of these complexes were dramatically affected by both the electronic and steric properties of the substituents at the ortho and para positions. Kinetic data showed that the polymerizations are both first-order in monomer and initiator. All these complexes furnish heterotactic PLA materials from rac-LA. It is worthwhile to note that a heterotactic PLA with a high $P_{\mathrm{r}}$ value up to 0.91 can be obtained at $-55^{\circ} \mathrm{C}$ by using complex 25. 


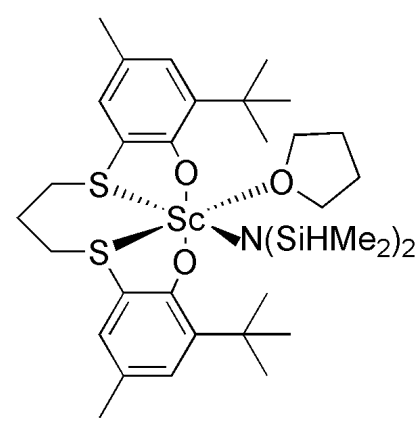

26

Exciting advances were made when rare earth metal complexes were applied in rac-LA polymerization. Okuda et al. ${ }^{47,48}$ synthesized a series of scandium complexes supported by 1, $\omega$-dithiaalkanediyl bridged bis(phenolate) ligands. These complexes showed excellent heterotactic-control in rac-LA polymerization. It was found that both THF as a solvent and bulky substituents at the ortho position of the phenol group largely improve the heterotacticity of the isolated PLAs. Moreover, polymerization data revealed that the complex with a propylene dithialkane bridge improved the heteroselectivity. At $25^{\circ} \mathrm{C}$ in THF, complex $\mathbf{2 6}$ furnished heterotactic PLA materials from $r a c$-LA with a $P_{\mathrm{r}}$ up to 0.96 . A scandium tert-butoxy- $R$-lactate complex was synthesized from complex $\mathbf{2 6}$ and isolated as a key model complex. Structural analysis revealed that this model complex has a dimeric structure with a single ligand conformation of $\Lambda, \Lambda^{49}$ in the solid state. ${ }^{1} \mathrm{H}$ NMR spectroscopy of this model complex revealed that the dimeric structure of the complex in the solid state is retained in solution, and the $R$ configuration of the lactate ester has selectively induced the $\Lambda$ conformation of the ligand in the complex because of steric repulsion, which additionally favors the insertion of $(S, S)$-LA. 


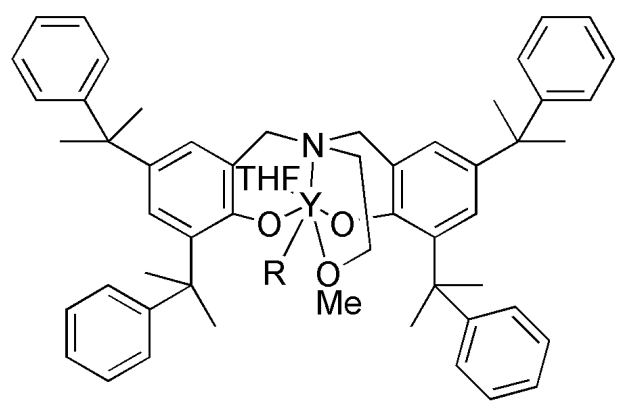

$\mathrm{R}=\mathrm{N}(\mathrm{SiHMe})_{2}, 27$.

Carpentier et al. discovered that yttrium amido complexes supported by an amine bis(phenolate) ligand have good heteroselectivity in the polymerization of rac-LA. ${ }^{50-52}$ By introducing bulky substituents at the ortho and para positions of the phenol group and changing the donor group on the pendent chain from methoxy ether to a dimethyl substituted amine group, the heteroselectivity in rac-LA polymerization of the complex is improved. Complex 27 with bulky and conformationally flexible $\alpha, \alpha$-dimethylbenzyl groups at the ortho and para positions of the phenol group produced substantially heterotactic PLAs with a $P_{\mathrm{r}}$ up to 0.90 at $20^{\circ} \mathrm{C}$.

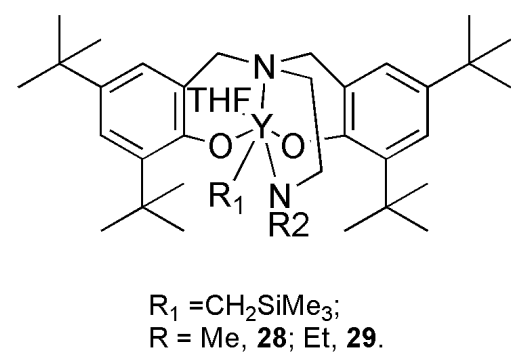

Cui et al. ${ }^{53}$ also reported a series of THF-solvated lanthanide (mono)alkyl complexes supported by $O, N, N, O$-tetradentate diamine bis(phenolate) ligands. Notably, complexes $\mathbf{2 8}$ and $\mathbf{2 9}$ displayed modest activity but high stereoselectivity in the polymerization of $r a c$-LA to give highly heterotactic PLA materials with $P_{\mathrm{r}}$ values ranging from 0.95 to 0.99 . An active oligomer connected to complex 28 prepared from rac-LA was characterized by ${ }^{1} \mathrm{H}$ NMR. The spectrum of the active oligomer 
demonstrated that the ligand and the pendent nitrogen atom remain coordinated to the metal ion, and the geometry around the central metal in complex $\mathbf{2 8}$ did not collapse but retained its structure in solution upon monomer coordination and insertion. The spatially steric environment in the resulting propagating sites will favor the incorporation of a configurationally opposite enantiomer to lower the transition state energy.

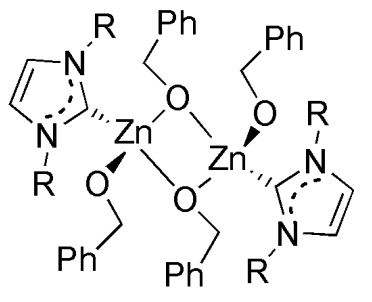

$\mathrm{R}=2,4,6-\mathrm{Me}_{3} \mathrm{C}_{6} \mathrm{H}_{2}, 30$.<smiles>[R]c1c([R])[n+]([R])cn1[R]</smiles>

$\mathrm{R}=2,4,6-\mathrm{Me}_{3} \mathrm{C}_{6} \mathrm{H}_{2}, \mathrm{R}_{1}=\mathrm{H}, 31$;

$\mathrm{R}=2,4,6-\mathrm{Me}_{3} \mathrm{C}_{6} \mathrm{H}_{2}, \mathrm{R}_{1}=\mathrm{Ph}, 32$;

$\mathrm{R}=\mathrm{CH}(\mathrm{Me}) \mathrm{Ph}, \mathrm{R}_{1}=\mathrm{Ph}, 33$.

Tolman et al. ${ }^{54,55}$ discovered that the dinuclear zinc complex 30, comprising monodentate N-heterocyclic carbenes (NHCs), furnished heterotactic-biased PLA materials with a $P_{\mathrm{r}}$ value of 0.60 at room temperature in rac-LA polymerization. To address whether a free carbene was participating in lactide polymerization, the free carbene 31 was exploited as a catalyst in the presence of benzyl alcohol as initiator in rac-LA polymerization. A striking difference in the tacticity of the resulting polymers obtained by using the free carbene compared to using the zinc complex $\mathbf{3 0}$ was discovered. Free carbene $\mathbf{3 1}$ produced isotactic enriched PLA with a $P_{\mathrm{m}}$ value of 0.75 from rac-LA in $\mathrm{CH}_{2} \mathrm{Cl}_{2}$ at $-20{ }^{\circ} \mathrm{C}$. Further studies using the more sterically hindered NHCs in lactide polymerization were carried out by Waymouth and Hedrick. ${ }^{56}$ Most notably, achiral carbene 32 produced highly isotactic PLA material with a $P_{\mathrm{m}}$ value up to 0.90 from $\mathrm{r} a c$-LA at $-70{ }^{\circ} \mathrm{C}$, and heterotactic-biased material with a $P_{\mathrm{r}}$ value of 0.83 from meso-LA at $-40{ }^{\circ} \mathrm{C}$. Lactide polymerizations using chiral free carbene 33 were also investigated. The enantiomerically pure and racemic carbene $\mathbf{3 3}$ both furnished highly isotactic poly $\left(\mathrm{rac}\right.$-LA) material at $-70^{\circ} \mathrm{C}$ with a $P_{\mathrm{m}}$ value of 0.88 . 


\section{Formation of Stereoregular PLAs from meso-LA}

Coates et al. ${ }^{24,57}$ showed that the enantiomerically pure aluminum complex $(R, R)-\mathbf{2}$ affords syndiotactic PLA from meso-LA via an enantiomorphic site control mechanism. The polymerization data showed that when the polymerization proceeded at $70{ }^{\circ} \mathrm{C}$ in toluene for $40 \mathrm{~h}$, the syndiotacticity of the resulting PLA is 0.96 . Due to the high degree of syndiotacticity, the PLA produced by meso-LA polymerization using $(R, R)-2$ is crystalline. Following annealing at $95{ }^{\circ} \mathrm{C}$ for $60 \mathrm{~min}$, this polymer exhibits a glass-transition temperature $\left(T_{\mathrm{g}}\right)$ at approximately $45{ }^{\circ} \mathrm{C}$, and a $T_{\mathrm{m}}$ as high as $153{ }^{\circ} \mathrm{C}$. So far this is the only example of a PLA material with high syndiotacticity. Coates et al. also investigated the ROP of meso-lactide using rac- $2 .{ }^{24} \mathrm{After} 40 \mathrm{~h}$ at $70{ }^{\circ} \mathrm{C}$, the polymerization reached $98 \%$ conversion. Although the resulting polymer has a heterotacticity of 0.80 , it was amorphous and only exhibited a $T_{\mathrm{g}}$ at $43.2^{\circ} \mathrm{C}$. To explain the novel formation of the heterotactic structure from meso-LA by using rac-2, a polymer exchange mechanism (Figure 2.7) was proposed, whereby each individual polymer chain effectively switches between enantiomeric aluminum centers before the insertion of the next monomer unit.

Some other achiral metal complexes were also applied in meso-LA polymerization aiming for a chain-end-control mechanism. However, the chain-end-control of these complexes on the stereochemistry in meso-LA polymerization is very poor. Coates et al. ${ }^{39}$ reported that the dinuclear zinc isopropoxide complex $\mathbf{1 4}$ supported by $\beta$-diketiminate ligand affords syndiotactic PLA with a $P_{\mathrm{r}}$ value of 0.76 . The yttrium amido complex 24 supported by bulky bis(phenoxy) amine ligand reported by Carpentier $^{51}$ also furnished a moderate syndiotactic PLA material with a $P_{\mathrm{r}}$ value of 0.75 . 


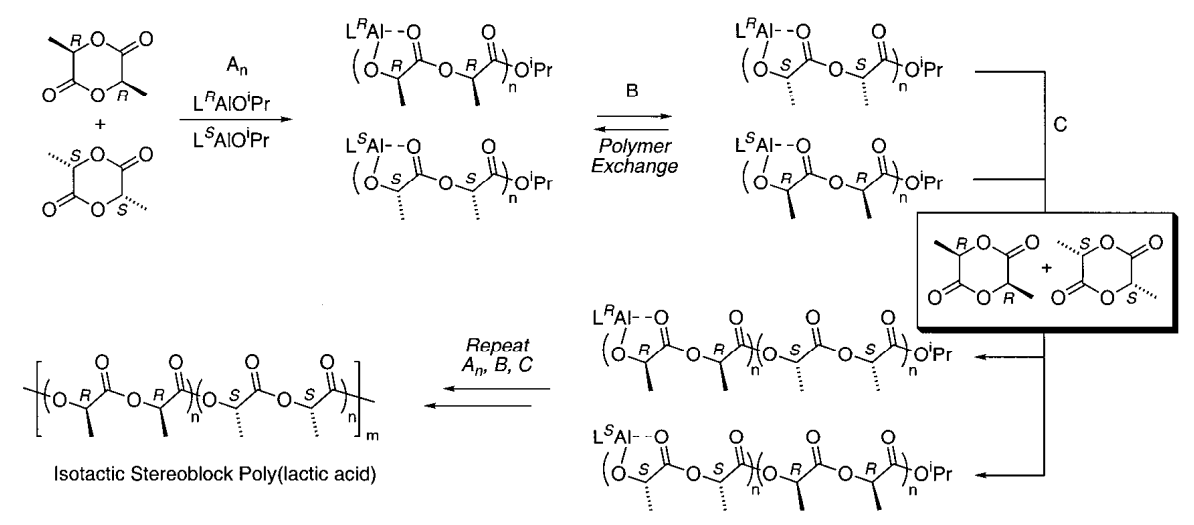

Figure 2.7 Polymer exchange mechanism for the formation of heterotactic PLA from meso-LA by using rac-2.

\section{Summary and Perspectives}

Remarkable advances have been made in the design and synthesis of various kinds of single-site metal complexes that exert excellent stereocontrol in lactide polymerization. So far, highly isotactic and heterotactic PLA materials are formed from rac-LA, while highly syndiotactic PLA is prepared from meso-LA. Among all these single-site metal complexes, five-coordinated aluminum complexes are key catalysts due to their unique ability to form isotactic PLA materials from rac-LA. Most of the research related to five-coordinated aluminum complexes is focused on the Schiff base aluminum complexes, derived from substituted-salicylaldehydes, which exert a significant stereocontrol in lactide polymerization. However, so far, no systematic studies were performed on the structural factors that determine their polymerization behavior, including the activity and stereoselectivity. The aim of this thesis is to develop a relationship between the structures of these complexes and their polymerization behavior by studying a series of achiral substituted-salicylaldehyde Schiff base aluminum ethyls and isopropoxides.

The second problem encountered for the existing substituted-salicylaldehyde Schiff base aluminum catalysts is their low activity. Lactide polymerization requires hours or even days to reach full conversion. Therefore, we investigated new five-coordinated 
aluminum complexes, which possess high activity as well as isoselectivity in lactide polymerization. In order to adjust the tetradentate $N, N, O, O$-coordination mode in the bis(salicylidene) Schiff base system to a $N, N, N, N$-mode, we prepared new bis(pyrrolidene) Schiff base aluminum catalysts that meet our goal.

Finally, although diamine bis(phenolate) (salan) ligands occupy important positions in the catalyst list, and many metal complexes stabilized by salan ligands have been fully exploited in the field of asymmetric catalysis, olefin polymerization, and cylic ester polymerization in the past decade, the structures of aluminum complexes supported by chiral salan ligands and their application in lactide polymerization have never been reported. As an extension of our previous work, we developed new chiral salan aluminum complexes exhibiting diverse stereoselectivies for lactide polymerization.

\section{REFERENCES AND NOTES}

[1] Barskaya, I. G.; Lyudvig, Y. B.; Shifrina, R. R.; Izyumnikov, A. L., Vysokomolekulyarnye Soedineniya Seriya A 1983, 25, 1283-1288.

[2] Emig, N.; Nguyen, H.; Krautscheid, H.; Reau, R.; Cazaux, J. B.; Bertrand, G., Organometallics 1998, 17, 3599-3608.

[3] Bourissou, D.; Martin-Vaca, B.; Dumitrescu, A.; Graullier, M.; Lacombe, F., Macromolecules 2005, 38, 9993-9998.

[4] Basko, M.; Kubisa, P., J. Polym. Sci., Polym Chem. 2006, 44, 7071-7081.

[5] Stere, C.; Iovu, M.; Boborodea, A.; Vasilescu, D. S.; Fazakas-Anca, I. S., Polym. Advan. Technol. 1998, 9, 322-325.

[6] Bhaw-Luximon, A.; Jhurry, D.; Spassky, N.; Pensec, S.; Belleney, J., Polymer 2001, 42, 9651-9656.

[7] McGuinness, D. S.; Marshall, E. L.; Gibson, V. C.; Steed, J. W., J. Polym. Sci., Polym Chem. 2003, 41, 3798-3803.

[8] Csihony, S.; Beaudette, T. T.; Sentman, A. C.; Nyce, G. W.; Waymouth, R. M.; Hedrick, J. L., Adv. Syn. Catal. 2004, 346, 1081-1086. 
[9] Dechy-Cabaret, O.; Martin-Vaca, B.; Bourissou, D., Chem. Rev. 2004, 104, 6147-6176.

[10] Yamashit.Y; Tsuda, T.; Ishida, H.; Uchikawa, A.; Kuriyama, Y., Macromol. Chem. Phys. 1968, 113, 139-\&.

[11] Bero, M.; Adamus, G.; Kasperczyk, J.; Janeczek, H., Polym. Bull. 1993, 31, 9-14.

[12] Rafler, G.; Dahlmann, J., Acta. Polym. 1992, 43, 91-95.

[13] Bassi, M. B.; Padias, A. B.; Hall, H. K., Polym. Bull. 1990, 24, 227-232.

[14] Nijenhuis, A. J.; Grijpma, D. W.; Pennings, A. J., Macromolecules 1992, 25 , 6419-6424.

[15] Dubois, P.; Jacobs, C.; Jerome, R.; Teyssie, P., Macromolecules 1991, 24, 2266-2270.

[16] Degee, P.; Dubois, P.; Jerome, R., Macromol. Symp. 1997, 123, 67-84.

[17] Degee, P.; Dubois, P.; Jacobsen, S.; Fritz, H. G.; Jerome, R., J. Polym. Sci., Polym Chem. 1999, 37, 2413-2420.

[18] Kowalski, A.; Duda, A.; Penczek, S., Macromolecules 1998, 31, 2114-2122.

[19] Stevels, W. M.; Ankone, M. J. K.; Dijkstra, P. J.; Feijen, J., Macromolecules 1996, 29, 6132-6138.

[20] O'Keefe, B. J.; Monnier, S. M.; Hillmyer, M. A.; Tolman, W. B., J. Am. Chem. Soc. 2001, 123, 339-340.

[21] Coates, G. W., Chem. Rev. 2000, 100, 1223-1252.

[22] Spassky, N.; Wisniewski, M.; Pluta, C.; LeBorgne, A., Macromol. Chem. Phys. 1996, 197, 2627-2637.

[23] Ovitt, T. M.; Coates, G. W., J. Polym. Sci., Polym Chem. 2000, 38, 4686-4692.

[24] Ovitt, T. M.; Coates, G. W., J. Am. Chem. Soc. 2002, 124, 1316-1326.

[25] Radano, C. P.; Baker, G. L.; Smith, M. R., J. Am. Chem. Soc. 2000, 122, 1552-1553.

[26] Zhong, Z.; Dijkstra, P. J.; Feijen, J., Angew. Chem., Int. Ed. 2002, 41, 4510-4513.

[27] Zhong, Z.; Dijkstra, P. J.; Feijen, J., J. Am. Chem. Soc. 2003, 125, 11291-11298. 
[28] Chisholm, M. H.; Patmore, N. J.; Zhou, Z. P., Chem. Commun. 2005, 127-129.

[29] Chisholm, M. H.; Gallucci, J. C.; Quisenberry, K. T.; Zhou, Z. P., Inorg. Chem. 2008, 47, 2613-2624.

[30] Nomura, N.; Ishii, R.; Akakura, M.; Aoi, K., J. Am. Chem. Soc. 2002, 124, 5938-5939.

[31] Tang, Z.; Chen, X.; Pang,; Yang, Y.; Zhang, X.; Jing, X., Biomacromolecules 2004, 5, 965-970.

[32] Tang, Z.; Chen, X.; Yang, Y.; Pang, X.; Sun, J.; Zhang, X.; Jing, X., J. Polym. Sci., Polym Chem. 2004, 42, 5974-5982.

[33] Ishii, R.; Nomura, N.; Kondo, T., Polym. J. 2004, 36, 261-264.

[34] Nomura, N.; Ishii, R.; Yamamoto, Y.; Kondo, T., Chem-Eur. J. 2007, 13, 4433-4451

[35] Pang, X.; Du, H.; Chen, X.; Zhuang, X.; Cui, D.; Jing, X., J. Polym. Sci., Polym Chem. 2005, 43, 6605-6612.

[36] Pang, X.; Du, H.; Chen, X.; Wang, X.; Jing, X., Chem-Eur. J. 2008, 14, 3126-3136.

[37] Tang, Z.; Gibson, V. C., Eur. Polym. J. 2007, 43, 150-155.

[38] Coates, G. W.; Ovitt, T. M., Abstracts of Papers of the American Chemical Society 2000, 219, U356-U356.

[39] Chamberlain, B. M.; Cheng, M.; Moore, D. R.; Ovitt, T. M.; Lobkovsky, E. B.; Coates, G. W., J. Am. Chem. Soc. 2001, 123, 3229-3238.

[40] Chisholm, M. H.; Huffman, J. C.; Phomphrai, K., J. Chem. Soc., Dalton Trans. 2001, 222-224.

[41] Chisholm, M. H.; Gallucci, J.; Phomphrai, K., Inorg. Chem. 2002, 41, 2785-2794.

[42] Chisholm, M. H.; Phomphrai, K., Inorg. Chim. Acta. 2003, 350, 121-125.

[43] Chisholm, M. H.; Gallucci, J. C.; Phomphrai, K., Inorg. Chem. 2004, 43, 6717-6725.

[44] Chmura, A. J.; Chuck, C. J.; Davidson, M. G.; Jones, M. D.; Lunn, M. D.; Bull, S. D.; Mahon, M. F., Angew. Chem., Int. Ed. 2007, 46, 2280-2283. 
[45] Hormnirun, P.; Marshall, E. L.; Gibson, V. C.; White, A. J. P.; Williams, D. J., J. Am. Chem. Soc. 2004, 126, 2688-2689.

[46] Chen, H. Y.; Tang, H. Y.; Lin, C. C., Macromolecules 2006, 39, 3745-3752.

[47] Ma, H.; Spaniol, T. P.; Okuda, J., Angew. Chem., Int. Ed. 2006, 45, 7818-7821.

[48] Ma, H.; Spaniol, T. P.; Okuda, J., Inorg. Chem. 2008, 47, 3328-3339.

[49] $\Lambda$ and $\Delta$ represent the helicity of the complex structure which is chiral-at-metal.

[50] Cai, C. X.; Amgoune, A.; Lehmann, C. W.; Carpentier, J. F., Chem. Commun. 2004, 330-331.

[51] Amgoune, A.; Thomas, C. M.; Roisnel, T.; Carpentier, J. F., Chem-Eur. J. 2005, $12,169-179$.

[52] Amgoune, A.; Thomas, C. M.; Carpentier, J. F., Macromol. Rapid Commun. 2007, 28, 693-697.

[53] Liu, X.; Shang, X.; Tang, T.; Hu, N.; Pei, F.; Cui, D.; Chen, X.; Jing, X., Organometallics 2007, 26, 2747-2757.

[54] Jensen, T. R.; Breyfogle, L. E.; Hillmyer, M. A.; Tolman, W. B., Chem. Commun. 2004, 2504-2505.

[55] Jensen, T. R.; Schaller, C. P.; Hillmyer, M. A.; Tolman, W. B., J. Organometallic Chem. 2005, 690, 5881-5891.

[56] Dove, A. P.; Li, H. B.; Pratt, R. C.; Lohmeijer, B. G. G.; Culkin, D. A.; Waymouth, R. M.; Hedrick, J. L., Chem. Commun. 2006, 2881-2883.

[57] Ovitt, T. M.; Coates, G. W., J. Am. Chem. Soc. 1999, 121, 4072-4073. 


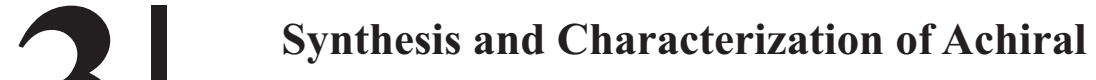 3 Bis(salicylidene) Schiff Base Aluminum Compounds
}

\begin{abstract}
A series of aluminum ethyls and isopropoxides comprising an $\mathrm{N}, \mathrm{N}, \mathrm{O}, \mathrm{O}$-tetradentate bis(salicylidene) Schiff base ligand framework were prepared. X-ray diffraction analysis of single crystals revealed that these Schiff base aluminum ethyls and isopropoxides were all monomeric species with a five-coordinated central aluminum ion. Contrary to the aluminum ethyls which all retain their monomeric structure in a toluene solution, ${ }^{1} \mathrm{H}$ NMR experiments of the aluminum isopropoxides showed that complexes are either in their monomeric or dimeric form. Whereas in the presence of the tert-butyl substituents at the ortho position of the phenolic groups only a monomeric form is present, the absence of substituents leads to equilibrium between monomeric and dimeric forms.
\end{abstract}

\section{INTRODUCTION}

Because of their good coordination ability with different metals, bis(salicylidene) Schiff bases are nowadays widely studied as ligands in metal catalyzed polymerization reactions. ${ }^{1}$ Although many bis(salicylidene) Schiff base metal complexes have been prepared, the solid state structure of only a few bis(salicylidene) Schiff base aluminum alkyls and alkoxides, which can be used in the ring-opening polymerization of lactones, have been reported.

Up to now only the solid state structures of the bis(salicylidene) Schiff base aluminum methyls SalenAlMe, ${ }^{2}$ Salen $(\mathrm{tBu}) \mathrm{AlMe},{ }^{3}$ and Salomphen(tBu)AlMe ${ }^{3}$ (Figure 3.1) with a two carbon diimine bridge were reported by Goedken and Atwood. In their solid state they all adopt square pyramidal geometries with the four chelating $\mathrm{N}$, 
$\mathrm{N}, \mathrm{O}, \mathrm{O}$ atoms placed in an equatorial plane and the Al-methyl group oriented along the central vertical axis. Spectroscopic data $\left({ }^{1} \mathrm{H} \mathrm{NMR}, \mathrm{CDCl}_{3}\right)$ are consistent with the five-coordinated, monomeric structures in the solid state. ${ }^{2,3}$
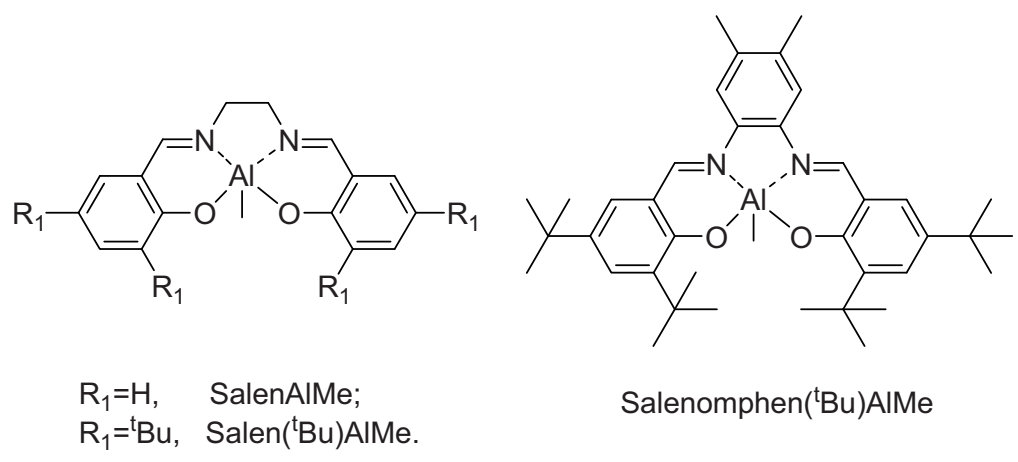

Salenomphen('(B))AIMe

Figure 3.1 Reported structures of bis(salicylidene) Schiff base aluminum methyls.

When these bis(salicylidene) Schiff base aluminum alkyls were reacted with an alcohol to give the corresponding Schiff base aluminum alkoxide the formation of dimeric structures in solution was observed. It was found that in solution aluminum methoxides with non-tert-butylated Schiff base ligands gave dimeric structures with a distorted octahedral geometry, in which each aluminum atom was coordinated to the nitrogen atoms of one of the Schiff base ligands (Figure 3.2 I). ${ }^{4}$ Also, an aluminum methoxide with a Schiff base ligand with a propylene backbone and having tert-butyl substituents ortho to the phenolic oxygens, is flexible enough to allow dimerization in solution. A different geometry of a dimeric structure was recently reported by Coates and coworkers ${ }^{5}$ (Figure 3.2 II). The chiral binaphthyl aluminum methoxide adopts a $D_{2}$ symmetry, in which the two aluminum atoms were coordinated to the nitrogen atoms of both Schiff base ligands. Cao et $\mathrm{al}^{6}$ have reported a similar dimeric structure for the chiral Jacobsen aluminum methoxide.

To gain insight in the correlation between the structure of bis(salicylidene) Schiff base aluminum complexes in the solid state and in solution and their catalytic activity in lactide polymerization, we synthesized and structurally characterized a series of 
achiral bis(salicylidene) schiff base aluminum ethyls and representative aluminum isopropoxides. The influence of the length and structure of the diimine bridge and

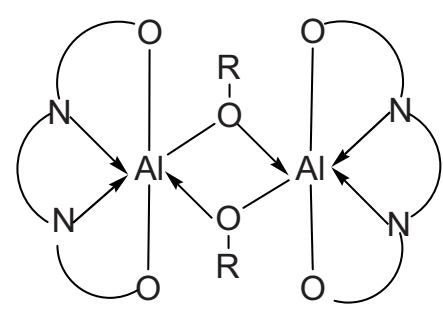

I

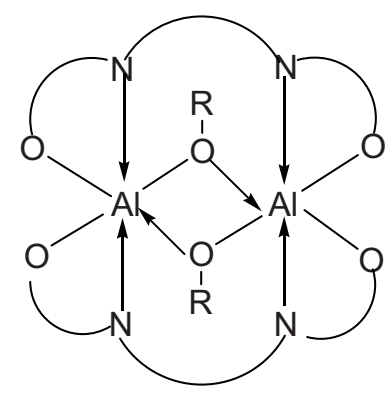

II

Figure 3.2 Geometries for dimeric bis(salicylidene) Schiff base aluminum alkoxide derivatives.

placement of bulky substituents at the ortho position of the phenolic groups on the complex geometry in the solid and solution state have been investigated.

\section{EXPERIMENTAL SECTION}

$\mathrm{AlEt}_{3}$, 2,4-di-tert-butylphenol, 3,5-dichlorosalicylaldehyde, 1,2-diaminoethane, 1,3-diaminopropane, 1,4-diaminobutane, 2,2-dimethyl-1,3-propanediamine, 2-methyl-1,2-propanediamine, 1,2-phenylenediamine, and 2-aminobenzylamine from Aldrich (Germany) and TCI (Japan) were used as received. Aluminum isopropoxide from Acros was distilled under vacuum before use. Toluene was distilled from Na-benzophenone. Ethyl acetate and 2-propanol were distilled from $\mathrm{CaH}_{2}$. Salicylaldehyde from Aldrich was distilled under vacuum and 3,5-di-tert-butylsalicylaldehyde was synthesized by published procedures. ${ }^{7} \mathrm{H}$ and ${ }^{13} \mathrm{C}$ nuclear magnetic resonance (NMR) spectra of compounds dissolved in $\mathrm{CDCl}_{3}$ were recorded on a Bruker AV $300 \mathrm{M}$, Bruker AV $400 \mathrm{M}$ at $25^{\circ} \mathrm{C}$. Chemical shifts were given in parts per million using TMS as a reference. 
General Procedure for the Synthesis of Ligands. All the bis(salicylidene) Schiff base ligands $\left(\mathrm{SB}\left(\mathrm{H}_{2}\right)\right)$ were prepared by condensation of salicylaldehyde or 3,5-di-tert-butylsalicyaldehyde with 1,2-diaminoethane, 1,3-diaminopropane, 1,4-diaminobutane, 2,2-dimethyl-1,3-propanediamine, 2-methyl-1,2-propanediamine, 1,2-phenylenediamine or 2-amino benzylamine, and 3,5-dichlorosalicylaldehyde with 1,2-diaminoethane or 2,2-dimethyl-1,3-propanediamine in a 2:1 molar ratio followed by recrystallization from ethanol. In a representative procedure, the ligand $\mathrm{SB}\left(\mathrm{H}_{2}\right)-\mathbf{1 a}$ was prepared by addition of a solution of 1,2-diaminoethane (1.03 g, 17.1 mmol) in 10 $\mathrm{ml}$ of methanol to a stirred solution of salicylaldehyde (4.16 g, $34.1 \mathrm{mmol})$ in $100 \mathrm{ml}$ of methanol. The reaction mixture was refluxed for $4 \mathrm{~h}$ and then slowly cooled to room temperature. Removal of the solvent under reduced pressure gave a pale yellow solid, which was purified by recrystallization from ethanol.

Synthesis of Complexes. For bis(salicylidene) Schiff base aluminum ethyls, a representative procedure for the synthesis of (SB-1a)AlEt was as follows: $\mathrm{AlEt}_{3}$ (4.0 mmol, $0.46 \mathrm{~g}$ ) dissolved in $4 \mathrm{ml}$ of toluene was added to a stirred solution of the ligand $\mathrm{SB}\left(\mathrm{H}_{2}\right)-\mathbf{1 a}(4.0 \mathrm{mmol}, 1.07 \mathrm{~g})$ in $6 \mathrm{ml}$ of toluene. The reaction mixture was stirred at $70{ }^{\circ} \mathrm{C}$ overnight and then slowly cooled to room temperature. The solvent was evaporated under vacuum to leave a powder. The product was purified by repeated washing with anhydrous hexane.

The bis(salicylidene) Schiff base aluminum isopropoxides (SB-1d)AlO ${ }^{\mathrm{P} r}$, (SB-2d)AlO $\mathrm{Pr}$, and $(\mathrm{SB}-\mathbf{3 b}) \mathrm{AlO}^{\mathrm{i}} \mathrm{Pr}$ were prepared by mixing the corresponding aluminum ethyl complexes in toluene with an equimolar amount of anhydrous 2-propanol under a nitrogen atmosphere and subsequent stirring overnight. Removal of the solvent under reduced pressure afforded the products in quantitative yields.

${ }^{1} \mathrm{H}$ and ${ }^{13} \mathrm{C}$ NMR spectroscopic data of (SB-1a)AlEt, (SB-1b)AlEt, (SB-2a)AlEt, (SB-2b)AlEt, (SB-2d)AlEt, (SB-2g)AlEt, (SB-3a)AlEt and (SB-2d)AlO ${ }^{\mathrm{i}}$ Pr were in agreement with previously reported data. ${ }^{8-10}$

(SB-1c)AlEt, ${ }^{1} \mathrm{H}$ NMR (400 $\left.\mathrm{MHz}, \mathrm{CDCl}_{3}, 25{ }^{\circ} \mathrm{C}\right): \delta=8.20(\mathrm{~d}, 2 \mathrm{H}, \mathrm{CH}=\mathrm{N})$, 7.31-7.19 (m, 4H, ArH), 6.88 (d, 2H, ArH ), 6.77 (t, 2H, ArH), 4.13 (d, 2H, CH $\left.\boldsymbol{H}_{2}\right), 3.87$ 
(d, 2H, CH $\left.\boldsymbol{H}_{2}\right), 2.36$ (d, 2H, CH 2$), 2.08$ (d, 2H, CH $\left.\boldsymbol{H}_{2}\right), 0.95$ (t, 3H, $\left.\mathrm{AlCH}_{2} \mathrm{CH}_{3}\right),-0.27$ (m, $\left.2 \mathrm{H}, \mathrm{AlCH}_{2} \mathrm{CH}_{3}\right) \cdot{ }^{13} \mathrm{C} \mathrm{NMR}\left(100 \mathrm{MHz}, \mathrm{CDCl}_{3}, 25{ }^{\circ} \mathrm{C}\right): \delta=169.45(\boldsymbol{C H}=\mathrm{N}), 166.21$ (ArCOAl), 137.80, 133.23, 121.76, 119.38, $114.74(\mathrm{ArC}), 60.36\left(\mathrm{NCH}_{2}\right), 28.84\left(\mathrm{CH}_{2}\right)$, $10.17\left(\mathrm{AlCH}_{2} \mathrm{CH}_{3}\right), 3.68\left(\mathrm{AlCH}_{2} \mathrm{CH}_{3}\right)$. Anal. Calcd (found) for $\mathrm{C}_{20} \mathrm{H}_{23} \mathrm{AlN}_{2} \mathrm{O}_{2}$ : C 68.56 (68.23), H 6.62 (6.74), N 7.99 (8.12).

(SB-1d)AlEt, ${ }^{1} \mathrm{H}$ NMR $\left(400 \mathrm{MHz}, \mathrm{CDCl}_{3}, 25^{\circ} \mathrm{C}\right): \delta=8.13(\mathrm{~s}, 2 \mathrm{H}, \mathrm{CH}=\mathrm{N})$, 7.33-7.26 (m, 4H, ArH), 7.00-6.94 (m, 4H, ArH), 3.72 (d, 2H, CH $\left.\boldsymbol{H}_{2}\right), 3.21$ (d, 2H, $\left.\mathrm{CH}_{2}\right), 1.16$ (s, 3H, C(CH $\left.)_{2}\right), 1.05$ (s, 3H, C(CH $\left.)_{2}\right), 0.78$ (t, 3H, $\left.\mathrm{AlCH}_{2} \mathrm{CH}_{3}\right),-0.20$ (q, $\left.2 \mathrm{H}, \mathrm{AlCH}_{2} \mathrm{CH}_{3}\right) .{ }^{13} \mathrm{C} \mathrm{NMR}\left(100 \mathrm{MHz}, \mathrm{CDCl}_{3}, 25{ }^{\circ} \mathrm{C}\right): \delta=169.20(\boldsymbol{C H}=\mathrm{N}), 165.96$ (ArCOAl), 135.68, 132.82, 122.36, 118.67, $116.28(\mathrm{ArC}), 69.51\left(\mathrm{NCH}_{2}\right), 35.77$ $\left(\boldsymbol{C}\left(\mathrm{CH}_{3}\right)_{2}\right), 23.14,20.66\left(\mathrm{C}\left(\boldsymbol{C H}_{3}\right)_{2}\right), 10.02\left(\mathrm{AlCH}_{2} \boldsymbol{C H}_{3}\right)$. Anal. Calcd (found) for $\mathrm{C}_{21} \mathrm{H}_{25} \mathrm{AlN}_{2} \mathrm{O}_{2}$ : C 69.21 (69.32), H 6.91 (7.13), N 7.69 (7.54).

(SB-1e)AlEt, ${ }^{1} \mathrm{H}$ NMR $\left(400 \mathrm{MHz}, \mathrm{CDCl}_{3}, 25^{\circ} \mathrm{C}\right): \delta=8.30(\mathrm{~s}, 1 \mathrm{H}, \mathrm{CH}=\mathrm{N}), 8.27(\mathrm{~s}$, 1H, $\mathbf{C H}=\mathrm{N}), 7.40(\mathrm{~m}, 2 \mathrm{H}, \operatorname{Ar} \boldsymbol{H}), 7.37$ (t ,1H, ArH), 7.19 (t, 3H, ArH), 7.10 (d, 3H,

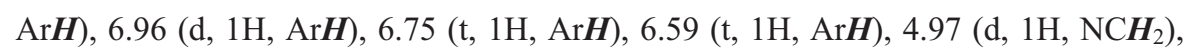
4.26 (d, 1H, NCH $\left.\boldsymbol{H}_{2}\right), 0.49$ (t, 3H, $\left.\mathrm{AlCH}_{2} \mathrm{CH}_{3}\right),-0.57$ (q, 1H, $\left.\mathrm{AlCH}_{2} \mathrm{CH}_{3}\right),-0.64$ (q, 1H, $\left.\mathrm{AlCH}_{2} \mathrm{CH}_{3}\right) .{ }^{13} \mathrm{C} \mathrm{NMR}\left(100 \mathrm{MHz}, \mathrm{CDCl}_{3}, 25{ }^{\circ} \mathrm{C}\right): \delta=165.15(\boldsymbol{C H}=\mathrm{N}), 163.51$ $(\boldsymbol{C H}=\mathrm{N}), 162.07(\mathrm{Ar} \boldsymbol{C O H}), 161.87(\mathrm{ArCOA1}), 140.36,139.93,139.26,133.90,129.38$, 128.32, 127.93, 126.29, 118.67, $118.36(\mathrm{Ar} \boldsymbol{C}), 57.57\left(\mathrm{NCH}_{2}\right), 10.23\left(\mathrm{AlCH}_{2} \boldsymbol{C H}_{3}\right), 0.96$ $\left(\mathrm{AlCH} \mathrm{CH}_{3}\right.$ ). Anal. Calcd (found) for $\mathrm{C}_{23} \mathrm{H}_{21} \mathrm{AlN}_{2} \mathrm{O}_{2}$ : C 71.86 (71.99), H 5.51 (5.82), N 7.29 (6.94).

(SB-2c)AlEt, ${ }^{1} \mathrm{H}$ NMR $\left(400 \mathrm{MHz}, \mathrm{CDCl}_{3}, 25^{\circ} \mathrm{C}\right): \delta=8.23(\mathrm{~d}, 2 \mathrm{H}, \mathrm{CH}=\mathrm{N}), 7.55(\mathrm{~d}$, 2H, ArH), 7.35 (t, 2H, ArH), 3.75 (m, 4H, CH $\left.\boldsymbol{H}_{2}\right), 1.89$ (m, 4H, CH $\left.\boldsymbol{H}_{2}\right), 1.50$ (s, 18H, $\left.\mathrm{C}\left(\mathrm{CH}_{3}\right)_{3}\right), 1.37$ (s, 18H, C(CH $\left.)_{3}\right), 0.95$ (t, 3H, $\left.\mathrm{AlCH}_{2} \mathrm{CH}_{3}\right),-0.08$ (q, 2H, $\mathrm{AlCH}_{2} \mathrm{CH}_{3}$ ). ${ }^{13} \mathrm{C} \mathrm{NMR}\left(100 \mathrm{MHz}, \mathrm{CDCl}_{3}, 25{ }^{\circ} \mathrm{C}\right): \delta=168.97(\boldsymbol{C H}=\mathrm{N}), 163.18$ (ArCOAl), 140.51, 134.68, 129.96, 127.13, $118.86(\mathrm{Ar} \boldsymbol{C}), 57.97\left(\mathrm{NCH}_{2}\right), 36.65\left(\boldsymbol{C}\left(\mathrm{CH}_{3}\right)_{3}\right), 33.74$ $\left(\boldsymbol{C}\left(\mathrm{CH}_{3}\right)_{3}\right), 31.57\left(\mathrm{C}(\boldsymbol{C H})_{3}\right), 29.35\left(\mathrm{C}\left(\boldsymbol{C H}_{3}\right)_{3}\right), 21.43(\boldsymbol{C H})_{2}, 14.10\left(\mathrm{AlCH}_{2} \boldsymbol{C H}_{3}\right),-0.07$ $\left(\mathrm{AlCH} \mathrm{CH}_{3}\right)$. Anal. Calcd (found) for $\mathrm{C}_{36} \mathrm{H}_{55} \mathrm{AlN}_{2} \mathrm{O}_{2}$ : C 75.22 (74.98), H 9.64 (10.01), N 4.87 (4.66). 
(SB-2e)AlEt, ${ }^{1} \mathrm{H}$ NMR $\left(400 \mathrm{MHz}, \mathrm{CDCl}_{3}, 25^{\circ} \mathrm{C}\right): \delta=8.24(\mathrm{~d}, 2 \mathrm{H}, \mathrm{C} \boldsymbol{H}=\mathrm{N}), 7.50(\mathrm{~d}$, 2H, $\operatorname{Ar} \boldsymbol{H}), 7.40$ (d, 2H, $\operatorname{Ar} \boldsymbol{H}$ ), 7.16 (m, 2H, $\operatorname{Ar} \boldsymbol{H}), 7.06$ (m, 2H, $\operatorname{Ar} \boldsymbol{H}), 4.84(\mathrm{~d}, 1 \mathrm{H}$, $\left.\mathrm{NCH}{ }_{2}\right), 4.21$ (d, 1H, NCH $\left.\boldsymbol{H}_{2}\right), 1.47$ (s, 9H, $\left.\mathrm{C}\left(\mathrm{CH}_{3}\right)_{3}\right), 1.31$ (s, 9H, C(CH $\left.\left.\boldsymbol{H}_{3}\right)_{3}\right), 1.28$ (s, 9H, $\left.\mathrm{C}\left(\mathrm{CH}_{3}\right)_{3}\right), 1.10$ (s, 9H, $\left.\mathrm{C}\left(\mathrm{CH}_{3}\right)_{3}\right), 0.64$ (t, 3H, $\left.\mathrm{AlCH}_{2} \mathrm{CH}_{3}\right),-0.42\left(\mathrm{q}, 1 \mathrm{H}, \mathrm{AlCH}_{2} \mathrm{CH}_{3}\right)$, -0.65 (q, $\left.1 \mathrm{H}, \mathrm{AlCH}_{2} \mathrm{CH}_{3}\right) .{ }^{13} \mathrm{C} \mathrm{NMR}\left(100 \mathrm{MHz}, \mathrm{CDCl}_{3}, 25^{\circ} \mathrm{C}\right): \delta=168.29(\mathrm{CH}=\mathrm{N})$, 164.23 (ArCOAl), 148.29, 141.50, 139.52, 132.94, 131.70, 130.00, 127.24, 126.58, 123.16, $119.17(\mathrm{ArC}), 62.57\left(\mathrm{NCH}_{2}\right), 35.60\left(\boldsymbol{C}\left(\mathrm{CH}_{3}\right)_{3}\right), 33.87\left(\boldsymbol{C}\left(\mathrm{CH}_{3}\right)_{3}\right), 31.30$

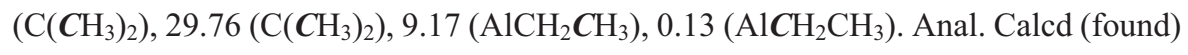
for $\mathrm{C}_{39} \mathrm{H}_{53} \mathrm{AlN}_{2} \mathrm{O}_{2}$ : C 76.94 (76.43), H 8.77 (8.92), N 4.60 (4.56).

(SB-2f)AlEt, ${ }^{1} \mathrm{H}$ NMR $\left(400 \mathrm{MHz}, \mathrm{CDCl}_{3}, 25^{\circ} \mathrm{C}\right): \delta=8.16(\mathrm{~s}, 1 \mathrm{H}, \mathrm{CH}=\mathrm{N}), 8.12(\mathrm{~s}$, $1 \mathrm{H}, \mathrm{C} \boldsymbol{H}=\mathrm{N}), 6.99(\mathrm{~d}, 2 \mathrm{H}, \mathrm{Ar} \boldsymbol{H}), 6.90(\mathrm{~d}, 2 \mathrm{H}, \mathrm{Ar} \boldsymbol{H}), 3.91\left(\mathrm{~d}, 1 \mathrm{H}, \mathrm{C}\left(\mathrm{CH}_{3}\right)_{2} \mathrm{CH}_{2}\right), 3.17$ (d, $\left.1 \mathrm{H}, \mathrm{C}\left(\mathrm{CH}_{3}\right)_{2} \mathrm{CH}_{2}\right), 1.46$ (s, 18H, C(CH $\left.)_{3}\right), 1.24$ (s, 18H, $\left.\mathrm{C}\left(\mathrm{CH}_{3}\right)_{3}\right), 1.17$ (s, 3H, $\left.\mathrm{C}\left(\mathrm{CH}_{3}\right)_{2} \mathrm{CH}_{2}\right), 0.79$ (s, 3H, C( $\left.\left.\mathrm{CH}_{3}\right)_{2} \mathrm{CH}_{2}\right), 0.64$ (t, 3H, $\left.\mathrm{AlCH}_{2} \mathrm{CH}_{3}\right),-0.46$ (q, 2H, $\left.\mathrm{AlCH}_{2} \mathrm{CH}_{3}\right) .{ }^{13} \mathrm{C}$ NMR $\left(100 \mathrm{MHz}, \mathrm{CDCl}_{3}, 25{ }^{\circ} \mathrm{C}\right): \delta=168.83(\boldsymbol{C H}=\mathrm{N}), 163.10$ (ArCOAl), 141.35, 138.99, 131.68, 127.75, $118.39(\mathrm{ArC}), 65.79\left(\mathrm{NCH}_{2}\right), 60.04$

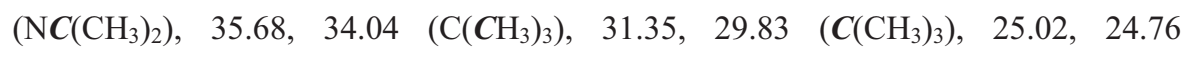
$\left(\mathrm{NC}\left(\mathrm{CH}_{3}\right)_{2}\right), \quad 16.17 \quad\left(\mathrm{AlCH}_{2} \mathrm{CH}_{3}\right), 0.19 \quad\left(\mathrm{AlCH}_{2} \mathrm{CH}_{3}\right)$. Anal. Calcd (found) for $\mathrm{C}_{36} \mathrm{H}_{55} \mathrm{AlN}_{2} \mathrm{O}_{2}$ : C 75.22 (74.96), H 9.64 (9.75), N 4.87 (5.12).

(SB-3b)AlEt, ${ }^{1} \mathrm{H}$ NMR $\left(400 \mathrm{MHz}\right.$, DMSO- $\left.d_{6}, 25^{\circ} \mathrm{C}\right): \delta=8.08(\mathrm{~s}, 2 \mathrm{H}, \mathrm{CH}=\mathrm{N}), 7.63$ (d, 2H, ArH), 7.38 (d, 2H, ArH), 3.50 (d, 2H, CH $\left.\boldsymbol{H}_{2}\right), 3.42$ (d, 2H, CH $\left.\boldsymbol{H}_{2}\right), 1.15$ (s, 3H, $\left.\mathrm{C}\left(\mathrm{CH}_{3}\right)_{2}\right), 1.08$ (s, 3H, $\left.\mathrm{C}\left(\mathrm{CH}_{3}\right)_{2}\right), 0.85$ (t, 3H, $\left.\mathrm{AlCH}_{2} \mathrm{CH}_{3}\right),-0.42$ (q, $\left.2 \mathrm{H}, \mathrm{AlCH} \boldsymbol{H}_{2} \mathrm{CH}\right)$. ${ }^{13} \mathrm{C}$ NMR (100 MHz, $\left.\mathrm{CDCl}_{3}, 25{ }^{\circ} \mathrm{C}\right): \delta=167.58(\mathrm{CH}=\mathrm{N}), 160.04(\mathrm{ArCOAl}), 134.69$, 130.05, 127.59, 120.14, $119.53(\mathrm{ArC}), 71.59\left(\mathrm{NCH}_{2}\right), 36.38\left(\boldsymbol{C}\left(\mathrm{CH}_{3}\right)_{2}\right), 22.65$ $\left(\mathrm{C}\left(\mathrm{CH}_{3}\right)_{2}\right), 22.45\left(\mathrm{C}\left(\mathrm{CH}_{3}\right)_{2}\right), 9.49\left(\mathrm{AlCH}_{2} \mathrm{CH}_{3}\right), 0.54\left(\mathrm{AlCH}_{2} \mathrm{CH}_{3}\right)$. Anal. Calcd (found) for $\mathrm{C}_{21} \mathrm{H}_{21} \mathrm{AlCl}_{4} \mathrm{~N}_{2} \mathrm{O}_{2}$ : C 50.22 (50.03), H 4.21 (4.54), N 5.58 (5.70).

(SB-1d)AlO ${ }^{\mathrm{P} r},{ }^{1} \mathrm{H}$ NMR ( $400 \mathrm{MHz}, \mathrm{CDCl}_{3}, 25^{\circ} \mathrm{C}$ ): Monomeric species, $\delta=8.13$ (s, $2 \mathrm{H}, \mathrm{C} \boldsymbol{H}=\mathrm{N}), 7.39(\mathrm{td}, 2 \mathrm{H}, \operatorname{Ar} \boldsymbol{H}), 7.21(\mathrm{dd}, 2 \mathrm{H}, \operatorname{Ar} \boldsymbol{H}), 7.07(\mathrm{~d}, 2 \mathrm{H}, \operatorname{Ar} \boldsymbol{H}), 6.72(\mathrm{t}, 2 \mathrm{H}$, $\mathrm{Ar} \boldsymbol{H}), 3.94$ (m, 1H, overlapped, $\left.\mathrm{OC} \boldsymbol{H}\left(\mathrm{CH}_{3}\right)_{2}\right), 3.93$ (d, 2H, CH $\left.\boldsymbol{H}_{2}\right), 3.31$ (d, 2H, CH $\boldsymbol{H}_{2}$ ), $1.28\left(\mathrm{~s}, 3 \mathrm{H}, \mathrm{C}\left(\mathrm{CH}_{3}\right)_{2}\right), 1.16$ (s, 3H, $\left.\mathrm{C}\left(\mathrm{CH}_{3}\right)_{2}\right), 1.07$ (br, 6H, overlapped, $\left.\mathrm{OCH}\left(\mathrm{CH}_{3}\right)_{2}\right)$; dimeric species, $\delta=7.83(\mathrm{~s}, 1 \mathrm{H}, \mathrm{C} \boldsymbol{H}=\mathrm{N}), 7.81(\mathrm{~s}, 1 \mathrm{H}, \mathrm{C} \boldsymbol{H}=\mathrm{N}), 7.17(\mathrm{td}, 2 \mathrm{H}, \mathrm{Ar} \boldsymbol{H}), 7.02$ 36 
(dd, 1H, ArH), 6.89 (d, 1H, ArH), 6.78 (d, 1H, ArH), 6.68 (dd, 1H, ArH), 6.59 (t, 1H, $\operatorname{Ar} \boldsymbol{H}), 6.49$ (t, 1H, ArH), 4.78 (d, 1H, CH $\left.\boldsymbol{H}_{2}\right), 3.93$ (m, 1H, overlapped, OCH(CH$\left.)_{2}\right)$, 3.53 (d, 1H, CH $\left.\boldsymbol{H}_{2}\right), 3.13$ (d, 1H, CH $\left.\boldsymbol{H}_{2}\right), 2.77$ (d, 1H, CH $\left.\boldsymbol{H}_{2}\right), 1.05$ (br, 6H, overlapped, $\left.\mathrm{OCH}\left(\mathrm{CH}_{3}\right)_{2}\right), 1.02$ (s, 3H, C(CH $\left.\left.\boldsymbol{H}_{3}\right)_{2}\right), 0.92$ (s, 3H, C(CH H $\left._{2}\right)$. Anal. Calcd (found) for $\mathrm{C}_{22} \mathrm{H}_{27} \mathrm{AlN}_{2} \mathrm{O}_{3}$ : C 66.99 (67.43), H 6.90 (6.56), N 7.10 (7.23).

(SB-3b)AlO ${ }^{\mathrm{i} r},{ }^{1} \mathrm{H}$ NMR (400 MHz, DMSO- $\left.d_{6}, 25^{\circ} \mathrm{C}\right): \delta=8.11(\mathrm{~s}, 1 \mathrm{H}, \mathrm{CH}=\mathrm{N})$, $7.86(\mathrm{~s}, 1 \mathrm{H}, \mathrm{C} \boldsymbol{H}=\mathrm{N}), 7.53$ (t, 1H, $\mathrm{Ar} \boldsymbol{H}), 7.30$ (d, 1H, ArH), 7.18 (t, 1H, ArH), 7.07 (d, 1H, $\mathrm{Ar} \boldsymbol{H}), 4.26\left(\mathrm{~d}, 1 \mathrm{H}, \mathrm{CH}_{2}\right), 4.02\left(\mathrm{~m}, 1 \mathrm{H}, \mathrm{OCH}\left(\mathrm{CH}_{3}\right)_{2}\right), 3.90$ (d, 1H, CH $\left.\boldsymbol{H}_{2}\right), 3.31$ (d, $\left.1 \mathrm{H}, \mathrm{CH}_{2}\right), 3.06\left(\mathrm{~d}, 1 \mathrm{H}, \mathrm{CH}_{2}\right), 1.19$ (s, 6H, OCH$\left.\left(\mathrm{CH}_{3}\right)_{2}\right), 0.97$ (s, 3H, C(CH $\left.)_{2}\right), 0.75$ (s, $\left.3 \mathrm{H}, \mathrm{C}\left(\mathrm{CH}_{3}\right)_{2}\right) .{ }^{13} \mathrm{C} \mathrm{NMR}\left(100 \mathrm{MHz}, \mathrm{DMSO}-d_{6}, 25{ }^{\circ} \mathrm{C}\right): \delta=166.19,165.25(\boldsymbol{C H}=\mathrm{N})$, 160.47, 159.48 (ArCOA1), 131.78, 131.57, 130.31, 130.06, 125.61, 125.24, 122.15, 121.70, 116.82, 116.21 (ArC), 70.61, $69.60\left(\mathrm{NCH}_{2}\right), 61.82\left(\mathrm{AlOCH}\left(\mathrm{CH}_{3}\right)_{2}\right), 36.91$, $36.03\left(\boldsymbol{C}\left(\mathrm{CH}_{3}\right)_{2}\right), 25.37\left(\mathrm{AlOCH}\left(\mathrm{CH}_{3}\right)_{2}\right), 17.99,15.67\left(\mathrm{C}\left(\mathrm{CH}_{3}\right)_{2}\right)$. Anal. Calcd (found) for $\mathrm{C}_{22} \mathrm{H}_{23} \mathrm{AlCl}_{4} \mathrm{~N}_{2} \mathrm{O}_{3}$ : C 49.65 (49.87), $\mathrm{H} 4.36$ (4.12), N 5.26 (5.65).

X-ray Crystallographic Studies. Slowly cooling saturated toluene solutions of (SB-1d)AlEt, (SB-2a)AlEt, (SB-2d)AlEt, (SB-2f)AlEt, (SB-3a)AlEt, (SB-3b)AlEt, (SB-1d)AlO ${ }^{\mathrm{i}} \mathrm{Pr}$, and (SB-3b)AlO ${ }^{\mathrm{i}} \mathrm{Pr}$ from $70{ }^{\circ} \mathrm{C}$ to room temperature afforded single crystals. The intensity data were collected from the $\omega$ scan mode $(187 \mathrm{~K})$ on a Bruker Smart APEX diffractometer with a CCD detector using Mo K $\alpha$ radiation $(\lambda=0.71073$ $\AA$ ). The crystal structures were solved using the SHELXTL program by means of direct methods; the remaining atoms were located from the difference Fourier synthesis, followed by full-matrix least-squares refinements. The positions of hydrogen atoms were calculated theoretically and included in the final cycles of refinements in a riding model along with attached carbons. Crystallographic data for these structural analyses have been deposited with the Cambridge Crystallographic Data Center, CCDC Nos. 291531, 298665, 292364, 292527, 295900, and 617430. 


\section{RESULTS AND DISSCUSSION}

Synthesis and Solid State Structures. The structures of the achiral bis(salicylidene) Schiff base ligands described in this chapter are summarized in Figure 3.3. The bis(salicylidene) Schiff base aluminum ethyls were prepared by reaction of the appropriate ligands with a stoichiometric equimolar amount of $\mathrm{AlEt}_{3}$ in toluene at 70 ${ }^{\circ} \mathrm{C}$ (Scheme 3.1).

\begin{tabular}{|c|c|c|c|c|c|}
\hline & $\mathrm{R}$ & $\mathrm{R}_{1}$ & & $\mathrm{R}$ & $\mathrm{R}_{1}$ \\
\hline 1a & $\left(\mathrm{CH}_{2}\right)_{2}$ & $\mathrm{H}$ & $2 a$ & $\left(\mathrm{CH}_{2}\right)_{2}$ & ${ }^{\mathrm{t}} \mathrm{Bu}$ \\
\hline $1 b$ & $\left(\mathrm{CH}_{2}\right)_{3}$ & $\mathrm{H}$ & $2 \mathbf{b}$ & $\left(\mathrm{CH}_{2}\right)_{3}$ & ${ }^{\mathrm{t}} \mathrm{Bu}$ \\
\hline $1 \mathrm{c}$ & $\left(\mathrm{CH}_{2}\right)_{4}$ & $\mathrm{H}$ & $2 c$ & $\left(\mathrm{CH}_{2}\right)_{4}$ & ${ }^{\mathrm{t}} \mathrm{Bu}$ \\
\hline 1d & $\mathrm{CH}_{2} \mathrm{C}\left(\mathrm{CH}_{3}\right)_{2} \mathrm{CH}_{2}$ & $\mathrm{H}$ & 2d & $\mathrm{CH}_{2} \mathrm{C}\left(\mathrm{CH}_{3}\right)_{2} \mathrm{CH}_{2}$ & ${ }^{\mathrm{t}} \mathrm{Bu}$ \\
\hline $1 e$ & o- $\mathrm{C}_{6} \mathrm{H}_{4} \mathrm{CH}_{2}$ & $\mathrm{H}$ & $2 \mathrm{e}$ & o- $\mathrm{C}_{6} \mathrm{H}_{4} \mathrm{CH}_{2}$ & ${ }^{\mathrm{t}} \mathrm{Bu}$ \\
\hline $3 a$ & $\left(\mathrm{CH}_{2}\right)_{2}$ & $\mathrm{Cl}$ & $2 f$ & $\left(\mathrm{CH}_{3}\right)_{2} \mathrm{CCH}_{2}$ & ${ }^{\mathrm{t}} \mathrm{Bu}$ \\
\hline $3 b$ & $\mathrm{CH}_{2} \mathrm{C}\left(\mathrm{CH}_{3}\right)_{2} \mathrm{CH}_{2}$ & $\mathrm{Cl}$ & $2 \mathrm{~g}$ & $\mathrm{o}-\mathrm{C}_{6} \mathrm{H}_{4}$ & ${ }^{\mathrm{t}} \mathrm{Bu}$ \\
\hline
\end{tabular}

Figure 3.3 Structures of achiral bis(salicylidene) Schiff base ligands.

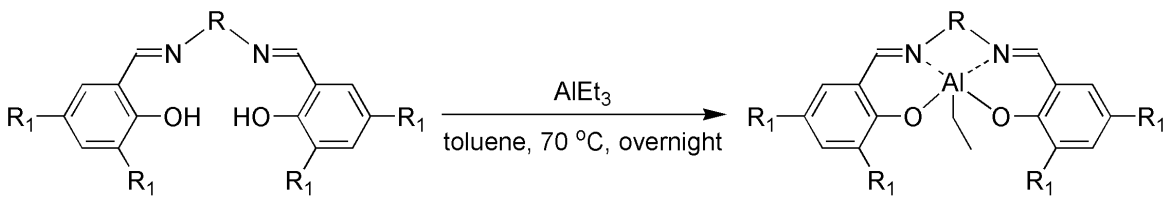

Scheme 3.1 Synthesis of achiral bis(salicylidene) Schiff base aluminum ethyls, $R$ and $R_{1}$ are given in Figure 3.3.

All the achiral bis(salicylidene) Schiff base aluminum ethyl complexes were isolated as solids in quantitative yields. Single crystals of the complexes (SB-1d)AlEt, (SB-2a)AlEt, (SB-2d)AlEt, ${ }^{11}$ (SB-2f)AlEt, (SB-3a)AlEt, and (SB-3b)AlEt were 
grown by cooling concentrated toluene solutions from $70{ }^{\circ} \mathrm{C}$ to room temperature. $\mathrm{X}$-ray diffraction analysis revealed that these complexes are monomeric with distinct geometries of the ligands around the central aluminum atoms (parameters are summarized in Table 3.1 and 3.2).

The geometry of a five-coordinated aluminum atom is classified as either square pyramidal (sqp) or trigonal bipyramidal (tbp), and can be represented by a $\tau$ value. This $\tau$ value, is expressed as $(\beta-\alpha) / 60$, where $\alpha$ and $\beta$ are the $\mathrm{N}-\mathrm{Al}-\mathrm{O}$ angles in the diagonal directions in the $x y$ plane with the Al-Et group oriented along the $z$-axis, ranges from 0 (for ideal sqp) to 1 (for ideal tbp) (Figure 3.4). ${ }^{12,13}$ Distortion from these geometries gives intermediate $\tau$ values.

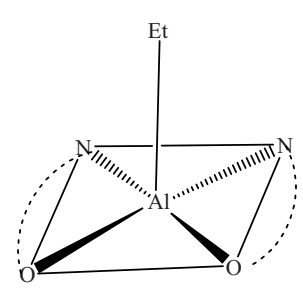

sqp

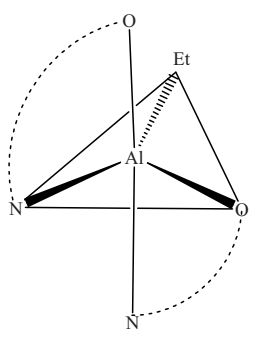

tbp

Figure 3.4 Square pyramidal (sqp) and trigonal bipyramidal (tbp) geometries of the five-coordinated central aluminum ethyl Schiff base complexes.

The aluminum ethyl complex (SB-3a)AlEt with chloro substituents on the phenolic rings and a diimine bridge containing two methylene units exhibits the most pronounced sqp geometry with a $\tau$ value of 0.17 . The structure of (SB-3a)AlEt (Figure 3.5) has an average compressed axial $\mathrm{N}(1)-\mathrm{Al}-\mathrm{O}(2)$ bond angle of $152.50(7)^{\circ}$ as well as equatorial $\mathrm{N}(2)-\mathrm{Al}-\mathrm{C}(17), \mathrm{N}(2)-\mathrm{Al}-\mathrm{O}(1)$, and $\mathrm{C}(17)-\mathrm{Al}-\mathrm{O}(1)$ bond angles of $105.13(8)^{\circ}, 142.24(7)^{\circ}$, and $111.80(8)^{\circ}$. The distances from the $\mathrm{Al}$ atom to $\mathrm{O}(1)$, $\mathrm{O}(2), \mathrm{N}(1), \mathrm{N}(2)$, and $\mathrm{C}(17)$ are 1.8144(15), 1.8268(15), 2.0472(18), 2.0129(18), and 1.974(2) $\AA$, respectively. The central aluminum atom is located $0.097 \AA$ above the equatorial plane formed by $\mathrm{C}(17), \mathrm{N}(2)$, and $\mathrm{O}(1)$ in the direction of $\mathrm{O}(2)$. 
Introducing bulky tert-butyl group at the ortho positions of the phenol groups, the geometry around the central aluminum in (SB-2a)AlEt and (SB-2f)AlEt becomes more distorted as shown by $\tau$ values of 0.44 and 0.48 , respectively. The molecular structure of (SB-2f)AlEt (Figure 3.6) depicts a sqp geometry with the ethyl group on the axial position, and the two nitrogen atoms and two oxygen atoms on the equatorial
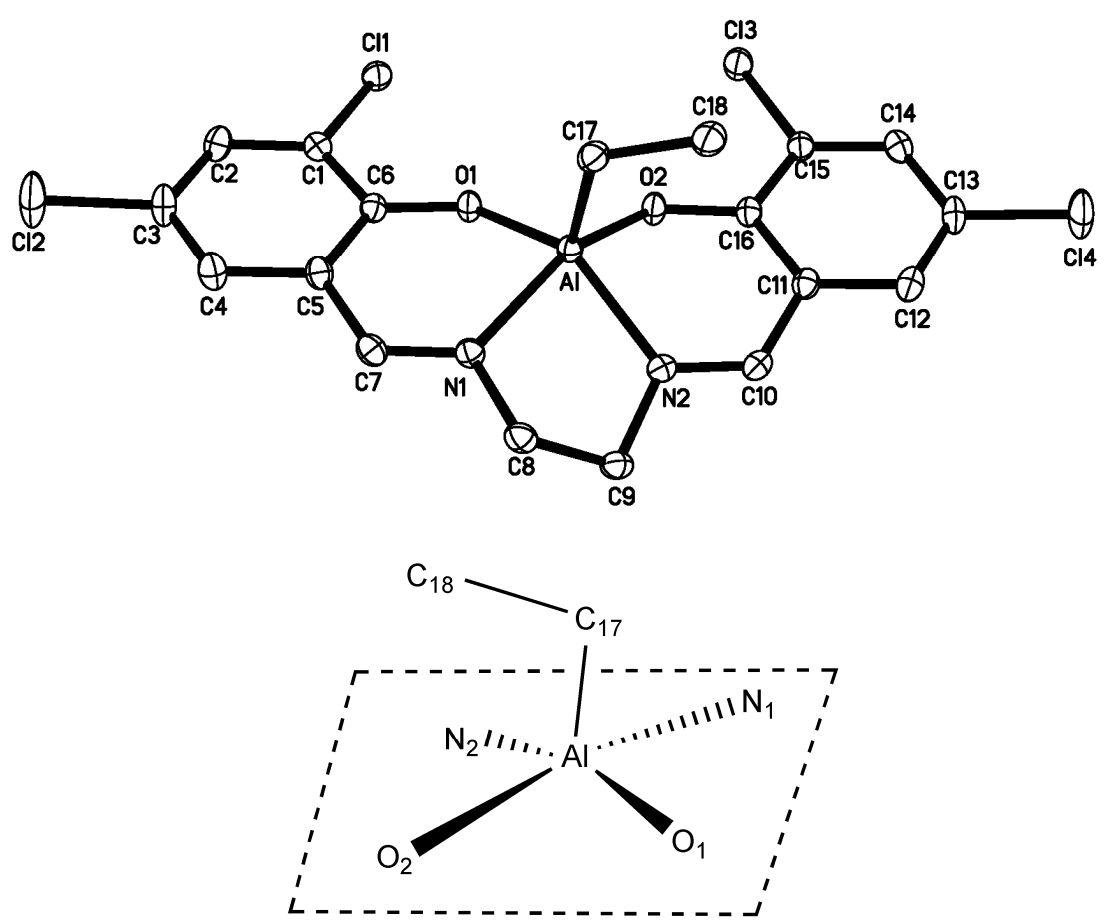

Figure 3.5 X-ray structure of (SB-3a)AlEt (top), with all non-hydrogen atoms shown as $50 \%$ thermal ellipsoids, and core structure of (SB-3a)AlEt (bottom).

positions. The aluminum atom is approximately $0.565 \AA$ above the $\mathrm{N}(1) \mathrm{N}(2) \mathrm{O}(1) \mathrm{O}(2)$ mean plane with a compressed axial $\mathrm{O}(1)-\mathrm{Al}-\mathrm{N}(2)$ bond angle of $158.80(9)^{\circ}$ as well as equatorial $\mathrm{N}(1)-\mathrm{Al}-\mathrm{C}(35), \mathrm{N}(1)-\mathrm{A} 1-\mathrm{O}(2)$, and $\mathrm{C}(35)-\mathrm{Al}-\mathrm{O}(2)$ bond angles of $115.31(10)^{\circ}, 129.73(9)^{\circ}$, and $114.35(10)^{\circ}$, respectively. The distances between the Al atom and $\mathrm{O}(1), \mathrm{O}(2), \mathrm{N}(1), \mathrm{N}(2)$, and $\mathrm{C}(35)$ are 1.8320(17), 1.7903(16), 2.013(2), 2.066(2), and 1.974(3) $\AA$, respectively. 
The complexes (SB-1d)AlEt, (SB-2d)AlEt, and (SB-3b)AlEt have $\tau$ values of 0.88 , 0.76 , and 0.82 , respectively. Thus, increasing the number of carbon atoms between the Schiff bases from two to three changes the geometry of the complexes from a distorted sqp into a distorted tbp. The molecular structure of (SB-1d)AlEt (Figure 3.7) exhibits a tbp geometry in which the $\mathrm{N}(2), \mathrm{O}(1)$ atoms occupy the axial sites, and the

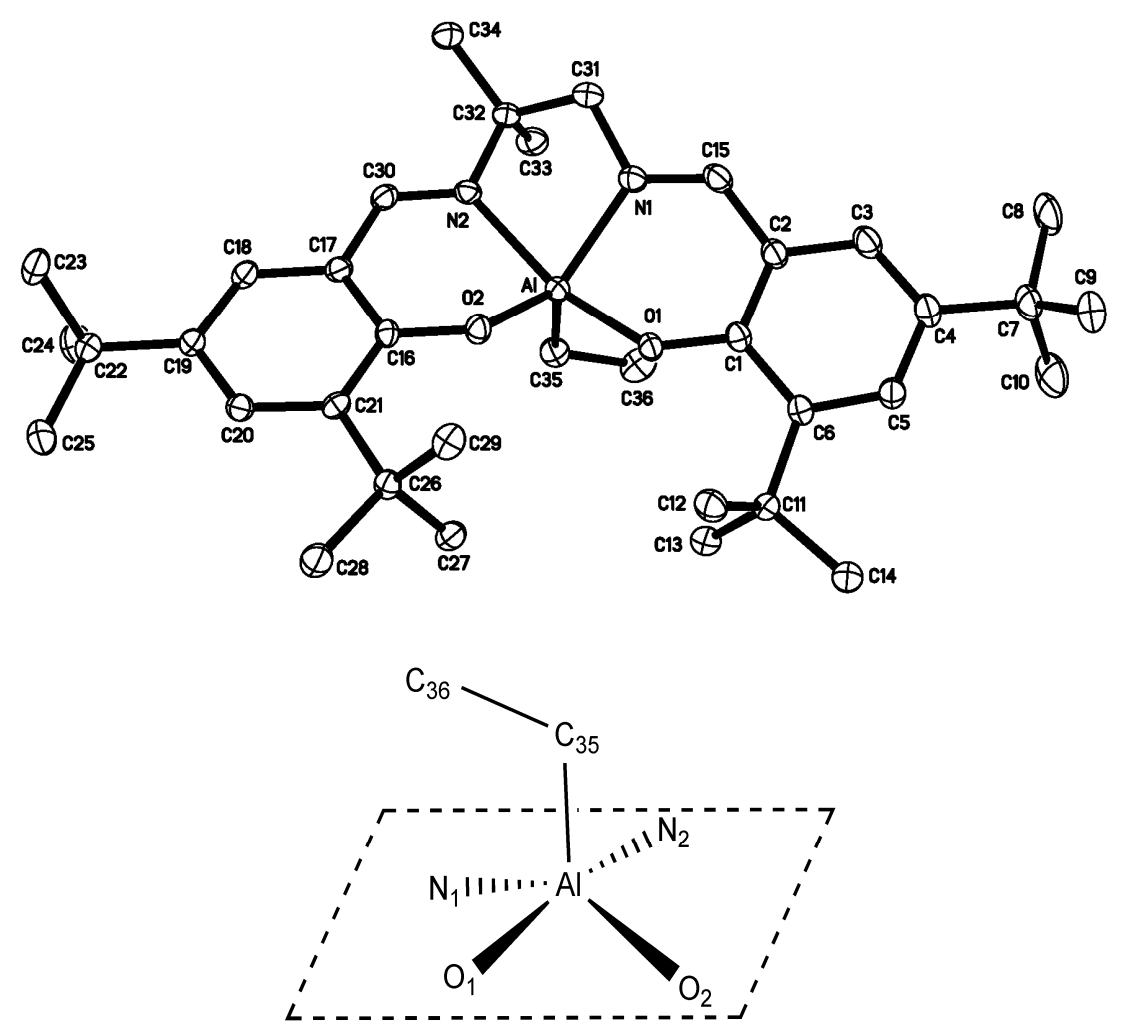

Figure 3.6 X-ray structure of (SB-2f)AlEt (top), with all non-hydrogen atoms shown as $50 \%$ thermal ellipsoids, and core structure of (SB-2f)AlEt (bottom).

$\mathrm{N}(1), \mathrm{O}(2)$ atoms and the ethyl group occupy the equatorial plane. The aluminum atom is located $0.094 \AA$ above the equatorial plane formed by $\mathrm{C}(20), \mathrm{N}(1)$, and $\mathrm{O}(2)$ in the direction of $\mathrm{O}(1)$. The average compressed axial $\mathrm{N}(2)-\mathrm{Al}-\mathrm{O}(1)$ bond angle is $170.53(8)^{\circ}$. The equatorial $\mathrm{O}(2)-\mathrm{A} 1-\mathrm{N}(1), \mathrm{O}(2)-\mathrm{Al}-\mathrm{C}(20)$, and $\mathrm{C}(20)-\mathrm{Al}-\mathrm{N}(1)$ bond angles are $117.47(8)^{\circ}, 118.77(11)^{\circ}$, and $122.05(11)^{\circ}$, respectively, very close to a 
typical tbp geometry. The distances from the aluminum atom to $\mathrm{O}(1), \mathrm{O}(2), \mathrm{N}(1), \mathrm{N}(2)$, and C(20) are 1.8302(16), 1.7887(17), 1.998(2), 2.080(2), and 1.980(3) $\AA$, respectively. The molecular structure of (SB-3b)AlEt (Figure 3.8) is similar to that of (SB-1d)AlEt.
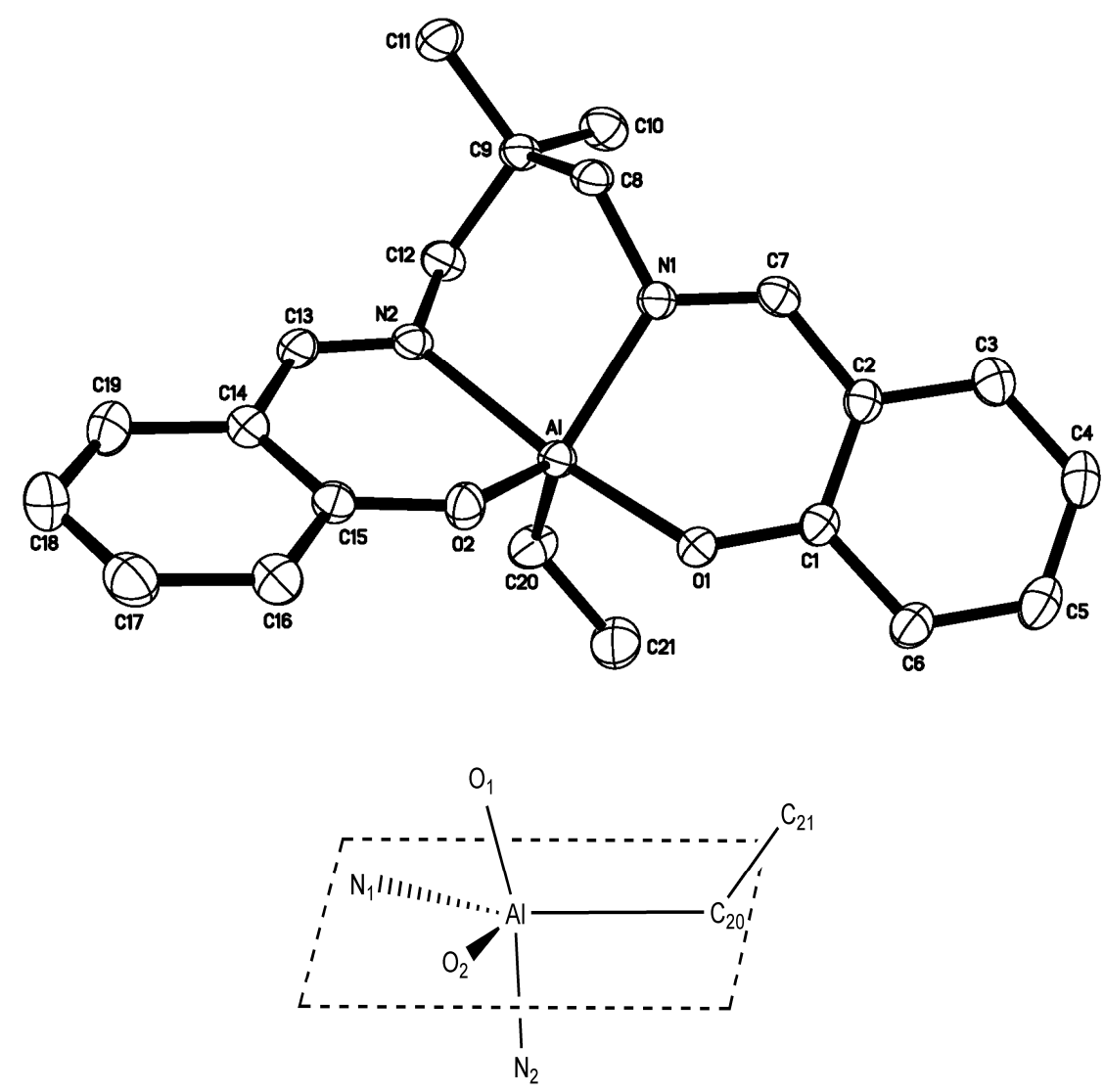

Figure 3.7 X-ray structure of (SB-1d)AlEt (top), with all non-hydrogen atoms shown as $50 \%$ thermal ellipsoids, and core structure of (SB-1d)AlEt (bottom).

The deviation between the sqp and tbp geometries of these bis(salicylidene) Schiff base aluminum ethyls indicates that both the diimine bridge between the Schiff bases and the bulky substituents at the ortho position of the phenol group lead to a dramatic change in the coordination geometry of the metal center. 
Bis(salicylidene) Schiff base aluminum ethyls do not induce the ring-opening polymerization (ROP) of lactones and lactides. However, in the presence of 2-propanol, bis(salicylidene) Schiff base aluminum isopropoxides will be formed which will initiate and catalyze the ring-opening polymerization. To investigate the structures of these actual initiating species in the solid state and solution, the bis(Sali-
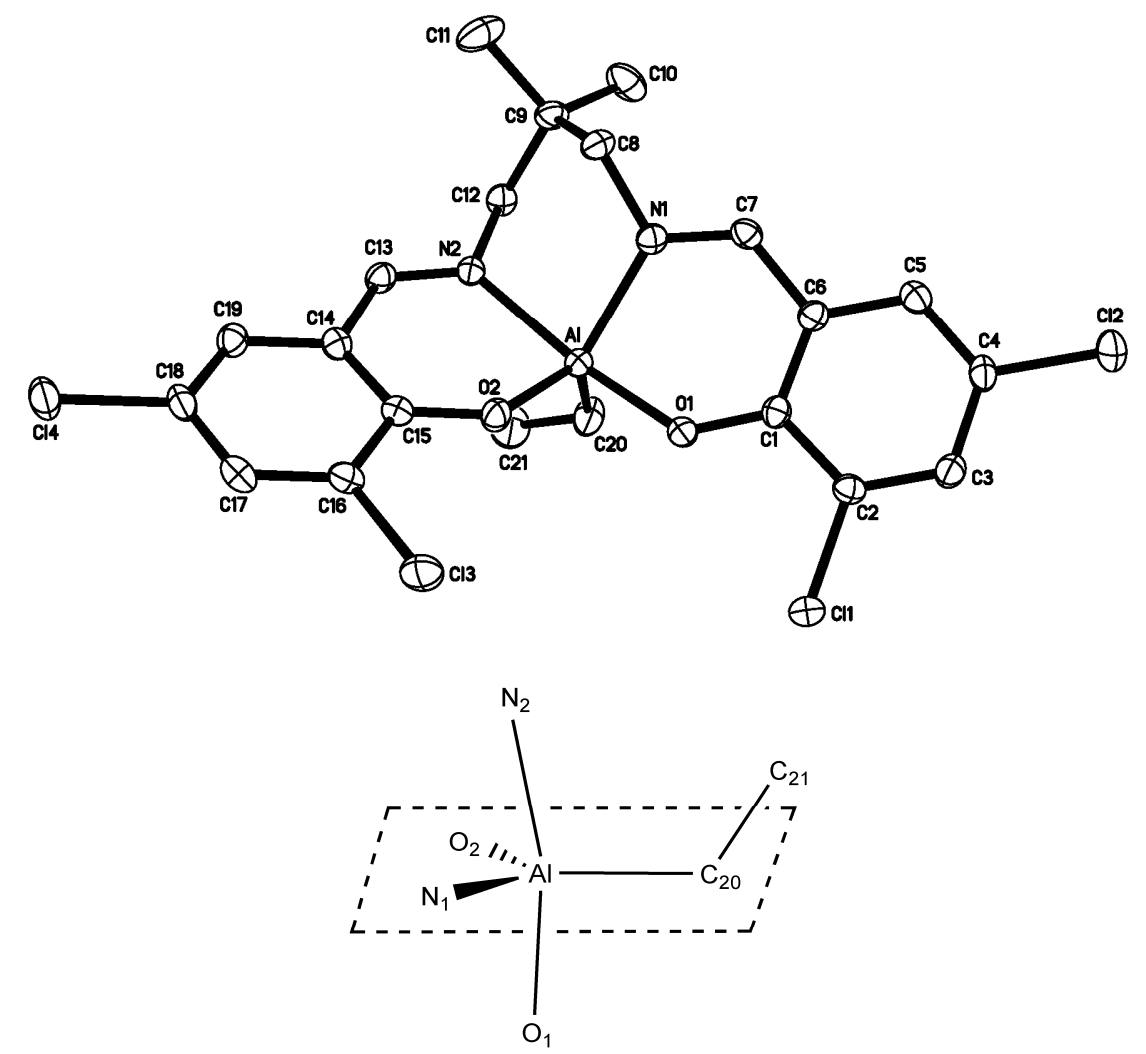

Figure 3.8 X-ray structure of (SB-3b)AlEt (top), with all non-hydrogen atoms shown as $50 \%$ thermal ellipsoids, and core structure of (SB-3b)AlEt (bottom). 


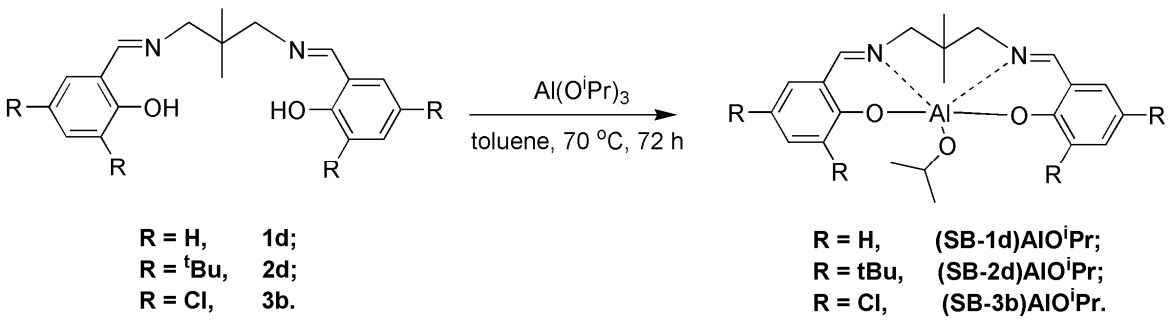

Scheme 3.2 Synthesis of representative achiral bis(salicylidene) Schiff base aluminum isopropoxides.

cylidene) Schiff base aluminum isopropoxides (SB-1d)AlO ${ }^{\mathrm{i}} \mathrm{Pr},(\mathrm{SB}-2 \mathbf{d}) \mathrm{AlO}^{\mathrm{i}} \mathrm{Pr}^{14}{ }^{14}$ and (SB-3b)AlO ${ }^{\mathrm{i}}$ Pr were prepared by in-situ alcoholysis of the corresponding aluminum ethyls. Treatment of the three corresponding aluminum ethyls (SB-1d)AlEt, (SB-2d)AlEt, and (SB-3b)AlEt with stoichiometric amounts of 2-propanol in toluene or treatment of the Schiff base ligands with $\mathrm{Al}\left(\mathrm{O}^{\mathrm{i}} \mathrm{Pr}\right)_{3}$ both resulted in the formation of the three desired aluminum isopropoxides (Scheme 3.2).

X-ray diffraction analysis revealed the molecular structure of (SB-2d)AlO ${ }^{\mathrm{i}} \mathrm{Pr}$ to be a monomeric species in a distorted tbp geometry with a $\tau$ value of $0.78 .{ }^{14}$ The X-ray diffraction analysis of single crystals of (SB-3b)AlO $\operatorname{Pr}$ (Figure 3.9) revealed a

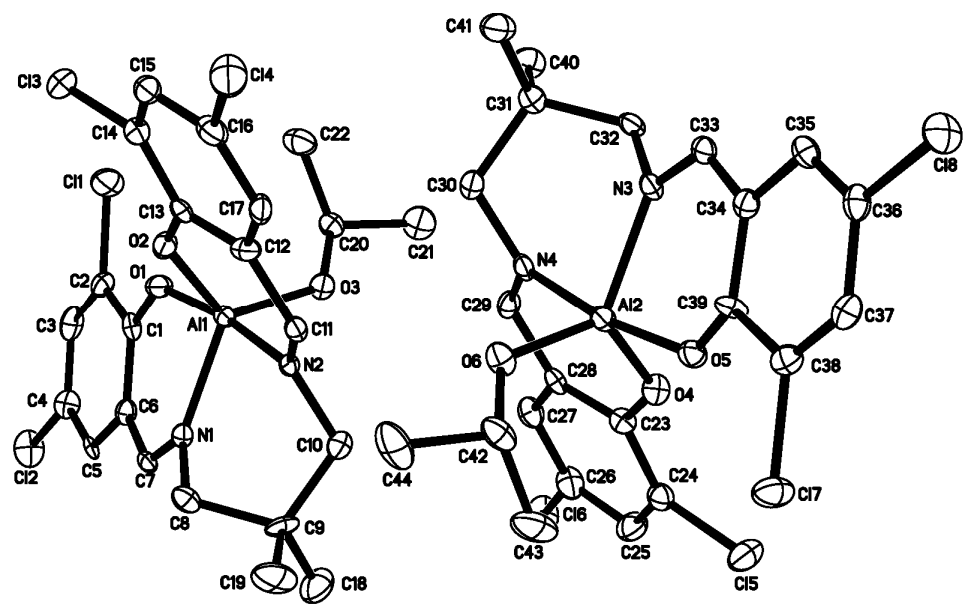




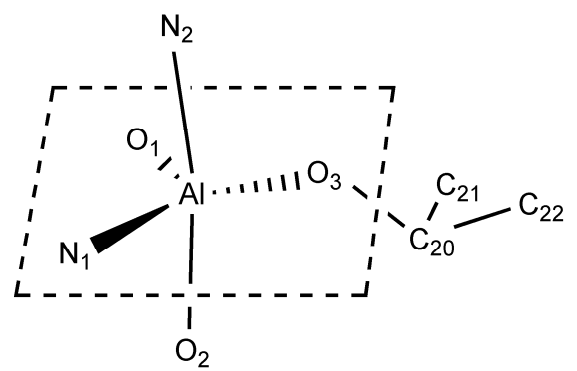

Figure 3.9 X-ray structure of (SB-3b)AlO $\mathrm{Pr}$ (top), with all non-hydrogen atoms shown as $50 \%$ thermal ellipsoids, and core structure of (SB-3b)AlOi $\operatorname{Pr}$ (bottom).

similar monomeric structure with a $\tau$ value of 0.85 , without significant perturbations of the central core. For example, the bond lengths of the Al-O [1.820 $\AA]$ and Al-N [2.031 $\AA]$ on the axial site of (SB-3b)AlO ${ }^{\mathrm{i}} \mathrm{Pr}$ are similar to the $\mathrm{Al}-\mathrm{O}[1.818 \AA]$ and $\mathrm{Al}-\mathrm{N}$ $[2.030 \AA]$ in $(\mathrm{SB}-2 \mathbf{d}) \mathrm{AlO}^{\mathrm{i}} \mathrm{Pr}$, while the other bond lengths in the aluminum central core are only slightly different from each other. Moreover, comparison of the bond angles in the central core of (SB-3b)AlO ${ }^{i}$ rr with (SB-3b)AlEt reveals that the axial average compressed angle $\mathrm{O}(1)-\mathrm{Al}(1)-\mathrm{N}(2)$ of $(\mathrm{SB}-3 \mathbf{b}) \mathrm{AlO}^{\mathrm{i}} \mathrm{Pr}$ is $172.2(2)^{\circ}$, larger than $168.33(11)^{\circ}$ of (SB-3b)AlEt. The largest equatorial angle in (SB-3b)AlO ${ }^{\mathrm{i}} \mathrm{Pr}$ is $118.2(2)^{\circ}$ of $\mathrm{N}(1)-\mathrm{Al}(1)-\mathrm{O}(2)$, less than $118.99(13)^{\circ}$ of (SB-3b)AlEt.

The molecular structure of (SB-1d)AlO $\operatorname{Pr}$ (Figure 3.10) as determined by X-ray diffraction, is also a monomeric species with a $\tau$ value of 0.82 . It is reasoned that the bis(salicylidene) Schiff base aluminum isopropoxides, even without the bulky tert-butyl substituents at the ortho position of the phenol group, all adopt monomeric species in their solid states due to a large steric effect caused by the secondary isopropoxide group, which is consistent with previous observations by Coates. ${ }^{5}$

Solution Structures. The ${ }^{27}$ Al NMR spectra of all aluminum ethyl complexes revealed that the monomeric complexes with a five-coordinated central aluminum atom were retained in solution with single peaks at $30-35 \mathrm{ppm}^{15}$ The aluminum isopropoxide complex (SB-2d)AlO $\mathrm{Pr}$ was shown to be monomeric in a $\mathrm{CDCl}_{3}$ solution. 
However, (SB-1d)AlO ${ }^{\mathrm{i}}$ Pr had a complex ${ }^{1} \mathrm{H}$ NMR spectrum with two sets of resonance peaks (Figure 3.11). The resonance peaks of the four protons of the $-\mathrm{CH}_{2}-$ groups in the ligand backbone may help to distinguish the different species present. Because the monomeric species could not retain its chirality due to a fast exchange between the two conformational stereoisomers on the NMR time scale, two major doublets appeared at 3.93 and $3.13 \mathrm{ppm}$, which are ascribed to the four methylene protons in the monomeric species. Four minor doublets appearing at 4.78, 3.53, 3.31, and $2.77 \mathrm{ppm}$ were also ascribed to these methylene protons. This implies that another
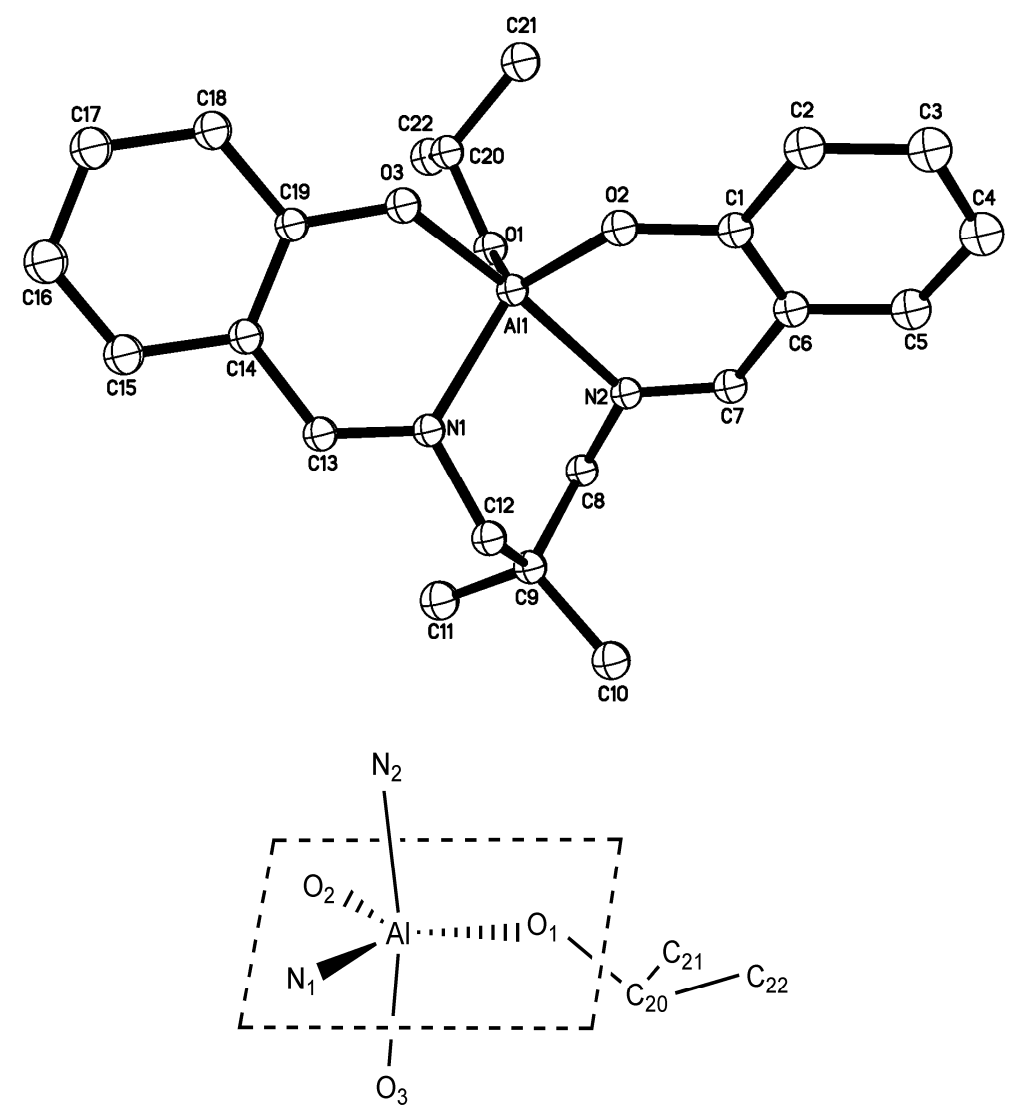

Figure 3.10 X-ray structure of (SB-1d)AlO $\mathrm{Pr}$ (top), with all non-hydrogen atoms shown as $50 \%$ thermal ellipsoids, and core structure of (SB-1d)AlO'Pr (bottom). 
species, which is rigid and non-tautomerized, is present in solution. The only probable reason for the disappearance of the tautomerization phenomenon for this species is the formation of a dimeric structure in solution. The existence of an equilibrium between monomeric and dimeric species was also confirmed by the appearance of two singlets at 34.37 and $3.75 \mathrm{ppm}$ in the ${ }^{27} \mathrm{Al}$ NMR spectrum of (SB-1d)AlO ${ }^{\mathrm{i}} \mathrm{Pr}$.

The monomeric species is present in approximately $70.6 \%$ according to the integrals in the ${ }^{1} \mathrm{H}$ NMR spectrum at room temperature. The ${ }^{1} \mathrm{H}$ NMR spectrum of (SB-3b)AlO'Pr revealed the presence of only a dimeric structure with two different

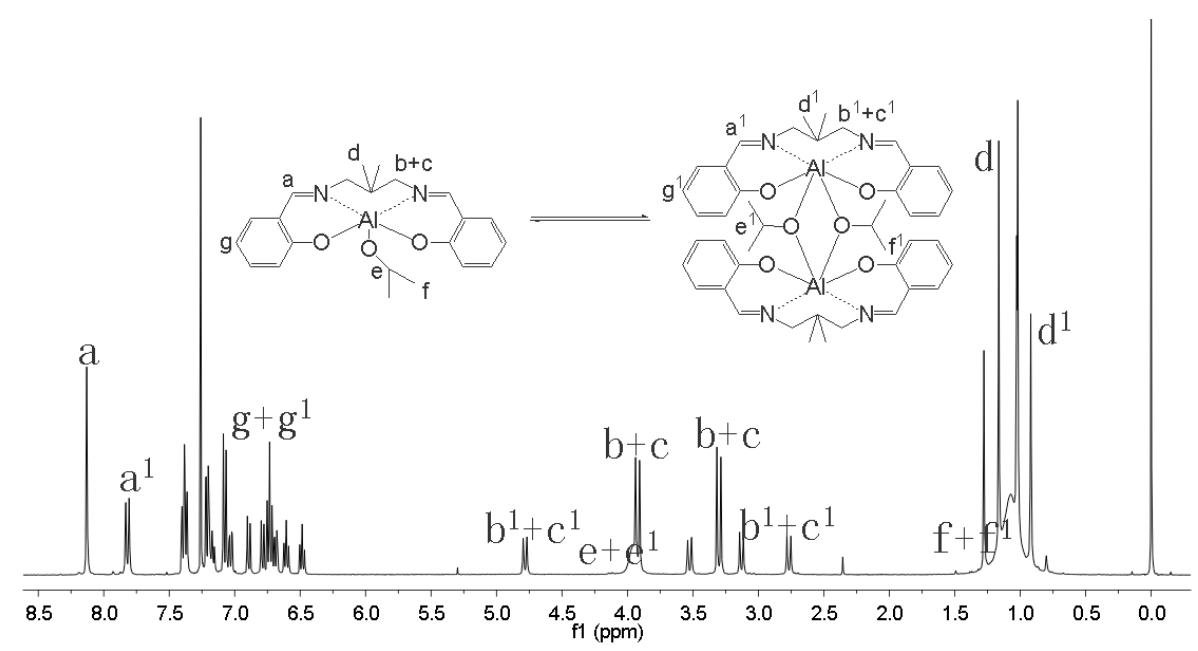

Figure 3.11 ${ }^{1} \mathrm{H}$ NMR spectrum of (SB-1d) $\mathrm{AlO}^{\mathrm{i}} \mathrm{Pr}$ in $\mathrm{CDCl}_{3}$ solution at $25^{\circ} \mathrm{C}$.

signals for the two imine protons and four different doublets for the four $-\mathrm{CH}_{2}-$ protons in the bridge. This dimeric structure was confirmed by the apperance of a singlet at $2.14 \mathrm{ppm}$ in the ${ }^{27} \mathrm{Al} \mathrm{NMR}$ spectrum. It is concluded that without the presence of the bulky tert-butyl substituents on the phenolate rings, the monomeric species of these Schiff base aluminum isopropoxides may dimerize in solution, and the electron withdrawing chlorine substituents at the ortho and para positions of the phenolate rings facilitate this dimerization due to electronic effects. 
Table 3.1 Crystal data and structure refinement parameters.

\begin{tabular}{|c|c|c|c|}
\hline & $\begin{array}{c}\text { (SB-1d)AlEt } \\
0.5 \mathrm{C}_{7} \mathrm{H}_{8}\end{array}$ & (SB-2f)AlEt & (SB-3a)AlEt \\
\hline Emp. Form. & $\mathrm{C}_{24.5} \mathrm{H}_{29} \mathrm{AlN}_{2} \mathrm{O}_{2}$ & $\mathrm{C}_{36} \mathrm{H}_{55} \mathrm{AlN}_{2} \mathrm{O}_{2}$ & $\mathrm{C}_{18} \mathrm{H}_{15} \mathrm{AlCl}_{4} \mathrm{~N}_{2} \mathrm{O}_{2}$ \\
\hline Form. mass & 410.48 & 574.80 & 460.10 \\
\hline Crystal system & Monoclinic & Monoclinic & Monoclinic \\
\hline Space group & $\mathrm{C} 2 / \mathrm{c}$ & $\mathrm{P} 2{ }_{1} / \mathrm{c}$ & $\mathrm{P} 2{ }_{1} / \mathrm{c}$ \\
\hline $\mathrm{a}(\AA)$ & $28.122(2)$ & $11.4152(7)$ & $13.4404(10)$ \\
\hline $\mathrm{b}(\AA)$ & $10.3119(8)$ & $26.7147(15)$ & $14.5891(10)$ \\
\hline$c(\AA)$ & $18.5176(14)$ & $11.6640(7)$ & $10.7266(8)$ \\
\hline$\alpha\left({ }^{o}\right)$ & 90 & 90 & 90 \\
\hline$\beta\left({ }^{\mathrm{o}}\right)$ & $124.0530(10)$ & $104.4920(10)$ & $112.8790(10)$ \\
\hline$\gamma\left({ }^{o}\right)$ & 90 & 90 & 90 \\
\hline $\mathrm{V}\left(\AA^{3}\right)$ & $4448.9(6)$ & $3443.8(4)$ & $1937.8(2)$ \\
\hline Z & 8 & 4 & 4 \\
\hline$\rho\left(\mathrm{mg} \mathrm{cm}^{-3}\right)$ & 1.226 & 1.109 & 1.577 \\
\hline $\begin{array}{l}\text { Absorption } \\
\text { coefficient }\end{array}$ & 0.114 & 0.091 & 0.673 \\
\hline $\mathrm{F}(000)$ & 1752 & 1256 & 936 \\
\hline Reflection collected & 11843 & 19046 & 11346 \\
\hline Independent reflections & 4139 & 6778 & 3822 \\
\hline$R$ (int) & 0.0393 & 0.0569 & 0.0272 \\
\hline Absorption correction & Semi-empirical & Semi-empirical & Semi-empirical \\
\hline GOF & 0.995 & 0.988 & 1.033 \\
\hline
\end{tabular}

\section{CONCLUSIONS}

In conclusion, we report the synthesis and characterization of a series of bis(salicylidene) Schiff base aluminum ethyl and isopropoxide complexes. Structural analysis of these complexes reveals that the aluminum ethyls are monomeric in both the solid and solution state. The aluminum isopropoxides can retain their monomeric structure in solution when bulky substituents are placed at the ortho position of the phenol group. 
Table 3.2 Crystal data and structure refinement parameters (continued)

\begin{tabular}{|c|c|c|c|}
\hline & (SB-3b)AlEt & $(\mathrm{SB}-1 \mathrm{~d}) \mathrm{AlO}^{\mathrm{i}} \mathrm{Pr}$ & $(\mathrm{SB}-3 \mathbf{b}) \mathrm{AlO}^{\mathrm{i}} \mathrm{Pr}$ \\
\hline Emp. Form. & $\mathrm{C}_{21} \mathrm{H}_{21} \mathrm{AlCl}_{4} \mathrm{~N}_{2} \mathrm{O}_{2}$ & $\mathrm{C}_{22} \mathrm{H}_{27} \mathrm{AlN}_{2} \mathrm{O}_{3}$ & $\mathrm{C}_{22} \mathrm{H}_{23} \mathrm{AlCl}_{4} \mathrm{~N}_{2} \mathrm{O}_{3}$ \\
\hline Form. mass & 502.18 & 394.44 & 532.20 \\
\hline Crystal system & Monoclinic & Monoclinic & Monoclinic \\
\hline Space group & $\mathrm{P} 2{ }_{1} / \mathrm{n}$ & $\mathrm{P} 2_{1 / \mathrm{c}}$ & $\mathrm{Cc}$ \\
\hline $\mathrm{a}(\AA)$ & $11.3955(8)$ & $11.0321(9)$ & $13.7448(18)$ \\
\hline $\mathrm{b}(\AA)$ & $17.6046(11)$ & $10.2287(8)$ & $17.259(2)$ \\
\hline $\mathrm{c}(\AA)$ & $11.5904(8)$ & $18.3383(15)$ & $21.561(3)$ \\
\hline$\alpha\left(^{\circ}\right)$ & 90 & 90 & 90 \\
\hline$\beta\left(^{\mathrm{o}}\right)$ & $99.7630(10)$ & $94.0610(10)$ & $107.278(2)$ \\
\hline$\gamma\left(\left(^{\mathrm{o}}\right)\right.$ & 90 & 90 & 90 \\
\hline $\mathrm{V}\left(\AA^{3}\right)$ & $2291.5(3)$ & $2064.2(3)$ & $4883.8(11)$ \\
\hline $\mathrm{Z}$ & 4 & 4 & 8 \\
\hline$\rho\left(\mathrm{mg} \mathrm{cm}^{-3}\right)$ & 1.456 & 1.269 & 1.448 \\
\hline $\begin{array}{l}\text { Absorption } \\
\text { coefficient }\end{array}$ & 0.576 & 0.123 & 0.548 \\
\hline $\mathrm{F}(000)$ & 1032 & 840 & 2192 \\
\hline Reflection collected & 12300 & 11248 & 13662 \\
\hline Independent reflections & 4257 & 4073 & 7578 \\
\hline$R$ (int) & 0.0435 & 0.0361 & 0.0439 \\
\hline Absorption correction & Semi-empirical & Semi-empirical & Semi-empirical \\
\hline GOF & 1.014 & 1.025 & 1.027 \\
\hline
\end{tabular}

\section{ACKNOWLEDGEMENTS}

This project was financially supported by the National Natural Science Foundation of China (20574066), the National Fund for Distinguished Young Scholars (50425309) and by the International Cooperation fund of Science and Technology (Key project 2005DFA50290). 


\section{REFERENCES AND NOTES}

[1] Cozzi, P. G. Chem. Soc. Rev. 2004, 33, 410-421.

[2] Gurian, P. L.; Cheatham, L. K.; Ziller, J. W.; Barron, A. R. J. Chem. Soc., Dalton Trans. 1991, 1449.

[3] Atwood, D. A.; Hill, M. S.; Jegier, J. A.; Rutherford, D. Organometallics 1997, 16, 2659-2664.

[4] Atwood, D. A.; Jegier, J. A. Rutherford, D. Inorg. Chem. 1996, 35, 63-70.

[5] Ovitt, T. M.; Coates, G. W.; J. Am. Chem. Soc. 2002, 124, 1316-1326.

[6] Yang, J.; Yu, Y. H.; Li, Q. B.; Li, Y.; Cao, A. M. J. Polym. Sci., Polym. Chem. 2005, 43, 373-384.

[7] Larrow, J. F.; Jacobsen, E.; N. Gao, Y.; Hong, Y. P.; Nie, X. Y.; Zepp, C. M. J. Org. Chem. 1994, 59, 1939-1942.

[8] Dzugan, S. J.; Goedken, V. J. Inorg. Chem. 1986, 25, 2858-2864.

[9] Atwood, D. A.; Harvey, M. J. Chem. Rev. 2001, 101, 37-52.

[10] Darenbourg, D. J.; Billodeaux, D. R. Inorg. Chem. 2005, 44, 1433-1442.

[11] Tang, Z.; Chen, X.; Pang, X.; Yang, Y.; Zhang, X.; Jing, X. Biomacromolecules 2004, 5, 965-970.

[12] Addison, A. W.; Rao, T. N.; Reedijk, J.; Van Rijin, J.; Verschoor, G. C. J. Chem. Soc., Dalton Trans. 1984, 7, 1349-1356.

[13] Munoz-Hernandez, M. A.; Keizer, T. S.; Wei, P. R.; Parkin, S.; Atwood, D. A. Inorg. Chem. 2001, 40, 6782-6787.

[14] Tang, Z.; Chen, X.; Yang, Y.; Pang, X.; Sun, J.; Zhang, X.; Jing, X. J. Polym. Sci., Polym. Chem. 2004, 42, 5974-5982.

[15] Benn, R.; Rufinska, A.; Lemkuhl, H.; Janssen, E.; Kruger, C. Angew. Chem. Int. Ed. 1983, 22, 779-780. 


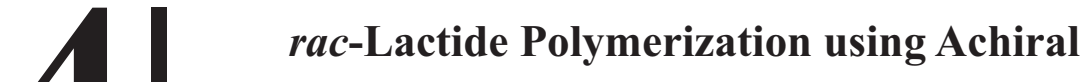 Bis(salicylidene) Schiff Base Aluminum \\ Compounds
}

\begin{abstract}
The activity and the stereoselectivity of a series of (in situ-formed) aluminum isopropoxides, comprising a $N, N, O, O$-tetradentate bis(salicylidene) Schiff base (SB) ligand framework, toward the ring-opening polymerization of rac-lactide are described Polymerization experiments showed that (SB-2d)AlO $\mathrm{Pr}$ exhibited the highest stereoselectivity and (SB-3b)AlO ${ }^{i} \operatorname{Pr}$ possessed the highest activity. Substituents on the phenolic rings and the number of carbon atoms in the diimine bridge both exerted a significant influence on the rate of the polymerization and the tacticity of the polymers isolated. The polymerization kinetics using (SB-3b)AlO $\mathrm{Pr}$ as a catalyst were studied in detail, and the experimental results revealed that the rate of polymerization was first-order in monomer, and had an order of 1.81 in the catalyst, which indicated that the catalyst exists as an equilibrium between monomeric and dimeric species.
\end{abstract}

\section{INTRODUCTION}

Poly(lactide)s (PLAs) are currently used for a variety of environmental, biomedical, and pharmaceutical applications. ${ }^{1,2}$ Although several methods for the synthesis of PLAs exist, the most convenient route is the ring-opening polymerization of lactide (LA), a cyclic dimer of lactic acid. The polymerization reaction can be catalyzed by a variety of organometallic compounds, comprising tin, ${ }^{3,4}$ zinc $^{5-7}$ ferrous, ${ }^{8-11}$ aluminum, ${ }^{12,13}$ yttrium $^{14}$ and titanium ${ }^{15}$ metal centers.

The presence of a chiral carbon atom in the lactic acid unit affords various chain stereochemistries, which play an important role in determining the physical and 
mechanical properties, biodegradability, and ultimately the end use of PLAs. Therefore, control of the stereochemistry in the ring-opening polymerization can also be used as a tool to control the polymer properties. One approach that has been explored in recent years is the use of achiral bis(salicylidene) Schiff base aluminum initiators which induce stereoselectivity by a chain-end-control mechanism. In such a ring-opening polymerization reaction the chirality of the lactic acid unit(s) attached to the metal center influences the insertion of the next monomer.

One class of achiral catalyst-initiator systems that has been studied are the aluminum complexes of the bis(salicylidene) Schiff bases as presented in Scheme 4.1. Gibson and coworkers ${ }^{16}$ discovered that the 5-Cl-Salen-Al-OMe (Scheme 4.1, I), can polymerize rac-LA at room temperature, with a polymerization rate higher than that of a Salen-Al-OMe (Scheme 4.1, II). Spassky and coworkers ${ }^{17}$ showed that Hapen-Al-OMe (Scheme 4.1, III) is an efficient isospecific initiator for controlled polymerization of rac-LA. It has a higher reactivity than Salen-Al-OMe, as well as 5-Cl-Salen-Al-OMe, and hardly induces transesterification reactions. They also reported that substitution of the methoxide group coordinated to the central aluminum by an isopropoxide group increases the polymerization rate, and replacement of the flexible ethylenediimine backbone by the more rigid phenylenediimine backbone decreases the polymerization rate.

Compared with Salen-Al-OMe designed by Spassky et al, Nomura and coworkers ${ }^{18}$ discovered an enhancement of the isotacticity of the PLA materials from rac-LA using catalysts with a flexible propylenediimine bridge and bulky tert-butyl substituents at the ortho positions of the phenolic rings (Scheme 4.1, IV) via a chain-end-control mechanism. However, up to now the influence of the structure of the ligand in these achiral bis(salicylidene) Schiff base aluminum catalyst-initiators on the kinetics and stereochemistry in rac-LA polymerization has not been fully explored. In this chapter, we focus on the relationship between the structure and catalytic 
<smiles></smiles>

I: Gibson, 5-Cl-Salen-Al-OMe<smiles></smiles>

III: Spassky, Hapen-Al-OMe<smiles></smiles>

II: Spassky, Salen-Al-OMe

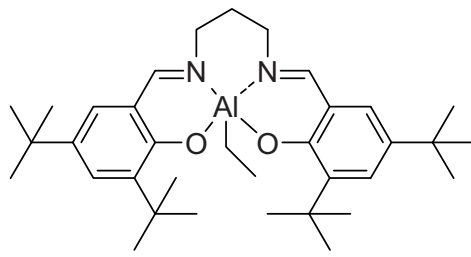

IV: Nomura,

Scheme 4.1 Achiral bis(salicylidene) Schiff base aluminum catalyst-initiators explored for stereoselective polymerization of $r a c$-LA.

behavior of the achiral bis(salicylidene) Schiff base aluminum initiators we described in Chapter 3. The influence of the number of carbon atoms in the diimine-bridge and substituents on the phenolic rings on the ring-opening polymerization of rac-LA is presented.

\section{EXPERIMENTAL SECTION}

rac-LA was purchased from Purac, purified by three times recrystallization from ethyl acetate and dried under vacuum at $30^{\circ} \mathrm{C}$ for $24 \mathrm{~h}$ before use. One dimensional ${ }^{1} \mathrm{H}$ and ${ }^{13} \mathrm{C}$ NMR spectra were recorded at $25{ }^{\circ} \mathrm{C}$ on a Bruker AV $300 \mathrm{MHz}$, Bruker AV $400 \mathrm{MHz}$, using $\mathrm{CDCl}_{3}$ as a solvent. Chemical shifts are given in parts per million using TMS as an internal reference. Monomer conversions were determined from the integrals of the methyl proton signals at $1.65 \mathrm{ppm}$ of LA and at $1.59 \mathrm{ppm}$ of PLA. The probabilities of meso linkages $\left(P_{\mathrm{m}} \mathrm{s}\right)$ were calculated from the different tetrad intensities measured by homonuclear decoupled ${ }^{1} \mathrm{H}$ NMR. Gel permeation chromatography (GPC) measurements were conducted with a Waters 410GPC using THF as the eluent (flow rate: $1 \mathrm{~mL} / \mathrm{min}$, at $35{ }^{\circ} \mathrm{C}$ ). The molecular weights were determined relative to polystyrene (PS) standards. 
General Procedure for the Polymerization of rac-LA. In the rac-LA polymerization, bis(salicylidene) Schiff base aluminum ethyl in the presence of 2-propanol as initiator and presynthesized Schiff base aluminum isopropoxides were both applied. In the following text, if not mentioned, the aluminum ethyls will always be used in the presence of 2-propanol as initiator, while the Schiff base aluminum isopropoxide will be first synthesized and then applied as initiator in polymerization directly.

In a typical polymerization experiment, rac-LA (1.00 g, $6.94 \mathrm{mmol})$, (SB-1a)AlEt (0.037 g, $0.12 \mathrm{mmol}), 2$-propanol $(7.21 \mathrm{mg}, 0.12 \mathrm{mmol})$ dissolved in $4 \mathrm{~mL}$ of toluene and $9 \mathrm{~mL}$ of toluene, respectively, were introduced successively into a flame-dried vessel equipped with a magnetic stirring bar. The vessel was placed in an oil bath thermostated at $70^{\circ} \mathrm{C}$. After certain times, aliquots were taken from the polymerization mixture to determine the monomer conversion by ${ }^{1} \mathrm{H}$ NMR. The polymer was isolated by precipitation into cold methanol, filtering and drying under vacuum at $40^{\circ} \mathrm{C}$ for 24 h. In a typical oligomer synthesis experiment, all operations were identical to the polymerization procedures mentioned above using a low monomer/catalyst molar ratio fixed at $13: 1$.

\section{RESULTS AND DISSCUSSION}

Mechanism and Kinetics of rac-LA Polymerization. The ${ }^{1} \mathrm{H}$ NMR spectrum of a polylactide oligomer prepared using (SB-2a)AlEt (Table 4.1) as a catalyst at a monomer to catalyst ratio of 13:1 and 2-propanol as an initiator is shown in Figure 4.1. The triplet of two overlapping doublets at $1.24 \mathrm{ppm}$ (a) and the quartet at $4.34 \mathrm{ppm}$ (f), were assigned to the methyl protons of the isopropoxycarbonyl end group and the methine proton neighboring the hydroxyl end group, respectively. An integral ratio close to $6: 1$ confirms that the ROP of lactide follows a coordination-insertion mechanism. 


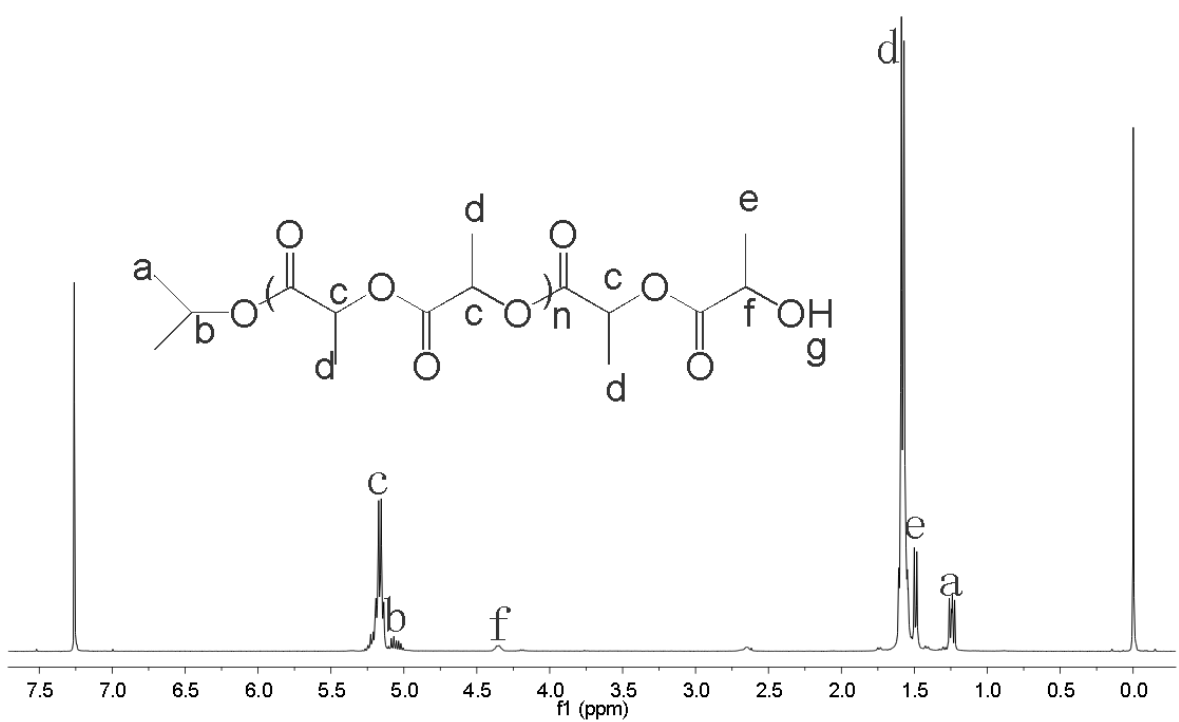

Figure 4.1 ${ }^{1} \mathrm{H}$ NMR spectrum of a poly $(r a c-L A)$ oligomer. $\left(400 \mathrm{MHz}, \mathrm{CDCl}_{3}, 25^{\circ} \mathrm{C}\right)$

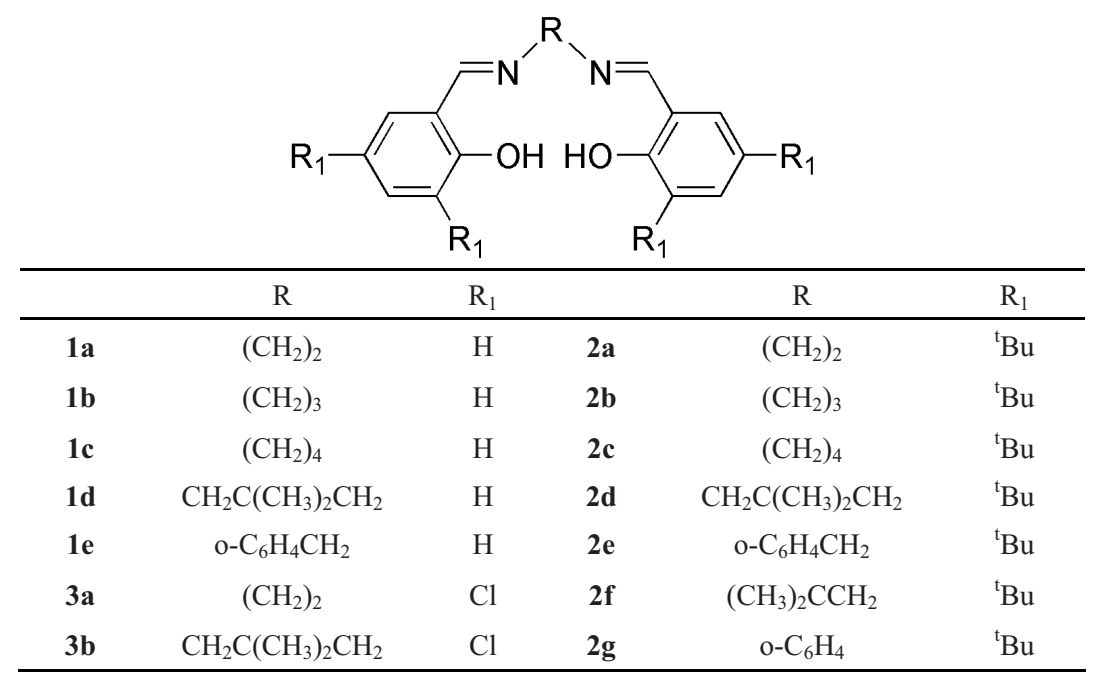

Figure 4.2 Structures of achiral bis(salicylidene) Schiff base ligands.

The introduction of bulky tert-butyl substituents at the ortho position of the phenol groups sterically shields the active center which results in a decrease of the polymerization rate. The complex (SB-3b)AlO $\mathrm{Pr}$ with chlorine atoms at both ortho and para positions appeared to possess the highest polymerization activity among all 
Table 4.1 rac-LA Polymerization using bis(salicylidene) Schiff Base Aluminum Catalysts and 2-Propanol as Initiator $^{a}$

\begin{tabular}{|c|c|c|c|c|c|c|c|c|c|}
\hline Cat & $\mathbf{M} / \mathbf{I}$ & $\begin{array}{l}\text { time } \\
\text { (h) }\end{array}$ & $\begin{array}{c}\text { conv. }^{b} \\
(\%)\end{array}$ & $\begin{array}{c}M_{\mathrm{n}, \mathrm{Cal}}{ }^{c} \\
\times 10^{-3}\end{array}$ & $\begin{array}{c}M_{\mathrm{n}, \mathrm{GPC}}{ }^{d} \\
\times 10^{-3}\end{array}$ & $\mathrm{PDI}^{d}$ & $\begin{array}{c}\text { Efficien } \\
\mathrm{cy}^{e}\end{array}$ & $P_{\mathrm{m}}^{f}$ & $\begin{array}{l}T_{\mathrm{m}}{ }^{g} \\
\left({ }^{0} \mathrm{C}\right)\end{array}$ \\
\hline $1 \mathrm{a}$ & 58.2 & 22 & 85 & 7.36 & 6.15 & 1.22 & 1.20 & 0.71 & n.a. \\
\hline $1 b$ & 60.7 & 9 & 96 & 8.53 & 9.11 & 1.53 & 0.94 & 0.67 & n.a. \\
\hline $1 \mathrm{c}$ & 62.0 & 9 & 86 & 7.74 & 7.83 & 1.10 & 0.99 & 0.71 & n.a. \\
\hline $1 d$ & 58.9 & 22 & 96 & 8.24 & 7.83 & 1.38 & 1.05 & 0.67 & n.a. \\
\hline $1 e$ & 61.1 & 9 & 91 & 8.18 & 5.57 & 1.12 & 1.47 & 0.69 & n.a. \\
\hline $2 \mathbf{a}$ & 62.2 & 72 & 16 & 1.46 & 1.40 & 1.09 & 1.05 & 0.82 & 166 \\
\hline $2 b$ & 59.4 & 9 & 41 & 3.57 & 4.06 & 1.06 & 0.89 & 0.86 & 183 \\
\hline $2 \mathrm{c}$ & 60.5 & 48 & 67 & 5.87 & 5.68 & 1.09 & 1.04 & 0.69 & 158 \\
\hline $2 d$ & 57.4 & 9 & 95 & 7.95 & 7.60 & 1.09 & 1.05 & 0.90 & 191 \\
\hline $2 e$ & 69.8 & 12 & 62 & 6.26 & 6.15 & 1.08 & 1.02 & 0.82 & 176 \\
\hline $2 f$ & 56.1 & 72 & 28 & 2.35 & 1.57 & 1.08 & 1.48 & 0.72 & 142 \\
\hline $2 \mathrm{~g}$ & 55.0 & 240 & 65 & 5.38 & 5.80 & 1.08 & 0.93 & 0.62 & n.a. \\
\hline $3 \mathbf{a}$ & 57.2 & 14 & 94 & 7.83 & 14.1 & 1.49 & 0.56 & 0.70 & n.a. \\
\hline $3 \mathbf{b}$ & 58.1 & 3 & 96 & 8.27 & 11.7 & 1.36 & 0.70 & 0.71 & n.a. \\
\hline
\end{tabular}

${ }^{a}$ All polymerizations were carried out in toluene solution at $70{ }^{\circ} \mathrm{C},[\mathrm{LA}]_{0}=0.53 \mathrm{~mol} \cdot \mathrm{L}^{-1} ;{ }^{b}$ Determined from ${ }^{1} \mathrm{H}$ NMR; ${ }^{c}$ Calculated from the equation: $M_{\mathrm{n}, \mathrm{Cal}}=(\mathrm{M} / \mathrm{I}) \times$ conversion $\times 144.13+$ $60 ;{ }^{d}$ Determined by GPC (THF), relative to PS standards. The value of $M_{\mathrm{n}}$ should be calculated according to $M_{\mathrm{n}}=0.58 M_{\mathrm{n}, \mathrm{GPC} ;}{ }^{e}$ The efficiency factor is defined as the ratio of the theoretical $M_{\mathrm{n}}$, assuming that each aluminum center of active species initiates one polymer chain, and the experimental $M_{\mathrm{n}}$; ${ }^{f}$ The parameter $P_{\mathrm{m}}$ is the tetrad probability to give meso enchainment between monomer units and is determined from the methine region of the homonuclear decoupled ${ }^{1} \mathrm{H}$ NMR spectrum: $[\mathrm{mmm}]=P_{\mathrm{m}}{ }^{2}+\left(1-P_{\mathrm{m}}\right) P_{\mathrm{m}} / 2,[\mathrm{mmr}]=[\mathrm{rmm}]=\left(1-P_{\mathrm{m}}\right) P_{\mathrm{m}},[\mathrm{rmr}]=\left(1-P_{\mathrm{m}}\right)^{2}$, and $[\mathrm{mrm}]$ $=\left[\left(1-P_{\mathrm{m}}\right)^{2}+P_{\mathrm{m}}\left(1-P_{\mathrm{m}}\right)\right] / 2 ;{ }^{g} T_{\mathrm{m}}$ is determined in the second heating scan by DSC analysis.

the bis(salicylidene) Schiff base aluminum isopropoxides we studied. Polymerization experiments revealed that the rac-LA polymerization initiated with (SB-3b)AlEt reached a conversion of $96 \%$ within $3 \mathrm{~h}$, much faster than those initiated with (SB-1d)AlEt ( $96 \%$ conversion in $22 \mathrm{~h}$ ) and (SB-2d)AlEt ( $95 \%$ conversion in $9 \mathrm{~h}$ ). The $p$-phenolate substituent was varied to provide the catalyst with different electron-donating abilities. It has been demonstrated that the effect of the substituents 
on the polymerization rate is complex. ${ }^{19,20}$ However, (SB-3b)AlEt exhibited much faster polymerization rate than (SB-1d)AlEt and (SB-2d)AlEt.

It is also indicated that the bridge between the two nitrogen atoms influences the polymerization rate. Comparing the polymerization rate between $(\mathrm{SB}-2 \mathrm{e}) \mathrm{AlEt}\left(k_{\mathrm{app}}=\right.$ $\left.2.10 \times 10^{-3} \mathrm{~min}^{-1}\right)$ and $(\mathrm{SB}-2 \mathbf{b}) \operatorname{AlEt}\left(k_{\text {app }}=1.17 \times 10^{-3} \mathrm{~min}^{-1}\right)($ Figure 4.2) revealed that the introduction of a conjugated structure resulting from the presence of a benzene ring in the bridge could accelerate the polymerization reaction. Moreover, the

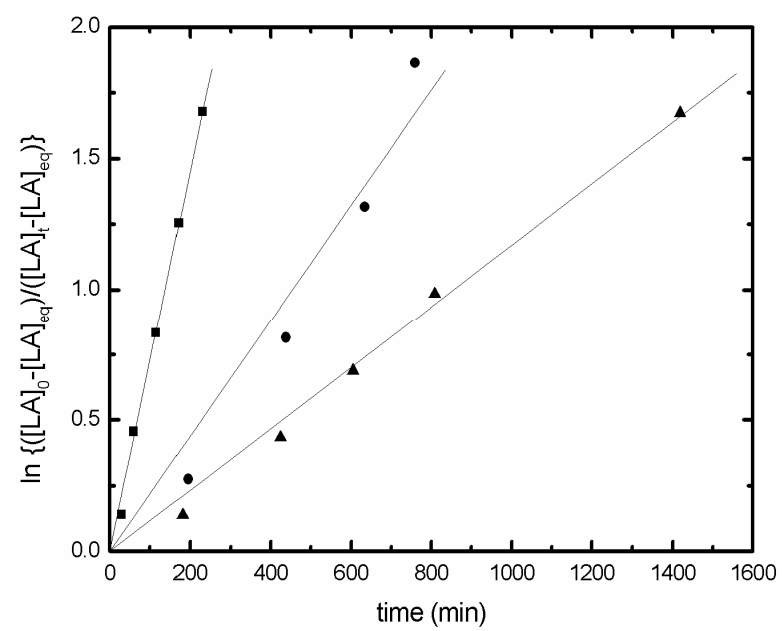

Figure 4.2 Semilogarithmic plots of rac-LA conversion with time in toluene at $70{ }^{\circ} \mathrm{C}$ using (SB-2e)AIEt, (SB-2b)AIEt, and (SB-2d)AIEt as catalysts in toluene in the presence of 2-propanol as initiator at $70{ }^{\circ} \mathrm{C}$ with $[\mathrm{LA}]_{0}=0.53 \mathrm{~mol} \cdot \mathrm{L}^{-1},[\mathrm{LA}]_{\mathrm{eq}}=0.046 \mathrm{~mol} \cdot \mathrm{L}^{-1}\left([\mathrm{LA}]_{\mathrm{eq}}\right.$ is the equilibrium concentration of lactide for polymerization at $70{ }^{\circ} \mathrm{C}$, determined by Duda et $\left.\mathrm{al}^{21}\right),[\mathrm{Al}]_{0}=8.67 \times$ $10^{-3} \mathrm{~mol} \cdot \mathrm{L}^{-1}:(\bullet)(\mathrm{SB}-2 \mathrm{e}) \mathrm{AlEt} / 2$-propanol, $k_{\text {app }}=2.10 \times 10^{-3} \mathrm{~min}^{-1} ;(\mathbf{\Delta})(\mathrm{SB}-2 \mathbf{b}) \mathrm{AlEt} / 2$-propanol, $k_{\text {app }}=1.17 \times 10^{-3} \mathrm{~min}^{-1} ;(\mathbf{\bullet})(\mathrm{SB}-2 \mathrm{~d}) \mathrm{AlEt}, k_{\mathrm{app}}=7.28 \times 10^{-3} \mathrm{~min}^{-1}$.

introduction of gem alkyl substituents on the diimine bridge also enhances the activity of the catalysts, which was shown by comparing by (SB-2b)AlEt $\left(k_{\mathrm{app}}=1.17 \times 10^{-3}\right.$ $\left.\min ^{-1}\right)$ and $(\mathrm{SB}-2 \mathbf{d}) \mathrm{AlO}^{\mathrm{i}} \operatorname{Pr}\left(k_{\mathrm{app}}=7.28 \times 10^{-3} \mathrm{~min}^{-1}\right)$, as well as (SB-2a)AlEt (reached $16 \%$ conversion after $72 \mathrm{~h}$ ) and (SB-2f)AlEt (reached $28 \%$ conversion after $72 \mathrm{~h}$ ) (Table 4.1). The presence of the propylene diimine bridge furnishes a high polymerization rate of the catalysts in rac-LA polymerization, as indicated by the high 
activity of (SB-1b)AlEt (reached 96\% conversion after 9 h) compared to (SB-1a)AlEt (reached $85 \%$ conversion after $22 \mathrm{~h}$ ) and (SB-1c)AlEt (reached 86\% conversion after 9 h), as well as the high activity of (SB-2b)AlEt (reached $41 \%$ conversion after $9 \mathrm{~h}$ ) compared to (SB-2a)AlEt (reached $16 \%$ conversion after $72 \mathrm{~h}$ ) and (SB-2c)AlEt (reached 67\% conversion after $48 \mathrm{~h}$ ). These results may be related to the flexibility of the propylene diimine bridge, allowing ready adaption to the next incoming lactide, which leads to a high activity of the catalyst.

In a previous study Tang et al. demonstrated that the polymerization rate of rac-LA using (SB-2d)A1O $P r$ as a catalyst/initiator was first-order in monomer and catalyst. ${ }^{22}$ In order to fully understand the nature of rac-LA polymerization using catalysts with less steric substituents, the conversions of rac-LA with time at various concentrations of (SB-3b)AlO ${ }^{\mathrm{i}} \mathrm{Pr}$ in toluene at $70{ }^{\circ} \mathrm{C}$ were monitored by ${ }^{1} \mathrm{H}$ NMR spectroscopy ([LA $]_{0}$ $=0.53 \mathrm{~mol} \cdot \mathrm{L}^{-1}:[\mathrm{LA}]_{0} /[\mathrm{Al}]=120,88$ and $69 ;[\mathrm{LA}]_{0}=0.20 \mathrm{~mol} \cdot \mathrm{L}^{-1}:[\mathrm{LA}]_{0} /[\mathrm{Al}]=100 ;$ $\left.[\mathrm{LA}]_{0}=0.10 \mathrm{~mol} \cdot \mathrm{L}^{-1}:[\mathrm{LA}]_{0} /[\mathrm{Al}]=60\right)$. In each case, an induction period and first-order kinetics in monomer were observed (Figure 4.3). Thus, the polymerization of $r a c-L A$ by (SB-3b)AlO ${ }^{\mathrm{i}}$ Pr presumably proceeds according to:

$$
-\mathrm{d}[\mathrm{LA}] / \mathrm{d} t=k_{\text {app }}[\mathrm{LA}]
$$

where $k_{\mathrm{app}}=k_{\mathrm{p}}[\mathrm{Al}]^{\mathrm{x}}$, and $k_{\mathrm{p}}$ is the propagation rate constant. To determine the order in catalyst, $\ln k_{\text {app }}$ was plotted versus $\ln [\mathrm{Al}]_{0}$ (Figure 4.4). The order in catalyst, calculated was 1.81. Therefore, the polymerization of rac-LA by (SB-3b)AlO ${ }^{\mathrm{i}} \mathrm{Pr}$ follows the following overall kinetic law:

$$
-\mathrm{d}[\mathrm{LA}] / \mathrm{d} t=k_{\mathrm{p}}[\mathrm{Al}]^{1.81}[\mathrm{LA}]
$$

In several reports on the ring-opening polymerization of lactones using zinc, ${ }^{23}$ ferrous, ${ }^{9}$ and stannous ${ }^{24}$ alkoxides similar fractional dependencies were observed. Such non-integer orders in catalyst are difficult to interpret mechanistically, but it is commonly believed to result from an equilibrium between dimeric and monomeric species in the polymerization medium. ${ }^{25}$ It is hypothesized that, the dimeric species in the solution will be in equilibrium with monomeric species and that there is a fast exchange between these two forms. When the propagation rate of the dimeric species 


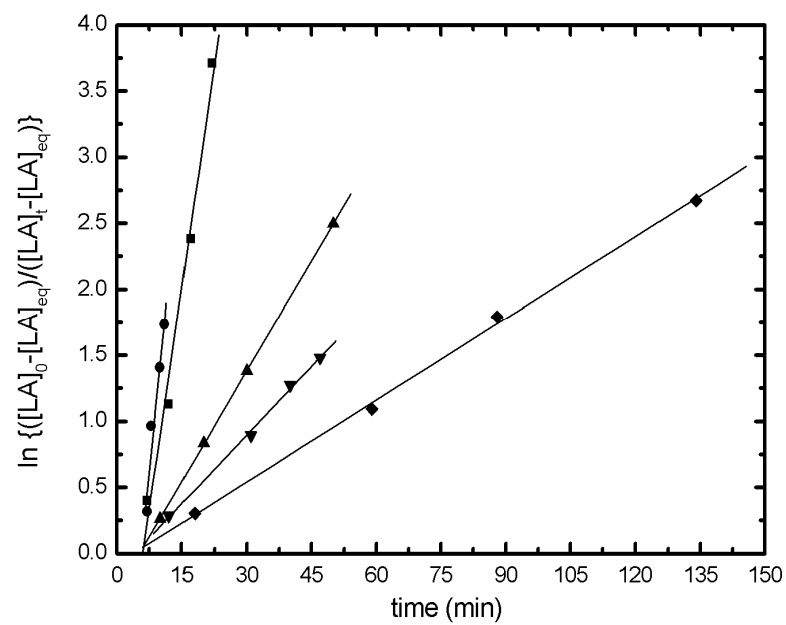

Figure 4.3 Semilogarithmic plots of rac-LA conversion with time in toluene at $70{ }^{\circ} \mathrm{C}$ with (SB-3b)AIO'Pr as catalyst $\left([\mathrm{LA}]_{0}=0.53 \mathrm{~mol} \cdot \mathrm{L}^{-1}: \bullet,[\mathrm{LA}]_{0} /[\mathrm{Al}]_{0}=69, k_{\mathrm{app}}=327 \times 10^{-3} \mathrm{~min}^{-1} ; \mathbf{m},[\mathrm{LA}]\right.$ ${ }_{0} /[\mathrm{Al}]_{0}=88, k_{\mathrm{app}}=224 \times 10^{-3} \mathrm{~min}^{-1} ; \boldsymbol{\Delta},[\mathrm{LA}]_{0} /[\mathrm{Al}]_{0}=120 k_{\mathrm{app}}=55.7 \times 10^{-3} \mathrm{~min}^{-1} ;[\mathrm{LA}]_{0}=0.20 \mathrm{~mol}$ $\mathrm{L}^{-1}: \boldsymbol{\nabla},[\mathrm{LA}]_{0} /[\mathrm{Al}]_{0}=100, k_{\mathrm{app}}=34.6 \times 10^{-3} \mathrm{~min}^{-1} ;[\mathrm{LA}]_{0}=0.10 \mathrm{~mol} \mathrm{~L}^{-1}: \bullet,[\mathrm{LA}]_{0} /[\mathrm{Al}]_{0}=60, k_{\mathrm{app}}=$ $\left.20.6 \times 10^{-3} \mathrm{~min}^{-1}\right)$.

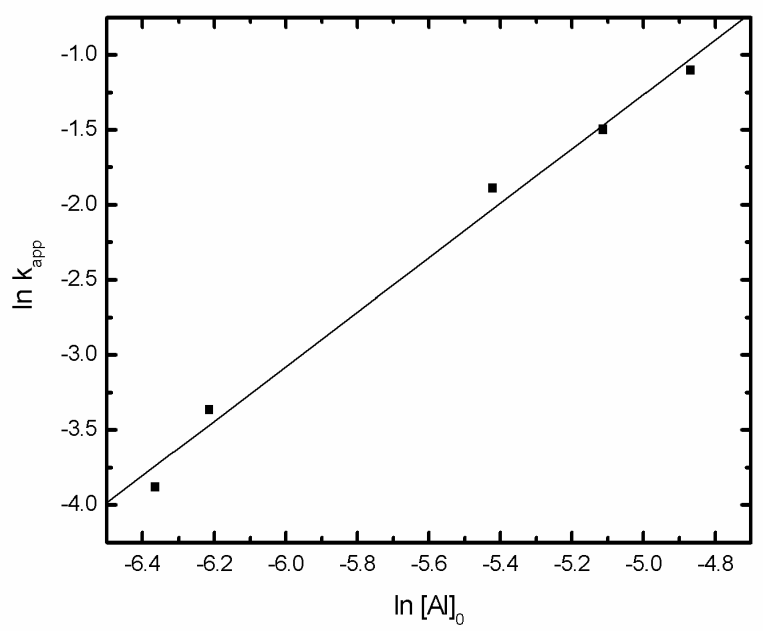

Figure 4.4 Plot of $\ln k_{\text {app }}$ versus $\ln$ concentration of (SB-3b)AlO ${ }^{\mathrm{i}} \mathrm{Pr}$ for the polymerization of rac-LA at $70^{\circ} \mathrm{C}$ in toluene.

is higher than that of the monomeric form, the kinetic order with respect to Al close to 2, may indicate that not all Al sites of the dimeric species are active in the 
polymerization. Comparison of the kinetic order in catalyst between (SB-2d)AlO $\mathrm{Pr}$ and (SB-3b)AlO ${ }^{\mathrm{i}} \mathrm{Pr}$ indicates that the bulky substituents ortho to the phenolic hydroxy group protect the active species to become aggregated, and thus form singular species in the polymerization system. It is also postulated that the singularity of active species accounts for the high stereoselectivity of catalysts and low PDI of the resultant polymers.

The "efficiency" factor is defined as the ratio of the theoretical $M_{\mathrm{n}}$, assuming that each aluminum atom of the active species initiates one polymer chain, and the experimentally found $M_{\mathrm{n}}$. Most of the efficiencies of the Schiff base aluminum initiators (Table 4.1) are approximately equal to 1.0, indicating that the molecular weights determined correlate well with the monomer conversion, and thus, reflect a controlled polymerization catalyzed by these initiators. The efficiencies of (SB-1e)AlEt and (SB-2f)AlEt were 1.47 and 1.48 respectively, much higher than 1.0, which suggests that significant transesterification took place during the polymerization. The initiators (SB-3a)AlEt and (SB-3b)AlEt bearing chlorine atoms on their phenolate rings had efficiencies of 0.56 and 0.70 , respectively. Most probably an equilibrium between monomeric and dimeric initiator species is present and not all Al centers are active in the polymerization.

Stereochemistry of rac-LA Polymerization. All polymerizations were carried out in toluene at $70{ }^{\circ} \mathrm{C}$, using bis(salicylidene) Schiff base aluminum isopropoxide catalysts generated by in-situ alcoholysis of bis(salicylidene) Schiff base aluminum ethyl complexes. Since all the Schiff base ligands prepared were achiral, it was anticipated that these catalysts only allow stereochemical control in the polymerization of rac-LA by a chain-end-control mechanism. ${ }^{26}$ According to Bernoullian statistics, successive additions of enantiomeric monomers are independent events, so the rates of addition of $(S, S)$ - and $(R, R)$-LA to the growing chain ends are not affected by the configuration of the last repeating unit attached to the aluminum center and atatic PLAs are most probably obtained. Because a preference for isotactic addition in the ROP of rac-LA was observed, Markovian statistics should be used to interpret the 60 
stereosequence distribution. ${ }^{27}$ According to first-order Markovian statistics, ${ }^{28}$ PLAs derived from rac-LA can exhibit up to five tetrad sequences in their ${ }^{1} \mathrm{H}$ NMR spectrum, which are denoted $m m m, m m r, r m m, m r m, r m r$. The relative ratios determine the ability of the catalyst to control racemic $[r$-diad] and meso [ $m$-diad] connectivity of the monomer units. Determination of the stereochemical microstructure of PLAs is performed by analysis of the signals in the methine region of homonuclear decoupled ${ }^{1} \mathrm{H}$ NMR spectra of the polymers. Analysis of PLA formed from rac-LA reveals that all the bis(salicylidene) Shiff base aluminum complexes have the ability to influence the tacticity of the polymer chains and this ability varies according to their different auxiliary ligand surroundings.

In previous work it was shown that $(\mathrm{SB}-2 \mathrm{~d}) \mathrm{AlO}^{\mathrm{i}} \mathrm{Pr}$ was a highly selective catalyst in rac-LA polymerization and afforded highly isotactic PLA with a $P_{\mathrm{m}}$ of 0.90 . At elevated temperatures of $110{ }^{\circ} \mathrm{C}$ or $130{ }^{\circ} \mathrm{C}$, the $P_{\mathrm{m}}$ decreased to 0.82 and 0.77 respectively.

According to first-order Markovian statistics, the probability for meso linkages is: ${ }^{29}$

$$
P_{m}=k_{m} /\left(k_{m}+k_{r}\right)=k_{S / S S}\left(k_{S / S S}+k_{S / R R}\right)=k_{R / R R} /\left(k_{R / R R}+k_{R / S S}\right)
$$

in which $k_{\mathrm{S} / \mathrm{SS}}$ and $k_{\mathrm{S} / \mathrm{RR}}$ are the propagation rates for the addition of a $(S, S)$-LA or $(R, R)$-LA monomer to the living chain with a $S$ lactic acid unit coordinated to the aluminum. $k_{\mathrm{R} / \mathrm{RR}}$ and $k_{\mathrm{R} / \mathrm{SS}}$ represent the propagation rate for the addition of a $(R, R)$-LA or $(S, S)$-LA monomer. According to the absolute reaction rate theory the following equations can be derived:

$$
\begin{aligned}
& P_{m}=k_{m} /\left(k_{m}+k_{r}\right)=k_{S / S S} /\left(k_{S / S S}+k_{S / R R}\right) \\
& P_{m}=k_{m} /\left(k_{m}+k_{r}\right)=k_{R / R R} /\left(k_{R / S S}+k_{R / R R}\right) \\
& k_{S / S S}=k_{R / R R}=k_{m}=(k T / h) \exp \left[\left(\Delta S_{m}^{\neq} / R\right)-\left(\Delta H_{m}^{\neq} / R T\right)\right] \\
& k_{S / R R}=k_{R / S S}=k_{r}=(k T / h) \exp \left[\left(\Delta S_{r}^{\neq} / R\right)-\left(\Delta H_{r}^{\neq} / R T\right)\right]
\end{aligned}
$$

defining the activation entropy and enthalpy differences between the formation of isotactic and syndiotactic stereosequences. Combination of equations 4 and 5 give equation 6 : 


$$
\frac{P_{m}}{1-P_{m}}=\frac{k_{m}}{k_{r}}=\exp \left[\left(\Delta S_{m}^{\neq}-\Delta S_{r}^{\neq}\right) / R-\left(\Delta H_{m}^{\neq}-\Delta H_{r}^{\neq}\right) / R T\right]
$$

The enthalpy difference can be determined from the slope of a line of $\ln P_{\mathrm{m}} /\left(1-P_{\mathrm{m}}\right)$ against $10^{3} / \mathrm{T}$ while the entropy difference is obtained from the intercept. A plot is presented in Figure 4.6 and the analysis reveals an activation entropy difference $\left(\Delta S_{\mathrm{m}} \neq\right.$ $\left.-\Delta S_{\mathrm{r}}^{\ddagger}\right)$ of $-18.0 \mathrm{cal} \cdot \mathrm{K}^{-1} \cdot \mathrm{mol}^{-1}$ and activation enthalpy difference $\left(\Delta H_{\mathrm{m}}^{\neq}-\Delta H_{\mathrm{r}}^{\ddagger}\right)$ of $-12.2 \mathrm{kcal} \cdot \mathrm{mol}^{-1}$ for the system (SB-2d)AlOiPr or (SB-2d)AlEt/2-propanol. Similarly, analysis of the microstructures of the resulting poly(rac-LA)s prepared by using (SB-1e)AlEt afforded a $\left(\Delta S_{\mathrm{m}}^{\neq}-\Delta S_{\mathrm{r}}^{\neq}\right)$and $\left(\Delta H_{\mathrm{m}}^{\neq}-\Delta H_{\mathrm{r}}^{\neq}\right)$of $-14.6 \mathrm{cal} \cdot \mathrm{K}^{-1} \cdot \mathrm{mol}^{-1}$ and $-7.23 \mathrm{kcal} \cdot \mathrm{mol}^{-1}$, respectively. The large difference in activation enthalpy may thus explain the preferred formation of isotactic stereosequences.

Furthermore, the polymerization data indicate that substituents at the ortho positions of the phenol groups significantly affect the ability of the catalysts to control monomer insertion. For instance, the $P_{\mathrm{m}}=0.67$ of (SB-1d)AlEt largely increases to $P_{\mathrm{m}}=0.90$ by the introduction of tert-butyl substituents as in (SB-2d)AlEt. Similar trends were found for the in-situ generated catalyst/initiators (SB-2a)AlEt $\left(P_{\mathrm{m}}=0.82\right)$ and (SB-1a)AlEt $\left(P_{\mathrm{m}}=0.71\right),(\mathrm{SB}-2 \mathbf{b})$ AlEt $\left(P_{\mathrm{m}}=0.86\right)$ and $(\mathrm{SB}-1 \mathbf{b})$ AlEt $\left(P_{\mathrm{m}}=0.67\right)$, and $(\mathrm{SB}-2 \mathrm{e}) \mathrm{AlEt}$ $\left(P_{\mathrm{m}}=0.82\right)$ and (SB-1e)AlEt $\left(P_{\mathrm{m}}=0.69\right)$ (Table 4.1). These large enhancements in stereoselectivities of catalysts in a chain-end-control polymerization by introducing bulky substituents at the ortho positions of the phenol group are consistent with previous observations reported by Nomura et $\mathrm{al}^{18}$ and Carpentier et $\mathrm{al}^{26}$ In such a reaction, the bulky substituents not only favor mononuclear complex formation, but also increase the influence of the stereogenic center coordinated to the aluminum on the insertion of the following chiral monomer.

Structural changes in the diimine bridge of the ligand also led to a significant change in selectivity of the catalysts. For example a PLA prepared with (SB-2g)AlEt $\left(P_{\mathrm{m}}=\right.$ $0.62)$ is less isotactic than that prepared with (SB-2a)AlEt $\left(P_{\mathrm{m}}=0.82\right)$. 


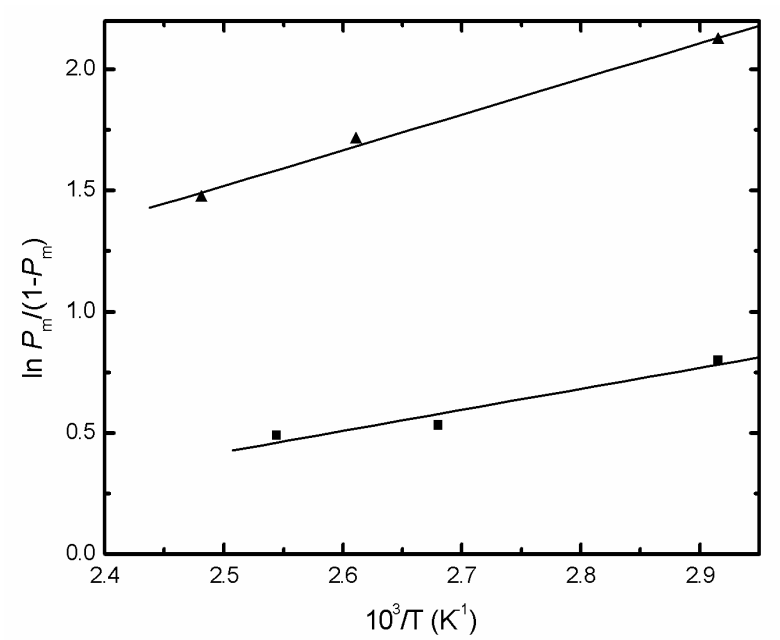

Figure 4.5 First-order Markovian relationship between the inverse of the polymerization temperature and the $\ln P_{\mathrm{m}} /\left(1-P_{\mathrm{m}}\right)$ of the resulting PLAs from rac-LA by using ( $\left.\mathbf{\Delta}\right)$ (SB-2d)AlEt/2-propanol and (匹) (SB-1e)AlEt/2-propanol as catalyst/initiator system, respectively.

The conjugated molecular structure resulting from the incorporation of a benzene ring in the backbone and the more rigid planar geometry leads to a decreased stereoselectivity. Comparing (SB-2e)AlEt $\left(P_{\mathrm{m}}=0.82\right)$ and $(\mathrm{SB}-2 \mathbf{b})$ AlEt $\left(P_{\mathrm{m}}=0.86\right)$ also confirms that an increase of rigidity in the diimine bridge leads to a decrease in stereoselectivity. The number of carbon atoms in the diimine bridge also has a large effect on the stereoselectivity of the catalyst. Catalyst (SB-2b)AlEt with a three carbon atom backbone was found to have a higher stereoselectivity $\left(P_{\mathrm{m}}=0.86\right)$ than (SB-2a)AlEt $\left(P_{\mathrm{m}}=0.82\right)$ with a two carbon atom backbone. Increasing the number of carbon atoms to four as in (SB-2c)AlEt gives a large decrease in stereoselectivity $\left(P_{\mathrm{m}}=\right.$ 0.69). Catalysts which are unsubstituted on the ortho position of the phenol groups like (SB-1a)AlEt, (SB-1b)AlEt and (SB-1c)AlEt show only minor differences in stereoselectivity towards $r a c$-LA polymerization.

By the introduction of gem alkyl groups in a three carbon atom diimine bridge (SB-2d)AlEt a higher stereoselectivity $\left(P_{\mathrm{m}}=0.90\right)$ is observed compared to (SB-2b)AlEt $\left(P_{\mathrm{m}}=0.86\right)$. These results reveal that structural factors, including substituents at the ortho positions of the phenol groups, the length of the diimine bridge 
and gem alkyl groups have a mutual effect in determining the stereoselectivity of the catalysts in rac-LA polymerization.

Transesterification reactions during polymerization influence the tacticity of the polymers and can be determined by ${ }^{13} \mathrm{C}$ NMR analyses of the methine region of PLA materials (Figure 4.6). According to Bero et al., ${ }^{30}$ in the ring-opening polymerization of $r a c$-LA the existence of the mrr tetrad with a chemical shift at 69.4 ppm can only result from transesterification. The transesterification coefficient $(\boldsymbol{T})$, calculated from the ratio $\boldsymbol{I}_{\mathrm{mrr}} / \boldsymbol{I}_{\max }$, where $\boldsymbol{I}_{\mathrm{mrr}}$ is the intensity of the $m r r$ tetrad signal and $\boldsymbol{I}_{\max }$ is the maximal intensity in a completely transesterified poly(rac-LA), was used to quantitatively estimate the degree of transesterification. The calculated $T$ values for (SB-1d)AlEt, (SB-2d)AlEt, and (SB-3b)AlEt systems are 47\%, 11\%, and 11\%, respectively (Table 4.2). The low $\boldsymbol{T}$ value (11\%) for (SB-2d)AlEt is in agreement with its efficiency factor (1.05) which is close to 1 . However, the high $\boldsymbol{T}$ value (47\%) for (SB-1d)AlEt will hypothetically lead to an efficiency factor much higher than 1, which is not in agreement with the efficiency factor of 1.05 found. A possible explanation is that although the extensive transesterification by using (SB-1d)AlEt will cause an efficiency much higher than 1 , the fact that there exists an equilibrium between the monomeric and dimeric species for (SB-1d)AlEt, and that not all Al centers may be active in the polymerization will counterbalance the effect of transesterification. The $m r m$ tetrad represents the frequency of changes between the two different enantiomeric blocks $-(R R)_{\mathrm{n}}-$ and $-(S S)_{\mathrm{n}}-$ along the propagating chains, and thus, its intensity is a measure for the chain-end-control ability of the catalyst. The $m r m$ tetrad intensities $(\boldsymbol{S})$ for the materials prepared by (SB-1d)AlEt, (SB-2d)AlEt, and (SB-3b)AlEt systems are 15.4\%, 7.2\%, and $15.4 \%$, respectively (Table 4.3). Considering that the $\mathrm{mrm}$ tetrad intensities of materials prepared by using (SB-1d)AlEt and (SB-3b)AlEt are approximately the same, the lower stereoselectivity of (SB-1d)AlEt $\left(P_{\mathrm{m}}=0.67\right)$ compared to $(\mathrm{SB}-3 \mathbf{b})$ AlEt $\left(P_{\mathrm{m}}=0.71\right)$ was largely attributed to the more extensive transesterification reactions $(T=47 \%)$ encountered for (SB-1d)AlEt than for (SB-3b)AlEt ( $T=11 \%)$. Moreover, transesterification reactions applying (SB-2d)AlEt with bulky tert-butyl substituents and (SB-3b)AlEt with chlorine substituents were at 64 
the same level ( $T$ values of $11 \%$ ), which suggests that the much higher stereoselectivity of (SB-2d)AlEt $\left(P_{\mathrm{m}}=0.90\right)$ as compared to (SB-3b)AlEt was mainly caused by its high chain-end-control ability, which is also reflected by a relatively low $\mathrm{mrm}$ tetrad intensity of $7.2 \%$.

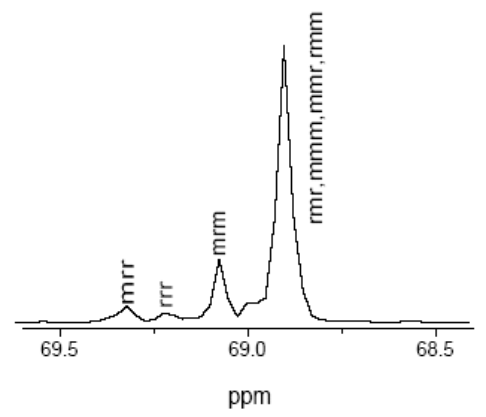

(a)

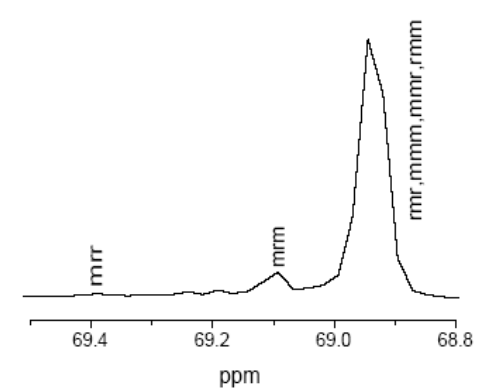

(b)

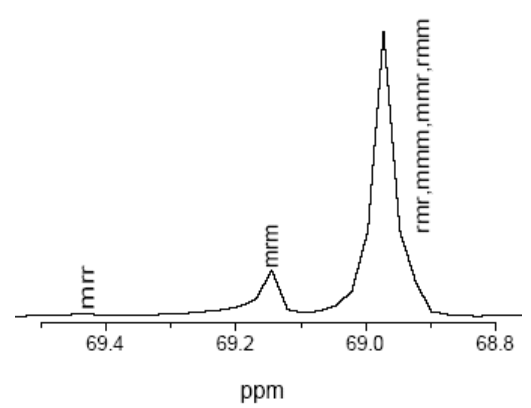

(c)

Figure 4.6 ${ }^{13} \mathrm{C}$ NMR spectra of poly(rac-LA) (methine region) prepared from (a) (SB-1d)AlEt; (b) (SB-2d)AlEt and (c) (SB-3b)AlEt in the presence of 2-propanol as an initiator. 
Table 4.2 Coefficient $T$ and $S$ for compounds (SB-1d)AlO ${ }^{\mathrm{i}} \mathrm{Pr}$, (SB-2d)AlO ${ }^{\mathrm{i}} \mathrm{Pr}$, and (SB-3b)AlO'Pr.

\begin{tabular}{|c|c|c|}
\hline Compound & $T^{a}$ & $\mathbf{S}^{\mathbf{b}}$ \\
\hline$(\mathrm{SB}-2 \mathrm{~d}) \mathrm{AlO}^{\mathrm{i}} \mathrm{Pr}$ & $11 \%$ & $7.2 \%$ \\
\hline (SB-1d)AIO'Pr & $47 \%$ & $15.4 \%$ \\
\hline (SB-3b)AlO'Pr & $11 \%$ & $15.4 \%$ \\
\hline
\end{tabular}

${ }^{a} \boldsymbol{T}$ is the transesterification coefficient used to quantitatively estimate the degree of transesterification; ${ }^{b} \boldsymbol{S}$ is the $m r m$ tetrad intensity, reflecting the percentage of stereo-errors in the polymer chains.

\section{CONCLUSIONS}

Microstructural analysis of the polymers formed by ring-opening polymerization of rac-LA initiated and catalyzed by in-situ generated achiral Schiff base aluminum isopropoxide complexes reveals that the tacticity of the growing polymer chains was largely influenced by the different ligand surroundings. Bulky substituents influence the enantiomeric form of the lactide monomer incorporated into the growing polymer chain and thus, significantly influence the stereoselectivity. Furthermore, kinetic analyses show that polymerizations of rac-LA by these complexes are first-order in lactide monomer. Without bulky substituents the active initiating species gave noninteger orders in catalysts, whereas for catalysts with bulky substituents the active species (not aggregated) gave first-order kinetics in catalyst. Bulky substituents reduce the polymerization rate of the catalysts. In contrast, electron-withdrawing chlorine substituents dramatically raise the polymerization rate. In addition, the presence of a highly conjugated structure as a bridge also raises the polymerization rate and lowers the selectivity as compared to the use of a more flexible ethylene bridge.

\section{ACKNOWLEDGEMENT}

This project was financially supported by the National Natural Science Foundation of China (20574066), the National Fund for Distinguished Young Scholars (50425309) and by the International Cooperation fund of Science and Technology (Key project 
2005DFA50290).

\section{REFERENCES AND NOTES}

[1] Jeong, B.; Bae, Y. H.; Lee, D. S.; Kim, S. W., Nature 1997, 388, 860-862.

[2] Uhrich, K. E.; Cannizzaro, S. M.; Langer, R. S.; Shakesheff, K. M., Chem. Rev. 1999, 99, 3181-3198.

[3] Dove, A. P.; Gibson, V. C.; Marshall, E. L.; Rzepa, H. S.; White, A. J. P.; Williams, D. J., J. Am. Chem. Soc. 2006, 128, 9834-9843.

[4] Chisholm, M. H.; Gallucci, J. C.; Krempner, C., Polyhedron 2007, 26, 4436-4444.

[5] Chisholm, M. H.; Huffman, J. C.; Phomphrai, K., J. Chem. Soc-Dalton Trans. 2001, 222-224.

[6] Chisholm, M. H.; Phomphrai, K., Inorganica Chimica Acta 2003, 350, 121-125.

[7] Chamberlain, B. M.; Cheng, M.; Moore, D. R.; Ovitt, T. M.; Lobkovsky, E. B.; Coates, G. W., J. Am. Chem. Soc. 2001, 123, 3229-3238.

[8] O'Keefe, B. J.; Monnier, S. M.; Hillmyer, M. A.; Tolman, W. B., J. Am. Chem. Soc. 2001, 123, 339-340.

[9] O'Keefe, B. J.; Breyfogle, L. E.; Hillmyer, M. A.; Tolman, W. B., J. Am. Chem. Soc. 2002, 124, 4384-4393.

[10] McGuinness, D. S.; Marshall, E. L.; Gibson, V. C.; Steed, J. W., J. Polym. Sci., Polym Chem. 2003, 41, 3798-3803.

[11] Wang, X.; Liao, K.; Quan, D.; Wu, Q., Macromolecules 2005, 38, 4611-4617.

[12] Chisholm, M. H.; Navarro-Llobet, D.; Simonsick, W. J., Macromolecules 2001, $34,8851-8857$.

[13]Chisholm, M. H.; Lin, C. C.; Gallucci, J. C.; Ko, B. T., J. Chem. Soc-Dalton Trans. 2003, 406-412.

[14]Stevels, W. M.; Ankone, M. J. K.; Dijkstra, P. J.; Feijen, J., Macromolecules 1996, 29, 6132-6138.

[15] Russell, S. K.; Gamble, C. L.; Gibbins, K. J.; Juhl, K. C. S.; Mitchell, W. S.; Tumas, A. J.; Hofmeister, G. E., Macromolecules 2005, 38, 10336-10340. 
[16] Cameron, P. A.; Jhurry, D.; Gibson, V. C.; White, A. J. P.; Williams, D. J.; Williams, S., Macromol. Rapid Commun. 1999, 20, 616-618.

[17] Bhaw-Luximon, A.; Jhurry, D.; Spassky, N., Polym. Bull. 2000, 44, 31-38.

[18] Nomura, N.; Ishii, R.; Akakura, M.; Aoi, K., J. Am. Chem. Soc. 2002, 124, 5938-5939.

[19] Jhurry, D.; Bhaw-Luximon, A.; Spassky, N., Macromol. Symp. 2001, 175, 67-79.

[20] Alcazar-Roman, L. M.; O'Keefe, B. J.; Hillmyer, M. A.; Tolman, W. B., J. Chem. Soc-Dalton Trans. 2003, 3082-3087.

[21] Duda, A.; Penczek, S., Macromolecules 1990, 23, 1636-1639.

[22] Yang, Y.; Tang, Z.; Pang, X.; Du, H.; Chen, X.; Jing, X., Chem. J. Chin. Univ. 2006, 27, 352-355.

[23] Williams, C. K.; Breyfogle, L. E.; Choi, S. K.; Nam, W.; Young, V. G.; Hillmyer, M. A.; Tolman, W. B., J. Am. Chem. Soc. 2003, 125, 11350-11359.

[24] Kowalski, A.; Libiszowski, J.; Duda, A.; Penczek, S., Macromolecules 2000, 33, 1964-1971.

[25] Ropson, N.; Dubois, P.; Jerome, R.; Teyssie, P., Macromolecules 1995, 28, 7589-7598.

[26] Amgoune, A.; Thomas, C. M.; Roisnel, T.; Carpentier, J. F., Chem-Eur. J. 2005, $12,169-179$.

[27] Thakur, K. A. M.; Kean, R. T.; Hall, E. S.; Kolstad, J. J.; Munson, E. J., Macromolecules 1998, 31, 1487-1494.

[28] Kasperczyk, J. E., Macromolecules 1995, 28, 3937-3939.

[29] Hocking, P. J.; Marchessault, R. H., Macromolecules 1995, 28, 6401-6409.

[30] Bero, M.; Kasperczyk, J.; Jedlinski, Z. J., Macromol. Chem. Phys. 1990, 191, 2287-2296. 


\section{Stereoselective Polymerization of Lactides using}

Bis(pyrrolidene) Schiff Base Aluminum Complexes

\section{ABSTRACT}

A series of aluminum ethyls and isopropoxides based upon a bis(pyrrolidene) Schiff base ligand framework has been prepared and characterized. NMR studies of the dissolved complexes indicate that they adopt a symmetric structure with a monomeric, five-coordinated aluminum center core. The aluminum ethyls used as catalysts in the presence of 2-propanol as initiator and the aluminum isopropoxides were applied for lactide polymerization in toluene to test their activities and stereoselectivities. All polymerizations are living, as evidenced by the narrow polydispersities and the good fit between calculated and found number-average molecular weights of the isolated polymers. All of these aluminum complexes polymerized $(S, S)$-lactide to highly isotactic PLA without epimerization of the monomer, furnished isotactic-biased polymer from rac-lactide, and gave atactic polymer from meso-lactide. The study of kinetics indicated that the activity of the bis(pyrrolidene) Schiff base aluminum initiator systems toward lactide polymerization decreases in the following order: $(S, S)$-lactide $>$ rac-lactide $>$ meso-lactide. The methyl substituents on the diimine bridge or on the pyrrole rings both exert significant influence on the course of the polymerizations, affecting both the stereoselectivity and the polymerization rate. Kinetics using $\left[\mathrm{L}^{2} \mathrm{AlEt}\right] / 2$-propanol (2a/2-propanol) and $\left[\mathrm{L}^{2} \mathrm{AlO}{ }^{\mathrm{i}} \mathrm{Pr}\right](\mathbf{2} \mathbf{b})$ indicated that the polymerizations are both first-order with respect to rac-lactide monomer and catalyst. The higher polymerization rate constant $\left(k_{\mathrm{p}}\right)$ values for $\left[\mathrm{L}^{2} \mathrm{AlO}{ }^{\mathrm{i}} \mathrm{Pr}\right](\mathbf{2} \mathbf{b})$ compared with those of $\left[\mathrm{L}^{2} \mathrm{AlEt}\right] / 2$-propanol (2a/2-propanol) revealed that in this case the overall polymerization rate was influenced by the relatively slow in situ alcoholysis reaction of aluminum ethyls. Polymerization experiments with $\left[\mathrm{L}^{2} \mathrm{AlO}{ }^{\mathrm{i}} \mathrm{Pr}\right](\mathbf{2 b})$ 
revealed that with this complex much faster $\left(k_{\mathrm{p}}=13.0 \mathrm{~L} \cdot \mathrm{mol}^{-1} \cdot \mathrm{min}^{-1}\right)$ lactide polymerizations can be achieved compared with other aluminum complexes.

\section{INTRODUCTION}

Since last decade, many single-site catalysts comprising zinc, ${ }^{1,2}$ and magnesium alkoxides $^{3-5}$ stabilized by $\beta$-diiminate ligand, aluminum complexes supported by fluorinated dialkoxy-diimino ligands, ${ }^{6}$ germanium, titanium, and lanthanide complexes ligated by mono- or multiphenolates the phenolate and bisphenolate ligated metal complexes $^{7-9}$ have been proven to be efficient initiator/catalyst systems that give a well controlled and stereoselective polymerization of LAs. The five-coordinated aluminum alkoxides supported by $N, N, O, O$-tetradentate bis(salicylidene) Schiff base ligands also occupy an important position among these catalysts. Because Spassky and coworkers ${ }^{10}$ have found that enantiomerically pure $(R)$-(SalBinap)-AlOCH 3 exhibited a 20:1 preference for the polymerization of $(S, S)$-LA over $(R, R)$-LA, leading to a tapered stereoblock microstructure, many achiral and chiral bis(salicylidene) Schiff base aluminum complexes have been reported that furnish highly isotactic, stereoblock PLAs from rac-LA via a chain-end-controlled mechanism (CEM) or site-control mechanism (SCM), and highly syndiotactic PLA material from meso-LA through a site-control mechanism. Recent studies reported by Gibson and coworkers ${ }^{11}$ and us ${ }^{12}$ have re-evaluated the achiral bis(salicylidene) Schiff base aluminum catalyst system to show the steric and electronic factor that influence the polymerization rate and stereoselectivity. However, almost all these bis(salicylidene) Schiff base aluminum catalysts do not have a high activity in LA polymerization, and the polymerization rates are much slower than the other reported metal catalyst systems.

Compared with the existing aluminum catalysts with a five-coordinated salicyaldehyde Schiff base ligand system, which have a high tacticity control toward rac-LA polymerization, the use of five-coordinated aluminum catalyst ligated by bis(pyrrolidene) Schiff base ligands in the ring-opening polymerizations has not been 
disclosed. Here, we report the synthesis of a series of aluminum ethyls and corresponding isopropoxides based on bis(pyrrolidene) Schiff base ligands. The stereoselectivity of in situ-formed aluminum isopropoxides from the corresponding aluminum ethyls toward rac-LA and meso-LA as well as the kinetics of the ring-opening polymerization of rac-LA, meso-LA, and $(S, S)$-LA with these systems were determined.

\section{EXPERIMENTAL SECTION}

General. All experiments were carried out under a dry nitrogen atmosphere using standard Schlenk techniques or in a glovebox. Toluene and hexane were distilled from Na-benzophenone before use. A $25 \mathrm{wt} \%$ solution of triethylaluminum in toluene (Aldrich) was used without prior purification. 1,3-Propanediamine (99\%) 2,2-dimethyl-1,3-propanediamine (99\%), pyrrole-2-carboxaldehyde $\quad(98 \%)$, 3,5-dimethylpyrrole-2-carboxaldehyde (95\%) from Aldrich were used without further purification. The monomers (S,S)-LA, rac-LA, and meso-LA (Purac Biochem b.v., The Netherlands) were purified two times by recrystallization from dry toluene and dried under vacuum. All glassware was dried in an oven before use.

1D ${ }^{1} \mathrm{H}(300 \mathrm{MHz})$ and ${ }^{13} \mathrm{C}(75 \mathrm{MHz})$ nuclear magnetic resonance (NMR) spectra were recorded on a Varian Unity 300 NMR spectrometer using $\mathrm{CDCl}_{3}$ solutions at 298 $\mathrm{K}$ and were referenced to shifts of residual $\mathrm{CHCl}_{3}\left(\delta=7.26\right.$ for ${ }^{1} \mathrm{H} \mathrm{NMR}$ and 77.0 for ${ }^{13} \mathrm{C}$ NMR). Homonuclear decoupled ${ }^{1} \mathrm{H}$ NMR, ${ }^{1} \mathrm{H}-{ }^{1} \mathrm{H}$ COSY, ${ }^{1} \mathrm{H}-{ }^{1} \mathrm{H}$ NOESY, and diffusion-ordered spectroscopy (DOSY) spectra were recorded on a Bruker Avance II $600 \mathrm{MHz}$ spectrometer operating at $600.13 \mathrm{MHz}$ at $295 \mathrm{~K}$, and variable temperature (VT) ${ }^{1} \mathrm{H}$ NMR spectra were recorded on the same Bruker Avance II 600.13 MHz spectrometer in the temperature range of 295 to $360 \mathrm{~K}$. The spectrometer was equipped with a Great 3/10 gradient amplifier and a triple-nucleus TXI probe with z gradient. All experiments were performed using standard pulse sequences from the Bruker library. Pulsed filed gradient stimulated echo (PFGSE) diffusion experiments were performed using the bipolar stimulated echo sequence with 32 increments in the gradient strength 
(2-95\%), typically 16 averages per increment step, and $100 \mathrm{~ms}$ diffusion time. Gel permeation chromatography (GPC) measurements were conducted with a Waters 410 GPC with tetrahydrofuran (THF) as the eluent (flow rate: $1 \mathrm{~mL} \cdot \mathrm{min}^{-1}$ at $35^{\circ} \mathrm{C}$ ). The molecular weights were calibrated against polystyrene (PS) standards. Matrix assisted laser desorption ionization time-of-flight (MALDI-TOF) mass spectrometry using a Voyager-DE-RP MALDI-TOF mass spectrometer (Applied Biosystems/PerSeptive Biosystems, Framingham, MA) equipped with delayed extraction. A 337 nm UV nitrogen laser producing $4 \mathrm{~ns}$ pulses was used, and the mass spectra were obtained in the linear and reflection modes.

Synthesis of Ligands. Synthesis of 1,3-Bis(pyrrole-2-yl-methyleneamine)propane $\left(\mathbf{H}_{2} \mathbf{L}^{\mathbf{1}}\right)$. Pyrrole-2-carboxaldehyde (1.90 g, $\left.20 \mathrm{mmol}\right)$ and 1,3-propanediamine (0.74 g, $10 \mathrm{mmol}$ ) were dissolved in $10 \mathrm{~mL}$ of methanol. The mixture was stirred and a catalytic amount of glacial acetic acid was added. After a few seconds, a white precipitate was formed. The suspension was allowed to stir at room temperature for 2 h. The white solid was collected by filtration, washed with cold methanol and dried under vacuum to give the pure product. Yield: $1.78 \mathrm{~g}(78 \%) .{ }^{1} \mathrm{H}$ NMR (300 MHz, $\left.\mathrm{CDCl}_{3}, 25^{\circ} \mathrm{C}\right): \delta=8.05(\mathrm{~s}, 2 \mathrm{H}, \mathrm{N}=\mathrm{CH}), 6.87\left(\mathrm{~d}, J_{\mathrm{H}-\mathrm{H}}=1.2 \mathrm{~Hz}, 2 \mathrm{H}\right.$, pyrrole- $\left.\boldsymbol{H}\right), 6.46$ $\left(\mathrm{dd}, J_{\mathrm{H}-\mathrm{H}}=1.5 \mathrm{~Hz}, J_{\mathrm{H}-\mathrm{H}}=3.6 \mathrm{~Hz}, 2 \mathrm{H}\right.$, pyrrole- $\left.\boldsymbol{H}\right), 6.23\left(\mathrm{dd}, J_{\mathrm{H}-\mathrm{H}}=3.0 \mathrm{~Hz}, J_{\mathrm{H}-\mathrm{H}}=3.6\right.$ $\mathrm{Hz}, 2 \mathrm{H}$, pyrrole- $\boldsymbol{H}), 3.60\left(\mathrm{td}, 4 \mathrm{H}, J_{\mathrm{H}-\mathrm{H}}=1.2 \mathrm{~Hz}, J_{\mathrm{H}-\mathrm{H}}=7.2 \mathrm{~Hz}, \mathrm{NCH}_{2}\right), 1.98\left(\mathrm{t}, 2 \mathrm{H}, J_{\mathrm{H}-\mathrm{H}}\right.$ $\left.=6.6 \mathrm{~Hz}, \mathrm{CH}_{2} \mathrm{CH}_{2} \mathrm{CH}_{2}\right) .{ }^{13} \mathrm{C} \mathrm{NMR}\left(75 \mathrm{MHz}, \mathrm{CDCl}_{3}, 25{ }^{\circ} \mathrm{C}\right): \delta=152.3(\boldsymbol{C H}=\mathrm{N})$, 130.1, 122.0, 114.3, 109.5 (pyrrole-C), $58.1\left(\mathrm{NCH}_{2}\right), 32.6\left(\mathrm{CH}_{2} \mathrm{CH}_{2} \mathrm{CH}_{2}\right)$. Anal. Calcd for $\mathrm{C}_{13} \mathrm{H}_{16} \mathrm{~N}_{4}$ : C, 68.39; H, 7.06; N, 24.54. Found C, 68.10; H, 6.89; N, 24.87.

Synthesis of 2,2-Dimethyl-1,3-Bis(pyrrole-2-yl-methyleneamine)propane $\left(\mathbf{H}_{2} \mathbf{L}^{2}\right)$. The method is similar to that used for $\mathbf{H}_{2} \mathbf{L}^{\mathbf{1}}$ except that 2,2-dimethyl-1,3-propanediamine (1.02 g, $10 \mathrm{mmol}$ ) was used as reagent. Yield: 76\%. ${ }^{1} \mathrm{H}$ NMR (300 MHz, $\left.\mathrm{CDCl}_{3}, 25{ }^{\circ} \mathrm{C}\right): \delta=7.98(\mathrm{~s}, 2 \mathrm{H}, \mathrm{N}=\mathrm{C} \boldsymbol{H}), 6.90(\mathrm{~s}, 2 \mathrm{H}$, pyrrole- $\boldsymbol{H}), 6.46\left(\mathrm{dd}, J_{\mathrm{H}-\mathrm{H}}=1.5\right.$ $\mathrm{Hz}, J_{\mathrm{H}-\mathrm{H}}=3.6 \mathrm{~Hz}, 2 \mathrm{H}$, pyrrole- $\left.\boldsymbol{H}\right), 6.24\left(\mathrm{dd}, J_{\mathrm{H}-\mathrm{H}}=2.4 \mathrm{~Hz}, J_{\mathrm{H}-\mathrm{H}}=3.9 \mathrm{~Hz}, 2 \mathrm{H}\right.$, pyrrole- $\boldsymbol{H}), 3.41\left(\mathrm{~d}, J_{\mathrm{H}-\mathrm{H}}=1.2 \mathrm{~Hz}, 4 \mathrm{H}, \mathrm{NCH}_{2}\right), 0.97\left(\mathrm{~s}, 6 \mathrm{H}, \mathrm{C}\left(\mathrm{CH}_{3}\right)_{2}\right) .{ }^{13} \mathrm{C} \mathrm{NMR}(75$ $\left.\mathrm{MHz}, \mathrm{CDCl}_{3}, 25^{\circ} \mathrm{C}\right): \delta=152.2(\boldsymbol{C H}=\mathrm{N}), 130.4,122.1,114.2,109.5$ (pyrrole- $\boldsymbol{C}$ ), 69.7 72 
$\left(\mathrm{NCH}_{2}\right), 37.2\left(\boldsymbol{C}\left(\mathrm{CH}_{3}\right)_{2}\right), 24.4\left(\mathrm{C}\left(\boldsymbol{C H}_{3}\right)_{2}\right)$. Anal. Calcd for $\mathrm{C}_{15} \mathrm{H}_{20} \mathrm{~N}_{4}: \mathrm{C}, 70.28 ; \mathrm{H}, 7.86$; N, 21.86. Found C, 70.07; H, 8.01; N, 21.97.

Synthesis of 2, 2-Dimethyl-1, 3-Bis(3, 5-dimethyl-pyrrole-2-yl-methyleneamine) propane $\left(\mathbf{H}_{2} \mathbf{L}^{3}\right)$. The method is similar to that used for $\mathbf{H}_{2} \mathbf{L}^{1}$ except that 3,5dimethylpyrrole-2-carboxaldehyde (2.46 g, $20 \mathrm{mmol})$ and 2,2-dimethyl-1,3propanediamine (1.02 g, $10 \mathrm{mmol})$ were used as reagents. Yield: 75\%. ${ }^{1} \mathrm{H}$ NMR (300 $\left.\mathrm{MHz}, \mathrm{CDCl}_{3}, 25^{\circ} \mathrm{C}\right): \delta=8.00(\mathrm{~s}, 2 \mathrm{H}, \mathrm{N}=\mathrm{CH}), 5.73(\mathrm{~s}, 2 \mathrm{H}$, pyrrole- $\boldsymbol{H}), 3.37(\mathrm{~s}, 4 \mathrm{H}$, $\left.\mathrm{NCH}_{2}\right), 2.23$ (s, 6H, pyrrole- $\left.\mathrm{CH}_{3}\right), 2.14$ (s, 6H, pyrrole- $\left.\mathrm{CH}_{3}\right), 0.97$ (s, 6H, C(CH $\left.\left.{ }_{3}\right)_{2}\right)$. ${ }^{13} \mathrm{C}$ NMR $\left(75 \mathrm{MHz}, \mathrm{CDCl}_{3}, 25{ }^{\circ} \mathrm{C}\right): \delta=149.9(\boldsymbol{C H}=\mathrm{N}), 131.4,125.4,124.4,109.7$ (pyrrole- $\boldsymbol{C}$ ), $70.3\left(\mathrm{NCH}_{2}\right), 37.1\left(\boldsymbol{C}\left(\mathrm{CH}_{3}\right)_{2}\right), 24.5\left(\mathrm{C}\left(\boldsymbol{C} \mathrm{H}_{3}\right)_{2}\right), 13.0$ (pyrrole- $\left.\boldsymbol{C H} \mathrm{H}_{3}\right), 10.4$ (pyrrole- $\mathrm{CH}_{3}$ ). Anal. Calcd for $\mathrm{C}_{19} \mathrm{H}_{28} \mathrm{~N}_{4}$ : C, 73.04; H, 9.03; N, 17.93. Found C, 73.21; H, 8.97; N, 18.27.

Synthesis of Complexes. Synthesis of $\left[\mathrm{L}^{1} \mathrm{AlEt}\right]$ (1a). Triethylaluminum $(0.10 \mathrm{~g}$, $0.88 \mathrm{mmol})$ in $3 \mathrm{~mL}$ of toluene was added to a suspension of $\mathbf{H}_{2} \mathbf{L}^{1}(0.20 \mathrm{~g}, 0.88 \mathrm{mmol})$ in $1 \mathrm{~mL}$ of toluene. After stirring for $2 \mathrm{~h}$ at room temperature, the mixture was heated to $70{ }^{\circ} \mathrm{C}$ for another $2 \mathrm{~h}$. The white precipitate was filtered, washed with hexane, and subsequently dried under vacuum for $24 \mathrm{~h}$. An analytical pure product was obtained in $82 \%$ yield. ${ }^{1} \mathrm{H}$ NMR $\left(300 \mathrm{MHz}, \mathrm{CDCl}_{3}, 25{ }^{\circ} \mathrm{C}\right): \delta=8.08(\mathrm{~s}, 2 \mathrm{H}, \mathrm{N}=\mathrm{CH}), 7.53\left(\mathrm{~d}, J_{\mathrm{H}-\mathrm{H}}\right.$ $=1.8 \mathrm{~Hz}, 2 \mathrm{H}$, pyrrole- $\boldsymbol{H}), 6.85\left(\mathrm{dd}, J_{\mathrm{H}-\mathrm{H}}=0.6 \mathrm{~Hz}, J_{\mathrm{H}-\mathrm{H}}=3.3 \mathrm{~Hz}, 2 \mathrm{H}\right.$, pyrrole- $\left.\boldsymbol{H}\right), 6.50$ $\left(\mathrm{dd}, J_{\mathrm{H}-\mathrm{H}}=1.8 \mathrm{~Hz}, J_{\mathrm{H}-\mathrm{H}}=3.3 \mathrm{~Hz}, 2 \mathrm{H}\right.$, pyrrole- $\left.\left.\boldsymbol{H}\right), 3.86(\mathrm{~d}, 2 \mathrm{H}, \mathrm{NCH})_{2}\right), 3.75(\mathrm{~d}, 2 \mathrm{H}$, $\left.\mathrm{NCH}_{2}\right), 2.10$ (s, 1H, $\left.\mathrm{CH}_{2} \mathrm{CH}_{2} \mathrm{CH}_{2}\right), 1.89$ (s, 1H, $\left.\mathrm{CH}_{2} \mathrm{CH}_{2} \mathrm{CH}_{2}\right), 0.80$ (t, 3H, $\mathrm{AlCH}_{2} \mathrm{CH}_{3}$ ), -0.15 (q, 2H, $\left.\mathrm{AlCH}_{2} \mathrm{CH}_{3}\right) .{ }^{13} \mathrm{C} \mathrm{NMR}$ data are not available due to the limited solubility of complex [ $\left.\mathrm{L}^{1} \mathrm{AlEt}\right]$ (1a). Anal. Calcd for $\mathrm{C}_{15} \mathrm{H}_{19} \mathrm{AlN}_{4}$ : C, 63.81; H, 6.78; N, 19.85 . Found C, 64.06; H, 7.11; N, 19.37.

Synthesis of $\left[\mathrm{L}^{2} \mathrm{AlEt}\right]$ (2a). Triethylaluminum $(0.089 \mathrm{~g}, 0.78 \mathrm{mmol})$ in $5 \mathrm{~mL}$ of hexane was added to a solution of $\mathbf{H}_{2} \mathbf{L}^{2}(0.20 \mathrm{~g}, 0.78 \mathrm{mmol})$ in $2 \mathrm{~mL}$ of toluene. After stirring for $2 \mathrm{~h}$ at room temperature, the mixture was heated to $70{ }^{\circ} \mathrm{C}$ for another $2 \mathrm{~h}$. The mixture was slowly cooled to room temperature overnight to yield colorless crystals. After washing with hexane and subsequent drying under vacuum for $24 \mathrm{~h}$ an 
analytically pure product was obtained in $71 \%$ yield. ${ }^{1} \mathrm{H}$ NMR $\left(300 \mathrm{MHz}, \mathrm{CDCl}_{3}, 25\right.$ $\left.{ }^{\circ} \mathrm{C}\right): \delta=7.84(\mathrm{~s}, 2 \mathrm{H}, \mathrm{N}=\mathrm{CH}), 7.40\left(\mathrm{t}, J_{\mathrm{H}-\mathrm{H}}=0.6 \mathrm{~Hz}, 2 \mathrm{H}\right.$, pyrrole- $\left.\boldsymbol{H}\right), 6.69\left(\mathrm{dd}, J_{\mathrm{H}-\mathrm{H}}=\right.$ $0.6 \mathrm{~Hz}, J_{\mathrm{H}-\mathrm{H}}=3.6 \mathrm{~Hz}, 2 \mathrm{H}$, pyrrole- $\left.\boldsymbol{H}\right), 6.35\left(\mathrm{dd}, J_{\mathrm{H}-\mathrm{H}}=1.8 \mathrm{~Hz}, J_{\mathrm{H}-\mathrm{H}}=3.6 \mathrm{~Hz}, 2 \mathrm{H}\right.$, pyrrole- $\boldsymbol{H}), 3.82\left(\mathrm{~d}, J_{\mathrm{H}-\mathrm{H}}=12.0 \mathrm{~Hz}, 2 \mathrm{H}, \mathrm{NCH}_{2}\right), 3.26\left(\mathrm{~d}, J_{\mathrm{H}-\mathrm{H}}=12.0 \mathrm{~Hz}, 2 \mathrm{H}, \mathrm{NCH}_{2}\right)$, 1.06 (s, 3H, C(CH $\left.)_{2}\right), 0.89$ (s, 3H, C(CH $\left.)_{2}\right), 0.82$ (t, 3H, $\left.\mathrm{AlCH}_{2} \mathrm{CH}_{3}\right),-0.15$ (q, 2H, $\left.\mathrm{AlCH}_{2} \mathrm{CH}_{3}\right) .{ }^{13} \mathrm{C} \mathrm{NMR}\left(75 \mathrm{MHz}, \mathrm{CDCl}_{3}, 25{ }^{\circ} \mathrm{C}\right): \delta=159.1(\mathrm{~N}=\boldsymbol{C H}), 135.4,134.6$, 116.3, 113.5 (pyrrole- $\boldsymbol{C}$ ), $\left.67.7\left(\mathrm{NCH}_{2}\right), 35.6\left(\boldsymbol{C}\left(\mathrm{CH}_{3}\right)_{2}\right), 25.8,22.1\left(\mathrm{C}_{(} C_{3}\right)_{2}\right), 9.1$ $\left(\mathrm{AlCH}_{2} \mathrm{CH}_{3}\right),-0.4\left(\mathrm{AlC} \mathrm{H}_{2} \mathrm{CH}_{3}\right)$. Anal. Calcd for $\mathrm{C}_{17} \mathrm{H}_{23} \mathrm{AlN}_{4}: \mathrm{C}, 65.79 ; \mathrm{H}, 7.47 ; \mathrm{N}$, 18.05. Found C, 66.20; H, 7.99; N, 17.92 .

Synthesis of $\left[\mathrm{L}^{3} \mathrm{AlEt}\right]$ (3a). Triethylaluminum $(0.073 \mathrm{~g}, 0.64 \mathrm{mmol})$ in $4.1 \mathrm{~mL}$ of hexane was added to a solution of $\mathbf{H}_{2} \mathbf{L}^{3}(0.20 \mathrm{~g}, 0.64 \mathrm{mmol})$ in $2 \mathrm{~mL}$ of toluene. After stirring for $2 \mathrm{~h}$ at room temperature, the mixture was heated to $70{ }^{\circ} \mathrm{C}$ for another $2 \mathrm{~h}$. The mixture was slowly cooled to room temperature overnight to yield colorless crystals. After washing with hexane and drying under vacuum for $24 \mathrm{~h}$ an analytical pure product was obtained in $69 \%$ yield. ${ }^{1} \mathrm{H} \mathrm{NMR}\left(300 \mathrm{MHz}, \mathrm{CDCl}_{3}, 25{ }^{\circ} \mathrm{C}\right): \delta=7.69$ (s, 2H, N=CH), $5.84(\mathrm{~s}, 2 \mathrm{H}$, pyrrole- $\boldsymbol{H}), 3.54\left(\mathrm{~d}, J_{\mathrm{H}-\mathrm{H}}=12.0 \mathrm{~Hz}, 2 \mathrm{H}, \mathrm{NCH} \boldsymbol{H}_{2}\right), 3.24$ (d, $\left.J_{\mathrm{H}-\mathrm{H}}=12.0 \mathrm{~Hz}, 2 \mathrm{H}, \mathrm{NCH} \boldsymbol{H}_{2}\right), 2.17\left(\mathrm{~s}, 6 \mathrm{H}\right.$, pyrrole- $\left.\mathrm{CH}_{3}\right), 2.12\left(\mathrm{~s}, 6 \mathrm{H}\right.$, pyrrole-C $\left.\boldsymbol{H}_{3}\right), 1.12$ (s, 3H, C(CH $\left.)_{2}\right), 0.92$ (s, 3H, C(CH $\left.)_{2}\right), 0.84$ (t, 3H, $\left.\mathrm{AlCH}_{2} \mathrm{CH}_{3}\right), 0.02$ (q, 2H, $\left.\mathrm{AlCH}_{2} \mathrm{CH}_{3}\right) .{ }^{13} \mathrm{C} \mathrm{NMR}\left(75 \mathrm{MHz}, \mathrm{CDCl}_{3}, 25{ }^{\circ} \mathrm{C}\right): \delta=154.8(\mathrm{~N}=\boldsymbol{C H}), 147.9,132.9$, 129.9, 115.0 (pyrrole- $\boldsymbol{C}$ ), $\left.66.1\left(\mathrm{NCH}_{2}\right), 35.8\left(\boldsymbol{C}\left(\mathrm{CH}_{3}\right)_{2}\right), 26.5,25.8\left(\mathrm{C}_{(} \boldsymbol{C} \mathrm{H}_{3}\right)_{2}\right), 15.6$ (pyrrole- $\boldsymbol{C H}$ ), 10.7 (pyrrole- $\boldsymbol{C H}$ ), $9.7\left(\mathrm{AlCH}_{2} \boldsymbol{C H}_{3}\right), 2.7\left(\mathrm{AlCH}_{2} \mathrm{CH}_{3}\right)$. Anal. Calcd for $\mathrm{C}_{21} \mathrm{H}_{31} \mathrm{AlN}_{4}$ : C, 68.82; H, 8.53; N, 15.29. Found C, 69.41; H, 8.89; N, 15.02.

Synthesis of $\left[\mathrm{L}^{2} \mathrm{AlO}{ }^{\mathrm{i}} \mathrm{Pr}\right]$ (2b). 2-Propanol $(0.019 \mathrm{~g}, 0.32 \mathrm{mmol})$ in $2 \mathrm{~mL}$ of toluene was added to a suspension of [ $\left.\mathrm{L}^{2} \mathrm{AlEt}\right](\mathbf{2 a})(0.10 \mathrm{~g}, 0.32 \mathrm{mmol})$ in $5 \mathrm{~mL}$ of a mixed solution of toluene and hexane $(1: 3 \mathrm{v} / \mathrm{v})$ at room temperature. After the mixture was stirred for $2 \mathrm{~h}$ at $70{ }^{\circ} \mathrm{C}$, it was slowly cooled to room temperature overnight. Colorless crystals were obtained which were filtered and washed with hexane. After drying under vacuum for $24 \mathrm{~h}$, an analytically pure product was obtained in $65 \%$ yield. ${ }^{1} \mathrm{H}$ NMR $\left(300 \mathrm{MHz}, \mathrm{CDCl}_{3}, 25^{\circ} \mathrm{C}\right): \delta=7.82(\mathrm{~s}, 2 \mathrm{H}, \mathrm{N}=\mathrm{CH}), 7.36\left(\mathrm{t}, J_{\mathrm{H}-\mathrm{H}}=0.6 \mathrm{~Hz}, 2 \mathrm{H}\right.$, pyrrole- $\boldsymbol{H}), 6.67\left(\mathrm{dd}, J_{\mathrm{H}-\mathrm{H}}=0.6 \mathrm{~Hz}, J_{\mathrm{H}-\mathrm{H}}=3.6 \mathrm{~Hz}, 2 \mathrm{H}\right.$, pyrrole- $\left.\boldsymbol{H}\right), 6.33\left(\mathrm{dd}, J_{\mathrm{H}-\mathrm{H}}=1.8\right.$ 74 
$\mathrm{Hz}, J_{\mathrm{H}-\mathrm{H}}=3.6 \mathrm{~Hz}, 2 \mathrm{H}$, pyrrole- $\left.\boldsymbol{H}\right), 3.88\left(\mathrm{~d}, J_{\mathrm{H}-\mathrm{H}}=12.0 \mathrm{~Hz}, 2 \mathrm{H}, \mathrm{NC} \boldsymbol{H}_{2}\right), 3.79(\mathrm{~m}, 1 \mathrm{H}$, $\left.\mathrm{OCH}\left(\mathrm{CH}_{3}\right)_{2}\right), 3.23\left(\mathrm{~d}, J_{\mathrm{H}-\mathrm{H}}=12.0 \mathrm{~Hz}, 2 \mathrm{H}, \mathrm{NCH}_{2}\right), 1.07\left(\mathrm{~s}, 3 \mathrm{H}, \mathrm{C}\left(\mathrm{CH}_{3}\right)_{2}\right), 1.00(\mathrm{~m}, 6 \mathrm{H}$, $\left.\mathrm{OCH}\left(\mathrm{CH}_{3}\right)_{2}\right), 0.89\left(\mathrm{~s}, 3 \mathrm{H}, \mathrm{C}\left(\mathrm{CH}_{3}\right)_{2}\right) \cdot{ }^{13} \mathrm{C} \mathrm{NMR}\left(75 \mathrm{MHz}, \mathrm{CDCl}_{3}, 25{ }^{\circ} \mathrm{C}\right): \delta=159.8$ $(\mathrm{N}=\boldsymbol{C H}), 136.0,134.4,117.1,113.8$ (pyrrole- $\boldsymbol{C}), 67.4\left(\mathrm{NCH}_{2}\right), 62.9\left(\mathrm{O} \boldsymbol{C H}\left(\mathrm{CH}_{3}\right)_{2}\right)$, $35.7\left(\boldsymbol{C}\left(\mathrm{CH}_{3}\right)_{2}\right), 30.9,27.6\left(\mathrm{OCH}\left(\mathrm{CH}_{3}\right)_{2}\right), 25.8,22.3\left(\mathrm{C}\left(\boldsymbol{C H}_{3}\right)_{2}\right)$. Anal. Calcd for $\mathrm{C}_{18} \mathrm{H}_{25} \mathrm{AlN}_{4} \mathrm{O}: \mathrm{C}, 63.51 ; \mathrm{H}, 7.40 ; \mathrm{N}, 16.46$. Found $\mathrm{C}, 63.89 ; \mathrm{H}, 7.76 ; \mathrm{N}, 16.12$.

Synthesis of $\left[\mathrm{L}^{3} \mathrm{AlO} \mathrm{i}^{\mathrm{P}}\right]$ (3b). 2-Propanol $(0.038 \mathrm{~g}, 0.63 \mathrm{mmol})$ in $4 \mathrm{~mL}$ of toluene was added to a suspension of $\left[\mathrm{L}^{3} \mathrm{AlEt}\right](3 \mathrm{a})(0.23 \mathrm{~g}, 0.63 \mathrm{mmol})$ in $5 \mathrm{~mL}$ of a mixed solution of toluene and hexane $(1: 3 \mathrm{v} / \mathrm{v})$ at room temperature. After the mixture was stirred for $2 \mathrm{~h}$ at $70^{\circ} \mathrm{C}$, it was slowly cooled to room temperature overnight. Colorless crystals were obtained which were filtered and washed with hexane. After drying under vacuum for $24 \mathrm{~h}$, an analytically pure product was obtained in $62 \%$ yield. ${ }^{1} \mathrm{H}$ $\operatorname{NMR}\left(300 \mathrm{MHz}, \mathrm{CDCl}_{3}, 25^{\circ} \mathrm{C}\right): \delta=7.68(\mathrm{~s}, 2 \mathrm{H}, \mathrm{N}=\mathrm{C} \boldsymbol{H}), 5.82(\mathrm{~s}, 2 \mathrm{H}$, pyrrole- $\boldsymbol{H}), 3.83$ $\left.\left(\mathrm{m}, 1 \mathrm{H}, \mathrm{OCH}\left(\mathrm{CH}_{3}\right)_{2}\right), 3.46\left(\mathrm{~d}, J_{\mathrm{H}-\mathrm{H}}=12.0 \mathrm{~Hz}, 2 \mathrm{H}, \mathrm{NCH}\right)_{2}\right), 3.24\left(\mathrm{~d}, J_{\mathrm{H}-\mathrm{H}}=12.0 \mathrm{~Hz}, 2 \mathrm{H}\right.$, $\left.\mathrm{NCH}_{2}\right), 2.14$ (s, 12H, pyrrole- $\left.\mathrm{CH}_{3}\right), 1.20$ (s, 3H, C(CH $\left.)_{2}\right), 1.01\left(\mathrm{~d}, 6 \mathrm{H}, \mathrm{OCH}\left(\mathrm{CH}_{3}\right)_{2}\right)$, $0.96\left(\mathrm{~s}, 3 \mathrm{H}, \mathrm{C}\left(\mathrm{CH}_{3}\right)_{2}\right) .{ }^{13} \mathrm{C} \mathrm{NMR}\left(75 \mathrm{MHz}, \mathrm{CDCl}_{3}, 25^{\circ} \mathrm{C}\right): \delta=155.3(\mathrm{~N}=\boldsymbol{C H}), 148.6$, 132.5, 130.8, 115.3 (pyrrole- $\boldsymbol{C}$ ), $65.5\left(\mathrm{NCH}_{2}\right), 62.5\left(\mathrm{OCH}\left(\mathrm{CH}_{3}\right)_{2}\right), 35.6\left(\boldsymbol{C}\left(\mathrm{CH}_{3}\right)_{2}\right)$, 28.0, $26.8\left(\mathrm{OCH}\left(\boldsymbol{C H}_{3}\right)_{2}\right), 26.6,26.5\left(\mathrm{C}\left(\boldsymbol{C H}_{3}\right)_{2}\right), 15.3$ (pyrrole- $\left.\boldsymbol{C} \mathrm{H}_{3}\right), 10.6$ (pyrrole- $\left.\boldsymbol{C} \mathrm{H}_{3}\right)$. Anal. Calcd for $\mathrm{C}_{22} \mathrm{H}_{33} \mathrm{AlN}_{4} \mathrm{O}$ : C, 66.64; H, 8.39; N, 14.13. Found C, 67.25; H, 8.48; N, 13.99.

Lactide Polymerization. In a glovebox, rac-LA (1.00 g, $6.94 \mathrm{mmol})$, 2-propanol (4.33 mg, $0.072 \mathrm{mmol})$ in $2 \mathrm{~mL}$ of toluene, and $1 \mathrm{a}(0.020 \mathrm{~g}, 0.072 \mathrm{mmol})$ dissolved in $2 \mathrm{~mL}$ of toluene, and another $9 \mathrm{ml}$ of toluene was added successively to a flame-dried reaction vessel equipped with a magnetic stirring bar. The vessel was removed from the glovebox and placed in an oil bath thermostatted at $70^{\circ} \mathrm{C}$. At certain time intervals, an aliquot of the reaction mixture was taken out to determine the monomer conversion by ${ }^{1} \mathrm{H}$ NMR. A few drops of acetic acid were added to quench the polymeriztion after it reached a certain conversion. The polymer was isolated by precipitation in cold methanol, filtered and dried under vacuum at room temperature for $24 \mathrm{~h}$. 


\section{RESULTS AND DISSCUSSION}

Synthesis and Analysis of Complexes. The bis(pyrrolidene) Schiff base ligands $\mathbf{H}_{2} \mathbf{L}^{\mathbf{1}}$, $\mathbf{H}_{2} \mathbf{L}^{2}$, and $\mathbf{H}_{2} \mathbf{L}^{3}$ (Scheme 5.1) were obtained in good yields by reaction of 1,3-propanediamine with pyrrole-2-carboxaldehyde, and 2,2-dimethyl-1,3-propanediamine with pyrrole-2-carboxaldehyde or 3,5-dimethylpyrrole-2-carboxaldehyde in absolute methanol at room temperature. Reaction of the ligands $\mathbf{H}_{2} \mathbf{L}^{\mathbf{1}}, \mathbf{H}_{2} \mathbf{L}^{\mathbf{2}}$, and $\mathbf{H}_{2} \mathbf{L}^{3}$ with $\mathrm{AlEt}_{3}$ in anhydrous toluene at 70 ${ }^{\circ} \mathrm{C}$ (Scheme 5.1) afforded the corresponding aluminum ethyl complexes 1a, 2a, and 3a.

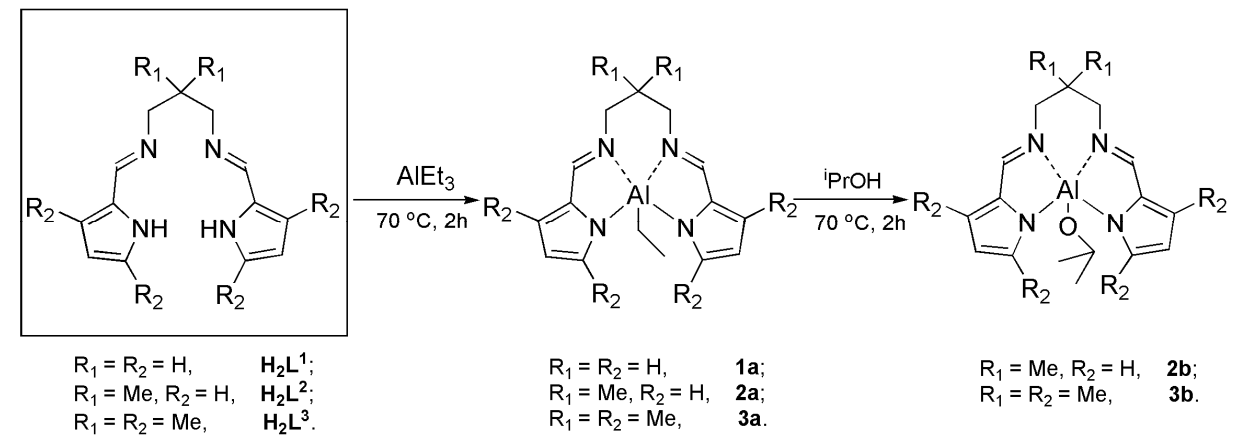

Scheme 5.1. Synthesis of bis(pyrrolidene) Schiff base aluminum ethyls and isopropoxides.

The ${ }^{1} \mathrm{H}$ NMR spectrum of compound 2a (Figure 5.1) showed signals at $\delta-0.15$ and 0.82, which are attributed to the methylene protons and methyl protons of the aluminum ethyl group, respectively. In $\mathbf{2 a}$, the $\mathrm{C}\left(\mathrm{CH}_{3}\right)_{2}$ protons display two singlets at 1.06 and $0.89 \mathrm{ppm}$, and the $\mathrm{N}=\mathrm{CH}$ protons show a singlet at $7.84 \mathrm{ppm}$. The four $\mathrm{NCH}_{2}$ protons show two doublets at 3.82 and $3.26 \mathrm{ppm}$, respectively, which indicates a monomeric structure with a five-coordinated aluminum center. The equal intensities of the signals at $3.82,3.26,7.84$, and -0.15 ppm confirmed the structure of product $\mathbf{2 a}$. The geometry of the five-coordinated aluminum complexes is either square pyramidal (sqp) or trigonal bipyramidal (tbp). ${ }^{13}$ The symmetric pattern of the pyrrolic protons in the ${ }^{1} \mathrm{H}$ NMR spectrum of $\mathbf{2 a}$ indicates either an exchange between tbp conformations 
through a sqp transition state on the NMR time scale or a predominantly sqp conformation. Compared with compound $\mathbf{2 a}$, the signal of the pyrrole- $4 \boldsymbol{H}$ proton in $\mathbf{3 a}$ has significantly shifted upfield from 6.35 to $5.84 \mathrm{ppm}$ because of the shielding effect of the neighbouring methyl groups. The two doublets at 3.54 and $3.24 \mathrm{ppm}$ of the four $\mathrm{NCH}_{2}$ protons and two singlets at 2.17 and $2.12 \mathrm{ppm}$ for the four methyls on the pyrrolic rings also show a symmetric pattern for $\mathbf{3 a}$.

The aluminum isopropoxides $\mathbf{2} \mathbf{b}$ and $\mathbf{3} \mathbf{b}$ were obtained by the reaction of the aluminum ethyls 2a and 3a with an equimolar amount of 2-propanol in anhydrous toluene at $70{ }^{\circ} \mathrm{C}$ (Scheme 5.1). Similar to $\mathbf{2 a}$, the major peaks in the ${ }^{1} \mathrm{H}$ NMR spectrum of compound $\mathbf{2} \mathbf{b}$ in $\mathrm{CDCl}_{3}$ show a symmetric pattern with two doublets at 3.88 and 3.23 ppm corresponding to $\mathrm{NCH}_{2}$ protons, which indicate a monomeric structure for 2b with a five-coordinated aluminum center. The appearance of the $\mathrm{OCH}\left(\mathrm{CH}_{3}\right)_{2}$ methine protons as a multiplet at $3.79 \mathrm{ppm}$ and a doublet of the methyl protons at 1.00 ppm as well as the absence of signals for the aluminum ethyl group showed the complete conversion to the corresponding aluminum isopropoxide complex.

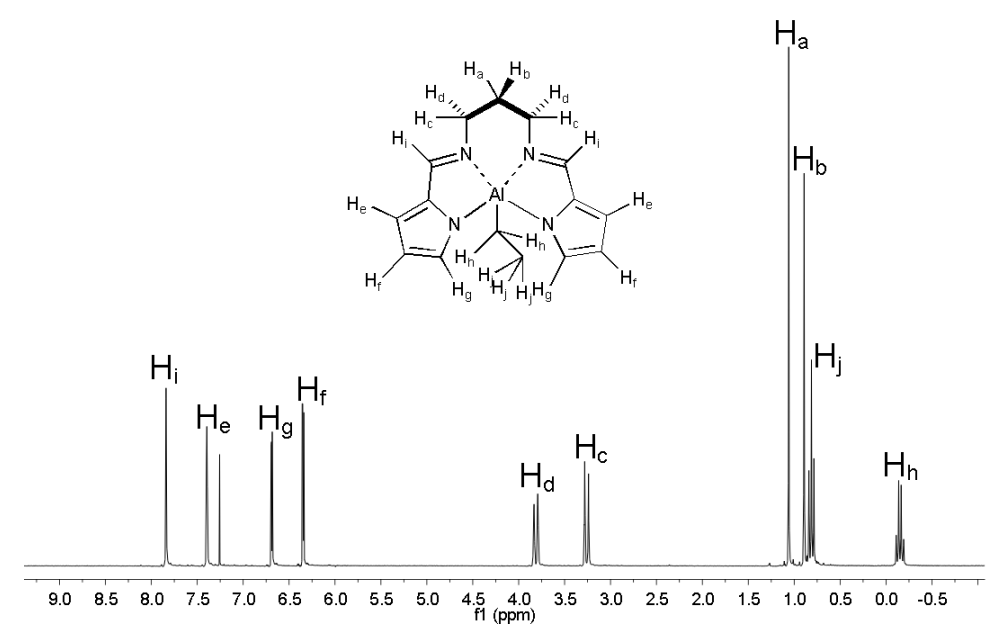

Figure 5.1 ${ }^{1} \mathrm{H}$ NMR spectrum of compound $2 \mathbf{a}\left(600 \mathrm{MHz}, \mathrm{CDCl}_{3}, 295 \mathrm{~K}\right)$. 


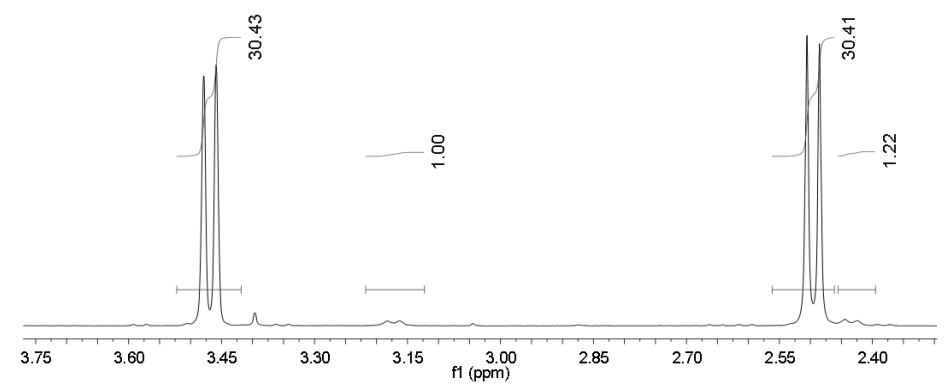

Figure 5.2 Expanded region of ${ }^{1} \mathrm{H}$ NMR for $\mathrm{NCH}_{2}$ protons in $\mathbf{2 b}\left(600 \mathrm{MHz}, \mathrm{C}_{6} \mathrm{D}_{5} \mathrm{CD}_{3}, 295 \mathrm{~K}\right)$.

However, a minor set of peaks was also observed for $\mathbf{2} \mathbf{b}$ both in $\mathrm{CDCl}_{3}$ and $\mathrm{C}_{6} \mathrm{D}_{5} \mathrm{CD}_{3}$ solutions at room temperature, suggesting the presence of another species that accounts for only $\mathbf{3} \%$ in $\mathbf{2 b}$ (Figure 5.2). It is interesting to note that there exists a slow exchange on the NMR time scale between the two species demonstrated by the presence of positive off-diagonal cross peaks (having phased the diagonal cross peaks in positive sign, and the NOE cross peaks observed at opposite sign) between their $\mathrm{NCH}_{2}$ protons in the ${ }^{1} \mathrm{H}^{-}{ }^{1} \mathrm{H}$ NOESY NMR spectrum of $\mathbf{2 b}$ (Figure 5.3). Because the aluminum alkoxides have a tendency to aggregate in solution, a DOSY NMR experiment was carried out using $\mathrm{C}_{6} \mathrm{D}_{5} \mathrm{CD}_{3}$ as the solvent, revealing the same diffusion coefficient for the major and minor species. This suggests that the minor species has an effective hydrodynamic radius that is similar to that of the major one, excluding the formation of dimeric species in the solution.

VT ${ }^{1} \mathrm{H}$ NMR experiments were carried out in the range of 295 to $360 \mathrm{~K}$, revealing that the percentage of the minor species increased as the temperature increased (Figure 5.4). The two minor doublets appearing at 3.18 and $2.43 \mathrm{ppm}(295 \mathrm{~K})$ showed no coalescence up to $360 \mathrm{~K}$, indicating that the two Al-N bonds are stable in this minor species. So far, the origin of the formation of the minor species is not clear. However, we propose that compound $\mathbf{2 b}$ mainly adopts a distorted tbp geometry in solution, and the minor species observed for $\mathbf{2} \mathbf{b}$ is probably related to an intermediate species formed in the tranformation from one tbp conformational stereoisomer to the other. 


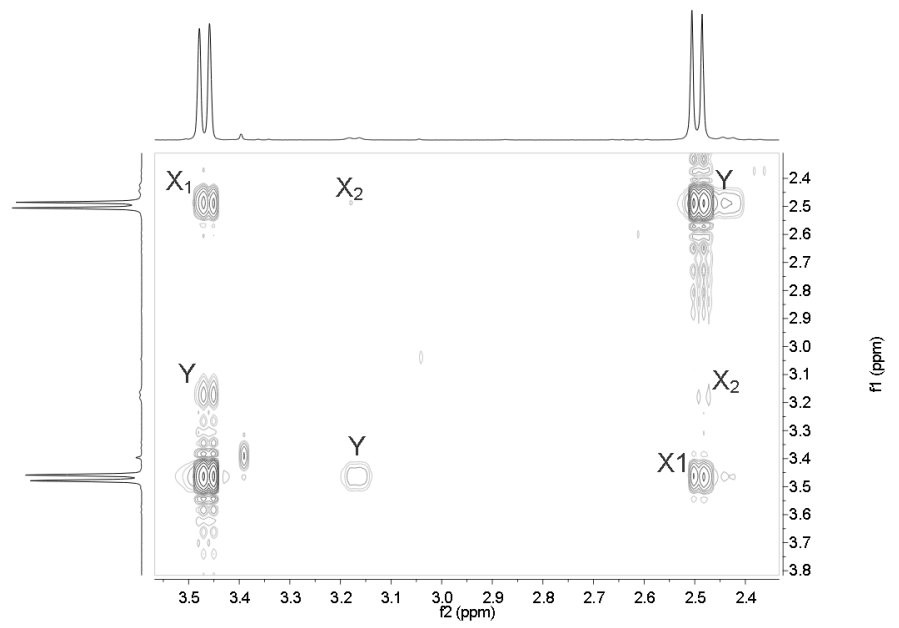

Figure 5.3 ${ }^{1} \mathrm{H}-{ }^{1} \mathrm{H}$ NOESY NMR spectrum of compound $\mathbf{2 b}\left(600 \mathrm{MHz}, \mathrm{C}_{6} \mathrm{D}_{5} \mathrm{CD}_{3}, 295 \mathrm{~K}\right)$. The intense cross-peaks labeled $\mathrm{X}_{1}$ and $\mathrm{X}_{2}$ arise from conformational exchange between the $\mathrm{NCH}_{2}$ protons within species $\mathbf{2} \mathbf{b} \mathbf{1}$ and $\mathbf{2} \mathbf{b} \mathbf{2}$, respectively, due to a fluxional process. Firm evidence that the exchange between species $\mathbf{2 b} \mathbf{1}$ and $\mathbf{2} \mathbf{b} \mathbf{2}$ is provided by the presence of additional exchange-NOE cross-peaks labeled Y.

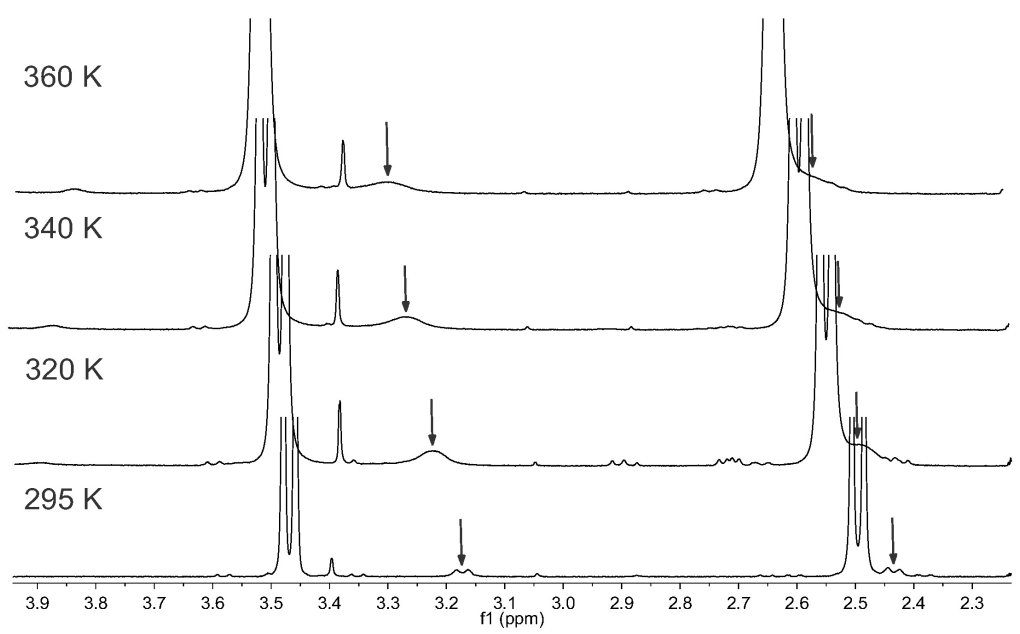

Figure 5.4 VT ${ }^{1} \mathrm{H}$ NMR spectra of compound $\mathbf{2 b}\left(600 \mathrm{MHz}, \mathrm{C}_{6} \mathrm{D}_{5} \mathrm{CD}_{3}, 295-360 \mathrm{~K}\right)$. 
$(\boldsymbol{S}, \boldsymbol{S})$-lactide Polymerization. Polymerizations of $(S, S)$-LA in toluene at $70{ }^{\circ} \mathrm{C}$ using 1a, 2a, and $\mathbf{3 a}$ in the presence of 2-propanol as in situ-forming catalyst/initiator systems were systematically investigated (Table 5.1). From Table 5.1, it can be seen that the three complexes 1a, 2a, and 3a are efficient catalysts for the polymerization of $(S, S)$-LA. PLAs are obtained with the expected molecular weights and with narrow molecular weight distributions, indicating that the $(S, S)$-LA polymerizations initiated by $\mathbf{1 a}, \mathbf{2 a}$, and $\mathbf{3 a}$ in the presence of 2-propanol were living. The polymerization of ca. 100 equiv of $(S, S)$-LA goes to completion within $60 \mathrm{~min}\left(93 \%\right.$ conversion) at $70{ }^{\circ} \mathrm{C}$ applying 1a/2-propanol. However, this period is prolonged to $180 \mathrm{~min}$ when the $\mathbf{2 a} / 2$-propanol (98\% conversion) or 3a/2-propanol ( $96 \%$ conversion) system is used. Nonligated metal alkoxides usually give epimerization of LA monomer, PLA`s or both when applied in $(S, S)$-LA polymerization. ${ }^{14,15}$ Therefore, $(S, S)$-LA polymerization was performed under similar conditions using $\mathbf{2 a}$ /2-propanol as the catalyst/initiator system. The appearance of only one single peak of a $\mathrm{mmmmm}$ hextrad in the methine carbon region in the ${ }^{13} \mathrm{C}$ NMR spectrum (Figure 5.5) revealed that in the presence of 2-propanol complex 2a afforded a highly isotactic PLLA material without significant epimerization of either the monomer or the resulting polymer.

Table 5.1 Polymerization of $(S, S)$-LA in toluene using complexes 1a - 3a in the presence of 2-propanol ${ }^{a}$

\begin{tabular}{|c|c|c|c|c|c|c|c|c|c|}
\hline entry & $\begin{array}{l}\text { comp } \\
\text { lex }\end{array}$ & $\mathbf{M} / \mathbf{I}$ & $\begin{array}{l}T \\
\left({ }^{\circ} \mathrm{C}\right)\end{array}$ & $\begin{array}{l}\text { time } \\
\text { (min) }\end{array}$ & $\begin{array}{l}\operatorname{conv}^{b} \\
(\%)\end{array}$ & $\begin{array}{l}M_{\mathrm{n}, \text { calc }}{ }^{c} \\
\times 10^{3}\end{array}$ & $\begin{array}{l}M_{\mathrm{n}, \mathrm{NMR}} \\
\times 10^{3}\end{array}$ & $\begin{array}{l}M_{\mathrm{n}, \mathrm{GPC}}{ }^{d} \\
\times 10^{3}\end{array}$ & PDI \\
\hline 1 & 1a & 96 & 70 & 60 & 93 & 12.9 & 14.1 & 12.3 & 1.09 \\
\hline 2 & $2 a$ & 92 & 70 & 180 & 98 & 12.9 & 13.2 & 11.1 & 1.10 \\
\hline 3 & $3 a$ & 96 & 70 & 180 & 96 & 13.3 & 13.2 & 11.7 & 1.07 \\
\hline
\end{tabular}

${ }^{a}$ All polymerizations were carried out in toluene at $70{ }^{\circ} \mathrm{C},[\mathrm{LA}]_{0}=0.474 \mathrm{~mol} \cdot \mathrm{L}^{-1} \cdot{ }^{b}$ Measured by ${ }^{1} \mathrm{H}$ NMR. ${ }^{c}$ Calculated from the equation: $M_{\mathrm{n}}$, calc $=(\mathrm{M} / \mathrm{I}) \times \operatorname{conv} \times 144 .{ }^{d}$ Determined by GPC in THF, relative to PS standard. The true value of $M_{\mathrm{n}}$ was calculated according to formula $M_{\mathrm{n}}=0.58 M_{\mathrm{n}}, \mathrm{GPC}$. 


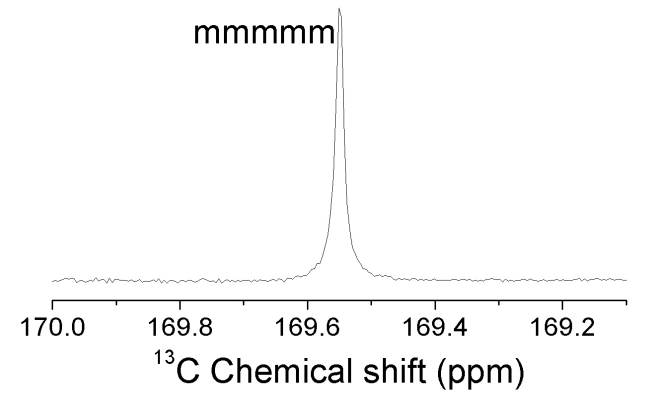

Figure $5.5{ }^{13} \mathrm{C}$ NMR spectra $\left(75 \mathrm{MHz}, \mathrm{CDCl}_{3}\right)$ of the methine carbon region of the resultant (S)-PLA (Table 5.1, entry $2-4)$.
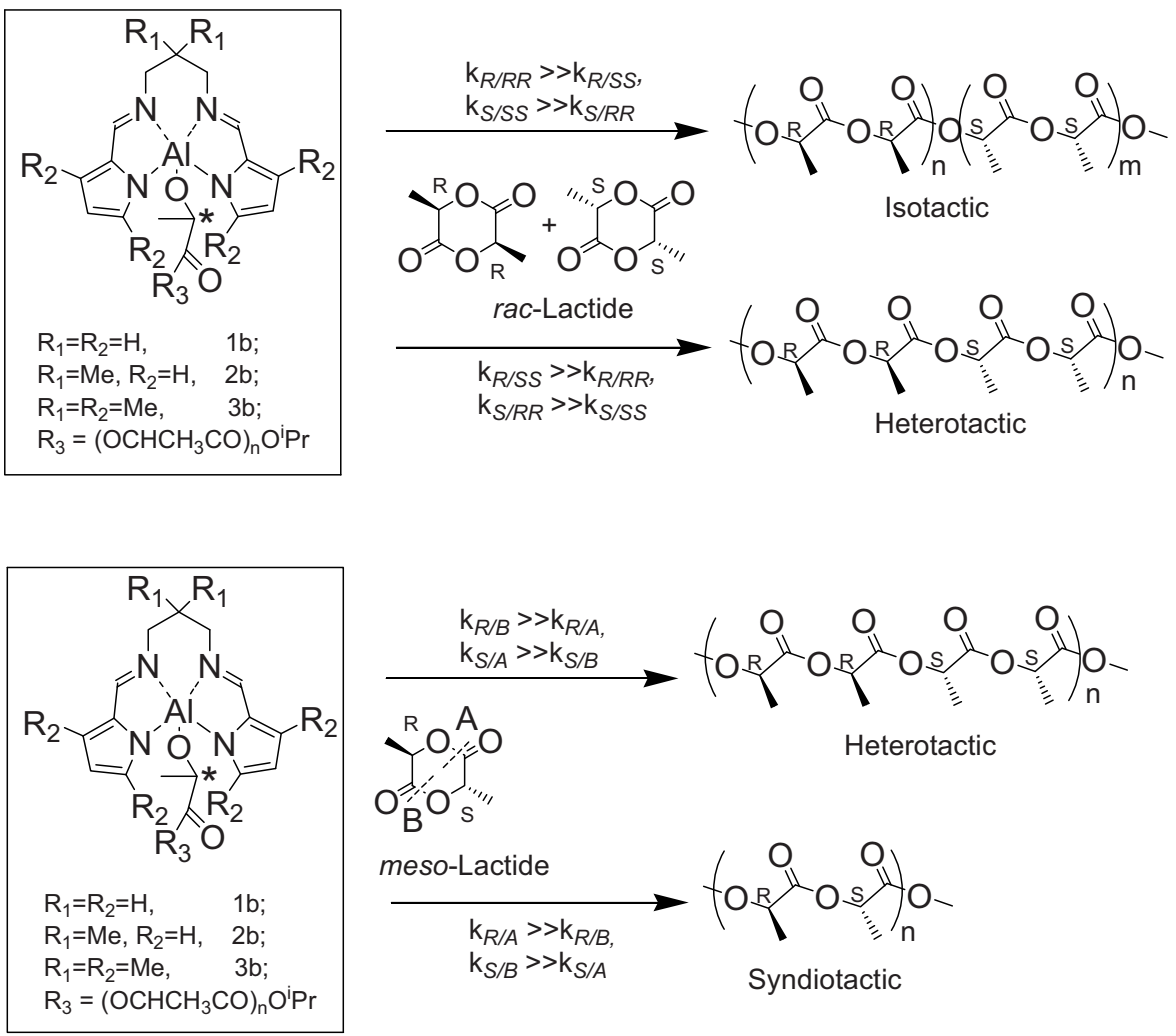

Scheme 5.2 Stereochemistry of rac-and meso-LA polymerization (* represents the $R$ stereogenic center in the last unit along the propagating chain). 
Stereochemistry of Lactide Polymerization. The stereochemical microstructures of the isolated PLAs were determined from the methine region of the homonuclear decoupled ${ }^{1}$ H NMR spectra. Because all bis(pyrrolidene) Schiff base ligands prepared were achiral, it was anticipated that stereoselectivity in the polymerization of $\mathrm{rac}$ - and meso-LA by this achiral catalyst/initiator system takes place via the chain-end-control mechanism. In such a reaction, the configuration of the inserted monomer in rac-LA polymerization or the cleavage site of the monomer in meso-LA polymerization is determined by the stereogenic center of the last lactic acid unit along the propagating chain (Scheme 5.2). If the stereogenic center in the last repeating unit favors a meso-enchainment, which means a chain end of R stereochemistry selects $(R, R)$-LA in

Table 5.2 Polymerization of rac-LA in toluene using complexes 1a - 3a in the presence of 2-propanol, $\mathbf{2} \mathbf{b}$, and $\mathbf{3} \mathbf{b}^{a}$

\begin{tabular}{|c|c|c|c|c|c|c|c|c|c|}
\hline entry & cat & $\mathbf{M} / \mathbf{I}$ & $\begin{array}{l}\mathbf{T} \\
\left({ }^{\circ} \mathrm{C}\right)\end{array}$ & $\begin{array}{l}\text { time } \\
(\mathrm{min})\end{array}$ & $\begin{array}{l}\operatorname{conv}^{b} \\
(\%)\end{array}$ & $\begin{array}{l}M_{\mathrm{n}, \text { calc }}{ }^{c} \\
\times 10^{3}\end{array}$ & $\begin{array}{l}M_{\mathrm{n}, \mathrm{GPC}}{ }^{d} \\
\times 10^{3}\end{array}$ & $\boldsymbol{P}_{\mathrm{m}}^{e}$ & PDI \\
\hline 1 & 1a & 96 & 70 & 60 & 93.0 & 12.9 & 15.4 & 0.65 & 1.10 \\
\hline 2 & $2 a$ & 48 & 70 & 150 & 99.0 & 6.85 & 8.82 & 0.74 & 1.20 \\
\hline 3 & $2 a$ & 72 & 70 & 150 & 98.0 & 10.2 & 12.6 & 0.74 & 1.11 \\
\hline 4 & $2 a$ & 84 & 70 & 150 & 88.5 & 10.8 & 14.9 & 0.74 & 1.07 \\
\hline 5 & $2 a$ & 96 & 70 & 150 & 74.6 & 10.4 & 15.0 & 0.74 & 1.07 \\
\hline 6 & $2 a$ & 96 & 90 & 90 & 94.6 & 13.1 & 15.5 & 0.72 & 1.13 \\
\hline 7 & $2 a$ & 96 & 110 & 60 & 92.0 & 12.7 & 15.5 & 0.68 & 1.24 \\
\hline 8 & $2 b$ & 96 & 70 & 90 & 96.2 & 13.3 & 19.1 & 0.75 & 1.24 \\
\hline 9 & $3 \mathbf{a}$ & 96 & 70 & 240 & 96.4 & 13.3 & 15.4 & 0.60 & 1.04 \\
\hline 10 & $3 b$ & 96 & 70 & 120 & 87.6 & 12.1 & 11.6 & 0.62 & 1.05 \\
\hline
\end{tabular}

${ }^{a}$ All polymerizations were carried out in toluene at $70{ }^{\circ} \mathrm{C},[\mathrm{LA}]_{0}=0.474 \mathrm{~mol} \cdot \mathrm{L}^{-1} \cdot{ }^{b}$ Measured by ${ }^{1} \mathrm{H}$ NMR. ${ }^{c}$ Calculated from the equation: $M_{\mathrm{n}}$, calc $=(\mathrm{M} / \mathrm{I}) \times \operatorname{conv} \times 144 .{ }^{d}$ Determined by GPC in THF, relative to PS standard. The true value of $M_{\mathrm{n}}$ was calculated according to formula $M_{\mathrm{n}}=$ $0.58 M_{\mathrm{n}, \mathrm{GPC}}{ }^{29 e}$ The parameter $P_{\mathrm{m}}$ is the probability to give meso enchainment between monomer units and is determined from the methine region of the homonuclear decoupled ${ }^{1} \mathrm{H}$ NMR spectrum. 
rac-LA or selects the B site to cleave meso-LA, isotactic PLA is obtained from rac-LA $\left(k_{\mathrm{R} / \mathrm{RR}}>k_{\mathrm{R} / \mathrm{SS}}\right)$ and heterotactic PLA will be obtained by using meso-LA $\left(k_{\mathrm{R} / \mathrm{B}}>>k_{\mathrm{R} / \mathrm{A}}\right)$. However, if the stereogenic center in the last repeating unit favors a racemic-enchainment, which means a chain end of $\mathrm{R}$ stereochemistry selects $(S, S)$-LA in rac-LA or selects the A site to cleave meso-LA, hetereotactic PLA will be obtained from rac-LA $\left(k_{\mathrm{R} / \mathrm{SS}}>>k_{\mathrm{R} / \mathrm{RR}}\right)$, and syndiotactic PLA from meso-LA $\left(k_{\mathrm{R} / \mathrm{A}}>>k_{\mathrm{R} / \mathrm{B}}\right)$.

The PLA material produced by $\mathbf{2 a}$ /2-propanol in the ring-opening polymerization of rac-LA at $70{ }^{\circ} \mathrm{C}$ in toluene is substantially isotactic with a $P_{\mathrm{m}}$ of 0.74 (Table 5.2, entries $2-5$ ). The methine region of the homonuclear decoupled ${ }^{1} \mathrm{H}$ NMR spectrum is depicted in Figure 5.7a. Increasing the temperature of reaction mixture to either 90 or $110{ }^{\circ} \mathrm{C}$ results in a decrease in the $P_{\mathrm{m}}$ of the resulting polymer to, respectively 0.72 and 0.68 (Table 5.2, entries 6 and 7). According to first-order Markovian statistics ${ }^{16}$ and absolute reaction rate theory, eq 1 can be used to determine the activation entropy difference $\left(\Delta S_{\mathrm{m}}^{\neq}-\Delta S_{\mathrm{r}}^{\neq}\right)$and activation enthalpy difference $\left(\Delta H_{\mathrm{m}}^{\neq}-\Delta H_{\mathrm{r}}^{\neq}\right)$between homo- propagation $\left(k_{\mathrm{m}}\right)$ and cross-propagation $\left(k_{\mathrm{r}}\right)$ :

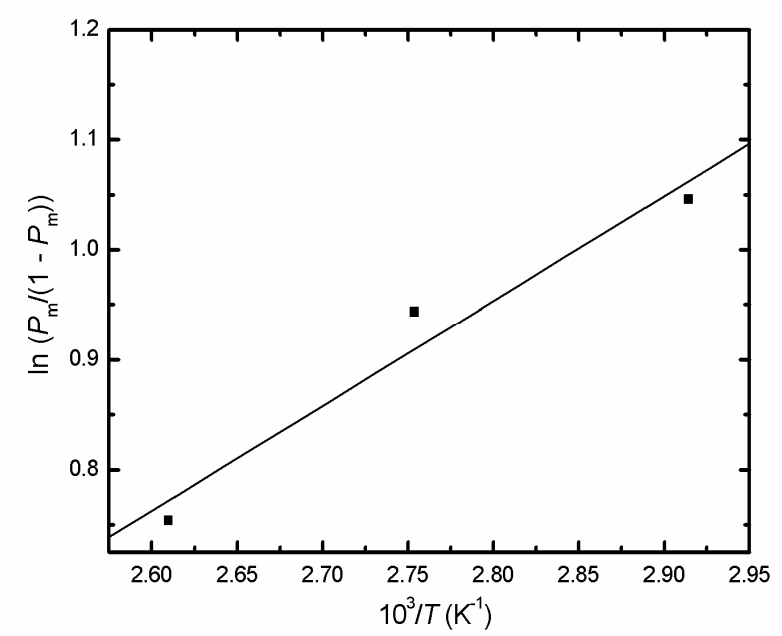

Figure 5.6 First-order Markovian relationship between the inverse of the polymerization temperature and the $\ln P_{\mathrm{m}} /\left(1-P_{\mathrm{m}}\right)$ of the resulting PLAs from rac-LA by using 2a/2-propanol as catalyst/initiator. 


$$
P_{\mathrm{m}} /\left(1-P_{\mathrm{m}}\right)=k_{\mathrm{m}} / k_{\mathrm{r}}=\exp \left[\left(\Delta S_{\mathrm{m}}^{\neq}-\Delta S_{\mathrm{r}}^{\neq}\right) / R-\left(\Delta H_{\mathrm{m}}^{\neq}-\Delta H_{\mathrm{r}}^{\neq}\right) / R T\right]
$$

Ln $\left[P_{\mathrm{m}} /\left(1-P_{\mathrm{m}}\right)\right]$ was plotted against $10^{3} / T$ (Figure 5.6). From this plot, an activation entropy difference $\left(\Delta S_{\mathrm{m}}^{\neq}-\Delta S_{\mathrm{r}}^{\neq}\right)$of $-14.27 \mathrm{cal} \cdot \mathrm{K}^{-1} \cdot \mathrm{mol}^{-1}$ and an activation enthalpy difference $\left(\Delta H_{\mathrm{m}}^{\neq}-\Delta H_{\mathrm{r}}^{\neq}\right)$of $-7.93 \mathrm{kcal} \cdot \mathrm{mol}^{-1}$ were found, showing the preference of isotactic enchainment.

Furthermore, the polymerization data indicate that the introduction of methyl groups to the auxiliary ligand significantly affects the stereoselectivity. For instance, polymerization of rac-LA using 1a/2-propanol furnished an isotactic-biased material with a $P_{\mathrm{m}}$ of 0.65 (Table 5.2, entry 1$)$, which is lower than that of $2 \mathrm{a} / 2$-propanol $\left(P_{\mathrm{m}}=\right.$ 0.74 ), indicating that the presence of the gem methyls on the propylene diimine bridge remarkably enhances the stereoselectivity, which is consistent with a previous study. ${ }^{12}$ However, it is interesting to note that the catalyst/initiator system 3a/2-propanol affords PLA material from $r a c$-LA with a lower $P_{\mathrm{m}}$ value of 0.60 (Table 5.2, entry 9) compared with the PLA formed by 2a/2-propanol $\left(P_{\mathrm{m}}=0.74\right)$, revealing that the enhanced chain-end-control in the polymerization by the methyl substituents on pyrrolic rings leads to an increased heterotactic enchainment.

Table 5.3 Polymerization of meso-LA in toluene using complexes $1 \mathbf{a}-\mathbf{3 a}$ in the presence of 2-propanol ${ }^{a}$

\begin{tabular}{|c|c|c|c|c|c|c|c|c|c|}
\hline entry & cat & $\mathbf{M} / \mathbf{I}$ & $\begin{array}{l}T \\
\left({ }^{\circ} \mathrm{C}\right)\end{array}$ & $\begin{array}{l}\text { time } \\
\text { (min) }\end{array}$ & $\begin{array}{l}\text { conv }^{b} \\
(\%)\end{array}$ & $\begin{array}{l}M_{\mathrm{n}, \text { calc }}{ }^{c} \\
\times 10^{3}\end{array}$ & $\begin{array}{l}M_{\mathrm{n}, \mathrm{GPC}}{ }^{d} \\
\times 10^{3}\end{array}$ & $P_{\mathrm{r}}^{e}$ & PDI \\
\hline 1 & $1 \mathrm{a}$ & 96 & 70 & 90 & 93 & 12.9 & 14.0 & 0.56 & 1.16 \\
\hline 2 & $2 a$ & 96 & 70 & 150 & 47 & 6.50 & 6.03 & 0.57 & 1.12 \\
\hline 3 & $3 \mathbf{a}$ & 96 & 70 & 240 & 94 & 13.0 & 10.8 & 0.53 & 1.06 \\
\hline
\end{tabular}

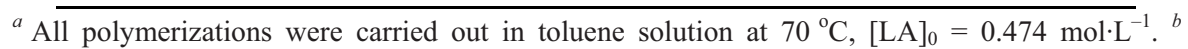
Measured by ${ }^{1} \mathrm{H}$ NMR. ${ }^{c}$ Calculated from the equation: $M_{\mathrm{n}}$, calc $=(\mathrm{M} / \mathrm{I}) \times \operatorname{conv} \times 144 .{ }^{d}$ Determined by GPC in THF, relative to PS standard. The true value of $M_{\mathrm{n}}$ was calculated according to formula $M_{\mathrm{n}}=0.58 M_{\mathrm{n}, \mathrm{GPC} .}{ }^{29 e}$ The parameter $P_{\mathrm{r}}$ is the probability to give racemic enchainment between monomer units and is determined from the methine region of the homonuclear decoupled ${ }^{1} \mathrm{H}$ NMR spectrum. 
A similar effect has been once reported by Gibson for a bis(salicylidene) Schiff base aluminum complex with a rigid diarylene diimine bridge. ${ }^{11}$ Polymerizations of meso-LA with 1a, 2a, and $\mathbf{3 a}$ in the presence of 2-propanol all furnish nearly atactic polymers with $P_{\mathrm{r}}$ values of 0.56 (Figure 5.7b), 0.57, and 0.53 (Table 5.3), respectively. The minor difference in the tacticities of these polymers also reveals that the substituent on the ligand hardly influences the chain-end-control ability toward meso-LA polymerization.
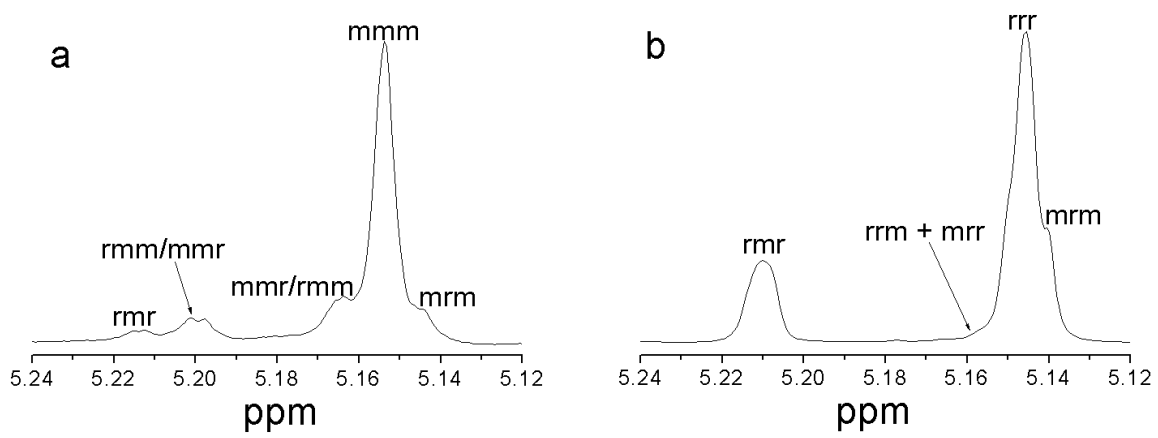

Figure 5.7 Methine region of homonuclear decoupled ${ }^{1} \mathrm{H}$ NMR spectra of isolated PLA materials: (a) from rac-LA using 2a/2-propanol; (b) from meso-LA using 1a/2-propanol.

The putative active species formed upon reaction of the bis(pyrrolidene) Schiff base aluminum ethyls with 2-propanol are the corresponding aluminum ispropoxides. Therefore, the bis(pyrrolidene) Schiff base aluminum isopropoxide $\mathbf{2} \mathbf{b}$ and $\mathbf{3 b}$ were prepared. The synthesis of PLAs by the ring-opening polymerization of rac-LA using $\mathbf{2 b}$ and $\mathbf{3 b}$ allowed a comparison between the behavior of aluminum isopropoxides and the compounds formed by the in situ reaction between the aluminum ethyl compounds and 2-propanol. The PLA obtained by the ring-opening polymerization of rac-LA using $2 \mathbf{b}$ has approximately the same $P_{\mathrm{m}}$ value of 0.75 (Table 5.2, entry 8 ) as the polymer obtained via $\mathbf{2 a} / 2$-propanol $\left(P_{\mathrm{m}}=0.74\right)$. Similarly, compound $\mathbf{3 b}$ furnished PLA with a $P_{\mathrm{m}}$ of 0.62 (Table 5.2, entry 10), which is close to that of $\mathbf{3 a} / 2$-propanol $\left(P_{\mathrm{m}}=0.60\right)$. Moreover, the $N, N, N, N$-tetradentate coordination mode of the bis(pyrrolidene) Schiff base ligand in $\mathbf{2} \mathbf{b}$ caused an isoselectivity enhancement $\left(P_{\mathrm{m}}=\right.$ 
0.75) in rac-LA polymerization compared with that of $N, N^{\prime}$-(2,2-dimethyl-1,3-propylene) bis(salicylideneiminato) aluminum ethyl in the presence of 2-propanol $\left(P_{\mathrm{m}}=0.67\right)$, which has a $N, N, O, O$-tetradentate coordination mode of the bis(salicylidene) Schiff base ligand. ${ }^{12}{ }^{1} \mathrm{H}$ NMR spectra revealed the presence of aggregated species of the $N, N^{`}$-(2,2-dimethyl-1,3-propylene) bis(salicylidene-iminato) aluminum isopropoxide, which is not the case for $\mathbf{2 b}$ in solution. The isoselectivity enhancement for $\mathbf{2 b}$ is most probably due to the presence of only a monomeric species in solution.

Mechanism and Kinetics of Lactide Polymerization. The ${ }^{1} \mathrm{H}$ NMR spectrum of PLA oligomers (Figure 5.8) prepared using 2a/2-propanol at a low monomer-to-initiator ratio of 13 showed a triplet of two overlapping doublets at 1.24 ppm and a quartet at $4.34 \mathrm{ppm}$, with an integral ratio close to 6:1. These peaks were assigned to the methyl protons of the isopropoxycarbonyl end group and the methine proton neighboring the hydroxyl end group, respectively. This clearly indicates that the oligomer is systematically capped with one isopropyl ester group and one hydroxyl group. This confirms that the aluminum isopropoxides were the actual active species in LA polymerizations when applying aluminum ethyls/2-propanol as catalyst/initiator systems. The $M_{\mathrm{n}}$ of the oligomer determined by end-group analysis is 1760 , close to the theoretical value of 1500 .

The kinetics of the ring-opening polymerization of rac-LA ([LA $]_{0}=0.534,0.474$, and $\left.0.237 \mathrm{~mol} \cdot \mathrm{L}^{-1}\right)$ at various concentrations of $2 \mathbf{a}\left((3.55\right.$ to 7.42$\left.) \times 10^{-3} \mathrm{~mol} \cdot \mathrm{L}^{-1}\right)$ in the presence of 2-propanol in toluene at $70{ }^{\circ} \mathrm{C}$ were monitored by ${ }^{1} \mathrm{H}$ NMR spectroscopy until all monomer was consumed. Semilogarithmic plots for these polymerizations are shown in Figure 5.9. In each case, an induction period and first-order kinetics in monomer were observed. The induction period implies that complex $\mathbf{2 a}$ reacted with 2-propanol to form the aluminum isopropoxide as the actual active species to initiate the polymerizations. Thus, the polymerization of rac-LA by using $\mathbf{2 a} / 2$-propanol proceeds according to:

$$
-\mathrm{d}[\mathrm{LA}] / \mathrm{d} t=k_{\text {app }}[\mathrm{LA}]
$$




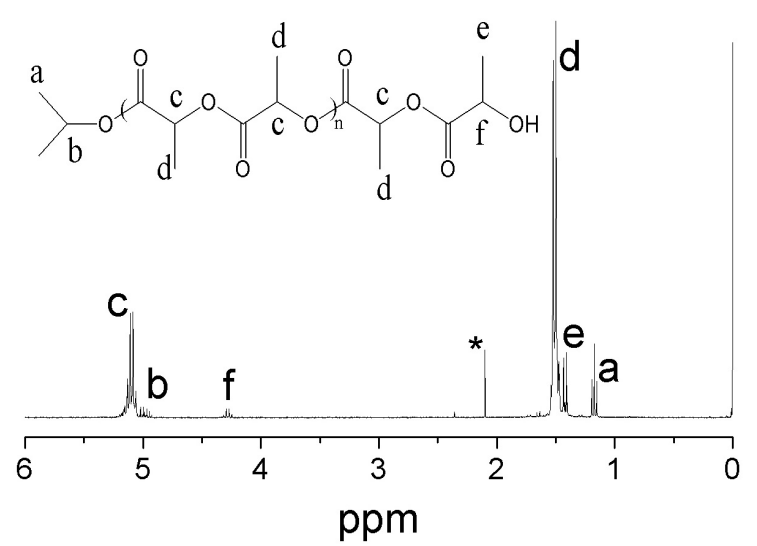

Figure 5.8 ${ }^{1} \mathrm{H}$ NMR spectrum of poly(rac-LA) oligomer prepared by using complex $\mathbf{2 a}$ in the presence of 2-propanol (300 MHz, $298 \mathrm{~K}, \mathrm{CDCl}_{3}$ ).

where $k_{\mathrm{app}}=k_{p}[\mathrm{Al}]^{x}$, and $k_{\mathrm{p}}$ is the polymerization rate constant. The linear relationship of $k_{\text {app }}$ versus $[\mathrm{Al}]_{0}$ reveals a first-order in catalyst (Figure 5.10). Therefore, the polymerization of $\mathrm{rac}$-LA initiated and catalyzed by $\mathbf{2 a} / 2$-propanol follows an overall kinetics law of the following form:

$$
-\mathrm{d}[\mathrm{LA}] / \mathrm{d} t=k_{\mathrm{p}}[\mathrm{Al}][\mathrm{LA}]
$$

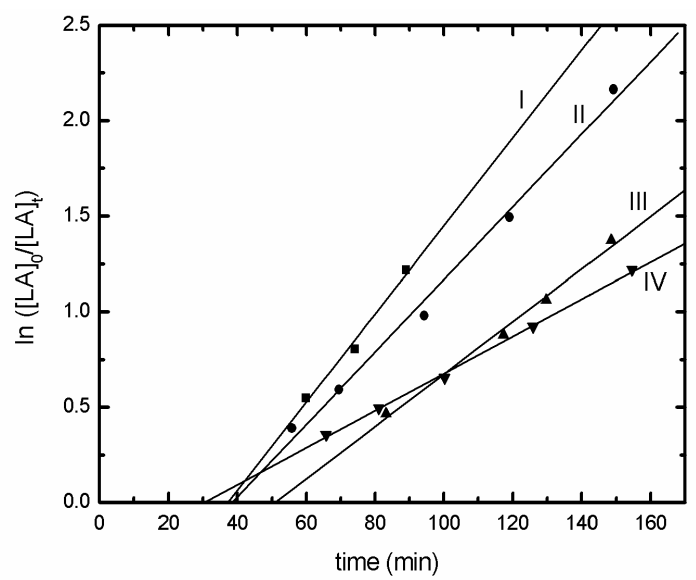

Figure 5.9 First-order kinetic plots for the polymerization of $r a c$-LA by applying 2a/2-propanol as catalyst/initiator in toluene at $70^{\circ} \mathrm{C}$ with $[\mathrm{LA}]_{0}=0.534 \mathrm{~mol} \cdot \mathrm{L}^{-1}:$ (I) $[\mathrm{Al}]_{0}=7.42 \times 10^{-3} \mathrm{~mol} \mathrm{~L}^{-1}, k_{\text {app }}$ $=23.1 \times 10^{-3} \mathrm{~min}^{-1} ;$ (II) $[\mathrm{Al}]_{0}=6.36 \times 10^{-3} \mathrm{~mol} \cdot \mathrm{L}^{-1}, k_{\text {app }}=19.0 \times 10^{-3} \mathrm{~min}^{-1} ;[\mathrm{LA}]_{0}=0.474$ $\mathrm{mol} \cdot \mathrm{L}^{-1}:\left(\right.$ III) $[\mathrm{Al}]_{0}=4.94 \times 10^{-3} \mathrm{~mol} \cdot \mathrm{L}^{-1}, k_{\text {app }}=13.7 \times 10^{-3} \mathrm{~min}^{-1} ;[\mathrm{LA}]_{0}=0.237 \mathrm{~mol} \cdot \mathrm{L}^{-1}:($ IV) $[\mathrm{Al}]_{0}=3.55 \times 10^{-3} \mathrm{~mol} \cdot \mathrm{L}^{-1}, k_{\text {app }}=9.72 \times 10^{-3} \mathrm{~min}^{-1}$. 


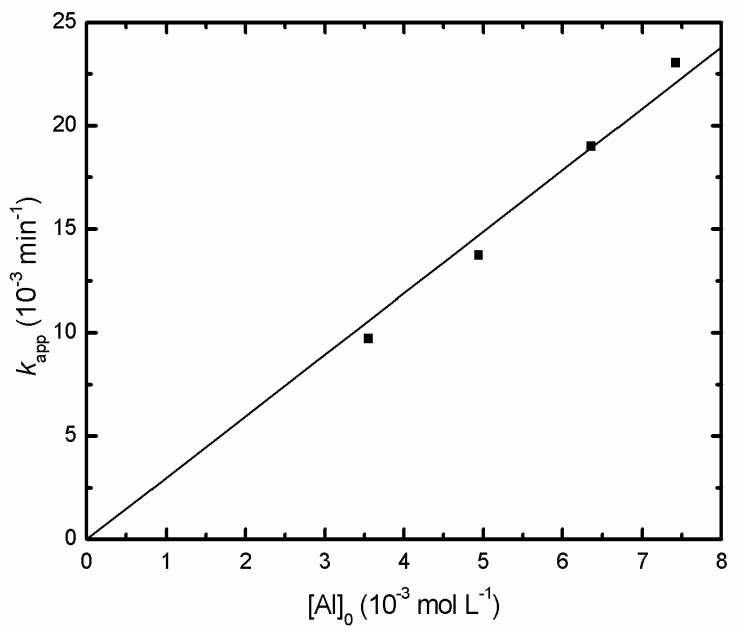

Figure 5.10 Linear plot of $k_{\text {app }}$ vs [Al $]_{0}$ for the polymerization of rac-LA using 2a/2-propanol as catalyst/initiator (toluene, $70^{\circ} \mathrm{C}, k_{\mathrm{p}}=2.97 \mathrm{~L} \cdot \mathrm{mol}^{-1} \cdot \mathrm{min}^{-1}, R^{2}=0.996$ ).

A $k_{\mathrm{p}}$ value of $2.97 \mathrm{~L} \cdot \mathrm{mol}^{-1} \cdot \mathrm{min}^{-1}$ was determined (Table 5.4, entry 3) for 2a/2-propanol in toluene at $70{ }^{\circ} \mathrm{C}$. This value is significantly lower than that determined for $(S, S)$-LA polymerization $\left(4.83 \mathrm{~L} \cdot \mathrm{mol}^{-1} \cdot \mathrm{min}^{-1}\right)$, and much higher than that determined for meso-LA polymerization $\left(0.93 \mathrm{~L} \cdot \mathrm{mol}^{-1} \cdot \mathrm{min}^{-1}\right)$ (Figure 5.11). Predominant formation of isotactic structures from rac-LA polymerization means a significantly higher rate of homopropagation $\left(k_{\mathrm{R} / \mathrm{RR}}\right.$ or $\left.k_{\mathrm{S} / \mathrm{SS}}\right)$ than cross propagation $\left(k_{\mathrm{R} / \mathrm{SS}}\right.$ or $\left.k_{\mathrm{S} / \mathrm{RR}}\right)$. The significantly faster polymerization of $(S, S)$-LA compared with that of $r a c$-LA is consistent with this observation.

Conversions versus time data were also collected for the polymerization of $\mathrm{rac}$ - and meso-LA with 1a and 3a in the presence of 2-propanol (toluene; $70{ }^{\circ} \mathrm{C} ;[\mathrm{LA}]_{0}=0.474$ $\left.\mathrm{mol} \cdot \mathrm{L}^{-1} ;[\mathrm{Al}]_{0}=4.94 \times 10^{-3} \mathrm{~mol} \cdot \mathrm{L}^{-1}\right)$. In each case, first-order kinetics in monomer was observed. The semilogarithmic plots for polymerizations using 1a/2-propanol are shown in Figure 5.12, and those for 3a/2-propanol are depicted in Figure 5.13. The corresponding $k_{\mathrm{p}}$ values were deduced according to the relationship $k_{\mathrm{p}}=k_{\mathrm{app}} /[\mathrm{Al}]_{0}$, and listed in Table 5.4. 


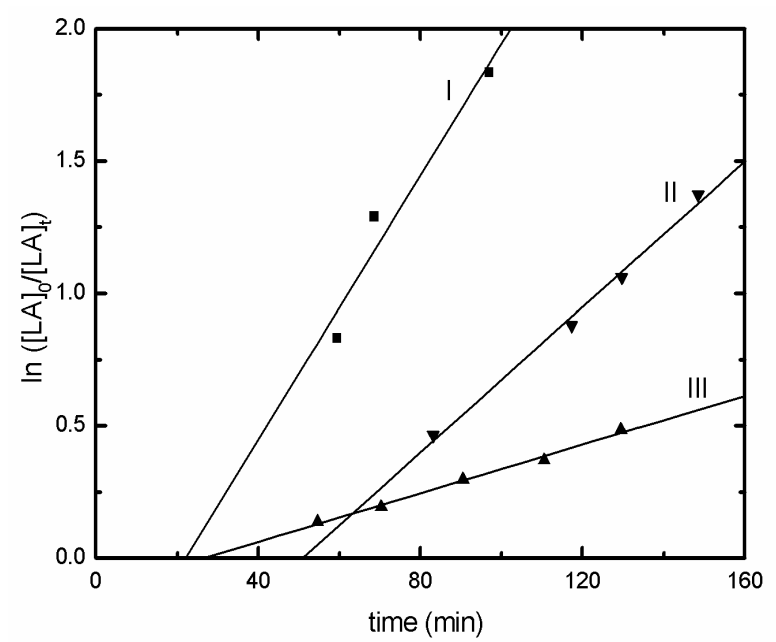

Figure 5.11 First-order kinetic plots for the polymerization of $(S, S)$-, rac-, and meso-LA by using 2a/2-propanol as catalyst/initiator in toluene at $70^{\circ} \mathrm{C}$ with $[\mathrm{LA}]_{0}=0.474 \mathrm{~mol} \cdot \mathrm{L}^{-1}:(I)(S, S)$-LA, $[\mathrm{Al}]_{0}=5.15 \times 10^{-3} \mathrm{~mol} \cdot \mathrm{L}^{-1}, k_{\mathrm{app}}=24.9 \times 10^{-3} \mathrm{~min}^{-1}$; (II) rac $-\mathrm{LA},[\mathrm{Al}]_{0}=4.94 \times 10^{-3} \mathrm{~mol} \cdot \mathrm{L}^{-1}, k_{\text {app }}=$ $13.7 \times 10^{-3} \mathrm{~min}^{-1} ;$ (III) meso-LA, $[\mathrm{Al}]_{0}=4.94 \times 10^{-3} \mathrm{~mol} \cdot \mathrm{L}^{-1}, k_{\mathrm{app}}=4.60 \times 10^{-3} \mathrm{~min}^{-1}$.

Table 5.4 Kinetic results of rac-and meso-LA polymerization using complexes 1a-3a, $\mathbf{2 b}$, and $\mathbf{2 c}$.

\begin{tabular}{|c|c|c|c|c|}
\hline entry & cat & Monomer & $\begin{array}{c}k_{\mathrm{app}}^{\mathrm{b}} \\
\left(\times 10^{-3} \mathrm{~min}^{-1}\right)\end{array}$ & $\begin{array}{c}k_{\mathrm{p}}^{\mathrm{c}} \\
\left(\mathrm{M}^{-1} \min ^{-1}\right)\end{array}$ \\
\hline 1 & $1 \mathrm{a}$ & $r a c-\mathrm{LA}$ & 38.5 & 7.79 \\
\hline 2 & $1 \mathrm{a}$ & meso-LA & 29.4 & 5.95 \\
\hline 3 & $2 a$ & $r a c-\mathrm{LA}$ & 13.7 & $2.97^{\mathrm{d}}$ \\
\hline 4 & $2 \mathbf{a}$ & meso-LA & 4.60 & 0.93 \\
\hline 5 & $2 b$ & $r a c-\mathrm{LA}$ & 55.3 & $13.0^{\mathrm{d}}$ \\
\hline 6 & $3 \mathbf{a}$ & $r a c-\mathrm{LA}$ & 17.0 & 3.44 \\
\hline 7 & $3 \mathbf{a}$ & meso-LA & 13.5 & 2.73 \\
\hline 8 & $3 b$ & $r a c-\mathrm{LA}$ & 17.1 & 3.46 \\
\hline
\end{tabular}

${ }^{\text {a }}$ All kinetic polymerizations were carried out in toluene solution at $70^{\circ} \mathrm{C},[\mathrm{LA}]_{0}=0.47 \mathrm{~mol} \cdot \mathrm{L}^{-1}$, $[\mathrm{Al}]_{0}=4.94 \times 10^{-3} \mathrm{~mol} \cdot \mathrm{L}^{-1} \cdot{ }^{\mathrm{b}}$ Measured by ${ }^{1} \mathrm{H}$ NMR. ${ }^{\mathrm{c}}$ Calculated from the relationship: $k_{\mathrm{p}}=k_{\mathrm{app}} /[\mathrm{Al}]_{0}$. $\mathrm{d}$ Deduced from the linear plot of $k_{\mathrm{p}}$ against $[\mathrm{Al}]_{0}$. 
The polymerization rate for meso-LA polymerization $\left(k_{\mathrm{p}}=5.95 \mathrm{~L} \cdot \mathrm{mol}^{-1} \cdot \mathrm{min}^{-1}\right)$ is slightly lower than that for rac-LA polymerization $\left(k_{\mathrm{p}}=7.97 \mathrm{~L} \cdot \mathrm{mol}^{-1} \cdot \mathrm{min}^{-1}\right)$ using 1a/2-propanol.In the polymerization applying 3a/2-propanol, the polymerization rate for meso-LA polymerization $\left(k_{\mathrm{p}}=2.73 \mathrm{~L} \cdot \mathrm{mol}^{-1} \cdot \mathrm{min}^{-1}\right)$ is slightly lower than that for rac-LA polymerization $\left(k_{\mathrm{p}}=3.44 \mathrm{~L} \cdot \mathrm{mol}^{-1} \cdot \mathrm{min}^{-1}\right)$. Consistent valence force field (CVFF) calculations revealed that meso-LA monomer is less stable in the groundstate than are $(S, S)$ - and rac-LA. ${ }^{17}$ This may imply that meso-LA will be more easily cleaved than $r a c$-LA monomer when coordinated to the metal center, which will lead to a higher polymerization rate for meso-LA than that for rac-LA. Therefore, it is apparent that the low activity for meso-LA polymerization by using the bis(pyrrolidene) Schiff base aluminum systems is mainly due to the chain-end selection effect caused by the presence of both $R$ - and $S$-stereogenic center in the last repeating unit along the propagation chain.

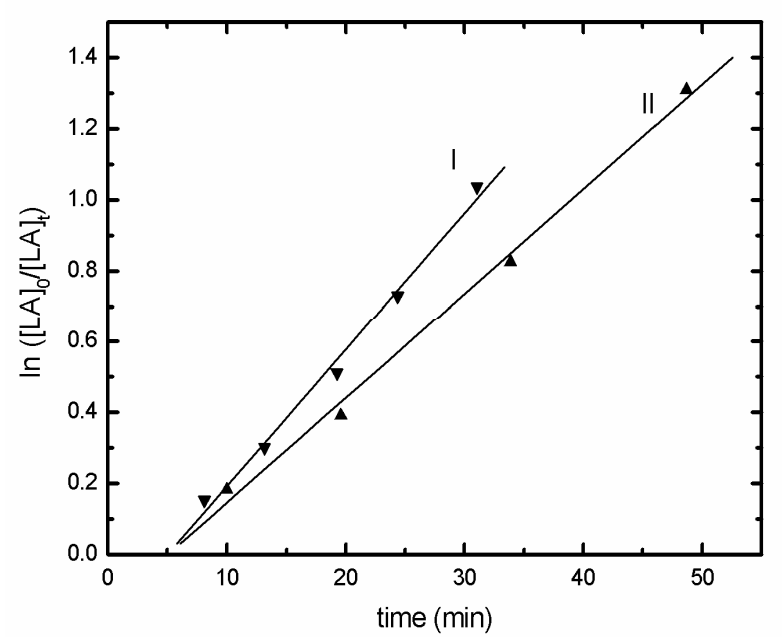

Figure 5.12 First-order kinetic plots for the polymerization of rac- and meso-LA by using 1a/2-propanol as catalyst/initiator in toluene at $70^{\circ} \mathrm{C}$ with $[\mathrm{LA}]_{0}=0.474 \mathrm{~mol} \cdot \mathrm{L}^{-1},[\mathrm{Al}]_{0}=4.94 \times$ $10^{-3} \mathrm{~mol} \cdot \mathrm{L}^{-1}$ : (I) rac-LA, $k_{\text {app }}=38.5 \times 10^{-3} \mathrm{~min}^{-1}$; (II) meso-LA, $k_{\text {app }}=29.4 \times 10^{-3} \mathrm{~min}^{-1}$. 


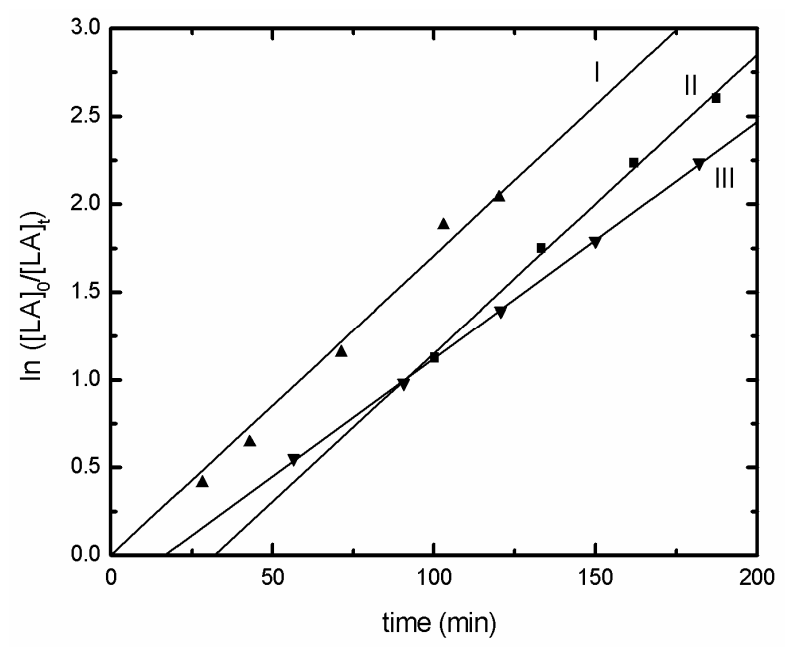

Figure 5.13 First-order kinetic plots for the polymerization of rac-LA by using 3a/2-propanol as catalyst/initiator and $\mathbf{3 b}$ in toluene at $70{ }^{\circ} \mathrm{C}$ with $[\mathrm{LA}]_{0}=0.474 \mathrm{~mol} \cdot \mathrm{L}^{-1},[\mathrm{Al}]_{0}=4.94 \times 10^{-3} \mathrm{~mol} \cdot \mathrm{L}^{-1}$ : (I) $3 \mathbf{b}, k_{\text {app }}=17.1 \times 10^{-3} \mathrm{~min}^{-1}$; (II) 3a, $k_{\text {app }}=17.0 \times 10^{-3} \mathrm{~min}^{-1}$; and first-order kinetic plots for the polymerization of meso-LA by using complex 3a/2-propanol as catalyst/initiator in toluene at $70^{\circ} \mathrm{C}$ with $[\mathrm{LA}]_{0}=0.474 \mathrm{~mol} \cdot \mathrm{L}^{-1},[\mathrm{Al}]_{0}=4.94 \times 10^{-3} \mathrm{~mol} \cdot \mathrm{L}^{-1}:$ (III) $3 \mathrm{a}, k_{\text {app }}=13.5 \times 10^{-3} \mathrm{~min}^{-1}$.

The influence of the temperature on the polymerization rate of rac-LA using 2a/2-propanol was also investigated. As depicted in Figure 5.14, the polymerization rate increased with increasing temperature. The values of $k_{\text {app }}$ were $31.9 \times 10^{-3} \mathrm{~min}^{-1}$ at $90{ }^{\circ} \mathrm{C}$ and $53.7 \times 10^{-3} \mathrm{~min}^{-1}$ at $110^{\circ} \mathrm{C}$, respectively. According to the relationship $k_{\mathrm{p}}=$ $k_{\text {app }} /[\mathrm{Al}]_{0}$, the values of $k_{\mathrm{p}}$ at $90{ }^{\circ} \mathrm{C}$ and $110{ }^{\circ} \mathrm{C}$ were calculated to be 6.46 and 10.9 $\mathrm{L} \cdot \mathrm{mol}^{-1} \cdot \mathrm{min}^{-1}$, respectively. From the three $k_{\mathrm{p}}$ values determined at different temperatures, the activation energy of the polymerization using $\mathbf{2 a}$ /2-propanol was deduced by fitting $\ln k_{\mathrm{p}}$ vs $10^{3} / T$ according to the Arrhenius equation (Figure 5.15). The activation energy $E_{a}$ for the rac- LA polymerization using 2a/2-propanol was 35.5 $\mathrm{kJ} \cdot \mathrm{mol}^{-1}$, which is comparable to that for the ring-opening polymerization of $(S, S)$-LA initiated by aluminum trialkoxides functionalized with (2-methacryloxy)ethyloxy $\left(35.5 \mathrm{~kJ} \cdot \mathrm{mol}^{-1}\right),{ }^{18}$ but much lower than that of $(S, S)$-LA polymerization initiated by tin octanoate $\left(70.9 \mathrm{~kJ} \cdot \mathrm{mol}^{-1}\right) .{ }^{19}$ 


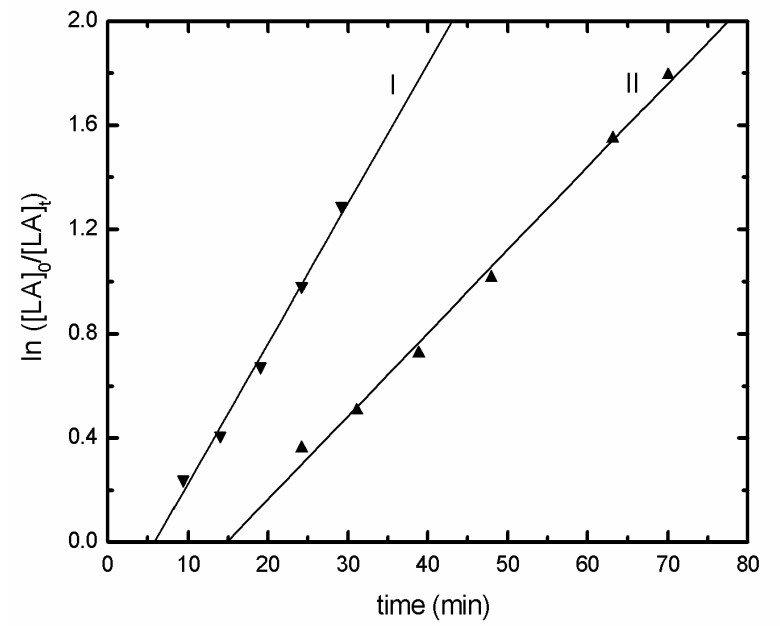

Figure 5.14 First-order kinetic plots for the polymerization of rac-LA by using 2a/2-propanol as catalyst/initiator in toluene at $90{ }^{\circ} \mathrm{C}$ and $110{ }^{\circ} \mathrm{C}$ with $[\mathrm{LA}]_{0}=0.474 \mathrm{~mol} \cdot \mathrm{L}^{-1}:$ (I) $110{ }^{\circ} \mathrm{C},[\mathrm{Al}]_{0}=$ $4.94 \times 10^{-3} \mathrm{~mol} \cdot \mathrm{L}^{-1}, k_{\text {app }}=53.7 \times 10^{-3} \mathrm{~min}^{-1}$; (II) $90^{\circ} \mathrm{C},[\mathrm{Al}]_{0}=4.94 \times 10^{-3} \mathrm{~mol} \cdot \mathrm{L}^{-1}, k_{\text {app }}=31.9 \times$ $10^{-3} \mathrm{~min}^{-1}$.

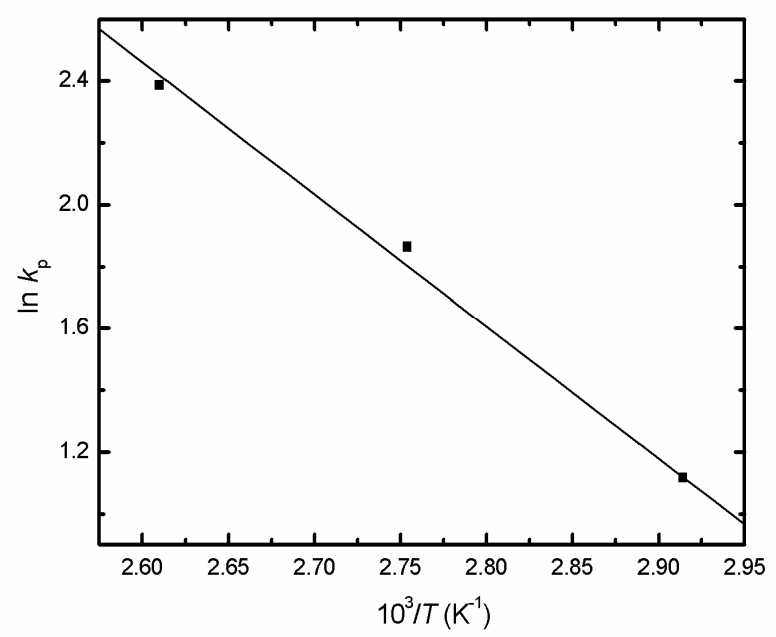

Figure 5.15 Arrhenius plot of $\ln k_{\mathrm{p}}$ versus $10^{3} / T$ for the polymerization of $\mathrm{rac}$-LA at different temperatures by using 2a/2-propanol $\left(E_{a}=35.5 \mathrm{~kJ} \cdot \mathrm{mol}^{-1}\right)$.

Aluminum isopropoxides $\mathbf{2} \mathbf{b}$ and $\mathbf{3 b}$, which were considered to be the initiating species, were subsequently investigated toward their reactivities in rac-LA polymerization. Interestingly, the single-site aluminum isopropoxide $\mathbf{2 b}$ exhibits a 
much higher activity compared with the in situ-formed aluminum isopropoxide from 2a/2-propanol. In each case, first-order kinetics in monomer was observed and the appropriate semilogarithmic plots $\left([\mathrm{LA}]_{0}=0.474 \mathrm{~mol} \cdot \mathrm{L}^{-1},[\mathrm{Al}]_{0}=(2.47\right.$ to 9.88$) \times 10^{-3}$ $\mathrm{mol} \cdot \mathrm{L}^{-1}$ ) for these polymerizations are shown in Figure 5.16.

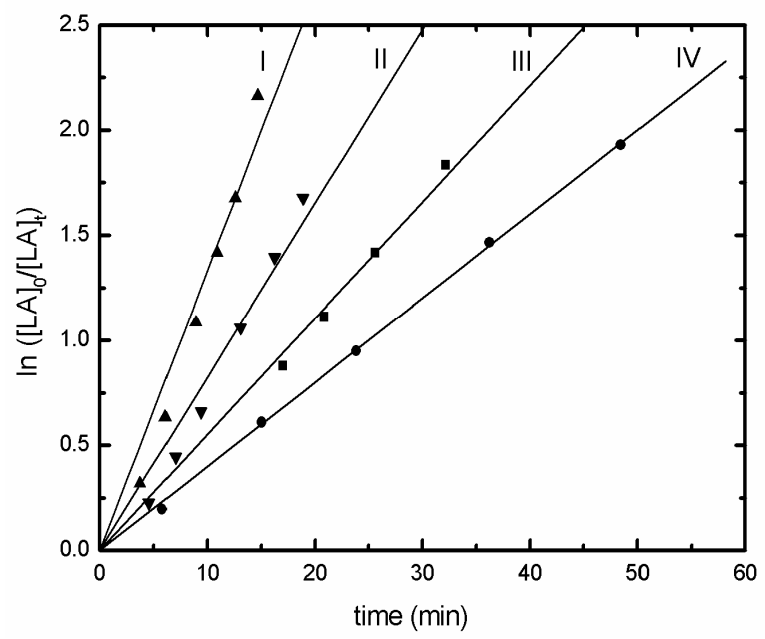

Figure 5.16. First-order kinetic plots for the polymerization of $\mathrm{rac}$-LA by complex $\mathbf{2 b}$ in toluene at $70^{\circ} \mathrm{C}$ with $[\mathrm{LA}]_{0}=0.474 \mathrm{~mol} \cdot \mathrm{L}^{-1}:(\mathbf{I})[\mathrm{Al}]_{0}=9.88 \times 10^{-3} \mathrm{~mol} \cdot \mathrm{L}^{-1}, k_{\text {app }}=133 \times 10^{-3} \mathrm{~min}^{-1} ;$ (II) $[\mathrm{Al}]_{0}$ $=6.58 \times 10^{-3} \mathrm{~mol} \cdot \mathrm{L}^{-1}, k_{\text {app }}=82.6 \times 10^{-3} \mathrm{~min}^{-1} ;$ (III) $[\mathrm{Al}]_{0}=4.94 \times 10^{-3} \mathrm{~mol} \cdot \mathrm{L}^{-1}, k_{\text {app }}=55.3 \times 10^{-3}$ $\min ^{-1} ;[\mathrm{LA}]_{0}=0.237 \mathrm{~mol} \cdot \mathrm{L}^{-1}:(\mathrm{IV})[\mathrm{Al}]_{0}=2.47 \times 10^{-3} \mathrm{~mol} \cdot \mathrm{L}^{-1}, k_{\text {app }}=40.0 \times 10^{-3} \mathrm{~min}^{-1}$.

No significant induction period was observed in each case, which indicates that the aluminum isopropoxide $\mathbf{2} \mathbf{b}$ acts as the actual active species in the ring-opening polymerization of LA. The linear relationship between $k_{\text {app }}$ versus $[\mathrm{Al}]_{0}$ as depicted in Figure 5.17, revealed that the polymerization using $\mathbf{2 b}$ is also first-order in both monomer and in catalyst. The $k_{\mathrm{p}}$ value for polymerization of rac-LA using $\mathbf{2} \mathbf{b}$ was calculated to be $13.0 \mathrm{~L} \cdot \mathrm{mol}^{-1} \cdot \mathrm{min}^{-1}$, which is even comparable to those of bis(salicylidene) Schiff base aluminum initiators with chlorine atoms at the ortho and para positions of the phenol group, ${ }^{11,12}$ and is much higher than those of aluminum initiators comprising non-substituted or tert-butyl-substituted bis(salicylidene) Schiff base ligands. $^{20}$ 
The $k_{\mathrm{p}}$ value for polymerization of $r a c$-LA using $\mathbf{2} \mathbf{b}$ is almost three times higher than that of 2a/2-propanol $\left(k_{\mathrm{p}}=2.97 \mathrm{~L} \cdot \mathrm{mol}^{-1} \cdot \mathrm{min}^{-1}\right)$. For polymerizations using in situ alcoholysis of aluminum ethyls, the polymerization consists of two steps. In the first step, the aluminum ethyls react with 2-propanol with a rate constant $k_{\text {rea }}$ to produce the aluminum isopropoxide as the active species. Consecutively, the aluminum isopropoxide initiates the LA polymerization with a polymerization rate constant $k_{\mathrm{p}}$ immediately after it is generated and until equilibrium of monomer conversion is reached. If $k_{\text {rea }}>k_{\mathrm{p}}$, then the observed polymerization rate is mainly determined by and presumably equal to $k_{\mathrm{p}}$. However, if $k_{\mathrm{rea}} \leq k_{\mathrm{p}}$, then the observed polymerization rate will be influenced by $k_{\text {rea }}$.

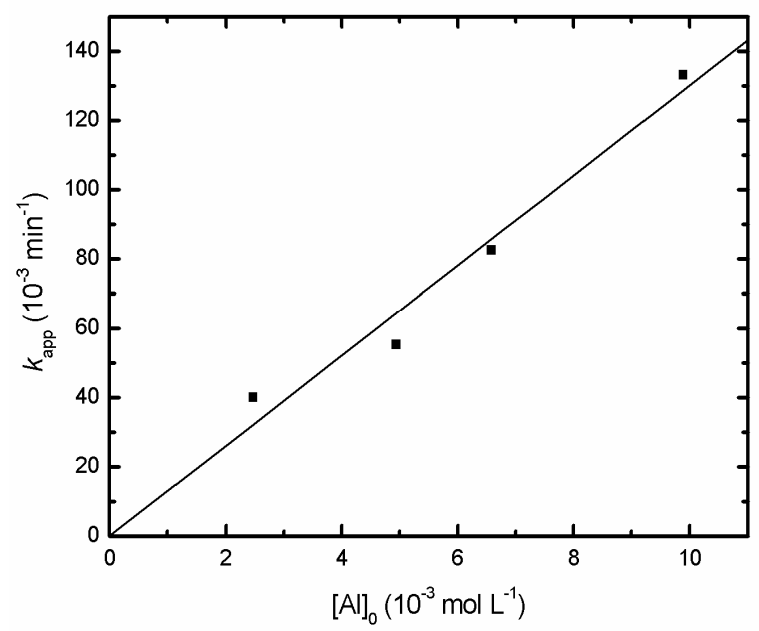

Figure 5.17 Linear plot of $k_{\text {app }}$ vs [Al $]_{0}$ for the polymerization of $r a c$-LA with complex $\mathbf{2 b}$ (toluene, $\left.70^{\circ} \mathrm{C}, k_{\mathrm{p}}=13.0 \mathrm{~L} \cdot \mathrm{mol}^{-1} \cdot \mathrm{min}^{-1}, R^{2}=0.966\right)$.

We assume that for 2a/2-propanol, the $k_{\mathrm{p}}$ is much higher than the $k_{\text {rea }}$, which causes the lower observed polymerization rate $\left(2.97 \mathrm{~L} \cdot \mathrm{mol}^{-1} \cdot \mathrm{min}^{-1}\right)$ for $\mathrm{rac}$-LA polymerization using 2a/2-propanol compared to the polymerization rate (13.0 $\mathrm{L} \cdot \mathrm{mol}^{-1} \cdot \mathrm{min}^{-1}$ ) of $\mathbf{2 b}$. On the basis of the narrow molecular weight distributions (Table 5.2, entries 2-7) observed and the fact that the number average molecular weights of the isolated PLAs initiated by 2a/2-propanol are in good accordance with the 
calculated ones, this indicates that fast chain transfer is taking place during polymerization. However, according to the kinetic data, it is apparent that the polymerizations of rac-LA using 3a/2-propanol or $\mathbf{3 b}$ have almost similar polymerization rate $\left(k_{\mathrm{p}}=3.44 \mathrm{~L} \cdot \mathrm{mol}^{-1} \cdot \mathrm{min}^{-1}\right.$ for $3 \mathrm{a} / 2$-propanol, compared to $k_{\mathrm{p}}=3.46$ $\mathrm{L} \cdot \mathrm{mol}^{-1} \cdot \mathrm{min}^{-1}$ for $\mathbf{3 b}$ ). Thus, it is envisioned that for the polymerization initiated by $\mathbf{3 a} / 2$-propanol, $k_{\mathrm{p}}$ is much lower than $k_{\text {rea. }}$. The $k_{\mathrm{p}}$ value for $\mathbf{3 b}$ is lower than that of $\mathbf{2} \mathbf{b}$, indicating that the presence of the methyl substituents at the ortho position of the pyrrolic rings retard the polymerization process. Although the rac-LA polymerization using the aluminum isopropoxide formed by 1a and 2-propanol has not been carried out, we assume that 1a/2-propanol has a much higher $k_{\text {rea }}$ than $k_{\mathrm{p}}$, which leads to no significant differences in $k_{\mathrm{p}}$ for $1 \mathrm{a} / 2$-propanol $\left(k_{\mathrm{p}}=7.79 \mathrm{~L} \cdot \mathrm{mol}^{-1} \cdot \mathrm{min}^{-1}\right)$ and its aluminum isopropoxide. From the comparison of $\mathbf{1 a} / 2$-propanol and $\mathbf{2 b}$, it is clear that, the gem methyls on the propylene backbones greatly enhance the rate of polymerization, which is consistent with our previous report. ${ }^{12}$

\section{CONCLUSIONS}

We report a series of aluminum ethyl and isopropoxide complexes ligated by $N, N, N, N$-tetradentate bis(pyrrolidene) Schiff base ligands that act as single-site catalysts for the polymerization of $(S, S)$-LA to isotactic PLA, rac-LA to predominant isotactic PLA, and meso-LA to atactic PLA. Kinetic studies indicate that the activity of the bis(pyrrolidene) Schiff base aluminum initiator system towards lactide polymerization decreases in the order of: $(S, S)$-LA $>$ rac-LA $>$ meso-LA, which is consistent with the observed isotacticity for the resulting PLAs prepared from rac-LA. The low stereoselectivity and low activity of the bis(pyrrolidene) Schiff base aluminum initiators in meso-LA polymerization compared to rac-LA polymerization reflect the chain-end selection effect by first-order Markovian statistics, caused by the presence of both R- and S-stereogenic centers in the last repeating unit along the propagating chain. Microstructural analysis of the polymers formed, as well as kinetic data, show that the gem methyls on the diimine bridge not only enhance the 
isoselectivity but also the polymerization rate of $\mathbf{2} \mathbf{a} / 2$-propanol or $\mathbf{2} \mathbf{b}$. However, the methyl substituents at the ortho position of the pyrrolic rings both decrease the polymerization rate and the isoselectivity of $\mathbf{3 a} / 2$-propanol or $\mathbf{3 b}$. Furthermore, kinetic analysis reveals that the polymerizations of rac-LA using 2a/2-propanol or $\mathbf{2} \mathbf{b}$ are first-order with respect to both monomer and catalyst. Finally, comparing $k_{\mathrm{p}}$ values reveals that the polymerization rate of $\mathbf{2} \mathbf{b}$ is higher than that of $\mathbf{2} \mathbf{a} / 2$-propanol.

\section{ACKNOWLEDGEMENT}

The authors thank the Chinese Academy of Sciences and the Royal Netherlands academy of Arts and Sciences for the CAS-KNAW joint training $\mathrm{PhD}$ program (06PhD09).

\section{REFERENCES AND NOTES}

[1] Chamberlain, B. M.; Cheng, M.; Moore, D. R.; Ovitt, T. M.; Lobkovsky, E. B.; Coates, G. W., J. Am. Chem. Soc. 2001, 123, 3229-3238.

[2] Chen, H. Y.; Huang, B. H.; Lin, C. C., Macromolecules 2005, 38, 5400-5405.

[3] Dove, A. P.; Gibson, V. C.; Marshall, E. L.; White, A. J. P.; Williams, D. J., J. Chem. Soc., Dalton Trans. 2004, 570-578.

[4] Chisholm, M. H.; Huffman, J. C.; Phomphrai, K., J. Chem. Soc., Dalton Trans. 2001, 222-224.

[5] Chisholm, M. H.; Gallucci, J.; Phomphrai, K., Inorg. Chem. 2002, 41, 2785-2794.

[6] Giesbrecht, G. R.; Whitener, G. D.; Arnold, J., J. Chem. Soc., Dalton Trans. 2001, 923-927.

[7] Tang, Z. H.; Gibson, V. C., Eur. Polym. J. 2007, 43, 150-155.

[8] Chmura, A. J.; Davidson, M. G.; Frankis, C. J.; Jones, M. D.; Lunn, M. D., Chem. Commun. 2008, 1293-1295.

[9] Ma, H.; Spaniol, T. P.; Okuda, J., Inorg. Chem. 2008, 47, 3328-3339.

[10] Spassky, N.; Wisniewski, M.; Pluta, C.; LeBorgne, A., Macromol. Chem. Phys. 
1996, 197, 2627-2637.

[11] Hormnirun, P.; Marshall, E. L.; Gibson, V. C.; Pugh, R. I.; White, A. J. P., Proc. Natl. Acad. Sci. U.S.A 2006, 103, 15343-15348.

[12] Du, H. Z.; Pang, X.; Yu, H. Y.; Zhuang, X. L.; Chen, X. S.; Cui, D. M.; Wang, X. H.; Jing, X. B., Macromolecules 2007, 40, 1904-1913.

[13] Atwood, D. A.; Harvey, M. J., Chem. Rev. 2001, 101, 37-52.

[14] Stolt, M.; Sodergard, A., Macromolecules 1999, 32, 6412-6417.

[15] Stolt, M.; Krasowska, K.; Rutkowska, M.; Janik, H.; Rosling, A.; Sodergard, A., Polym. Inter. 2005, 54, 362-368.

[16] Hocking, P. J.; Marchessault, R. H., Macromolecules 1995, 28, 6401-6409.

[17] Chisholm, M. H.; Eilerts, N. W.; Huffman, J. C.; Iyer, S. S.; Pacold, M.; Phomphrai, K., J. Am. Chem. Soc. 2000, 122, 11845-11854.

[18] Eguiburu, J. L.; Fernandez-Berridi, M. J.; Cossio, F. P.; San Roman, J., Macromolecules 1999, 32, 8252-8258.

[19] Witzke, D. R.; Narayan, R.; Kolstad, J. J., Macromolecules 1997, 30, 7075-7085.

[20] Bhaw-Luximon, A.; Jhurry, D.; Spassky, N., Polym. Bull. 2000, 44, 31-38. 


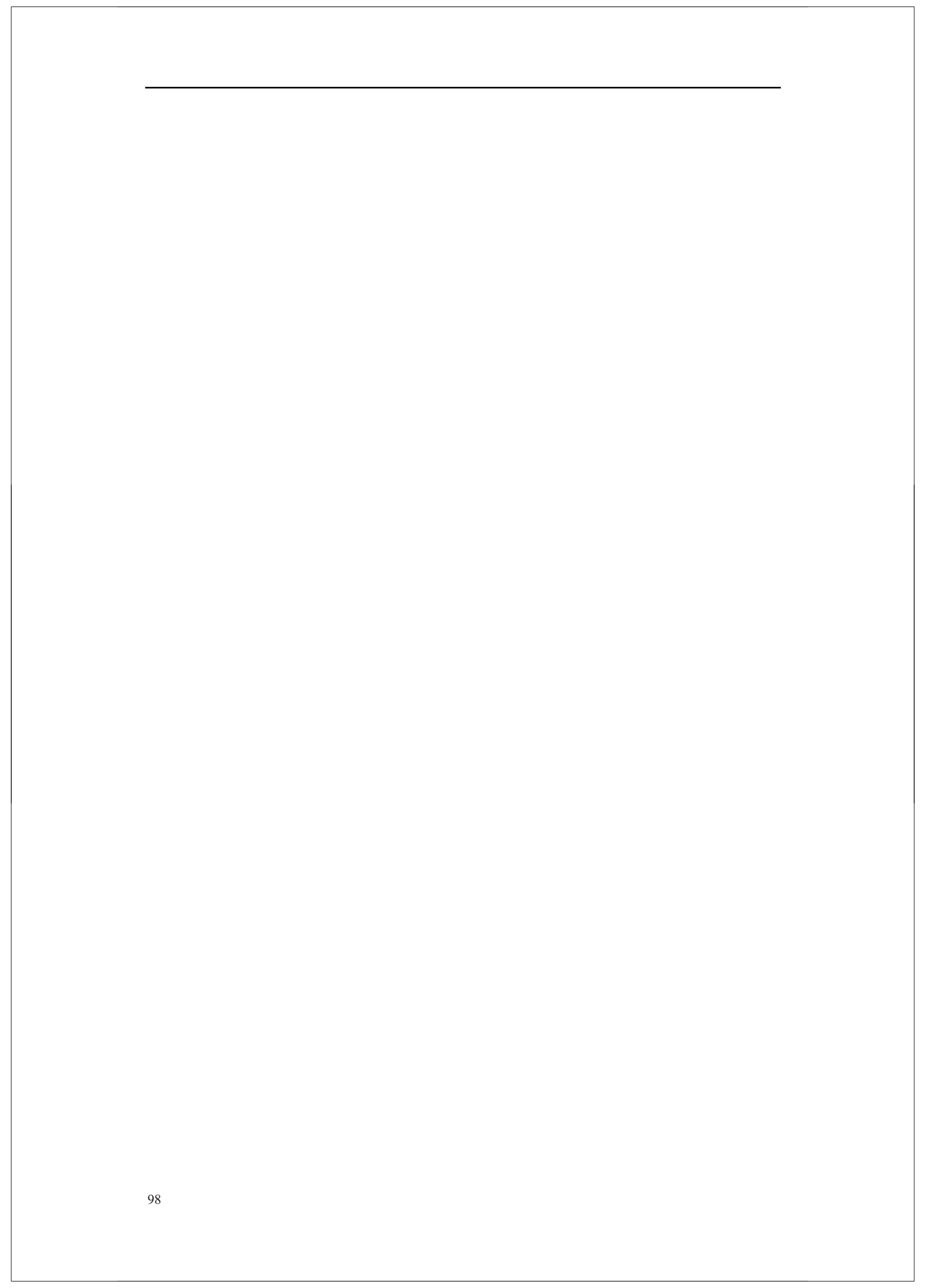




\section{Chiral Salan Aluminum Ethyl Complexes and}

\section{Their Application in Lactide Polymerization}

\section{ABSTRACT}

Synthetic routes to aluminum ethyl complexes supported by chiral tetradentate phenoxyamine (salan-type) ligands,

$\left[\mathrm{Al}\left(\mathrm{OC}_{6} \mathrm{H}_{2}(\mathrm{R}-6-\mathrm{R}-4) \mathrm{CH}_{2}\right)_{2}\left\{\mathrm{CH}_{3} \mathrm{~N}\left(\mathrm{C}_{6} \mathrm{H}_{10}\right) \mathrm{NCH}_{3}\right\}-\mathrm{C}_{2} \mathrm{H}_{5}\right](\mathbf{4}, \mathbf{7}: \mathrm{R}=\mathrm{H}, \mathbf{5}, \mathbf{8}: \mathrm{R}=\mathrm{Cl}, \mathbf{6}, \mathbf{9}$ : $\left.\mathrm{R}=\mathrm{CH}_{3}\right)$, are reported. Enantiomerically pure salan ligands (1-3) with a $(R, R)$ configuration at the cyclohexane ring afforded the complexes $\mathbf{4 , 5}$, and $\mathbf{6}$ as mixtures of two diastereoisomers (a and b). Diastereoisomer a was, as determined by X-ray analysis, monomeric with a five-coordinated aluminum central core in the solid state, adopting a cis- $(\mathrm{O}, \mathrm{O})$ and cis-(Me,Me) ligand geometry. Based on the results of variable temperature (VT) ${ }^{1} \mathrm{H}$ NMR in the temperature range of $220-335 \mathrm{~K},{ }^{1} \mathrm{H}-{ }^{1} \mathrm{H}$ NOESY at $220 \mathrm{~K}$, and diffusion-ordered spectroscopy (DOSY), it is concluded that diastereoisomer $\mathbf{b}$ is also monomeric with a five-coordinated aluminum central core. The geometry is intermediate between square pyramidal with a cis- $(\mathrm{O}, \mathrm{O})$, trans-(Me,Me) ligand disposition and trigonal bipyramidal with a trans- $(\mathrm{O}, \mathrm{O})$ and trans-(Me,Me) disposition. A slow exchange between these two geometries at $220 \mathrm{~K}$ was indicated by ${ }^{1} \mathrm{H}-{ }^{1} \mathrm{H}$ NOESY NMR. In the presence of 2-propanol as an initiator, enantiomerically pure complexes 4-6 and their racemic mixtures 7-9 were efficient catalysts in the ring-opening polymerization of lactide. Polylactide materials ranging from isotactic-biased $\left(P_{\mathrm{m}}\right.$ up to 0.66$)$ to medium heterotactic $\left(P_{\mathrm{r}}\right.$ up to 0.73$)$ were obtained from rac-lactide, and syndiotactic-biased polylactide $\left(P_{\mathrm{r}}\right.$ up to 0.70$)$ from meso-lactide. Kinetic studies revealed that the polymerization of $(S, S)$-LA using 4/2propanol had a much higher polymerization rate than that of $(R, R)$-LA polymerization $\left(k_{\mathrm{SS}} / k_{\mathrm{RR}}=10.1\right)$. 


\section{INTRODUCTION}

Tetradentate phenoxyamine ligands are usually referred to as salan-type ligands, which can be considered as fully reduced Schiff base (salen) ligands. ${ }^{1}$ Compared to salen ligands, the salan-type ligands have a more flexible structure due to the $s p^{3}$ hybridization of the amine nitrogen atoms. Salan ligands comprising a trans-1,2-diaminocyclohexane bridge may lead to various kinds of interesting chiral metal complexes. Recently, chiral Fe(salan), ${ }^{2,3}$ Ti(salan), ${ }^{4}$ and V(salan) ${ }^{5}$ complexes have been studied and applied in the asymmetric oxidation of sulfides. Chiral Ti(salan $)^{6-8}$ have been exploited in the asymmetric addition of metal alkyls to aldehydes and $\operatorname{Mo}(\text { salan })^{9}$ complexes have been used in the enantioselective pinacol coupling of aryl aldehydes. Moreover, Kol and co-workers demonstrated that chiral $\mathrm{Zr}$ (salan) complexes have the ability to initiate an isospecific polymerization of 1-hexene, 4-methyl-1-pentene, ${ }^{10}$ vinylcyclohexane, ${ }^{11}$ as well as the cyclopolymerization of 1,5 -hexadiene. ${ }^{10}$ However, the structures and catalytic applications of chiral Al(salan) complexes have never been reported. ${ }^{12}$ Previously, we described a chiral Jacobsen salen aluminum isopropoxide, which exerts a significant stereocontrol in rac-LA polymerization, affording highly isotactic PLAs with a $P_{\mathrm{i}}$ value up to $0.93 .^{13}$ In this chapter we describe the synthesis and structure of chiral salan aluminum ethyl complexes with respect to the ligand wrapping modes, as well as their catalytic behavior towards lactide polymerization in the presence of 2-propanol as an initiator.

\section{EXPERIMENTAL SECTION}

General. All manipulations requiring a dry atmosphere were performed under dry argon by use of standard Schlenk techniques or in a glovebox (Mbraun, Germany). Solvents were dried by refluxing over sodium/benzophenone (toluene and hexane) or calcium hydride (2-propanol) at least for $24 \mathrm{~h}$. Anhydrous deuterated solvents $\left(\mathrm{CDCl}_{3}\right.$, $\mathrm{C}_{6} \mathrm{D}_{5} \mathrm{CD}_{3}$ and $\mathrm{C}_{6} \mathrm{D}_{6}$, Aldrich) were kept under nitrogen on $4 \AA$ molecular sieves. 
Starting materials for the synthesis of ligand precusors 1-3 were purchased from Aldrich and were used without further purification. The ligands 1-3 were synthesized according to literature procedures. ${ }^{8}$ Triethylaluminum from Aldrich was used as received. $(S, S)$-, rac-, and meso-LA (Purac Biochem b.v., the Netherlands) were purified by recrystallization from anhydrous toluene three times, followed by drying under vacuum at $30^{\circ} \mathrm{C}$ for $24 \mathrm{~h}$ before use.

Nuclear magnetic resonance (NMR) spectra were recorded on a Bruker AV $400 \mathrm{MHz}$ at $298 \mathrm{~K}$ or a Varian Inova $600 \mathrm{MHz}$ spectrometer at $295 \mathrm{~K} . \mathrm{CDCl}_{3}, \mathrm{C}_{6} \mathrm{D}_{5} \mathrm{CD}_{3}$ and $\mathrm{C}_{6} \mathrm{D}_{6}$ were used as solvents. Homonuclear decoupled ${ }^{1} \mathrm{H}$ NMR, ${ }^{1} \mathrm{H}-{ }^{1} \mathrm{H}$ COSY, ${ }^{1} \mathrm{H}-{ }^{1} \mathrm{H}$ NOESY, and diffusion-ordered (DOSY) spectra were recorded on a Bruker Avance II $600 \mathrm{MHz}$ spectrometer operating at $600.13 \mathrm{MHz}$. The spectrometer was equipped with a Great 3/10 gradient amplifier and a triple-nucleus TXI probe with z-gradient. All experiments were performed at $295 \mathrm{~K}$ using standard pulse sequences from the Bruker library. Pulsed filed gradient stimulated echo (PFGSE) diffusion experiments were performed using the bipolar stimulated echo sequence with 32 increments in the gradient strength (2-95\%), typically 16 averages per increment step, and $100 \mathrm{~ms}$ diffusion time. Monomer conversions were determined from the integrals of signals at $1.65 \mathrm{ppm}$ representing lactide monomer and $1.59 \mathrm{ppm}$ representing PLA. $P_{\mathrm{m}} \mathrm{s}$ (the probability of meso linkages) and $P_{\mathrm{r}} \mathrm{s}$ (the probability of racemic linkages) were calculated from different tetrad intensities measured by homonuclear decoupled ${ }^{1} \mathrm{H}$ NMR. Gel permeation chromatography (GPC) measurements were conducted with a Waters $410 \mathrm{GPC}$ with $\mathrm{THF}$ as the eluent (flow rate: $1 \mathrm{~mL} / \mathrm{min}$, at $35^{\circ} \mathrm{C}$ ). The molecular weights were determined relative to polystyrene standards.

Synthesis of Ligands. $(\boldsymbol{R}, \boldsymbol{R})-\mathbf{1}:{ }^{1} \mathrm{H} \mathrm{NMR}\left(400 \mathrm{MHz}, \mathrm{CDCl}_{3}, 25{ }^{\circ} \mathrm{C}\right): \delta=10.33(\mathrm{br}$, $2 \mathrm{H}, \operatorname{ArOH}), 7.18\left(\mathrm{td}, J_{\mathrm{H}-\mathrm{H}}=1.2 \mathrm{~Hz}, J_{\mathrm{H}-\mathrm{H}}=8.4 \mathrm{~Hz}, 2 \mathrm{H}, \operatorname{Ar} \boldsymbol{H}\right), 6.98\left(\mathrm{~d}, J_{\mathrm{H}-\mathrm{H}}=7.2 \mathrm{~Hz}, 2 \mathrm{H}\right.$, $\operatorname{Ar} \boldsymbol{H}), 6.80(\mathrm{~m}, 4 \mathrm{H}, \operatorname{Ar} \boldsymbol{H}), 3.84\left(\mathrm{~d}, J_{\mathrm{H}-\mathrm{H}}=13.2 \mathrm{~Hz}, 2 \mathrm{H}, \operatorname{ArCH}_{2} \mathrm{NCH}_{3}\right), 3.64\left(\mathrm{~d}, J_{\mathrm{H}-\mathrm{H}}=\right.$ $\left.12.9 \mathrm{~Hz}, 2 \mathrm{H}, \mathrm{ArCH}_{2} \mathrm{NCH}_{3}\right), 2.71\left(\mathrm{~d}, J_{\mathrm{H}-\mathrm{H}}=8.4 \mathrm{~Hz}, 2 \mathrm{H}, \mathrm{CH}\right), 2.23\left(\mathrm{~s}, 6 \mathrm{H}, \mathrm{NCH}_{3}\right), 2.02$ $\left(\mathrm{d}, J_{\mathrm{H}-\mathrm{H}}=10.2 \mathrm{~Hz}, 2 \mathrm{H}\right.$, cyclohexane hydrogens $), 1.81\left(\mathrm{~d}, J_{\mathrm{H}-\mathrm{H}}=6.9 \mathrm{~Hz}, 2 \mathrm{H}\right.$, cyclohexane hydrogens), 1.15 (m, 4H, cyclohexane hydrogens); ${ }^{13} \mathrm{C}$ NMR (100 MHz, 
$\left.\mathrm{CDCl}_{3}, 25^{\circ} \mathrm{C}\right): \delta=157.84(\mathrm{Ar} C \mathrm{OH}), 129.03(\mathrm{Ar} C H), 128.61(\mathrm{Ar} C H), 122.31(\mathrm{ArCH})$, $119.03\left(\mathrm{ArCCH}_{2}\right), 116.49(\mathrm{Ar} \boldsymbol{C H}), 61.91$ (cyclohexane carbons), $56.97\left(\mathrm{ArCH}_{2} \mathrm{NCH}_{3}\right)$, 35.53 ( $\mathrm{NCH}_{3}$ ), 25.27 (cyclohexane carbons), 22.32 (cyclohexane carbons); Anal. Calcd for $\mathrm{C}_{22} \mathrm{H}_{30} \mathrm{~N}_{2} \mathrm{O}_{2}$ : C, 74.54; H, 8.53; N, 7.90. Found: C, 74.99; H, 8.32; N, 7.94.

$(\boldsymbol{R}, \boldsymbol{R})-2:{ }^{1} \mathrm{H}$ NMR $\left(400 \mathrm{MHz}, \mathrm{DMSO}, 25^{\circ} \mathrm{C}\right): \delta=7.32\left(\mathrm{~d}, J_{\mathrm{H}-\mathrm{H}}=2.7 \mathrm{~Hz}, 2 \mathrm{H}, \mathrm{Ar} \boldsymbol{H}\right)$, $7.18\left(\mathrm{~d}, J_{\mathrm{H}-\mathrm{H}}=2.7 \mathrm{~Hz}, 2 \mathrm{H}, \operatorname{Ar} \boldsymbol{H}\right), 3.80\left(\mathrm{~d}, J_{\mathrm{H}-\mathrm{H}}=13.5 \mathrm{~Hz}, 2 \mathrm{H}, \operatorname{ArCH} \boldsymbol{H}_{2} \mathrm{NCH}_{3}\right), 3.56(\mathrm{~d}$, $\left.J_{\mathrm{H}-\mathrm{H}}=13.2 \mathrm{~Hz}, 2 \mathrm{H}, \mathrm{ArCH}_{2} \mathrm{NCH}_{3}\right), 2.87\left(\mathrm{~d}, J_{\mathrm{H}-\mathrm{H}}=6.9 \mathrm{~Hz}, 2 \mathrm{H}, \mathrm{CH}\right), 2.14\left(\mathrm{~s}, 6 \mathrm{H}, \mathrm{NCH}_{3}\right)$, 1.98 (d, 2H, cyclohexane hydrogens), 1.76 (d, 2H, cyclohexane hydrogens), 1.19 (m, $4 \mathrm{H}$, cyclohexane hydrogens); ${ }^{13} \mathrm{C}$ NMR (100 MHz, DMSO, $\left.25{ }^{\circ} \mathrm{C}\right): \delta=153.46$ $(\mathrm{Ar} \boldsymbol{C O H}), 128.65(\mathrm{Ar} \boldsymbol{C H}), 127.92(\mathrm{Ar} C \mathrm{H}), 126.97(\mathrm{Ar} \boldsymbol{C}), 122.17(\mathrm{Ar} \boldsymbol{C}), 120.86(\mathrm{Ar} \boldsymbol{C})$, 61.96 (cyclohexane carbons), $52.97\left(\mathrm{ArCH}_{2} \mathrm{NCH}_{3}\right), 35.37\left(\mathrm{NCH}_{3}\right), 24.53$ (cyclohexane carbons), 22.40 (cyclohexane carbons); Anal. Calcd for $\mathrm{C}_{22} \mathrm{H}_{26} \mathrm{Cl}_{4} \mathrm{~N}_{2} \mathrm{O}_{2}$ : C, 53.68; $\mathrm{H}$, 5.32; N, 5.69. Found: C, 54.09; H, 5.02; N, 5.76.

$(\boldsymbol{R}, \boldsymbol{R})-3:{ }^{1} \mathrm{H} \mathrm{NMR}\left(400 \mathrm{MHz}, \mathrm{CDCl}_{3}, 25^{\circ} \mathrm{C}\right): \delta=10.00(\mathrm{br}, 2 \mathrm{H}, \mathrm{ArOH}), 6.78(\mathrm{~s}, 2 \mathrm{H}$, $\operatorname{Ar} \boldsymbol{H}), 6.56(\mathrm{~s}, 2 \mathrm{H}, \mathrm{Ar} \boldsymbol{H}), 3.67\left(\mathrm{~d}, J_{\mathrm{H}-\mathrm{H}}=13.2 \mathrm{~Hz}, 2 \mathrm{H}, \operatorname{ArCH}_{2} \mathrm{NCH}_{3}\right), 3.50\left(\mathrm{~d}, J_{\mathrm{H}-\mathrm{H}}=\right.$ 13.2 Hz, 2H, $\left.\mathrm{ArCH}_{2} \mathrm{NCH}_{3}\right), 2.59\left(\mathrm{~d}, J_{\mathrm{H}-\mathrm{H}}=7.8 \mathrm{~Hz}, 2 \mathrm{H}, \mathrm{CH}\right), 2.14\left(\mathrm{~s}, 6 \mathrm{H}, \mathrm{NCH}_{3}\right), 2.09$ (s, 6H, $\left.\operatorname{ArCH}_{3}\right), 2.06\left(\mathrm{~s}, 6 \mathrm{H}, \operatorname{ArCH}_{3}\right), 1.92\left(\mathrm{~d}, J_{\mathrm{H}-\mathrm{H}}=8.1 \mathrm{~Hz}, 2 \mathrm{H}\right.$, cyclohexane hydrogens), 1.73 (d, 2H, cyclohexane hydrogens), 1.06 (m, 4H, cyclohexane hydrogens $) ;{ }^{13} \mathrm{C} \mathrm{NMR}\left(100 \mathrm{MHz}, \mathrm{CDCl}_{3}, 25^{\circ} \mathrm{C}\right): \delta=153.59(\mathrm{ArCOH}), 130.60(\mathrm{ArCH})$, $127.32\left(\mathrm{ArCCH}_{3}\right), 127.12(\mathrm{ArCH}), 125.07\left(\mathrm{ArCCH}_{3}\right), 121.81\left(\mathrm{ArCCH}_{2}\right), 61.46$ (cyclohexane carbons), $57.00\left(\mathrm{ArCH}_{2} \mathrm{NCH}_{3}\right), 35.31\left(\mathrm{NCH}_{3}\right), 25.32$ (cyclohexane carbons), 22.27 (cyclohexane carbons), $20.47\left(\mathrm{ArCH} \mathrm{H}_{3}\right), 15.68\left(\mathrm{ArCH}_{3}\right)$; Anal. Calcd for $\mathrm{C}_{26} \mathrm{H}_{38} \mathrm{~N}_{2} \mathrm{O}_{2}$ : C, 76.06; H, 9.33; N, 6.82. Found: C, 76.09; H, 9.02; N, 6.76.

Synthesis of chiral aluminum ethyl complexes. 4: To a solution of $(R, R)-1(1.42 \mathrm{~g}$, $4 \mathrm{mmol}$ ) dissolved in toluene $(2 \mathrm{~mL}), 2.0 \mathrm{M}$ solution of triethylaluminum in toluene $(2$ $\mathrm{mL}$ ) was added dropwise via a syringe at room temperature. Instantaneous evolution of ethane was observed. The colorless reaction mixture was stirred at $70{ }^{\circ} \mathrm{C}$ overnight and slowly cooled to room temperature. The solvent was removed under reduced pressure, and the residue was repeatedly washed with anhydrous $n$-hexane to afford the product 102 
as colorless crystals in 67\% yield (1.09 g, $2.68 \mathrm{mmol})$. The ${ }^{1} \mathrm{H}$ NMR spectra clearly indicated the presence of two complexes. ${ }^{1} \mathrm{H}$ NMR $\left(600 \mathrm{MHz}, \mathrm{C}_{6} \mathrm{D}_{5} \mathrm{CD}_{3}, 22{ }^{\circ} \mathrm{C}\right): 4 \mathbf{a}, \delta$ $=7.17\left(\mathrm{dd}, J_{\mathrm{H}-\mathrm{H}}=1.2 \mathrm{~Hz}, J_{\mathrm{H}-\mathrm{H}}=7.2 \mathrm{~Hz}, 2 \mathrm{H}, \operatorname{Ar} \boldsymbol{H}\right), 7.07\left(\mathrm{t}, J_{\mathrm{H}-\mathrm{H}}=7.2 \mathrm{~Hz}, 2 \mathrm{H}, \operatorname{Ar} \boldsymbol{H}\right)$, $6.84\left(\mathrm{t}, J_{\mathrm{H}-\mathrm{H}}=5.4 \mathrm{~Hz}, 2 \mathrm{H}, \operatorname{Ar} \boldsymbol{H}\right), 6.74(\mathrm{~m}, 2 \mathrm{H}, \operatorname{Ar} \boldsymbol{H}), 3.70\left(\mathrm{~d}, J_{\mathrm{H}-\mathrm{H}}=13.0 \mathrm{~Hz}, 1 \mathrm{H}\right.$, $\left.\mathrm{ArCH}_{2} \mathrm{NCH}_{3}\right), 3.60\left(\mathrm{~d}, J_{\mathrm{H}-\mathrm{H}}=13.0 \mathrm{~Hz}, 1 \mathrm{H}, \mathrm{ArCH}_{2} \mathrm{NCH}_{3}\right), 3.19\left(\mathrm{~d}, J_{\mathrm{H}-\mathrm{H}}=13.0 \mathrm{~Hz}, 1 \mathrm{H}\right.$, $\left.\mathrm{ArCH}_{2} \mathrm{NCH}_{3}\right), 2.71\left(\mathrm{~d}, J_{\mathrm{H}-\mathrm{H}}=13.0 \mathrm{~Hz}, 1 \mathrm{H}, \mathrm{ArCH}_{2} \mathrm{NCH}_{3}\right), 2.29\left(\mathrm{td}, J_{\mathrm{H}-\mathrm{H}}=1.2 \mathrm{~Hz}, J_{\mathrm{H}-\mathrm{H}}\right.$ $=3.6 \mathrm{~Hz}, 1 \mathrm{H}, \mathrm{CH}), 2.02\left(\mathrm{td}, J_{\mathrm{H}-\mathrm{H}}=1.2 \mathrm{~Hz}, J_{\mathrm{H}-\mathrm{H}}=3.6 \mathrm{~Hz}, 1 \mathrm{H}, \mathrm{CH}\right), 1.84\left(\mathrm{~s}, 3 \mathrm{H}, \mathrm{NCH}_{3}\right)$, 1.72 (s, 3H, $\left.\mathrm{NCH}_{3}\right), 1.54$ (t, 3H, $\left.\mathrm{AlCH}_{2} \mathrm{CH}_{3}\right), 1.51$ (d, 2H, cylcohexane hydrogens), 1.34 (m, 2H, cyclohexane hydrogens), 0.58 (m, 4H, cyclohexane hydrogens), 0.10 (dq, $\left.1 \mathrm{H}, \mathrm{AlCH}_{2} \mathrm{CH}_{3}\right),-0.07\left(\mathrm{dq}, 1 \mathrm{H}, \mathrm{AlCH}_{2} \mathrm{CH}_{3}\right) ; \mathbf{4 b}, \delta=7.22(\mathrm{~m}, 4 \mathrm{H}, \mathrm{Ar} \boldsymbol{H}), 6.90\left(\mathrm{dd}, J_{\mathrm{H}-\mathrm{H}}\right.$ $\left.=1.2 \mathrm{~Hz}, J_{\mathrm{H}-\mathrm{H}}=7.2 \mathrm{~Hz}, 2 \mathrm{H}, \operatorname{Ar} \boldsymbol{H}\right), 6.77\left(\mathrm{dd}, J_{\mathrm{H}-\mathrm{H}}=1.2 \mathrm{~Hz}, J_{\mathrm{H}-\mathrm{H}}=7.2 \mathrm{~Hz}, 2 \mathrm{H}, \operatorname{Ar} \boldsymbol{H}\right)$, $3.44\left(\mathrm{~d}, J_{\mathrm{H}-\mathrm{H}}=13.0 \mathrm{~Hz}, 2 \mathrm{H}, \operatorname{ArCH}_{2} \mathrm{NCH}_{3}\right), 3.28\left(\mathrm{~d}, J_{\mathrm{H}-\mathrm{H}}=13.0 \mathrm{~Hz}, 2 \mathrm{H}, \mathrm{ArCH}_{2} \mathrm{NCH}_{3}\right)$, $2.05(\mathrm{~m}, 2 \mathrm{H}, \mathrm{CH}), 1.80\left(\mathrm{~s}, 6 \mathrm{H}, \mathrm{NCH}_{3}\right), 1.45$ (t, 3H, $\left.\mathrm{AlCH}_{2} \mathrm{CH}_{3}\right), 1.41$ (d, 2H, cylcohexane hydrogens), $0.78(\mathrm{~m}, 2 \mathrm{H}$, cyclohexane hydrogens $), 0.67$ (m, 4H, cyclohexane hydrogens), $0.23\left(\mathrm{dq}, 1 \mathrm{H}, \mathrm{AlCH}_{2} \mathrm{CH}_{3}\right), 0.04\left(\mathrm{dq}, 1 \mathrm{H}, \mathrm{AlCH}_{2} \mathrm{CH}_{3}\right) ;{ }^{13} \mathrm{C}$ $\operatorname{NMR}\left(100 \mathrm{MHz}, \mathrm{C}_{6} \mathrm{D}_{6}, 25^{\circ} \mathrm{C}\right): \delta=162.39,161.75,131.40,131.07,129.56,129.21$, $122.75,121.06,120.83,120.18,117.32,116.73,63.44,61.55,60.47,53.47,42.74$, 36.34, 24.85, 23.48, 22.84, 22.21, 11.99; Anal. Calcd for $\mathrm{C}_{24} \mathrm{H}_{33} \mathrm{AlN}_{2} \mathrm{O}_{2}$ : C, 70.56; $\mathrm{H}$, 8.14; N, 6.86. Found: C, 71.09; H, 8.02; N, 6.76.

5: The procedure was similar as described for 4 , starting with $(R, R)-2(1.97 \mathrm{~g}, 4$ mmol). A white powder was isolated in $80 \%$ yield $(1.75 \mathrm{~g}, 3.20 \mathrm{mmol})$. The ${ }^{1} \mathrm{H} \mathrm{NMR}$ spectra clearly indicated the presence of two complexes. ${ }^{1} \mathrm{H} \mathrm{NMR}\left(600 \mathrm{MHz}, \mathrm{C}_{6} \mathrm{D}_{5} \mathrm{CD}_{3}\right.$, $\left.22^{\circ} \mathrm{C}\right): \mathbf{5 a}, \delta=7.36\left(\mathrm{dd}, J_{\mathrm{H}-\mathrm{H}}=2.4 \mathrm{~Hz}, J_{\mathrm{H}-\mathrm{H}}=5.4 \mathrm{~Hz}, 1 \mathrm{H}, \operatorname{Ar} \boldsymbol{H}\right), 7.06(\mathrm{~s}, 1 \mathrm{H}, \operatorname{Ar} \boldsymbol{H}), 6.66$ $\left(\mathrm{dd}, J_{\mathrm{H}-\mathrm{H}}=3.6 \mathrm{~Hz}, J_{\mathrm{H}-\mathrm{H}}=5.4 \mathrm{~Hz}, 2 \mathrm{H}, \operatorname{Ar} \boldsymbol{H}\right), 3.52\left(\mathrm{~d}, J_{\mathrm{H}-\mathrm{H}}=13.2 \mathrm{~Hz}, 1 \mathrm{H}, \operatorname{ArCH}_{2} \mathrm{NCH}_{3}\right)$, $3.19\left(\mathrm{~d}, J_{\mathrm{H}-\mathrm{H}}=13.2 \mathrm{~Hz}, 1 \mathrm{H}, \operatorname{ArCH}_{2} \mathrm{NCH}_{3}\right), 3.06\left(\mathrm{~d}, J_{\mathrm{H}-\mathrm{H}}=13.2 \mathrm{~Hz}, 1 \mathrm{H}, \mathrm{ArCH}_{2} \mathrm{NCH}_{3}\right)$, $2.36\left(\mathrm{~d}, J_{\mathrm{H}-\mathrm{H}}=13.2 \mathrm{~Hz}, 1 \mathrm{H}, \operatorname{ArCH}_{2} \mathrm{NCH}_{3}\right), 2.23(\mathrm{td}, 1 \mathrm{H}, \mathrm{CH}), 1.84(\mathrm{td}, 1 \mathrm{H}, \mathrm{CH}), 1.59(\mathrm{~s}$, $\left.3 \mathrm{H}, \mathrm{NCH}_{3}\right), 1.51$ (t, 3H, $\left.\mathrm{AlCH}_{2} \mathrm{CH}_{3}\right), 1.45$ (s, 3H, NCH $), 1.42$ (m, 2H, cyclohexane hydrogens), 1.24 ( $\mathrm{m}, 2 \mathrm{H}$, cyclohexane hydrogens), 0.68-0.48 (m, 4H, cyclohexane hydrogens), $-0.10\left(\mathrm{dq}, 1 \mathrm{H}, \mathrm{AlCH}_{2} \mathrm{CH}_{3}\right),-0.22\left(\mathrm{dq}, 1 \mathrm{H}, \mathrm{AlCH}_{2} \mathrm{CH}_{3}\right) ; \mathbf{5 b}, \delta=7.38(\mathrm{~d}$, 
$2 \mathrm{H}, \operatorname{Ar} \boldsymbol{H}), 6.62(\mathrm{~d}, 2 \mathrm{H}, \operatorname{Ar} \boldsymbol{H}), 2.96\left(\mathrm{~d}, J_{\mathrm{H}-\mathrm{H}}=13.2 \mathrm{~Hz}, 2 \mathrm{H}, \operatorname{ArCH}_{2} \mathrm{NCH}_{3}\right), 2.57\left(\mathrm{~d}, J_{\mathrm{H}-\mathrm{H}}=\right.$ 13.2 Hz, 2H, ArCH $\left.\boldsymbol{H}_{2} \mathrm{NCH}_{3}\right), 2.16$ (m, 2H, CH), 1.87 (m, 2H, cyclohexane hydrogens), 1.62 (s, 6H, NCH 3$), 1.32$ (t, 3H, $\left.\mathrm{AlCH}_{2} \mathrm{CH}_{3}\right), 1.17$ (m, 2H, cyclohexane hydrogens), $0.76\left(\mathrm{~m}, 4 \mathrm{H}\right.$, cyclohexane hydrogens), 0.05 (dq, $\left.1 \mathrm{H}, \mathrm{AlCH}_{2} \mathrm{CH}_{3}\right),-0.16(\mathrm{dq}, 1 \mathrm{H}$, $\left.\mathrm{AlCH}_{2} \mathrm{CH}_{3}\right) ;{ }^{13} \mathrm{C}$ NMR $\left(100 \mathrm{MHz}, \mathrm{C}_{6} \mathrm{D}_{6}, 25{ }^{\circ} \mathrm{C}\right): \delta=156.02,155.55,130.64,130.52$, $127.84,127.56,126.26,126.13,124.43,123.30,121.53,120.08,63.74,62.06,59.51$, $58.63,42.96,35.83,24.53,23.40,22.81,22.57,11.43,0.86$; Anal. Calcd for $\mathrm{C}_{24} \mathrm{H}_{29} \mathrm{AlCl}_{4} \mathrm{~N}_{2} \mathrm{O}_{2}:$ C, 52.77; H, 5.35; N, 5.13. Found: C, 52.56; H, 5.58; N, 5.76.

6: The procedure was similar as described for $\mathbf{4}$, starting from $(R, R)-\mathbf{3}(4.10 \mathrm{~g}, 10$ mmol). A white powder was isolated in $72 \%$ yield $(3.35 \mathrm{~g}, 7.20 \mathrm{mmol})$. The ${ }^{1} \mathrm{H}$ NMR spectra clearly indicated the presence of two complexes. ${ }^{1} \mathrm{H}$ NMR $(600 \mathrm{MHz}$, $\left.\mathrm{C}_{6} \mathrm{D}_{5} \mathrm{CD}_{3}, 22^{\circ} \mathrm{C}\right): \mathbf{6 a}, \delta=7.02\left(\mathrm{~d}, J_{\mathrm{H}-\mathrm{H}}=12.0 \mathrm{~Hz}, 2 \mathrm{H}, \mathrm{Ar} \boldsymbol{H}\right), 6.56\left(\mathrm{~d}, J_{\mathrm{H}-\mathrm{H}}=6.0 \mathrm{~Hz}, 2 \mathrm{H}\right.$, $\operatorname{Ar} \boldsymbol{H}), 3.71\left(\mathrm{~d}, J_{\mathrm{H}-\mathrm{H}}=12.0 \mathrm{~Hz}, 1 \mathrm{H}, \operatorname{ArCH}_{2} \mathrm{NCH}_{3}\right), 3.66\left(\mathrm{~d}, J_{\mathrm{H}-\mathrm{H}}=12.0 \mathrm{~Hz}, 1 \mathrm{H}\right.$, $\left.\mathrm{ArCH}_{2} \mathrm{NCH}_{3}\right), 3.27\left(\mathrm{~d}, J_{\mathrm{H}-\mathrm{H}}=12.0 \mathrm{~Hz}, 1 \mathrm{H}, \mathrm{ArCH}_{2} \mathrm{NCH}_{3}\right), 2.70\left(\mathrm{~d}, J_{\mathrm{H}-\mathrm{H}}=12.0 \mathrm{~Hz}, 1 \mathrm{H}\right.$, $\left.\mathrm{ArCH}_{2} \mathrm{NCH}_{3}\right), 2.60$ (s, 3H, $\left.\operatorname{ArCH}_{3}\right), 2.46$ (s, 3H, $\left.\mathrm{ArCH}_{3}\right), 2.36$ (s, 6H, ArCH$\left.)_{3}\right), 2.01$ (td, 1H, cyclohexane hydrogens), 1.89 (s, 3H, $\left.\mathrm{NCH}_{3}\right), 1.73$ (s, 3H, $\mathrm{NCH}$ ) 1.57 (t, 3H, $\left.\mathrm{AlCH}_{2} \mathrm{CH}_{3}\right), 1.39$ (m, 4H, cyclohexane hydrogens), 0.62 (m, 4H, cyclohexane hydrogens), 0.06 (dq, $\left.1 \mathrm{H}, \mathrm{AlCH}_{2} \mathrm{CH}_{3}\right),-0.05$ (dq, $\left.1 \mathrm{H}, \mathrm{AlCH}_{2} \mathrm{CH}_{3}\right) ; \mathbf{6 b}, \delta=7.03(\mathrm{~s}, 2 \mathrm{H}$, $\operatorname{Ar} \boldsymbol{H}), 6.64(\mathrm{~s}, 2 \mathrm{H}, \mathrm{Ar} \boldsymbol{H}), 3.46\left(\mathrm{br}, 2 \mathrm{H}, \mathrm{ArCH}_{2} \mathrm{NCH}_{3}\right), 3.32$ (d, $J_{\mathrm{H}-\mathrm{H}}=12.0 \mathrm{~Hz}, 2 \mathrm{H}$, $\left.\mathrm{ArCH}_{2} \mathrm{NCH}_{3}\right), 2.59$ (s, 6H, ArCH $\left.\boldsymbol{H}_{3}\right), 2.34$ (s, 6H, $\left.\operatorname{ArCH} \boldsymbol{H}_{3}\right), 2.09$ (m, 2H, CH), 1.79 (s, 6H, $\mathrm{NCH}_{3}$ ), 1.44 (t, 3H, $\left.\mathrm{AlCH}_{2} \mathrm{CH}_{3}\right), 1.37$ (m, 4H, cyclohexane hydrogens), 0.65 (m, 4H, cyclohexane hydrogens), 0.21 (dq, $\left.1 \mathrm{H}, \mathrm{AlCH}_{2} \mathrm{CH}_{3}\right), 0.20$ (dq, $1 \mathrm{H}, \mathrm{AlCH}_{2} \mathrm{CH}_{3}$ ); ${ }^{13} \mathrm{C}$ NMR $\left(100 \mathrm{MHz}, \mathrm{C}_{6} \mathrm{D}_{6}, 25^{\circ} \mathrm{C}\right): \delta=157.08,156.45,131.79,131.59,131.41,126.85$, $126.48,124.25,122.84,62.84,61.17,59.42,53.16,42.09,35.19,24.30,22.69,22.20$, 21.76, 16.29, 11.50, 11.12; Anal. Calcd for $\mathrm{C}_{28} \mathrm{H}_{41} \mathrm{AlN}_{2} \mathrm{O}_{2}$ : C, 72.38; H, 8.89; N, 6.03. Found: C, 72.09; H, 9.02; N, 6.26.

General procedure for lactide polymerization. In a typical polymerization experiment, rac-LA (1.00 g, $6.94 \mathrm{mmol}), 4$ (0.057 g, $0.14 \mathrm{mmol})$, 2-propanol (8.41 mg, $0.14 \mathrm{mmol}$ in toluene $(4 \mathrm{~mL}))$ and an additional part of toluene $(9 \mathrm{~mL})$ were introduced 104 
successively into a flame-dried vessel equipped with a magnetic bar. The vessel was placed in an oil bath thermostated at $70^{\circ} \mathrm{C}$. After certain time intervals, aliquots were taken out to determine the monomer conversion by ${ }^{1} \mathrm{H}$ NMR. The polymer was isolated by precipitating into cold methanol. The precipitate was collected and dried under vacuum at $40^{\circ} \mathrm{C}$ for $24 \mathrm{~h}$.

X-ray Crystallographic Studies. Suitable single crystals of 4a and 9a were grown from a saturated toluene solution at room temperature. The intensity data were collected from the $\omega$ scan mode $(187 \mathrm{~K})$ on a Bruker Smart APEX diffractometer with a CCD detector using Mo K $\alpha$ radiation $(\lambda=0.71073 \AA$ ). The crystal structures were solved using the SHELXTL program by means of direct methods; the remaining atoms were located from the difference Fourier synthesis, followed by full-matrix least-squares refinements. The position of the hydrogen atoms was calculated theoretically and included in the final cycles of refinements in a riding model along with attached carbons. The molecular structures of $4 \mathbf{a}$ and $9 \mathrm{a}$ are shown in Figures 6.3 and 6.7, respectively, and their main crystallographic data are summarized in Table 6.1. Crystallographic data for these structural analyses have been deposited with the Cambridge Crystallographic Data Center, CCDC Nos. 632143 and 628811.

\section{RESULTS AND DISSCUSSION}

Synthesis of chiral salan aluminum ethyl complexes. Enantiomeric $(R, R)$-1,2-diaminocyclohexane was obtained from trans-1,2-diaminocyclohexane following a procedure described by Larrow et al. ${ }^{14}$ The synthesis of the ligand precursors $(R, R)-\mathbf{1}$ and rac-1 (Scheme 6.1) was accomplished by a three-step procedure. First, a condensation between racemic or $(R, R)$-1,2-diaminocyclohexane 


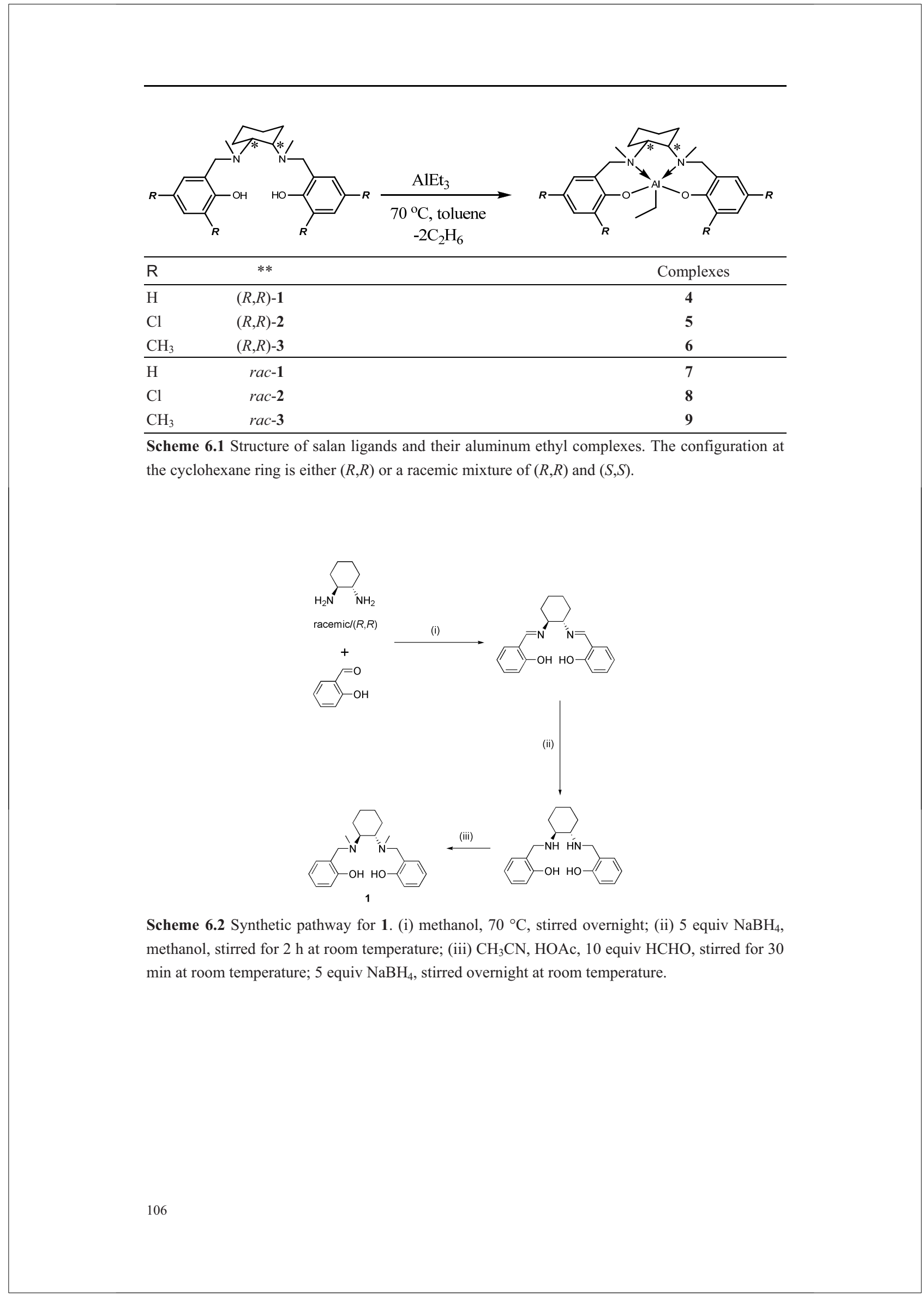




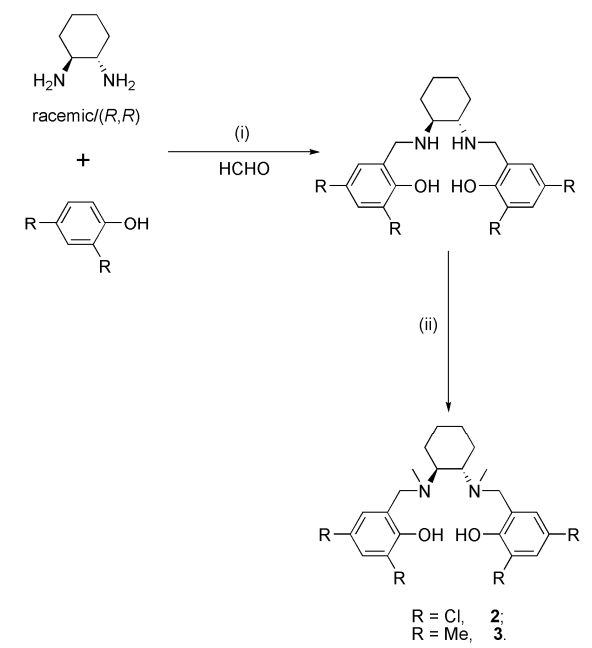

Scheme 6.3 Synthetic pathway for 2 and 3. (i) $\mathrm{CH}_{3} \mathrm{CN}$, HOAc, 10 equiv $\mathrm{HCHO}$, stirred for $30 \mathrm{~min}$ at room temperature; 5 equiv $\mathrm{NaBH}_{4}$, stirred overnight at room temperature; (ii) methanol, 10 equiv $\mathrm{HCHO}$, stirred at reflux overnight.

and 2 equivalents of salicylaldehyde yielded the salen intermediate. Subsequent reduction of the imine bonds using an excess of $\mathrm{NaBH}_{4}$ afforded the salan intermediate. The ligand precursors were obtained by condensation of the secondary amine groups with an excess formaldehyde and reduction using an excess of $\mathrm{NaBH}_{4}$ (Scheme 6.2). The synthesis of the ligand precursors rac-2, $(R, R)-\mathbf{2}, \mathrm{rac}-\mathbf{3}$ and $(R, R)-\mathbf{3}$ (Scheme 6.1) was carried out similarly, except that the salan intermediates were synthesized via a Mannich condensation of 2,4-substituted phenols, formaldehyde and racemic or $(R, R)$-1,2-diaminocyclohexane (Scheme 6.3). All ligands were isolated as white crystalline solids in high yields after recrystallization from acetone.

Treatment of the enantiomeric pure salan ligand precursors $(R, R) \mathbf{- 1},(R, R)-\mathbf{2}$, or $(R, R)$-3 with an equimolar amount of $\mathrm{AlEt}_{3}$ in toluene at $70{ }^{\circ} \mathrm{C}$ resulted in the formation of salan aluminum ethyl complexes 4, 5, and 6, respectively (Scheme 6.1). Interestingly, the ${ }^{1} \mathrm{H}$ NMR spectroscopic data of $\mathbf{4 , 5}$, and $\mathbf{6}$ in $\mathrm{C}_{6} \mathrm{D}_{5} \mathrm{CD}_{3}$ at $295 \mathrm{~K}$ clearly revealed the presence of two species. One species (a) gives a dissymmetric resonance pattern, while the other (b) gives a symmetric resonance pattern. The molar ratio of a:b in 4, 5, and $\mathbf{6}$ was 10:4, 10:2.5, and 10:3, respectively. As an example, in the ${ }^{1} \mathrm{H}$ NMR spectrum of 4 (Figure 6.1), the appearance of four doublets of the benzylic 
$\mathrm{ArCH}_{2}-\mathrm{NCH}_{3}$ protons at $3.70,3.60,3.19$, and $2.71 \mathrm{ppm}$ with a $J_{\mathrm{H}-\mathrm{H}}$ of $13.0 \mathrm{~Hz}$, as well as the two singlets at 1.84 and $1.72 \mathrm{ppm}$ of the $\mathrm{N}-\mathrm{CH}_{3}$ protons (Figure 6.1, top), both indicated dissymmetric surroundings of these groups in the salan complex and was denoted 4a. On the other hand, the symmetric resonance pattern includes two doublets of the benzylic $\mathrm{ArCH}_{2}-\mathrm{NCH}_{3}$ protons appearing at 3.44 and $3.28 \mathrm{ppm}$ with the same $J_{\mathrm{H}-\mathrm{H}}$ of $13.0 \mathrm{~Hz}$ and a singlet at $1.80 \mathrm{ppm}$ for the $\mathrm{N}-\mathrm{CH}_{3}$ protons (Figure 6.1, top) and was denoted $\mathbf{4 b}$.
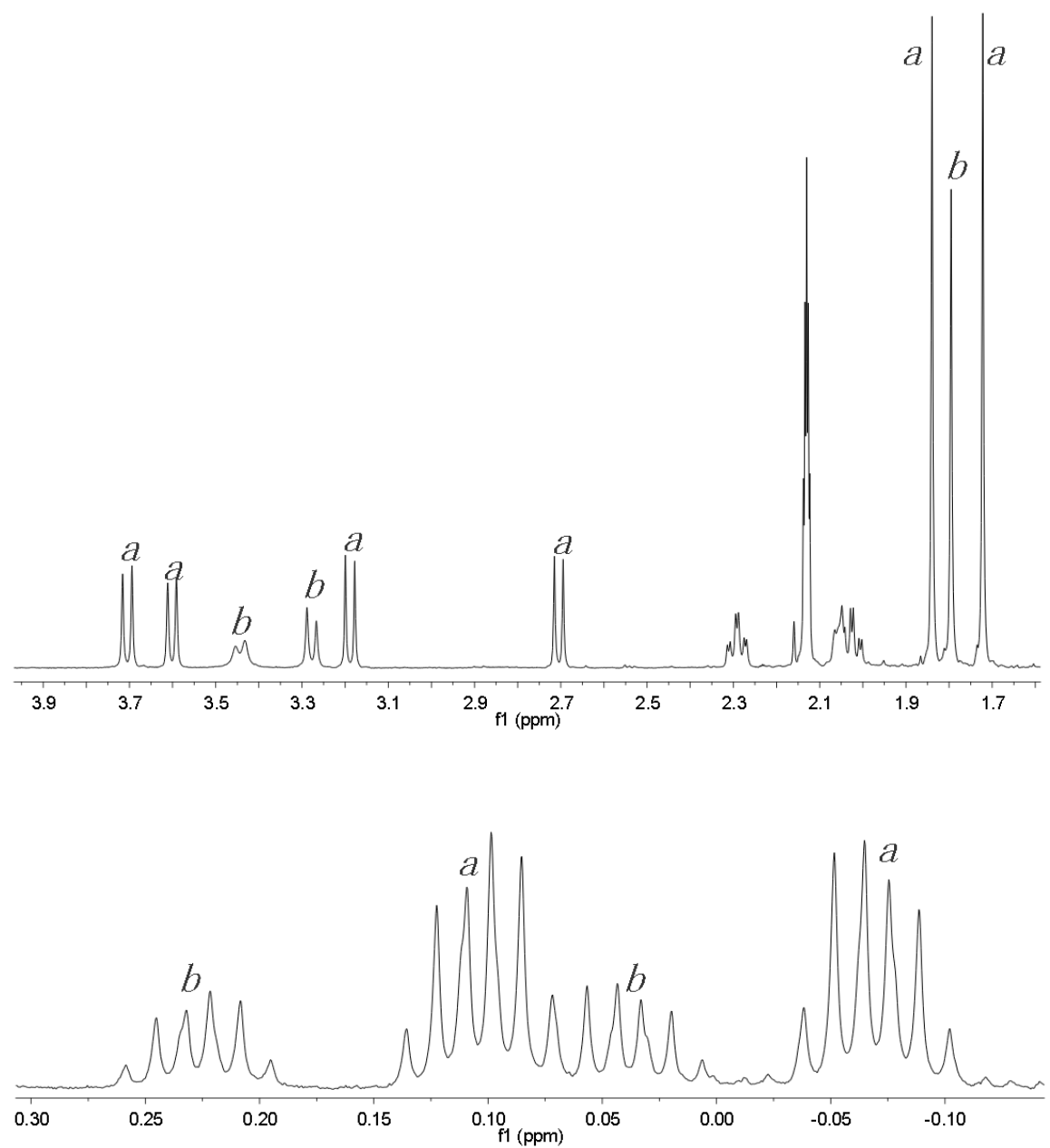

Figure 6.1 Expanded region for the ${ }^{1} \mathrm{H}$ NMR spectrum of 4, indicating the presence of two diastereoisomers a and b. (600 MHz, $\mathrm{C}_{6} \mathrm{D}_{5} \mathrm{CD}_{3}, 295 \mathrm{~K}, \mathrm{ArCH}_{2}-\mathrm{NCH}_{3}$, top; $\mathrm{AlCH}_{2} \mathrm{CH}_{3}$, bottom.) 
Moreover, the methylene protons in the aluminum ethyl groups in $\mathbf{4}$ displayed two double quartets (Figure 6.1, bottom), showing that these protons in $\mathbf{4 a}$ and $\mathbf{4 b}$ are diastereotopic. The ${ }^{1} \mathrm{H}-{ }^{1} \mathrm{H}$ NOESY spectrum of 4 in $\mathrm{C}_{6} \mathrm{D}_{5} \mathrm{CD}_{3}$ at $295 \mathrm{~K}$ revealed that there is no slow exchange between the species $\mathbf{4 a}$ and $\mathbf{4 b}$ on the NMR time scale (Figure 6.2). Single crystals of 4 a were isolated from a saturated toluene solution at room temperature and characterized by X-ray analysis (crystallographic data: Table 6.1). Despite several attempts, only single crystals of species $4 \mathbf{a}$ were obtained.

The complex 4a was monomeric with a five-coordinated central aluminum atom (Figure 6.3). The geometry around such a five-coordinated aluminum atom ideally would be square pyramidal or trigonal bipyramidal and can be expressed by a $\tau$ value which is 0 in case of an ideal square pyramidal (sqp) and 1 in case of an ideal trigonal bipyramidal (tbp) geometry. ${ }^{15}$ The $\tau$ value of $\mathbf{4 a}$ is 0.53 , revealing a geometry intermediate between $\mathbf{A}$, an ideal sqp, and $\mathbf{B}$, an ideal tbp in this complex (Scheme 6.4). The $\tau$ value of $\mathbf{4 a}$ is higher than that of the corresponding chiral salen aluminum methyl complex $(\tau=0.35),{ }^{16}$ indicating a more flexible ligand geometry, as a result of the $s p^{3}$ hybridization of the tertiary amine nitrogen atoms in the salan complex. The two phenolic oxygen atoms adopt a cis position relative to the central aluminum. The $\mathrm{Al}(1)-\mathrm{N}(1)[2.115(3) \AA]$ and $\mathrm{Al}(1)-\mathrm{N}(2)[2.222(4) \AA]$ bond lengths are both within the range of 2.01-2.26 $\AA$, values generally observed for $\mathrm{Al}-\mathrm{N}$ bond lengths in tetradentate salen aluminum ethyl complexes. ${ }^{17}$ The two methyl groups on the nitrogen atoms adopt a cis configuration relative to the five-membered ring formed by $\mathrm{Al}(1)$, $\mathrm{N}(1), \mathrm{N}(2), \mathrm{C}(1)$, and $\mathrm{C}(6)$. The nitrogen atoms become chiral due to the coordination with Al. The configurations of the two nitrogen atoms are $R$ for $\mathrm{N}(2)$ and $S$ for $\mathrm{N}(1)$, respectively. 


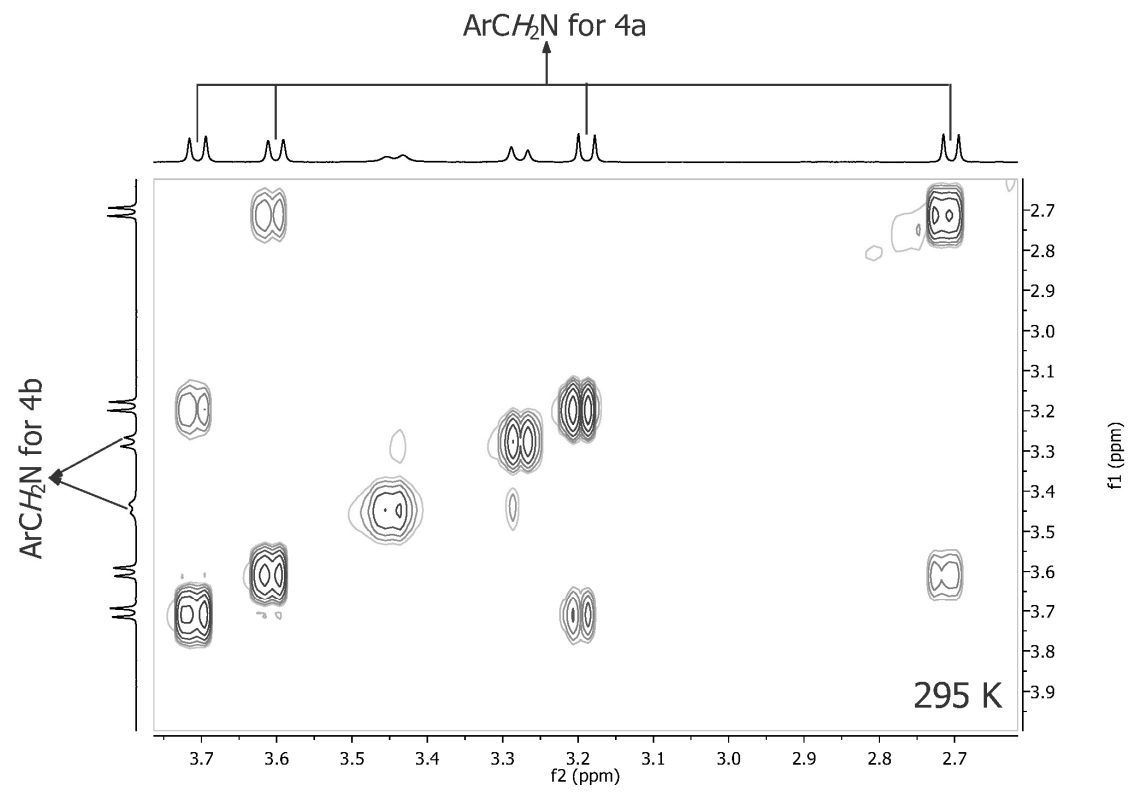

Figure 6.2 ${ }^{1} \mathrm{H}-{ }^{1} \mathrm{H}$ NOESY NMR spectrum of 4 at $295 \mathrm{~K}$ in $\mathrm{C}_{6} \mathrm{D}_{5} \mathrm{CD}_{3}\left(\mathrm{ArCH}_{2} \mathrm{NCH}_{3}\right.$ region).

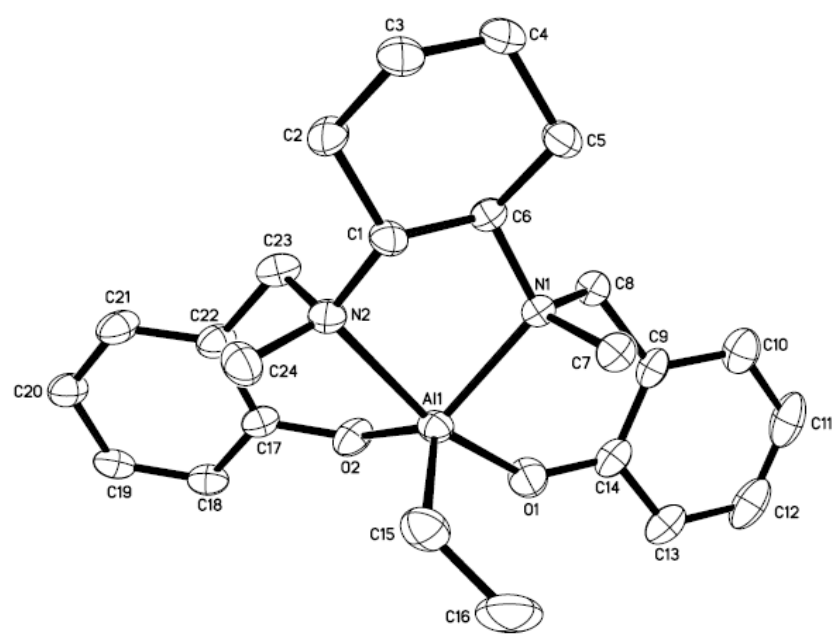

Figure 6.3 Molecular structure of $4 \mathrm{a}$; all hydrogen atoms are omitted for clarity. 
Table 6.1 Crystallographic data for $\mathbf{4 a}$ and $9 \mathbf{a}$.

\begin{tabular}{|c|c|c|}
\hline & $4 \mathrm{a}$ & $9 \mathrm{a}$ \\
\hline formula & $\mathrm{C}_{24} \mathrm{H}_{33} \mathrm{AlN}_{2} \mathrm{O}_{2}$ & $\mathrm{C}_{28} \mathrm{H}_{41} \mathrm{AlN}_{2} \mathrm{O}_{2}$ \\
\hline crystal size, $[\mathrm{mm}]$ & $0.20 \times 0.19 \times 0.09$ & $0.27 \times 0.13 \times 0.08$ \\
\hline formula weight & 408.50 & 464.61 \\
\hline cryst syst & Monoclinic & Monoclinic \\
\hline space group & $P 2_{1}$ & $P 2_{1} / \mathrm{c}$ \\
\hline$a[\AA]$ & $7.7422(10)$ & $14.5190(12)$ \\
\hline$b[\AA]$ & $17.058(2)$ & $14.5891(11)$ \\
\hline$c[\AA]$ & $8.7022(10)$ & $12.3277(10)$ \\
\hline$\alpha\left[^{0}\right]$ & 90 & 90 \\
\hline$\beta\left[^{\circ}\right]$ & $100.678(2)$ & $100.100(2)$ \\
\hline$\gamma\left[^{0}\right]$ & 90 & 90 \\
\hline$V\left[\AA^{3}\right]$ & $1129.4(2)$ & $2570.8(4)$ \\
\hline$Z$ & 2 & 4 \\
\hline$D_{\text {calcd }}\left[\mathrm{g} / \mathrm{cm}^{3}\right]$ & 1.201 & 1.200 \\
\hline radiation $(\lambda),[\AA]$ & $\mathrm{MoK} \quad(0.71073)$ & MoK (0.71073) \\
\hline $2 \theta_{\max },\left[{ }^{\circ}\right]$ & 26.05 & 26.08 \\
\hline$\mu\left[\mathrm{mm}^{-1}\right]$ & 0.112 & 0.106 \\
\hline $\mathrm{F}(000)$ & 440 & 1008 \\
\hline no. of obsd reflns & 6374 & 14235 \\
\hline no. of params refnd & 265 & 305 \\
\hline GOF & 1.050 & 1.017 \\
\hline$R_{1}$ & 0.0625 & 0.0583 \\
\hline $\mathrm{w} R_{2}$ & 0.0731 & 0.1269 \\
\hline
\end{tabular}

To further clarify the structure of $\mathbf{4 b}$, additional NMR characterizations were performed. In ${ }^{27} \mathrm{Al}$ NMR four-coordinated aluminum complexes give a resonance signal at $\sim 70 \mathrm{ppm}$, while five- or six-coordinated aluminum complexes give resonance signals at $\sim 40$ and $\sim 0 \mathrm{ppm}$, respectively. ${ }^{18}$ The ${ }^{27} \mathrm{Al}$ NMR spectrum of 4 did not exhibit any peaks in the -70 to $280 \mathrm{ppm}$ range, maybe due to the asymmetric coordination of the salan ligand around the aluminum center. ${ }^{19}$ However, DOSY NMR measurements revealed that $\mathbf{4 a}$ and $\mathbf{4 b}$ have comparable diffusion coefficients, indicating similar effective molecular radii, and further demonstrating that $\mathbf{4 b}$ is also monomeric. This also indicates that $\mathbf{4 b}$ may be a diastereoisomer of $\mathbf{4 a}$. The VT ${ }^{1} \mathrm{H}$ NMR spectra of $\mathbf{4}$ $\left(\mathrm{C}_{6} \mathrm{D}_{5} \mathrm{CD}_{3}\right)$ in the temperature range $295-335 \mathrm{~K}$ did not reveal a tendency for the resonances of the benzylic $\mathrm{ArCH}_{2}-\mathrm{NCH}_{3}$ protons of $\mathbf{4 b}$ to coalesce (Figure 6.4). This 
indicates that the two Al-N bonds in $\mathbf{4 b}$ are stable at room temperature or even higher temperatures.

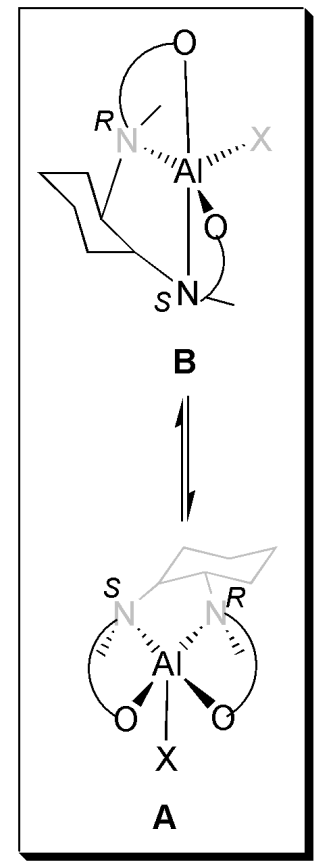

diastereoisomer a $\mathrm{N}$-methyls cis position

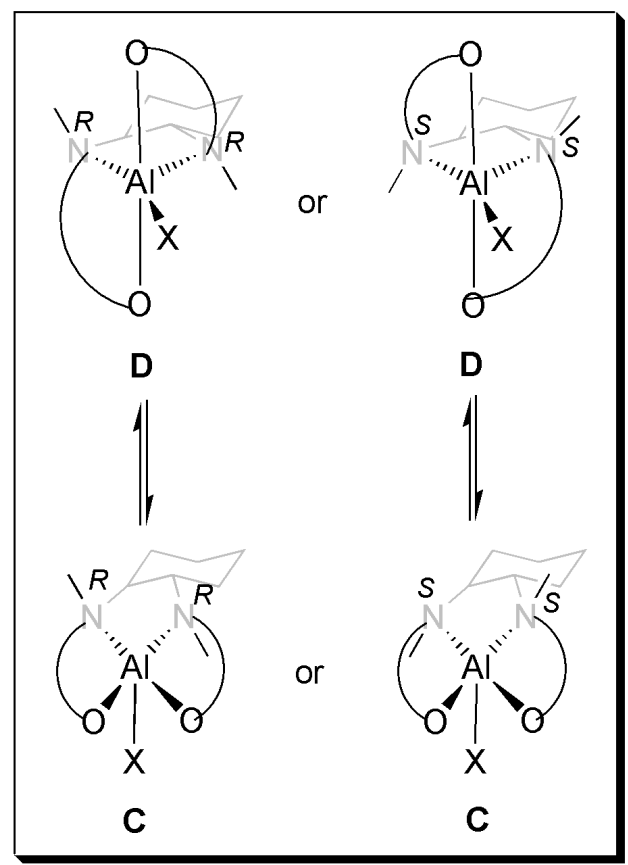

diastereoisomer $\mathbf{b}$ $\mathrm{N}$-methyls trans position

Scheme 6.4 Schematic representation of geometries adopted by diastereoisomers $\mathbf{a}$ and $\mathbf{b}$. Diastereoisomer a adopts a geometry intermediate between $\mathbf{A}$ and $\mathbf{B}$ with the $N$-methyl groups in a cis position, while diastereoisomer $\mathbf{b}$ adopts a geometry intermediate between $\mathbf{C}$ and $\mathbf{D}$ with the $N$-methyl groups in a trans position).

The symmetric resonance pattern for the four benzylic $\mathrm{ArCH}_{2}-\mathrm{NCH}_{3}$ protons of $\mathbf{4} \mathbf{b}$ at $295 \mathrm{~K}$ indicates that these protons are symmetrically arranged in the complex. Based on this information, either the highly symmetric sqp geometry $\mathbf{C}$ or tbp geometry $\mathbf{D}$, or even a geometry intermediate between $\mathbf{C}$ and $\mathbf{D}$ was considered the most probable for 4b (Scheme 6.4). Due to the presence of only one singlet for the $N$-methyls of $\mathbf{4 b}$ at 295 $\mathrm{K}$, it is assumed that the two $N$-methyls locate in a trans position. To fully reveal the structure of 4b, 1D and 2D NMR experiments were carried out. 
$335 \mathrm{~K}$

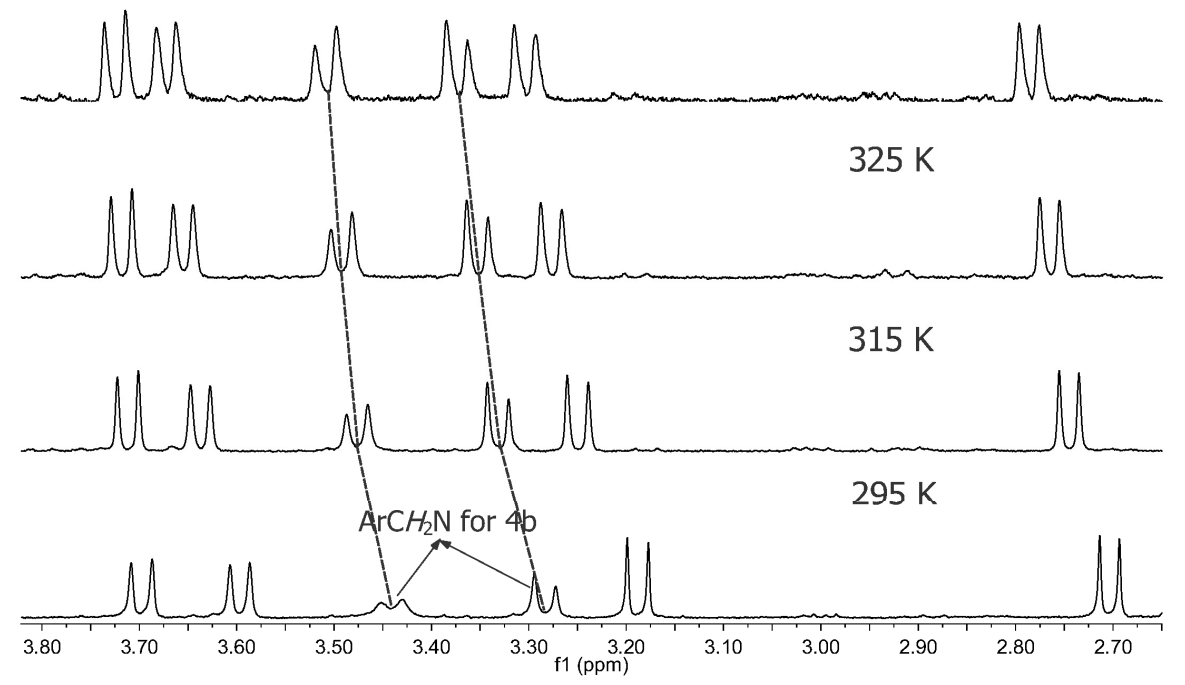

Figure 6.4 VT ${ }^{1} \mathrm{H}$ NMR spectra of 4 in the temperature range $295-335 \mathrm{~K}$ in $\mathrm{C}_{6} \mathrm{D}_{5} \mathrm{CD}_{3}$ ( $\mathrm{ArCH} \mathrm{NCH}_{3}$ region).

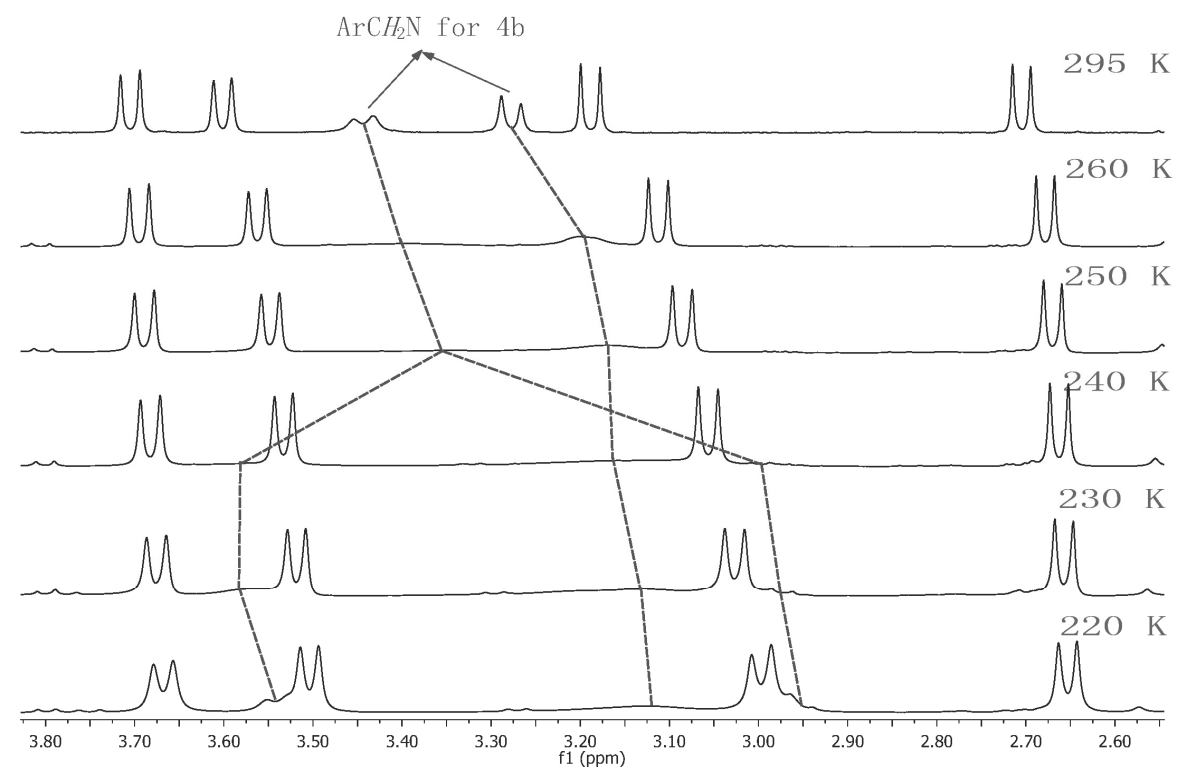




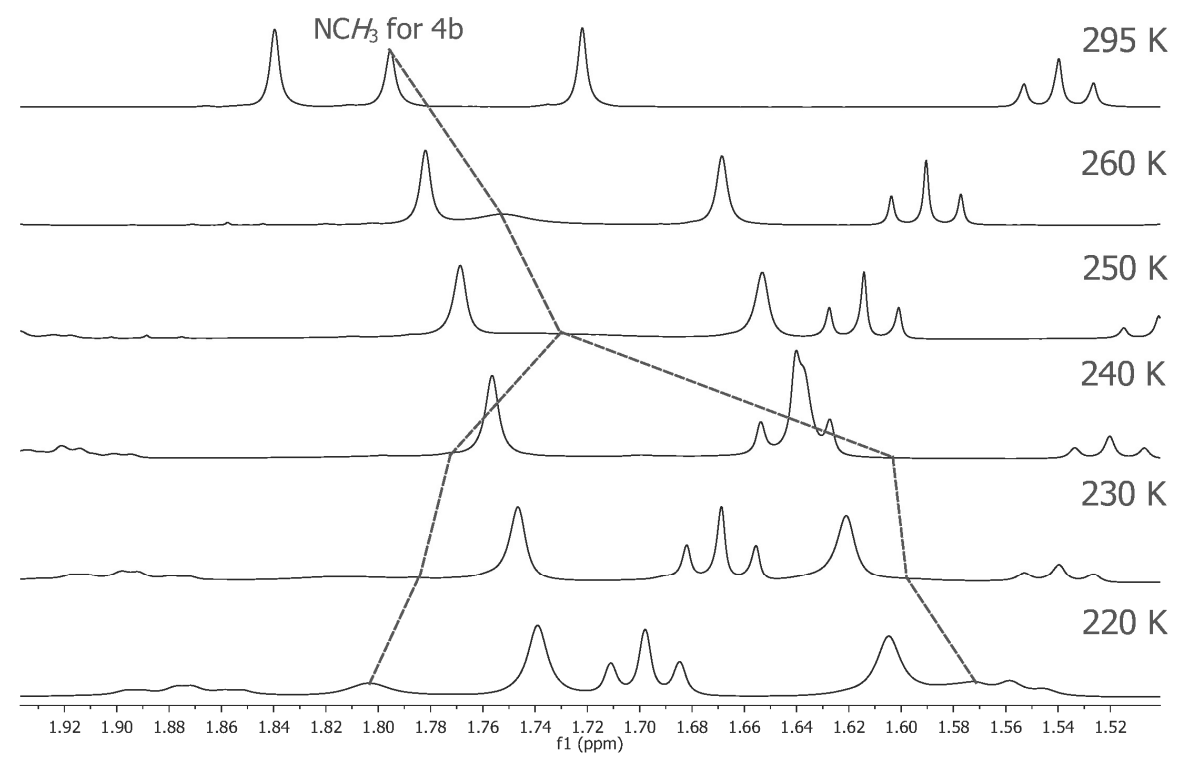

Figure 6.5 VT ${ }^{1} \mathrm{H}$ NMR spectra of 4 between $220-295 \mathrm{~K}_{\text {in }} \mathrm{C}_{6} \mathrm{D}_{5} \mathrm{CD}_{3}\left(\mathrm{ArCH}_{2}-\mathrm{NCH}_{3}\right.$ region, top; $\mathrm{ArCH}_{2} \mathrm{NCH}_{3}$ region, bottom).

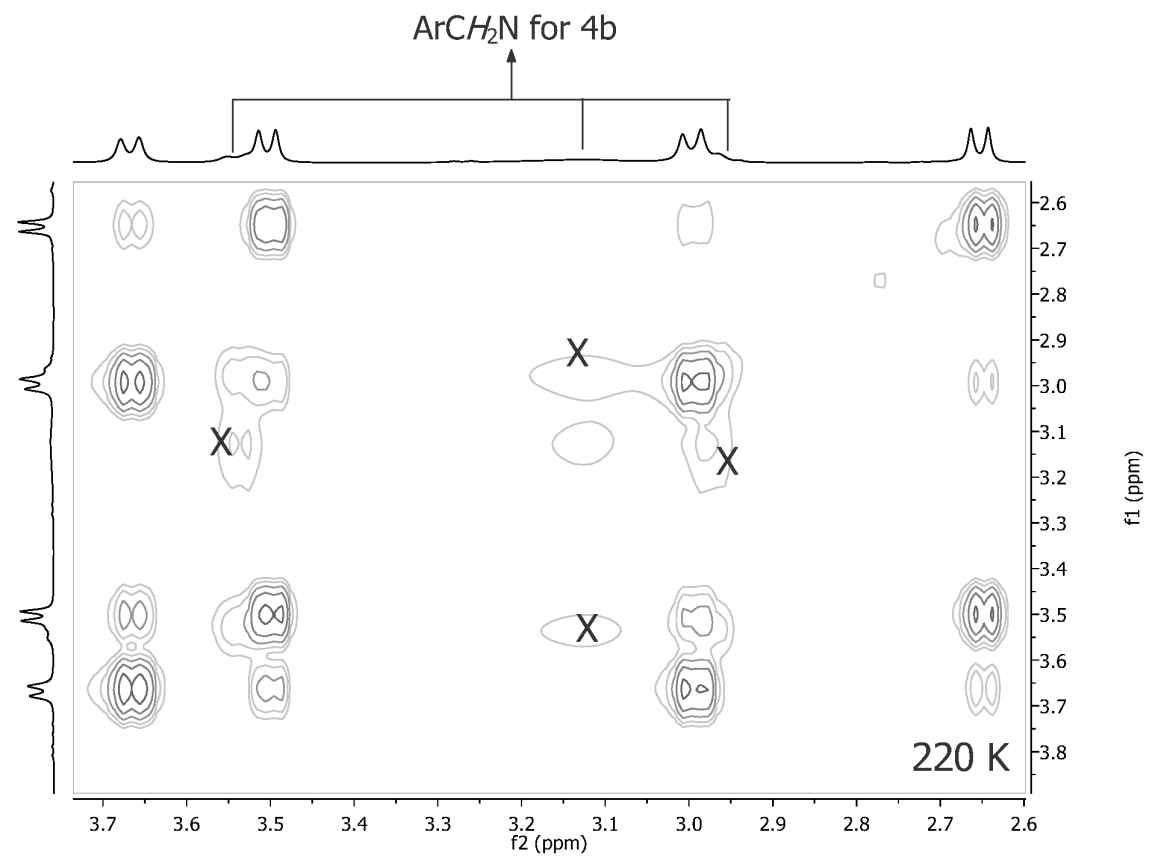




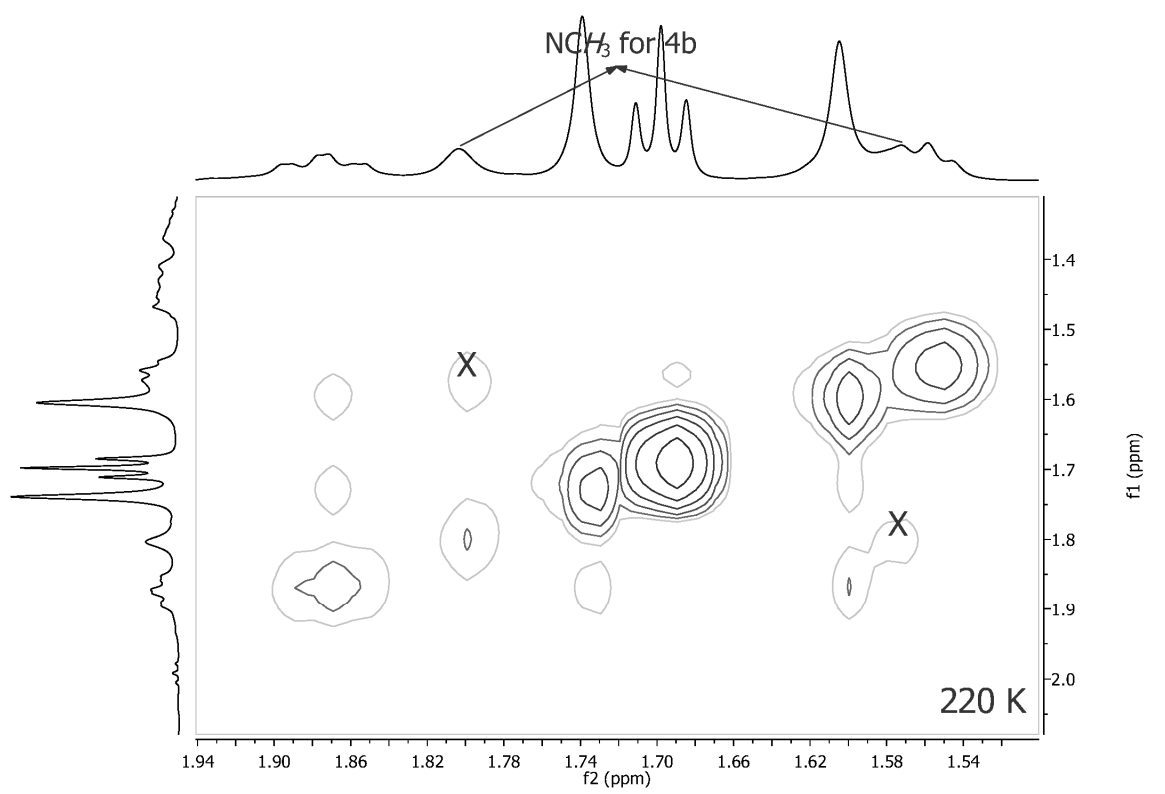

Figure 6.6 ${ }^{1} \mathrm{H}-{ }^{1} \mathrm{H}$ NOESY NMR spectrum of 4 at $220 \mathrm{~K}$ in $\mathrm{C}_{6} \mathrm{D}_{5} \mathrm{CD}_{3}\left(\mathrm{ArCH}_{2}-\mathrm{NCH}_{3}\right.$ region, top; $\mathrm{ArCH}_{2} \mathrm{NCH}_{3}$ region, bottom). Evidence for the exchange between the two geometries of $\mathbf{4} \mathbf{b}$ is provided by the presence of additional exchange-NOE cross-peaks labeled X.

First, VT ${ }^{1} \mathrm{H}$ NMR analysis of 4 in $\mathrm{C}_{6} \mathrm{D}_{5} \mathrm{CD}_{3}$ was performed. Upon decreasing the temperature the two doublets of the four benzylic $\mathrm{ArCH}_{2}-\mathrm{NCH}_{3}$ protons of $\mathbf{4 b}$ at $295 \mathrm{~K}$ split into two doublets (partly overlapping) and a broad peak at $220 \mathrm{~K}$ (Figure 6.5). It is speculated that by further decreasing the temperature this broad peak will also split into two doublets. Moreover, the singlet of the $\mathrm{N}-\mathrm{CH}_{3}$ protons at $295 \mathrm{~K}$ split into two broad peaks at $220 \mathrm{~K}$ (Figure 6.5). The ${ }^{1} \mathrm{H}-{ }^{1} \mathrm{H}$ NOESY NMR spectrum of 4 at $220 \mathrm{~K}$ displayed positive off-diagonal cross-peaks (having phased the diagonal cross-peaks in positive sign, and the NOE cross-peaks observed at opposite sign) between the $\mathrm{ArCH}_{2}-\mathrm{NCH}_{3}$ protons (Figure 6.6) as well as the $\mathrm{N}-\mathrm{CH}_{3}$ protons of $4 \mathbf{b}$ (Figure 6.6). All these observations indicate that at $220 \mathrm{~K}$ a slow exchange takes place between the two species of $\mathbf{4 b}$. Based on these data, it is assumed that diastereoisomer $\mathbf{4 b}$ adopts a geometry intermediate between $\mathbf{C}$ and $\mathbf{D}$ with the $N$-methyls located in a trans position (Scheme 6.4). At $295 \mathrm{~K}$, diastereoisomer 4b shows a fast exchange between the sqp geometry $\mathbf{C}$ and the tbp geometry $\mathbf{D}$ on the NMR time scale. At low temperatures, the 
exchange between these two geometries was slow enough to be observed by NMR. However, so far, we are not able to conclude whether either the $(R, R)$ or $(S, S)$ with respect to the nitrogen centers or even mixtures of these compounds are present in 4b (Scheme 6.4).

On the basis of the NMR and X-ray analysis, it is reasonable to assume two different pathways via which these chiral salan aluminum ethyls were formed. Because the conformation of the cyclohexane ring upon formation of the five-coordinated aluminum complex is fixed, the position of the methyl groups on the nitrogen atoms will also be fixed. Once the free ligand in the solution coordinates the aluminum atom with the $N$-methyl groups in a cis position, a wrapping mode with a cis- $(\mathrm{O}, \mathrm{O})$ geometry in between A (sqp) and B (tbp) will be favoured. The chiral salan ligand generates diastereoisomer $4 \mathbf{a}$ with $(R, S)$ chiral nitrogen centers. On the other hand, if the free ligand in the solution adopts a conformation with the $N$-methyl groups in a trans position, a geometry intermediate between $\mathbf{C}$ (sqp) and D (tbp) will be favoured as for diastereoisomer $\mathbf{4 b}$ with either $(R, R)$ or $(S, S)$, or even both configurations for the chiral nitrogen centers.

Starting from the racemic mixtures of the ligands 1-3 the salan aluminium complexes 7-9 were obtained (Scheme 6.1). Only single crystals of 9a could be isolated from a saturated toluene solution at room temperature. X-ray analysis (crystallographic data: Table 6.1) of 9a revealed the complex was also dissymmetric with a five-coordinated central aluminum atom like 4a (Figure 6.7). The packing modes in the unit cell of 9a shows that a racemate crystallization had occurred. A $\tau$ value of 0.90 is calculated, showing a trigonal bipyramidal geometry with $\mathrm{N}(1)$ and $\mathrm{O}(2)$ occupying the axial positions, and $\mathrm{N}(2), \mathrm{C}(17)$, and $\mathrm{O}(1)$ located in the equatorial plane. The central aluminum atom deviates ca. $0.201 \AA$ from the equatorial plane in the direction of $\mathrm{O}(2)$. The axial bond length of $\mathrm{Al}(1)-\mathrm{O}(2)$ [1.7931(18) $\AA$ ] is slightly longer than that of its equatorial counterpart $\mathrm{Al}(1)-\mathrm{O}(1)$ [1.7631(17) $\AA]$ (table S2). Moreover, compared to $\mathrm{N}(2)$ placed in the equatorial plane with a bond length of 2.039(2) $\AA$ from $\mathrm{Al}(1)$, the $\mathrm{N}(1)$ atom located on the axial site is weakly coordinated to $\mathrm{Al}(1)$ with a longer distance of $\mathrm{Al}(1)-\mathrm{N}(1)$ [2.448(2) $\AA$ ]. This weak interaction was also observed in an 116 
aluminum complex ligated by an achiral salan ligand reported by Gibson and co-workers $^{12}$ and an aluminum complex stabilized by a 1, $\omega$-dithiaalkanediyl-bridged bisphenol ligand reported by Okuda et al. ${ }^{20}$ Similar as for $\mathbf{4 a}$, the methyl groups on the nitrogen atoms are situated in a cis position relative to the five-membered ring formed by $\mathrm{C}(6), \mathrm{C}(1), \mathrm{N}(2), \mathrm{N}(1)$, and $\mathrm{Al}(1)$. The configurations of the two nitrogen atoms are $R$ for $\mathrm{N}(2)$ and $S$ for $\mathrm{N}(1)$, respectively.

Ring-opening polymerization of rac-and meso-LA in solution: Since so far it was not possible to separate diastereoisomers a and $\mathbf{b}$, complexes 4-6, and 7-9 were reacted with one equivalent of 2-propanol to generate in-situ the active isopropoxide initiators for the ROP of rac- or meso-LA. All polymerizations were carried out in toluene at 70 ${ }^{\circ} \mathrm{C}$, and the conversion was monitored by ${ }^{1} \mathrm{H}$ NMR determination of samples withdrawn from the reaction mixture. In the presence of 2-propanol as an initiator, 4-6, and 7-9 furnished PLAs with number average molecular weights similar as calculated, as well as narrow molecular weight distributions, indicating a well-controlled polymerization. Representative polymerization results are summarized in Table 6.2.

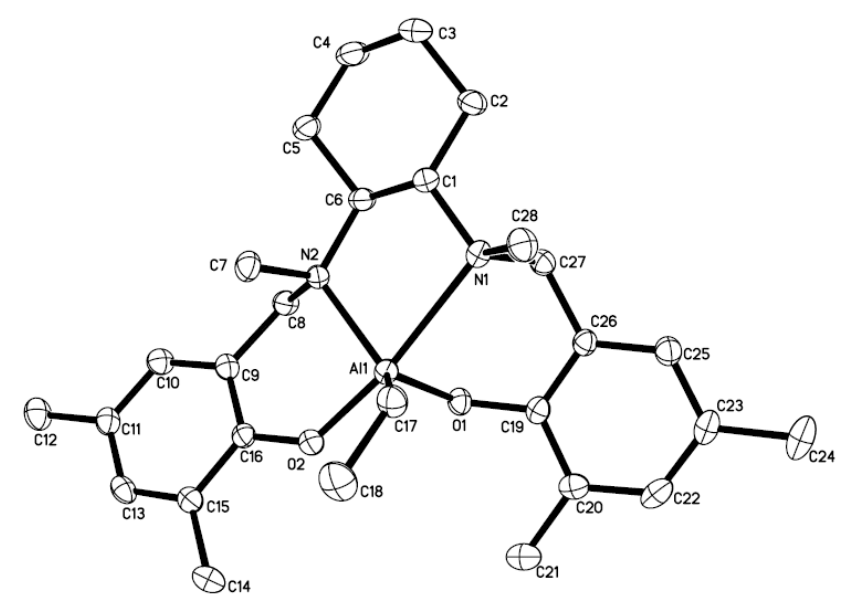

Figure 6.7 Molecular structure of $9 \mathrm{a}$; all hydrogen atoms are omitted for clarity. 
Table 6.2 Polymerization of $r a c$ - and meso-LA using salan aluminum ethyls 4-9 in the presence of 2-propanol ${ }^{a}$

\begin{tabular}{lccccccc}
\hline Cat & $\begin{array}{c}\text { time } \\
(\mathrm{h})\end{array}$ & $\begin{array}{c}\text { conv, } \\
(\%)\end{array}$ & $\begin{array}{c}M_{\mathrm{n}, \mathrm{Cal}}{ }^{c} \\
\times 10^{3}\end{array}$ & $\begin{array}{c}M_{\mathrm{n}, \mathrm{GPC}}{ }^{d} \\
\times 10^{3}\end{array}$ & PDI & $P_{\mathrm{m},} P_{\mathrm{r}}{ }^{e}$ \\
\hline rac-LA & $\mathbf{4}$ & 10 & 70.7 & 5.09 & 5.45 & 1.09 & $P_{\mathrm{m}}(0.66)$ \\
rac-LA & $\mathbf{5}$ & 57 & 87.6 & 6.31 & 5.59 & 1.10 & $P_{\mathrm{r}}(0.64)$ \\
rac-LA & $\mathbf{6}$ & 69 & 87.0 & 6.27 & 6.26 & 1.10 & $P_{\mathrm{r}}(0.55)$ \\
meso-LA & $\mathbf{4}$ & 23 & 97.3 & 7.01 & 5.79 & 1.12 & $P_{\mathrm{r}}(0.64)$ \\
meso-LA & $\mathbf{5}$ & 27 & 83.1 & 5.99 & 4.38 & 1.09 & $P_{\mathrm{r}}(0.70)$ \\
meso-LA & $\mathbf{6}$ & 69 & 87.0 & 6.27 & 6.26 & 1.10 & $P_{\mathrm{r}}(0.69)$ \\
rac-LA & $\mathbf{7}$ & 9 & 89.0 & 6.41 & 8.00 & 1.12 & $P_{\mathrm{m}}(0.62)$ \\
rac-LA & $\mathbf{8}$ & 34 & 84.8 & 6.11 & 5.59 & 1.10 & $P_{\mathrm{r}}(0.73)$ \\
rac-LA & $\mathbf{9}$ & 53 & 85.5 & 6.16 & 5.71 & 1.09 & $P_{\mathrm{r}}(0.57)$ \\
\hline All poly & 53 & & & & & &
\end{tabular}

a $\frac{\text { All polymerizations were carried out in toluene at } 70{ }^{\circ} \mathrm{C},[\mathrm{LA}]_{0}=0.534 \mathrm{~mol} \cdot \mathrm{L}^{-1},[\mathrm{Al}]_{0}}{}=$ $10.7 \times 10^{-3} \mathrm{~mol} \cdot \mathrm{L}^{-1} .{ }^{b}$ Determined from ${ }^{1} \mathrm{H}$ NMR. ${ }^{c}$ Determined by GPC (THF), relative to PS standards. The value of $M_{\mathrm{n}}$ was calculated according to $M_{\mathrm{n}}=0.58 M_{\mathrm{n}, \mathrm{GPC} .}{ }^{24 d} M_{\mathrm{n}}$ of PLA calculated from $M_{\mathrm{n}}=144.13 \times 50 \times$ conv $\%{ }^{e}{ }^{e}$ The parameters $P_{\mathrm{m}}$ and $P_{\mathrm{r}}$ are the probabilities to give meso and racemic enchainments of monomer units, respectively. $P_{\mathrm{m}}$ was calculated from: $[\mathrm{mmm}]=P_{\mathrm{m}}{ }^{2}+$ $\left(1-P_{\mathrm{m}}\right) P_{\mathrm{m}} / 2,[\mathrm{mmr}]=[\mathrm{rmm}]=\left(1-P_{\mathrm{m}}\right) P_{\mathrm{m}},[r m r]=\left(1-P_{\mathrm{m}}\right)^{2}$, and $[\mathrm{mrm}]=\left[\left(1-P_{\mathrm{m}}\right)^{2}+P_{\mathrm{m}}\left(1-P_{\mathrm{m}}\right)\right] / 2$, and $P_{\mathrm{r}}=1-P_{\mathrm{m}}$.

The tacticity of the resulting polymers was determined by inspection of the methine region in their homonuclear decoupled ${ }^{1} \mathrm{H}$ NMR spectra. 4/2-propanol and 7/2-propanol polymerized $r a c$-LA to form isotactic-biased polymers with $P_{\mathrm{m}}$ values of 0.66 (Figure 6.8a) and 0.62, respectively. In contrast, 6/2-propanol and 9/2-propanol with methyl substituents at the ortho and para positions of the phenolic group furnished atactic materials from rac-LA with $P_{\mathrm{r}}$ values of 0.55 and 0.57 , respectively. Interestingly, 5/2-propanol afforded heterotactic-biased PLAs with a $P_{\mathrm{r}}$ value of 0.64. Heterotactic PLAs can not be obtained from rac-LA via a site control mechanism (SCM) by using an enantiomeric pure complex. Thus, this fact reveals the presence of a chain-end control mechanism $(\mathrm{CEM})$ by using 5/2-propanol in the rac-LA polymerization. The heterotacticity of the resulting PLA from rac-LA increased to 0.73 when using 8/2-propanol (Figure 6.8b), which probably reveals the presence of a propagating chain exchange mechanism as proposed by Coates and co-workers. ${ }^{21}$ In this case, the heteroselectivity of 8 /2-propanol will be enhanced compared to 
5/2-propanol due to a more frequent positive-cooperation effect between a CEM and a SCM, resulting from the occurrence of rapid exchange between propagating chains
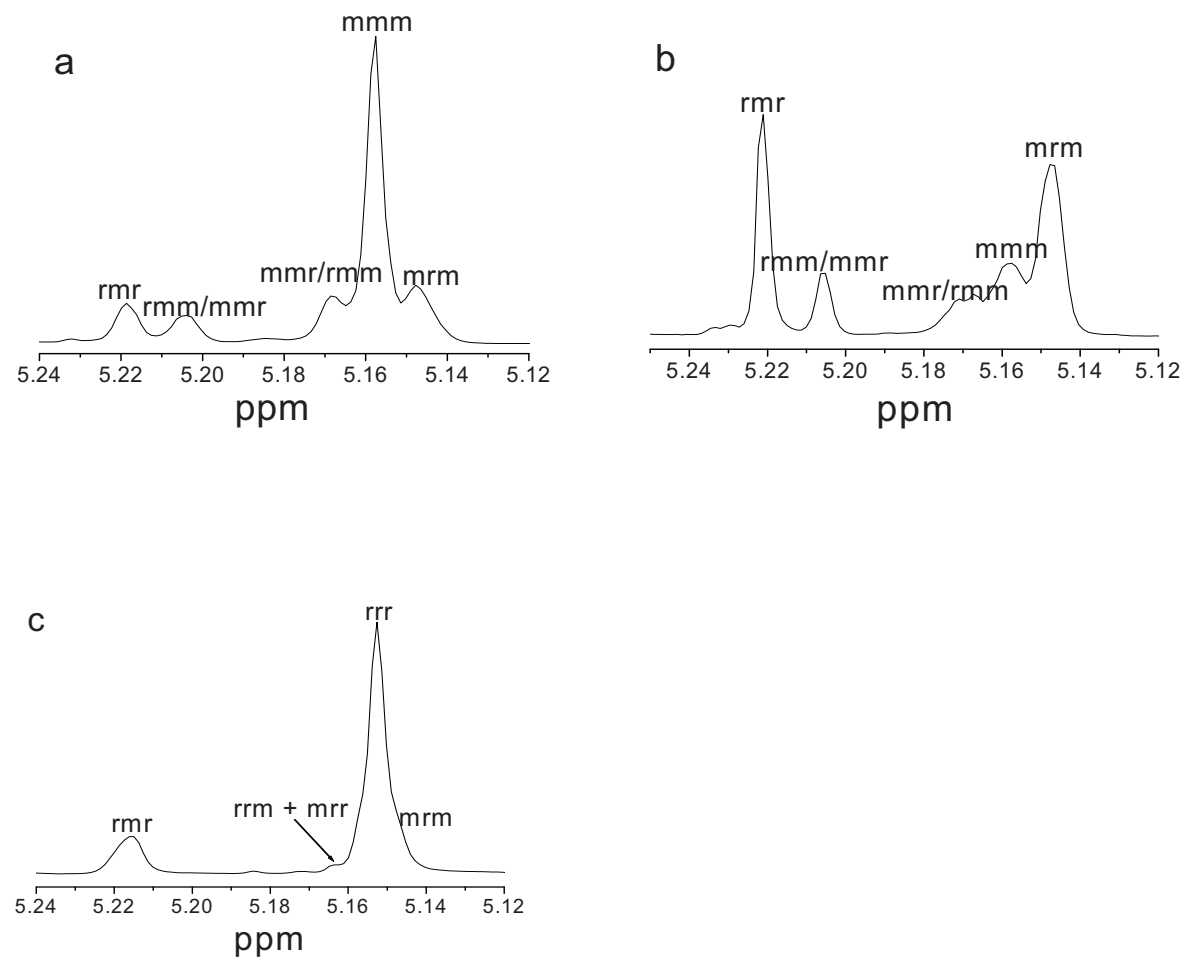

Figure 6.8 Methine region of homonuclear decoupled ${ }^{1} \mathrm{H}$ NMR spectra of resultant PLAs from rac-LA using (a) 4/2-propanol; (b) 8/2-propanol; and meso-LA using (c) 5/2-propanol as catalyst/initiator system.

bound to each different enantiomeric ligand before insertion of a subsequent monomer unit (Figure 6.9). ${ }^{21}$ 4/2-propanol, 5/2-propanol, and 6/2-propanol afforded syndiotactic-biased PLAs from meso-LA with $P_{\mathrm{r}}$ values of $0.64,0.70$ (Figure 6.8c), and 0.69 , respectively. This clearly confirms the presence of a SCM in meso-LA polymerization by using these chiral complexes. 

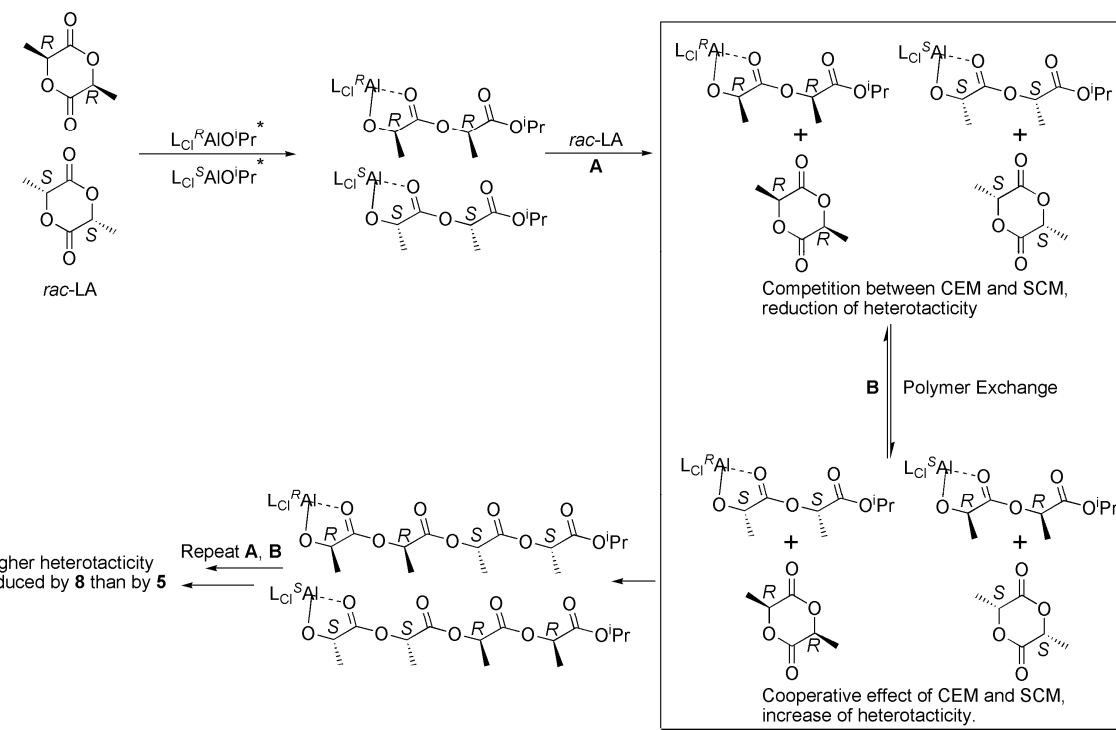

increase of heterotacticity.

Figure 6.9 Proposed polymer exchange mechanism for the explanation of the enhancement of heteroselectivity and activity of $\mathbf{8}$ compared to $\mathbf{5}$ (* indicate the aluminum isopropoxides formed by 8 upon adding 2-propanol).

To gain a better insight into the polymerization mechanism, detailed kinetic studies toward rac-LA by using 4-6 and 7-9 in the presence of 2-propanol as initiator were performed. Conversion of rac-LA in time at various concentrations of 7/2-propanol in toluene at $70{ }^{\circ} \mathrm{C}$ were monitored by ${ }^{1} \mathrm{H}$ NMR spectroscopy $\left([\mathrm{LA}]_{0}=0.534 \mathrm{~mol} \cdot \mathrm{L}^{-1}\right.$, $[\mathrm{Al}]_{0}=10.7$ to $21.4 \times 10^{-3} \mathrm{~mol} \cdot \mathrm{L}^{-1}$, and $[\mathrm{LA}]_{0}=0.267 \mathrm{~mol} \cdot \mathrm{L}^{-1},[\mathrm{Al}]_{0}=8.9 \times 10^{-3} \mathrm{~mol} \cdot \mathrm{L}^{-1}$ ). In each case, first-order kinetics in monomer was observed and the appropriate semilogarithmic plots are shown in Figure 6.10a. Thus, the polymerization of rac-LA by using 7/2-propanol as catalyst/initiator proceeds according to:

$$
-\mathrm{d}[\mathrm{LA}] / \mathrm{d} t=k_{\text {app }}[\mathrm{LA}]
$$

where $k_{\mathrm{app}}=k_{\mathrm{p}}[\mathrm{Al}]^{\mathrm{x}}$, and $k_{\mathrm{p}}$ is the propagation rate constant. To determine the order in aluminium (x), $k_{\text {app }}$ was plotted against $[\mathrm{Al}]_{0}$ (Figure 6.10b). In this plot, $k_{\text {app }}$ increased linearly with the aluminium concentration, indicating a first order in aluminium (x). Therefore, the polymerization of rac-LA using 7/2-propanol followed the overall kinetic equation:

$$
-\mathrm{d}[\mathrm{LA}] / \mathrm{d} t=k_{\mathrm{p}}[\mathrm{Al}][\mathrm{LA}]
$$


A $k_{\mathrm{p}}$ value of $23.8 \mathrm{~L} \cdot \mathrm{mol}^{-1} \cdot \mathrm{h}^{-1}$ was calculated (Table $\mathbf{6 . 3}$, entry 3) for rac-LA polymerization using $7 / 2$-propanol in toluene at $70{ }^{\circ} \mathrm{C}$.

a

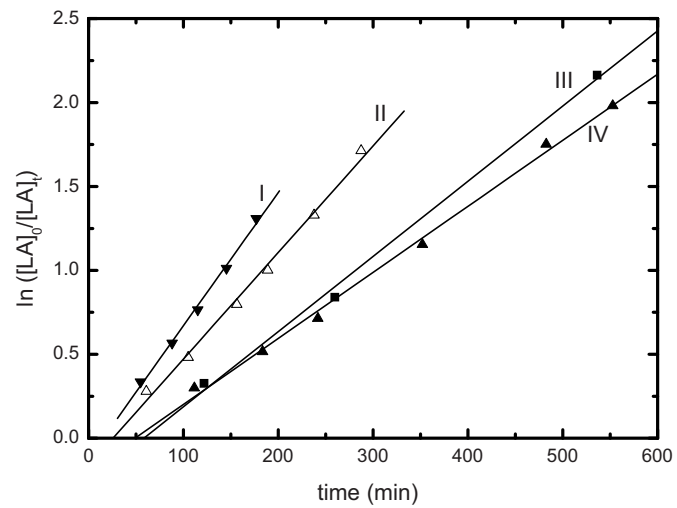

b

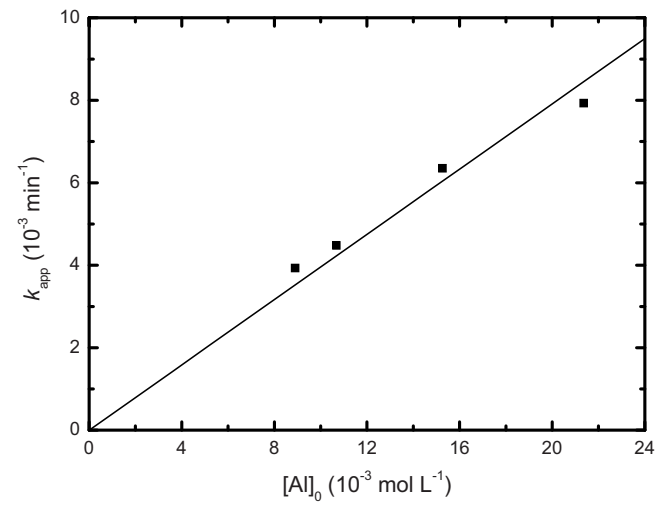

Figure 6.10 (a) First-order kinetic plots for the ROP of rac-LA by 7/2-propanol as catalyst/initiator system in toluene at $70{ }^{\circ} \mathrm{C}$ with $[\mathrm{LA}]_{0}=0.534 \mathrm{~mol} \cdot \mathrm{L}^{-1}$ : (I) $[\mathrm{LA}]_{0} /[\mathrm{Al}]_{0}=25 ;$ (II) $[\mathrm{LA}]_{0} /[\mathrm{Al}]_{0}=35$; (III) $[\mathrm{LA}]_{0} /[\mathrm{Al}]_{0}=50 ;[\mathrm{LA}]_{0}=0.267 \mathrm{~mol} \cdot \mathrm{L}^{-1}:\left(\right.$ IV) $[\mathrm{LA}]_{0} /[\mathrm{Al}]_{0}=30 ;(\mathrm{b})$ Linear plot of $k_{\text {app }} \mathrm{Vs}[\mathrm{Al}]_{0}$ for the polymerization of $r a c$-LA using 7/2-propanol as catalyst/initiator system. 


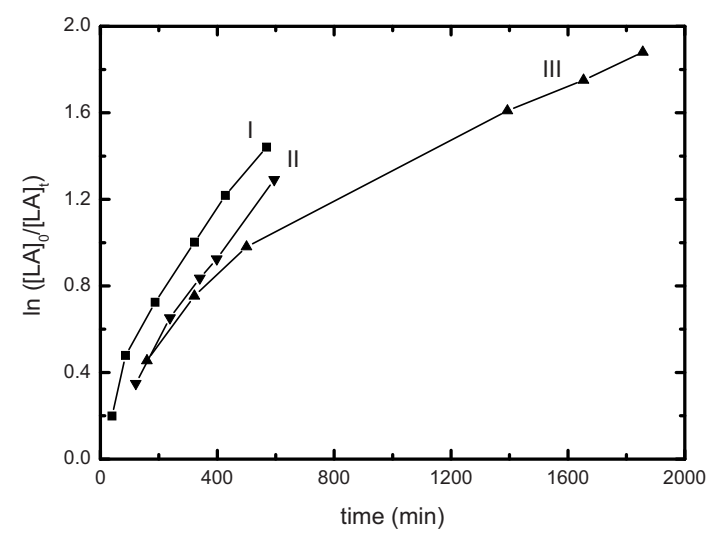

Figure 6.11 Kinetic plots for the ROP of rac-LA by applying 4/2-propanol as catalyst/initiator system in toluene at $70{ }^{\circ} \mathrm{C}$ with $[\mathrm{LA}]_{0}=0.534 \mathrm{~mol} \cdot \mathrm{L}^{-1}$ : (I) $[\mathrm{Al}]_{0}=17.8 \times 10^{-3} \mathrm{~mol} \cdot \mathrm{L}^{-1}$; (II) $[\mathrm{Al}]_{0}=$ $10.7 \times 10^{-3} \mathrm{~mol} \cdot \mathrm{L}^{-1} ;[\mathrm{LA}]_{0}=0.267 \mathrm{~mol} \cdot \mathrm{L}^{-1}:\left(\right.$ III) $[\mathrm{Al}]_{0}=6.68 \times 10^{-3} \mathrm{~mol} \cdot \mathrm{L}^{-1}$.

Table 6.3 Kinetic results of rac-LA polymerization using complexes 5-9 ${ }^{a}$

\begin{tabular}{llcc}
\hline entry & complex & $k_{\text {app }}{ }^{b}\left(\times 10^{-3} \mathrm{~h}^{-1}\right)$ & $k_{\mathrm{p}}{ }^{c}\left(\mathrm{~L} \cdot \mathrm{mol}^{-1} \cdot \mathrm{h}^{-1}\right)$ \\
\hline 1 & $\mathbf{5}$ & 37.3 & 3.49 \\
2 & $\mathbf{6}$ & 30.8 & 2.88 \\
3 & 7 & 269 & $23.8^{d}$ \\
4 & $\mathbf{8}$ & 56.2 & 5.26 \\
5 & $\mathbf{9}$ & 35.5 & 3.32 \\
\hline
\end{tabular}

${ }^{a}$ All polymerizations were carried out in toluene at $70^{\circ} \mathrm{C},[\mathrm{LA}]_{0}=0.534 \mathrm{~mol} \cdot \mathrm{L}^{-1},[\mathrm{Al}]_{0}=10.7 \times 10^{-3}$ $\mathrm{mol} \cdot \mathrm{L}^{-1} .{ }^{b}$ Measured by ${ }^{1} \mathrm{H}$ NMR. ${ }^{c}$ Calculated from: $k_{\mathrm{p}}=k_{\text {app }} /[\mathrm{Al}]_{0} \cdot{ }^{d}$ Deduced from the linear plot of $k_{\text {app }}$ vs $[\mathrm{Al}]_{0}$.

Conversion vs time data were also collected for the polymerization of rac-LA by using 4/2-propanol (toluene; $70{ }^{\circ} \mathrm{C}$; $[\mathrm{LA}]_{0}=0.534 \mathrm{~mol} \cdot \mathrm{L}^{-1}$, $[\mathrm{Al}]_{0}=10.7$ and $17.8 \times 10^{-3}$ $\mathrm{mol} \cdot \mathrm{L}^{-1}$, and $\left.[\mathrm{LA}]_{0}=0.267 \mathrm{~mol} \cdot \mathrm{L}^{-1},[\mathrm{Al}]_{0}=6.68 \times 10^{-3} \mathrm{~mol} \cdot \mathrm{L}^{-1}\right)$. In each case, a significant deviation from a first-order plot between $\ln [\mathrm{LA}]_{0} /[\mathrm{LA}]_{\mathrm{t}}$ vs time was observed at high conversions (Figure 6.11), suggesting a kinetic preference of 4 toward a certain lactide enantiomer. The polymerization of $(S, S)$ - or $(R, R)$-LA applying 4/2-propanol revealed one order of magnitude difference between $k_{\text {app }}$ values at the same aluminum concentration $\left((S, S)\right.$-LA: $k_{\text {app }}=517 \times 10^{-3} \mathrm{~h}^{-1} ;(R, R)$-LA: $k_{\text {app }}=51.0 \times$ 
$10^{-3} \mathrm{~h}^{-1}$, Figure 6.12), indicating that 4 has a marked preference for the polymerization of $(S, S)$-LA over $(R, R)$-LA, which is evidence for the operation of a SCM. However, the kinetic resolution ability of $\mathbf{4}$ toward $\mathrm{rac}$-LA $\left(k_{\mathrm{SS}} / k_{\mathrm{RR}}=10.1\right.$, Table $\mathbf{6 . 4}$, entry 1$)$ is much lower than that of other reported chiral Schiff base aluminum systems $\left(k_{\mathrm{RR}} / k_{\mathrm{SS}}=\right.$ $\sim 20$ reported by Spassky for $(R)$-(SalBinap)AlOCH${ }_{3}{ }^{22}$ and $k_{\mathrm{SS}} / k_{\mathrm{RR}}=\sim 14$ reported by us for $(R, R)$-cyclohexylsalen-AlO $\left.i \operatorname{Pr}^{13}\right)$. Moreover, the introduction of chlorine atoms or methyl groups both lead to a decreased kinetic resolution for $\mathbf{5}$ and $\mathbf{6}$ toward $(R, R)$ - and $(S, S)$-LA. Compared to 4 which shows a preference towards $(S, S)$-LA, 5 has a preference toward $(R, R)$-LA with a $k_{\mathrm{SS}} / k_{\mathrm{RR}}$ value of 0.62 (Table 6.4, entry 2 , Figure 6.13), and 6 with a $k_{\mathrm{SS}} / k_{\mathrm{RR}}$ value of 0.82 (Table 6.4, entry 3 , Figure 6.14).

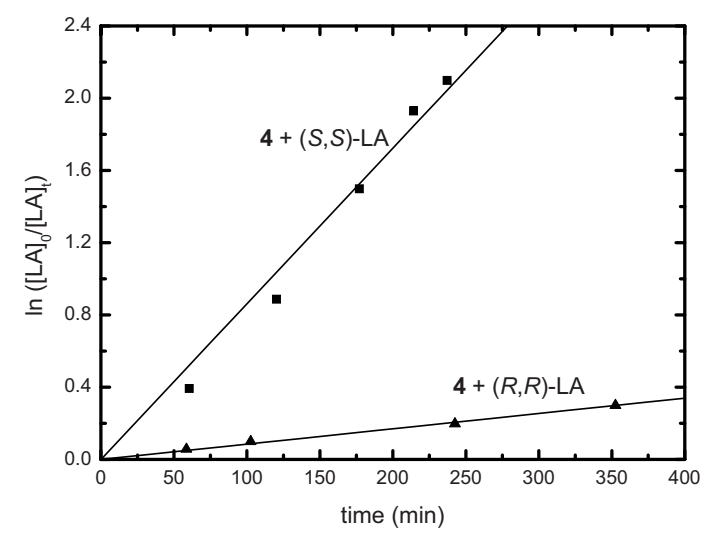

Figure 6.12 First-order kinetic plots for the ROP of $(S, S)$ - and $(R, R)$-LA by applying 4/2-propanol as catalyst/initiator system in toluene at $70{ }^{\circ} \mathrm{C}$ with $[\mathrm{LA}]_{0}=0.534 \mathrm{~mol} \cdot \mathrm{L}^{-1},[\mathrm{Al}]_{0}=10.7 \times 10^{-3}$ $\mathrm{mol} \cdot \mathrm{L}^{-1}:(S, S)$-LA, $k_{\text {app }}=8.62 \times 10^{-3} \mathrm{~min}^{-1} ;(R, R)$-LA, $k_{\text {app }}=0.85 \times 10^{-3} \mathrm{~min}^{-1}$. 


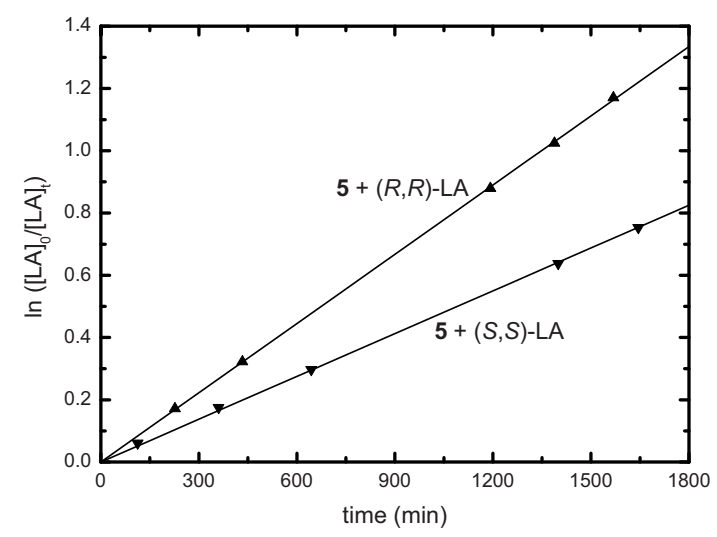

Figure 6.13 First-order kinetic plots for the ROP of $(S, S)$ - and $(R, R)$-LA by applying 5/2-propanol as catalyst/initiator system in toluene at $70{ }^{\circ} \mathrm{C}$ with $[\mathrm{LA}]_{0}=0.534 \mathrm{~mol} \cdot \mathrm{L}^{-1},[\mathrm{Al}]_{0}=10.7 \times 10^{-3}$ $\mathrm{mol} \cdot \mathrm{L}^{-1}:(S, S)$-LA, $k_{\text {app }}=0.458 \times 10^{-3} \mathrm{~min}^{-1} ;(R, R)$-LA, $k_{\text {app }}=0.741 \times 10^{-3} \mathrm{~min}^{-1}$.

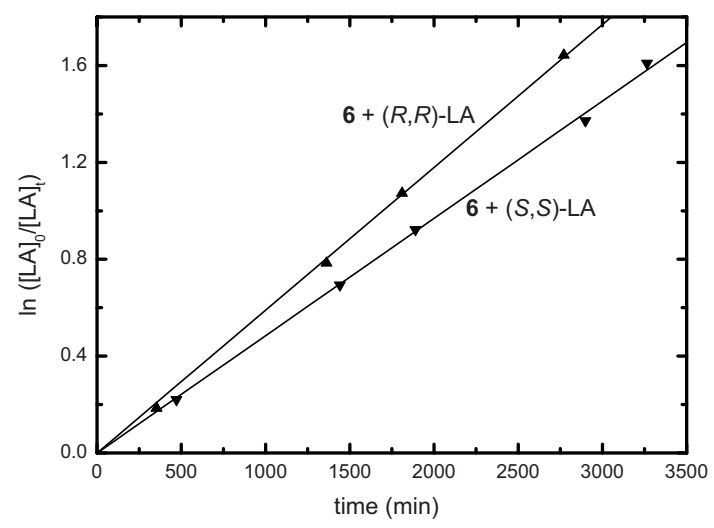

Figure 6.14 First-order kinetic plots for the ROP of $(S, S)$ - and $(R, R)$-LA by applying 6/2-propanol as catalyst/initiator system in toluene at $70{ }^{\circ} \mathrm{C}$ with $[\mathrm{LA}]_{0}=0.534 \mathrm{~mol} \cdot \mathrm{L}^{-1},[\mathrm{Al}]_{0}=10.7 \times 10^{-3}$ $\mathrm{mol} \cdot \mathrm{L}^{-1}:(S, S)$-LA, $k_{\text {app }}=0.484 \times 10^{-3} \min ^{-1} ;(R, R)$-LA, $k_{\text {app }}=0.590 \times 10^{-3} \mathrm{~min}^{-1}$.

Finally, conversion vs time data were collected for the polymerization of $r a c$-LA by using 5/2-propanol or 8/2-propanol and 6/2-propanol or 9/2-propanol (toluene; $70{ }^{\circ} \mathrm{C}$; $\left.[\mathrm{LA}]_{0}=0.534 \mathrm{~mol} \cdot \mathrm{L}^{-1} ;[\mathrm{Al}]_{0}=10.7 \times 10^{-3} \mathrm{~mol} \cdot \mathrm{L}^{-1}\right)$. In each case, first-order kinetics in monomer was observed and the semilogarithmic plots for these polymerizations are 
shown in Figures 6.15a and $\mathbf{6 . 1 5} \mathbf{b}$, respectively. The $k_{\text {app }}$ and $k_{\mathrm{p}}$ values determined are collected in Table 6.3. The $k_{\text {app }}$ and $k_{\mathrm{p}}$ values for $8 / 2$-propanol $\left(k_{\mathrm{p}}=5.26 \mathrm{~L} \cdot \mathrm{mol}^{-1} \cdot \mathrm{h}^{-1}\right)$ and 9/2-propanol $\left(k_{\mathrm{p}}=3.32 \mathrm{~L} \cdot \mathrm{mol}^{-1} \cdot \mathrm{h}^{-1}\right)$ are both slightly higher than those of $\mathbf{5}\left(k_{\mathrm{p}}=\right.$ $\left.3.49 \mathrm{~L} \cdot \mathrm{mol}^{-1} \cdot \mathrm{h}^{-1}\right)$ and $6\left(k_{\mathrm{p}}=2.88 \mathrm{~L} \cdot \mathrm{mol}^{-1} \cdot \mathrm{h}^{-1}\right)$, respectively, which further confirms a positive-cooperation effect between a CEM and a SCM resulting from the occurrence of polymer exchange. The substituents on the salan ligand phenolate rings also affect the polymerization rate significantly. Introducing methyl groups results in a remarkable decrease in $k_{\mathrm{p}}$ from $23.8 \mathrm{~L} \cdot \mathrm{mol}^{-1} \cdot \mathrm{h}^{-1}$ for 7 to $3.32 \mathrm{~L} \cdot \mathrm{mol}^{-1} \cdot \mathrm{h}^{-1}$ for 9 . The $k_{\mathrm{p}}$ values for 5 and $\mathbf{8}$ are much lower than the $k_{\mathrm{p}}$ value of $7\left(23.8 \mathrm{~L} \cdot \mathrm{mol}^{-1} \cdot \mathrm{h}^{-1}\right)$. This indicates that the introduction of chlorine substituents does not enhance the polymerization rate. Several studies indicated that the electron-withdrawing chlorine substituents on the ligand increase the Lewis acidity of the metal center, thereby enhancing the rate of lactone polymerization. ${ }^{23}$ These results indicate that the polymerization rate constant comprises several steps, including monomer approach and binding, nucleophilic addition via the metal-alkoxide bond, and rearrangement causing the cleavage of the acyl-oxygen bond. Although the enhancement of the Lewis acidity of the metal center most probably leads to a more facile approach and binding of the monomer, other changes resulting from the introduction of chlorine atoms may reduce the rate of other steps.

Table 6.4 Apparent rate constants in $(S, S)$ - and $(R, R)$-LA polymerizations using $\mathbf{4}, \mathbf{5}$, and $\mathbf{6}$ as catalysts and 2-propanol as an initiator ${ }^{a}$

\begin{tabular}{|c|c|c|c|c|}
\hline entry & complex & $\begin{array}{l}k_{\text {app },(S, S)-\mathrm{LA}} \\
\left(\times 10^{-3} \mathrm{~h}^{-1}\right)\end{array}$ & $\begin{array}{l}k_{\text {app },(R, R)-\mathrm{LA}} \\
\left(\times 10^{-3} \mathrm{~h}^{-1}\right)\end{array}$ & $k_{\mathrm{SS}} / k_{\mathrm{RR}}$ \\
\hline 1 & 4 & 517 & 51.0 & 10.1 \\
\hline 2 & 5 & 27.5 & 44.5 & 0.62 \\
\hline 3 & 6 & 29.1 & 35.4 & 0.82 \\
\hline
\end{tabular}

${ }^{a}$ All polymerizations were carried out in toluene at $70^{\circ} \mathrm{C},[\mathrm{LA}]_{0}=0.534 \mathrm{~mol} \cdot \mathrm{L}^{-1},[\mathrm{Al}]_{0}=10.7 \times 10^{-3}$ $\mathrm{mol} \cdot \mathrm{L}^{-1}$. 
a

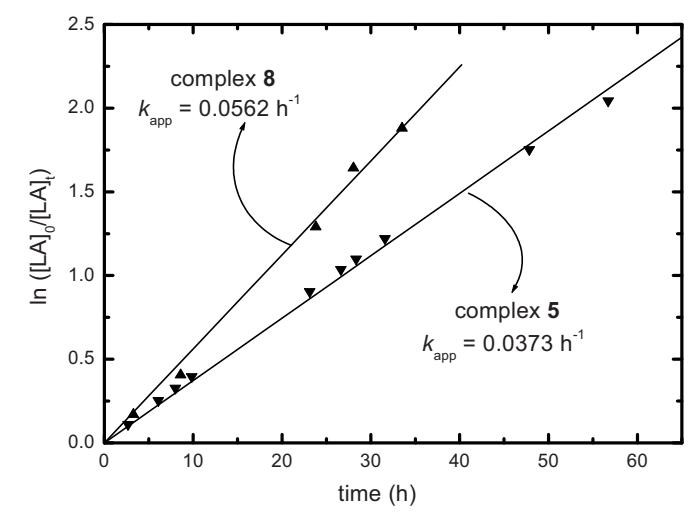

b

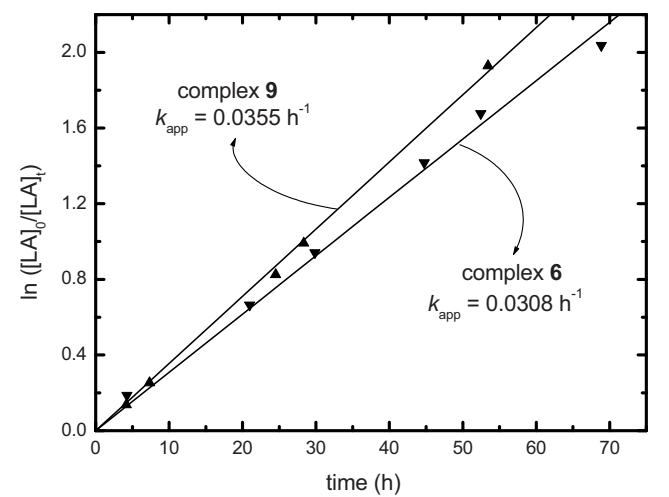

Figure 6.15 (a) First-order kinetic plots for the ROP of rac-LA by 8 and 5 in the presence of 2-propanol in toluene at $70{ }^{\circ} \mathrm{C}$ with $[\mathrm{LA}]_{0}=0.534 \mathrm{~mol} \cdot \mathrm{L}^{-1},[\mathrm{Al}]_{0}=10.7 \times 10^{-3} \mathrm{~mol} \cdot \mathrm{L}^{-1}$. (b) First-order kinetic plots for the ROP of rac-LA by using $\mathbf{9}$ and $\mathbf{6}$ in the presence of 2-propanol in toluene at $70{ }^{\circ} \mathrm{C}$ with $[\mathrm{LA}]_{0}=0.534 \mathrm{~mol} \cdot \mathrm{L}^{-1},[\mathrm{Al}]_{0}=10.7 \times 10^{-3} \mathrm{~mol} \cdot \mathrm{L}^{-1}$.

\section{CONCLUSIONS}

In conclusion, a series of aluminum ethyl complexes ligated by chiral salan ligands was reported. The structures of two different diastereoisomers $\mathbf{a}$ and $\mathbf{b}$ for these aluminum ethyls were revealed by ${ }^{1} \mathrm{H}$ NMR and X-ray analysis. Further NMR measurements demonstrated a slow exchange between a sqp and a tbp geometry for 126 
diastereoisomers $\mathbf{b}$ at low temperatures. In the presence of 2-propanol, the aluminum ethyl complexes acted as efficient initiators for the ROP of rac-LA and meso-LA. Microstructural analysis of the resulting polymers and detailed kinetics indicate the coexistence of a CEM and a SCM in lactide polymerization. A propagating chain exchange mechanism was proposed to explain the enhanced heteroselectivity and activity of $\mathbf{8}$ compared to those of $\mathbf{5}$ toward rac-LA polymerization. Furthermore, kinetic analysis revealed first-order kinetics for 7 in both rac-LA monomer and catalyst, as well as a kinetic resolution for $\mathbf{4}$ toward $(S, S)$-LA. Future work will focus on the separation of diastereoisomers $\mathbf{a}$ and $\mathbf{b}$ to explore their different catalytic behavior toward lactide polymerization in detail.

\section{ACKNOWLEDGEMENT}

The authors thank the Chinese Academy of Sciences and the Royal Netherlands academy of Arts and Sciences for the CAS-KNAW joint training $\mathrm{PhD}$ program (06PhD09).

\section{REFERENCES AND NOTES}

[1] Atwood, D. A.; Benson, J.; Jegier, J. A.; Lindholm, N. F.; Martin, K. J.; Pitura, R. A.; Rutherford, D. Main Group Chem. 1995, 1, 99.

[2] Egami, H.; Katsuki, T. J. Am. Chem. Soc. 2007, 129, 8940-8941.

[3] Egami, H.; Katsuki, T. Synlett 2008, 10, 1543.

[4] Bryliakov, K. P.; Talsi, E. P.; Eur. J. Org. Chem. 2008, 19, 3369.

[5] Sun, J.; Zhu, C.; Dai, Z.; Yang, M.; Pan, Y.; Hu, H. J. Org. Chem. 2004, 69, $8500-8503$.

[6] Dai, Z.; Zhu, C.; Yang, M.; Zheng, Y.; Pan, Y. Tetrahedron:Asymmetry 2005, 16, 605 .

[7] Dai, Z.; Shao, M.; Hou, X.; Zhu, C.; Zhu, Y.; Pan, Y. Appl. Catal., A 2005, 19, 898. 
[8] Yeori, A.; Groysman, S.; Goldberg, I.; Kol, M. Inorg. Chem. 2005, 44, 4466-4468.

[9] Yang, H.; Wang, H.; Zhu, C. J. Org. Chem. 2007, 72, 10029-10034.

[10] Yeori, A.; Goldberg, I.; Shuster, M.; Kol, M. J. Am. Chem. Soc. 2006, 128, 13062-13063.

[11] Segal, S.; Yeori, A.; Shuster, M.; Rosenberg, Y.; Kol, M. Macromolecules 2008, $41,1612-1617$.

[12] Achiral salan aluminum methyl complexes and their application in rac-LA polymerization has been reported: Hormnirum, P.; Marshall, E. L.; Gibson, V. C.; White, A. J. P.; Williams, D. J. J. Am. Chem. Soc. 2004, 126, 2688-2689.

[13] (a) Zhong, Z.; Dijkstra, P. J.; Feijen, J. Angew. Chem. Int. Ed. 2002, 4510-4513; (b) Zhong, Z.; Dijkstra, P. J.; Feijen, J. J. Am. Chem. Soc. 2003, 125, 11291-11298.

[14] Larrow, J. F.; Jacobsen, E. N.; Gao, Y.; Hong, Y.; Nie, X.; Zepp, C. M. J. Org. Chem. 1994, 59, 1939-1942.

[15] (a) Addison, A. W.; Rao, T. N.; Reedijk, J.; Van Rijn, J.; Verschoor, G. C. J. Chem. Soc. Dalton Trans. 1984, 1349; (b) Atwood, D. A.; Hill, M. S.; Jegier, J. A.; Rutherford, D. Organometallics 1997, 16, 2659-2664.

[16] Duxbury, J. P.; Warne, J. N. D.; Mushtaq, R.; Ward, C.; Thornton-Pett, M.; Jiang, M.; Greatrex, R.; Kee, T. P. Organometallics 2000, 19, 4445-4457.

[17] Atwood, D. A. Coord. Chem. Rev. 1997, 165, 267.

[18] (a) Akitt, J. W.; Duncan, R. H. J. Magn. Reson. 1974, 15, 162. (b) Kriz, O.; Casensky, B.; Lycka, A.; Fusek, J.; Hermanek, S. J. Magn. Reson. 1984, 60, 375.

[19] Nomura, N.; Aoyama, T.; Ishii, R.; Kondo, T. Macromolecules 2005, 38, 5363-5366.

[20] Ma, H.; Melillo, G.; Oliva, L.; Spaniol, T. P.; Englert, U.; Okuda, J. J. Chem. Soc. Dalton Trans. 2005, 721.

[21] Ovitt, T. M.; Coates, G. W. J. Am. Chem. Soc. 2002, 124, 1316-1326.

[22] Spassky, N.; Wisniewski, M.; Pluta, C.; Le Borgne, A. Macromol. Chem. Phys. 1996, 197, 2627-2637. 
[23] (a) Cameron, P. A.; Jhurry, D.; Gibson, V. C.; White, A. J. P.; Williams, D. J.; Williams, S. Macromol. Rapid Commun. 1999, 20, 616; (b) Jhurry, D.; Bhaw-Luximon, A.; Spassky, N. Macromol. Symp. 2001, 175, 67; (c) Du, H.; Pang, X.; Yu, H.; Zhuang, X.; Chen, X.; Cui, D.; Wang, X.; Jing, X. Macromolecules 2007, 40, 1904.

[24] Baran, J.; Duda, A.; Kowalski, A.; Szymanski, R.; Penczek, S. Macromol. Rapid Commun. 1997, 18, 325. 


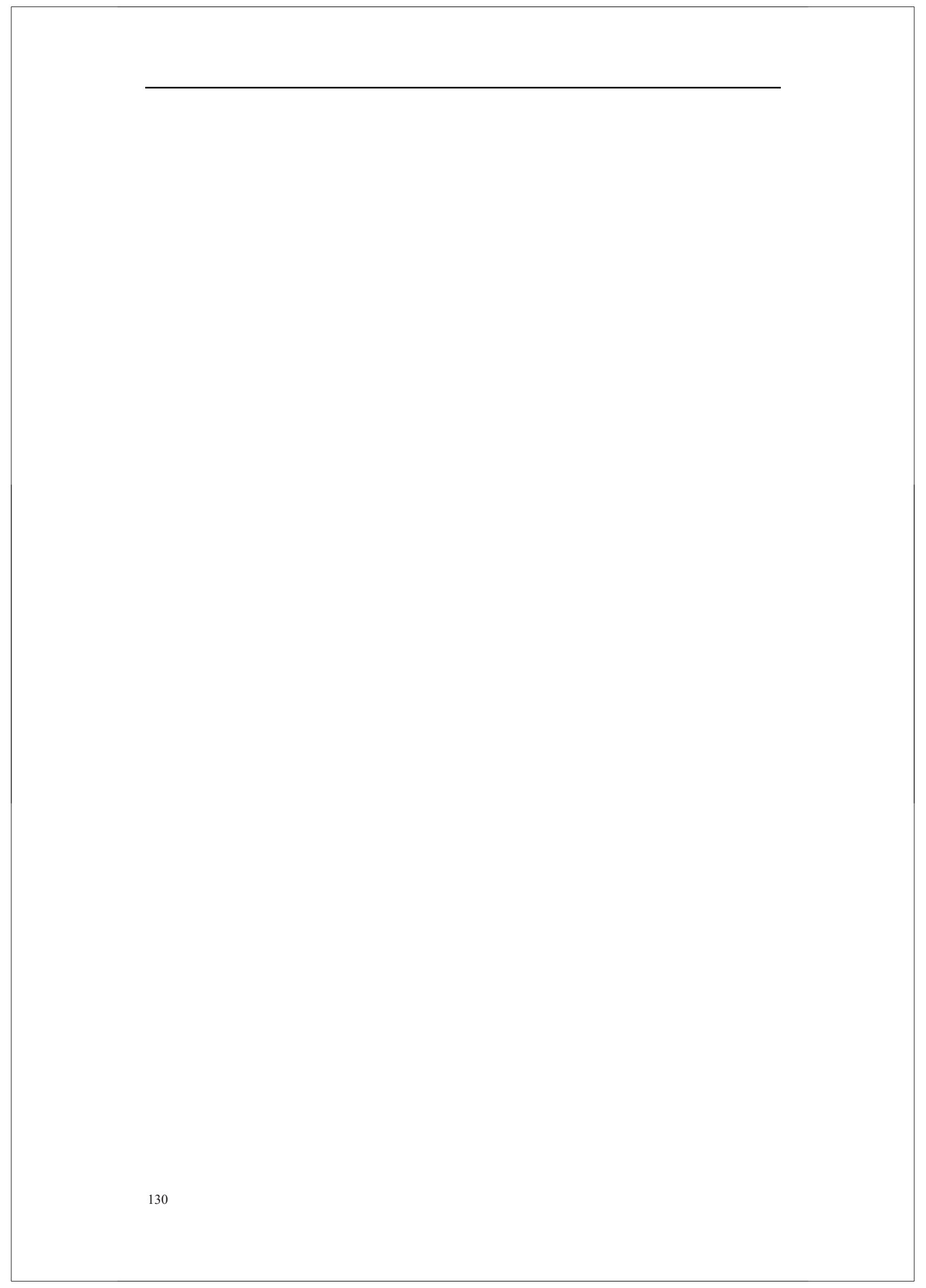




\section{Summary}

Biodegradable poly(lactide) (PLA) homopolymer and its copolymers are excellent materials to be applied as ecological commodity thermoplastics compared to traditional nondegradable plastics based on petrol resources. The development of synthetic pathways and catalyst/initiator systems to produce PLAs with narrow molecular weight distribution and controlled molecular weight has been a continuous topic in polymer chemistry. Especially, stereochemistry will be generated when rac-LA or meso-LA are applied in these polymerizations. Many researches nowadays are focused on the formation of stereoregular PLAs by using different single-site metal complexes. The aims of this research described in this thesis have been established to develop new single-site five-coordinated Schiff base (salen) and phenoxyamine (salan) aluminum complexes that could exert stereocontrol over lactide polymerization

After a short general introduction to the stereochemistry of PLAs in chapter 1, the advance of organometallic single-site catalysts for the stereoselective polymerization of rac- or meso-LA is reviewed in chapter 2. Diverse metal complexes based on different auxiliary ligand surroundings have been summarized, and strategies to achieve a high level of stereocontrol have been emphasized.

A pilot study on a series of achiral bis(salicylidene) Schiff base aluminum ethyls and three representative aluminum isopropoxides were synthesized.. Their structures were characterized by X-ray analysis to reveal their solid state structures and NMR measurements to identify their solution structures (chapter 3), demonstrating that the structural factors of the auxiliary ligand influence the geometries of the aluminum complexes. The activity and the stereoselectivity of this series of (in situ-formed) bis(salicylidene) aluminum isopropoxides toward the ROP of rac-LA are described in chapter 4 . The polymerization data indicate that the substituents on the phenolic rings, the number of carbon atoms in the diimine-bridge, and the substituents on the diimine-bridge all exerted a significant influence on the rate of the polymerization and the tacticity of the polymers isolated. The polymerization kinetics reveal that the 
propagation chain exists as an equilibrium between monomeric and dimeric species when bulky substituents are absence at the ortho position of the phenol group.

A series of aluminum ethyl and isopropoxide complexes ligated by $N, N, N, N$-tetradentate bis(pyrrolidene) Schiff base ligands that act as single-site catalysts for the polymerization of $(S, S)$-LA to isotactic PLA, rac-LA to predominant isotactic PLA, and meso-LA to atactic PLA were reported in chapter 5. Kinetic studies indicate that the activity of the bis(pyrrolidene) Schiff base aluminum initiator system towards lactide polymerization decreases in the order of: $(S, S)$-LA $>$ rac-LA $>$ meso-LA. Microstructural analysis of the polymers formed, as well as kinetic data, show that the gem methyls on the diimine-bridge not only enhance the isoselectivity but also the polymerization rate. However, the methyl substituents at the ortho position of the pyrrolic rings both decrease the polymerization rate and the isoselectivity. Furthermore, kinetic analysis reveals that the rac-LA polymerization using these catalyst/initiator systems are first-order with respect to both monomer and catalyst. Finally, comparing $k_{\mathrm{p}}$ values reveals that the polymerization rate of $\mathbf{2} \mathbf{b}$ is higher than that of 2a/2-propanol, which indicates the polymerization rate of the aluminum isopropoxide may be slowed by the in-situ reaction rate between the aluminum ethyl and 2-propanol.

A series of $(R, R)$ enantiomerically pure chiral salan aluminum ethyl complexes 4-6 and their racemic complexes 7-9 were reported in chapter 6. The structures of two different diastereoisomers a and $\mathbf{b}$ for these aluminum ethyls were revealed by ${ }^{1} \mathrm{H}$ NMR and X-ray analysis. Further NMR measurements demonstrated a slow exchange between a sqp and a tbp geometry for diastereoisomers $\mathbf{b}$ at low temperatures. In the presence of 2-propanol, these aluminum ethyl complexes acted as efficient initiators for the ROP of rac-LA and meso-LA. Microstructural analysis of the resulting polymers and detailed kinetics revealed the coexistence of chain-end control and site control mechanism in lactide polymerization. Furthermore, kinetic analysis revealed a first-order kinetic for 7 in both monomer and catalyst, as well as a kinetic resolution for 4 toward $(S, S)$-LA. 


\section{Samenvatting}

Poly(lactide) (PLA) homopolymeren en copolymeren zijn, vergeleken met traditionele niet-degradeerbare plastics gebaseerd op aardolieproducten, biodegradeerbare materialen die toepasbaar zijn als ecologisch vriendelijke plastics en als kunststoffen voor biomedische toepassingen. De ontwikkeling van syntheseroutes en katalysator/initiator systemen om PLA's met een gewenste molmassa te maken vanuit lactide is een belangrijk onderzoeksgebied binnen de polymeerchemie. Wanneer racemisch lactide of meso lactide wordt toegepast in deze polymerisatie speelt de stereochemie van de polymeerketens die verkregen worden een belangrijke rol in de uiteindelijke eigenschappen van het polymeer. Tegenwoordig wordt veel onderzoek verricht naar de vorming van PLA's met een regelmatige stereochemische structuur door verschillende metaalcomplexen als katalysator te gebruiken in de ringopening polymerisatie van lactides. Het doel van het onderzoek dat beschreven staat in dit proefschrift was om nieuwe Schiff-base (salen) en phenoxyamine (salan) aluminium complexen te ontwikkelen met een enkele initiërende groep, die stereochemisch gecontroleerde lactide polymerisatie mogelijk zou kunnen maken.

$\mathrm{Na}$ een korte inleiding over de stereochemie van PLA's in Hoofdstuk 1 wordt de huidige stand van zaken wat betreft organometaal katalysatoren voor stereoselectieve polymerisatie van racemisch en meso-lactide besproken in Hoofdstuk 2. Er wordt een overzicht gegeven van diverse complexen waarin het metaalion is omgeven door een chiraal of niet chiraal ligand. Strategieën om een grote mate van stereocontrole in de polymerisatie te bereiken worden benadrukt.

De resultaten van een eerste studie naar de synthese en karakterisering van een serie niet chirale bis(salicylidene) Schiff base aluminium ethyl en drie representatieve aluminium isopropoxide complexen worden beschreven in Hoofdstuk 3. De structuren van deze kristallijne verbindingen werden bepaald met behulp van röntgenanalyse en NMR werd toegepast om de structuren in oplossing te analyseren. De resultaten tonen aan dat de structuur van het ligand de geometrie van de aluminium complexen beïnvloedt. 
De activiteit en stereoselectiviteit van (in situ gevormde) bis(salicylidene) aluminium isopropoxides in de ringopening polymerisatie van rac-LA staan beschreven in Hoofdstuk 4. De polymerisatieresultaten tonen aan dat de substituenten op de fenolringen, het aantal koolstofatomen in de diimine brug en de substituenten op de diimine brug allemaal een grote invloed hebben op de polymerisatiesnelheid en de tacticiteit van de verkregen polymeren. De polymerisatiekinetiek laat zien dat er een evenwicht bestaat tussen een monomere en dimere vorm van de katalysator wanneer grote alkylsubstituenten afwezig zijn ortho ten opzichte van de fenolgroep.

Een serie complexen van een aluminium-ethyl of aluminium-isopropoxide met $N, N, N, N$-tetradentate bis(pyrrolidene) Schiff-base liganden werden vervolgens gemaakt en de polymerisatie van $(S, S)$-LA tot isotactisch PLA, rac-LA tot voornamelijk isotactisch PLA, en meso-LA tot atactisch PLA wordt besproken in Hoofdstuk 5. Kinetisch onderzoek toont aan dat de activiteit van het bis(pyrrolidene) Schiff-base aluminium initiator systeem ten aanzien van de polymerisatie van lactide afneemt in de volgorde: $(S, S)$-LA $>$ rac-LA > meso-LA. Microstructuur analyses van de gevormde polymeren, evenals kinetische data, laten zien dat de geminale methyl groepen in de diimine brug zowel de isoselectiviteit als de polymerisatiesnelheid verbeteren. De methylsubstituenten op de ortho-positie van de pyrrool ringen verlagen echter zowel de polymerisatiesnelheid als de isoselectiviteit. Verder liet kinetische analyse zien dat polymerisatie van rac-LA met deze katalysator/initiator systemen eerste orde is in zowel monomeer als katalysator. Ten slotte laat een vergelijking van de propagatie reactie snelheidsconstanten zien dat de polymerisatiesnelheid met een aluminium isopropoxide hoger is dan de polymerisatiesnelheid met een in situ gevormd aluminium isopropoxide.

Een serie chirale salan aluminium ethyl complexen gemaakt uit $(R, R)$ enantiomeer zuivere of racemische salan liganden wordt besproken in Hoofdstuk 6. ${ }^{1} \mathrm{H}$ NMR en röntgenanalyse lieten zien dat er twee verschillende diastereoisomere aluminium ethyl complexen a en b ontstonden. Gedetailleerde NMR analyse liet zien dat er een langzame uitwisseling in oplossing plaatsvindt tussen structuren met een rechthoekig vlakke en een trigonale bipyramide geometrie voor diastereoisomeren b bij lage 134 
temperaturen. In aanwezigheid van 2-propanol zijn deze aluminium ethyl complexen efficiënte initiatoren voor de ROP van rac-LA en meso-LA. Microstructuur analyse van de verkregen polylactides en gedetailleerde kinetische analyse toonden aan dat de polymerisatie reactie gecontroleerd wordt door zowel de groeiende keten als door het chirale ligand. 


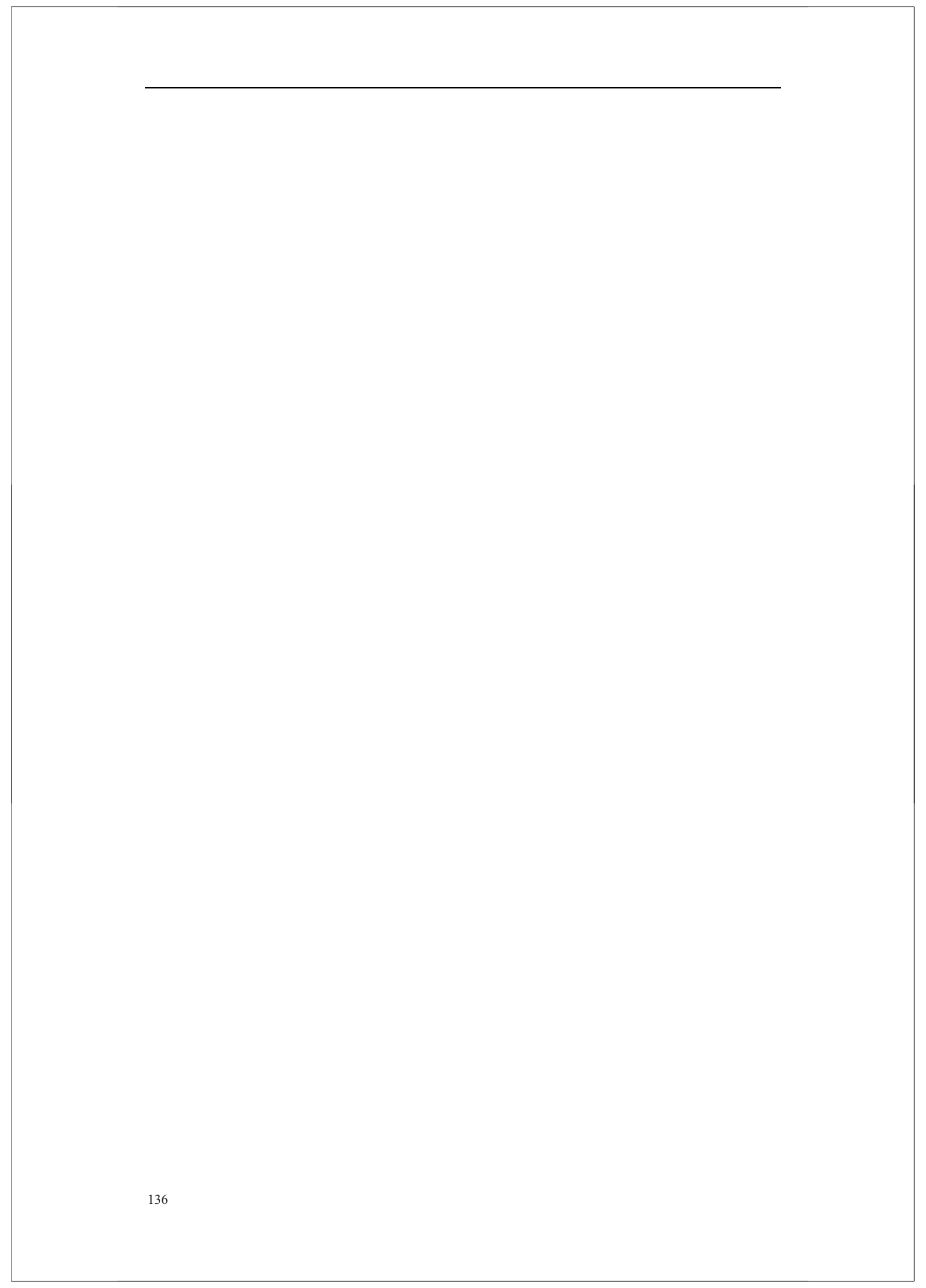




\section{Acknowledgements}

When I was a child, I never imagine that I will be a chemist. But after I have finishes my Ph.D training, I would say: yes, from now on, you will dedicate yourself into chemistry. Which encourage me to do this is that in my Ph.D. peroid, I joined two groups in the Netherlands and China, respectively, under the supervision of prof. dr. Jan Feijen and prof. dr. Xuesi Chen to study catalysis\&polymerization. This fantastic experience will benefit my career a lot.

Foremost, I would like to give my deepest thanks to my Dutch promoter, prof. dr. Jan Feijen, for kindly giving me such an opportunity to work in the PBM group. I appreciate the great help professor gave me when I first came to Twente. I will never forget lots of insightful discussions we have had, even on the day just before I would leave. Jan, wish you a happy life forever.

I also owe my wholehearted thanks to my Chinese promoter, prof. dr. Xuesi Chen for giving me admission to enter the biopolymer group in CIAC and also, the chance to carry on my further study in the Netherlands. Professor Chen not only instructed me how to be a good researcher, but also teaches me how to be a nice person, which I think is the most important in my whole life. Professor Chen, I will try my best, not to disappoint you in my whole career.

Dr. Piet Dijkstra, you are not only my co-promoter and direct supervisor, but also my close friend in research. When I look at this thesis, the first person comes into my mind is you. You give me suggestions on how to go further in experiments, you make models to make discussions easy, and you make revisions to all my papers. The first version of this thesis is totally different from the last one, which may be attributed to your great work. 
The thesis could not be accomplished without the contribution from dr. Aldrik Velders (SMCT group, MESA+ institute, University of Twente) and Mrs. Fengying Jing (Changchun Institute of Applied Chemistry, Chinese Academy of Sciences) for their elegant work in NMR measurement to determine the molecular structure in solution. Aldrik, I enjoyed talking with you very much, and have learned a lot of NMR knowledge from your work. Fengying, thank you very much for the always-quick measurement although I know you always have so much work to do. Without you, my samples will all be ruined by the air and moisture. I also obliged to Mrs. Bianca Snellink-Ruel (SMCT group, MESA+ institute, University of Twente) for all the homonuclear decoupled ${ }^{1} \mathrm{H}$ NMR determination.

I am awfully thankful to the people from PBM group for the happy time I enjoyed here. Especially, I shall give my thanks to my Chinese friends in the group, Yan, Rong, Wei, Chao, and Zheng, we have experienced two years of great time. Without you, there will be a huge mass for my life here. Special thanks are dedicated to my labmates, Sytze Buwalda, Niels Sijbrandi, for sharing almost all our labtime. Thank Hans, Erhan, Gregory, Janine, Jung Seok, Andries, Ferry, Martin, and Jos. I will never forget all of you. The administrative and/or technical supports from Karin Hendriks, Hetty ten Hoopen, Marc Ankone, and Zlata Rekenji are gratefully acknowledged.

I am also grateful to the people of the biopolymer group in CIAC, CAS. Zhaohui, Yongkun, Xuan, you are all my teachers in Schlenk technology. I appreciate your selfless instructions and advices. I also enjoy the happy starcraft time with Xueyu, Chao, Chaoliang, Zhigang, Yadong, Jun, Le, Jialiang, and Guojun, although almost all the time I will be the loser. Thank Nuo and Jia for taking all the $300 \mathrm{~Hz}$ NMR and GPC measurements. The administrative and/or technical supports from dr. Xiuli Zhuang, dr. Huayu Tian, and dr. Jingru Sun are also appreciated.

Yuhan, Ying, Guanghua, and Youhua, you are all my best friends in these six years. I wish our friendship would last forever 
Most of all, I am grateful to my parents, my parents-in-law for the inexhaustible and unconditional love and support. Wherever and whenever it is, I am always aware that I am not single. I own my earnest thanks to my wife Jing for her kindness and forgiveness. My dear Jing, you give me a thoughtful soul and a brand-new life. I cannot wait to go back to live a happy life with you and little Millet. 


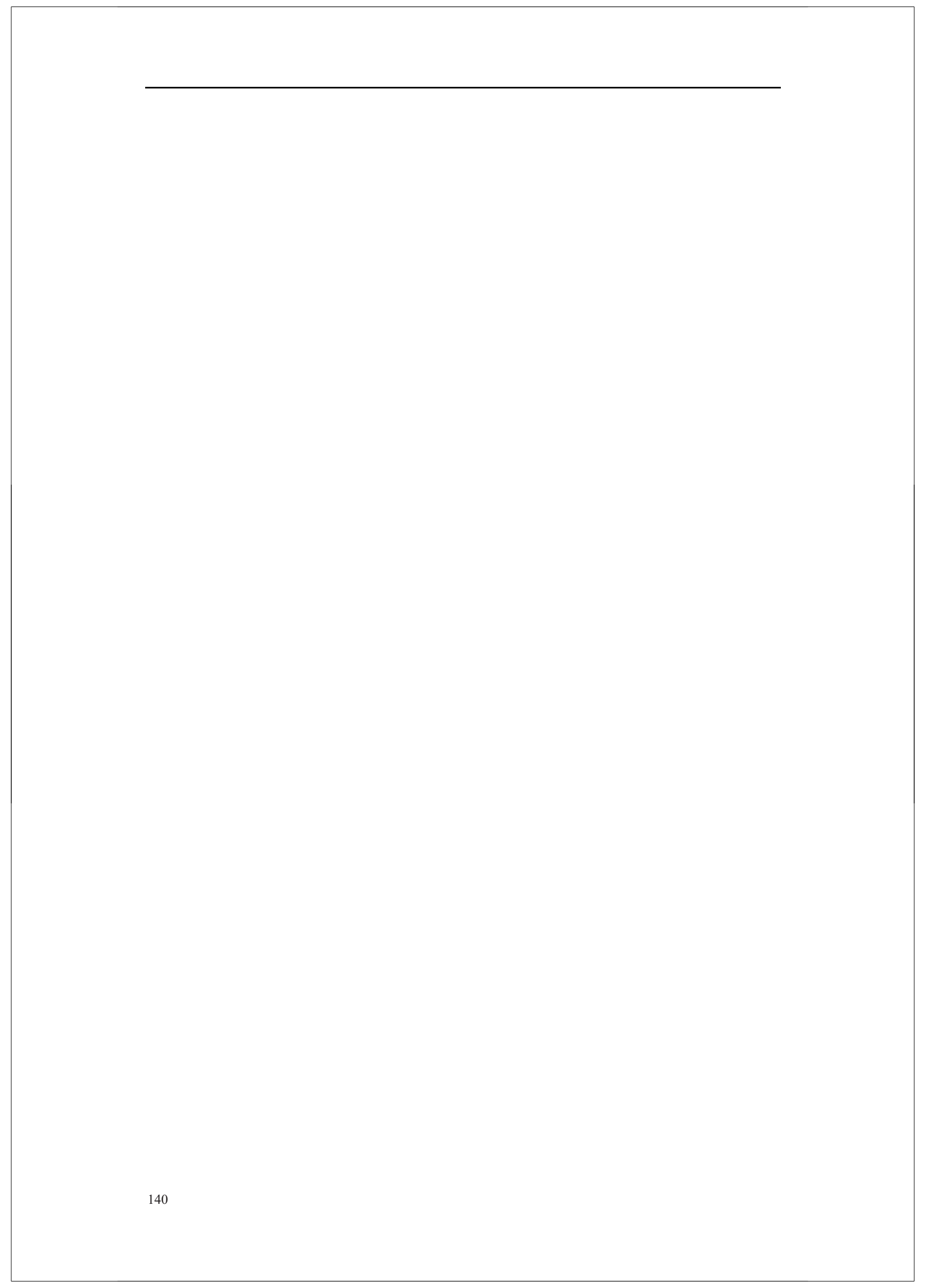




\section{Curriculum Vitae}
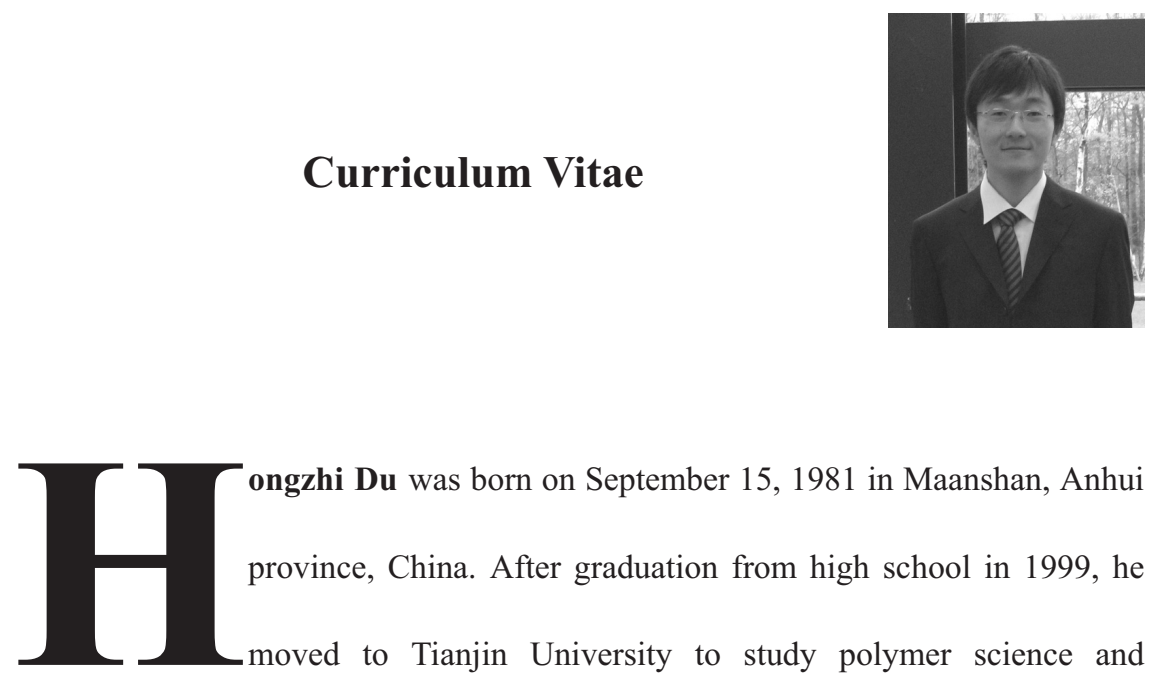

ongzhi Du was born on September 15, 1981 in Maanshan, Anhui province, China. After graduation from high school in 1999, he moved to Tianjin University to study polymer science and materials and acquired his B.Sc. degree in 2003. Subsequently, he was admitted to Changchun Institute of Applied Chemistry, Chinese Academy of Sciences, as a master student for further studies with a major in Polymer Chemistry. Under the supervision of prof. dr. Xuesi Chen, he started the research on the development of five-coordinated aluminum complexes and exploring their application in stereoselective polymerization of rac-lactide. In 2005, he was promoted to a master-PhD student. In 2007, in a joint program training PhD student (CAS-KNAW project 06PhD09), he joined the Polymer Chemistry and BioMaterials group of the faculty of Science and Technology, Twente University, the Netherlands. Under the supervision of prof. dr. Jan Feijen, he expanded his work on catalytic systems for meso-lactide polymerization. Most of his work was published in international journals and/or presented in international meetings. 


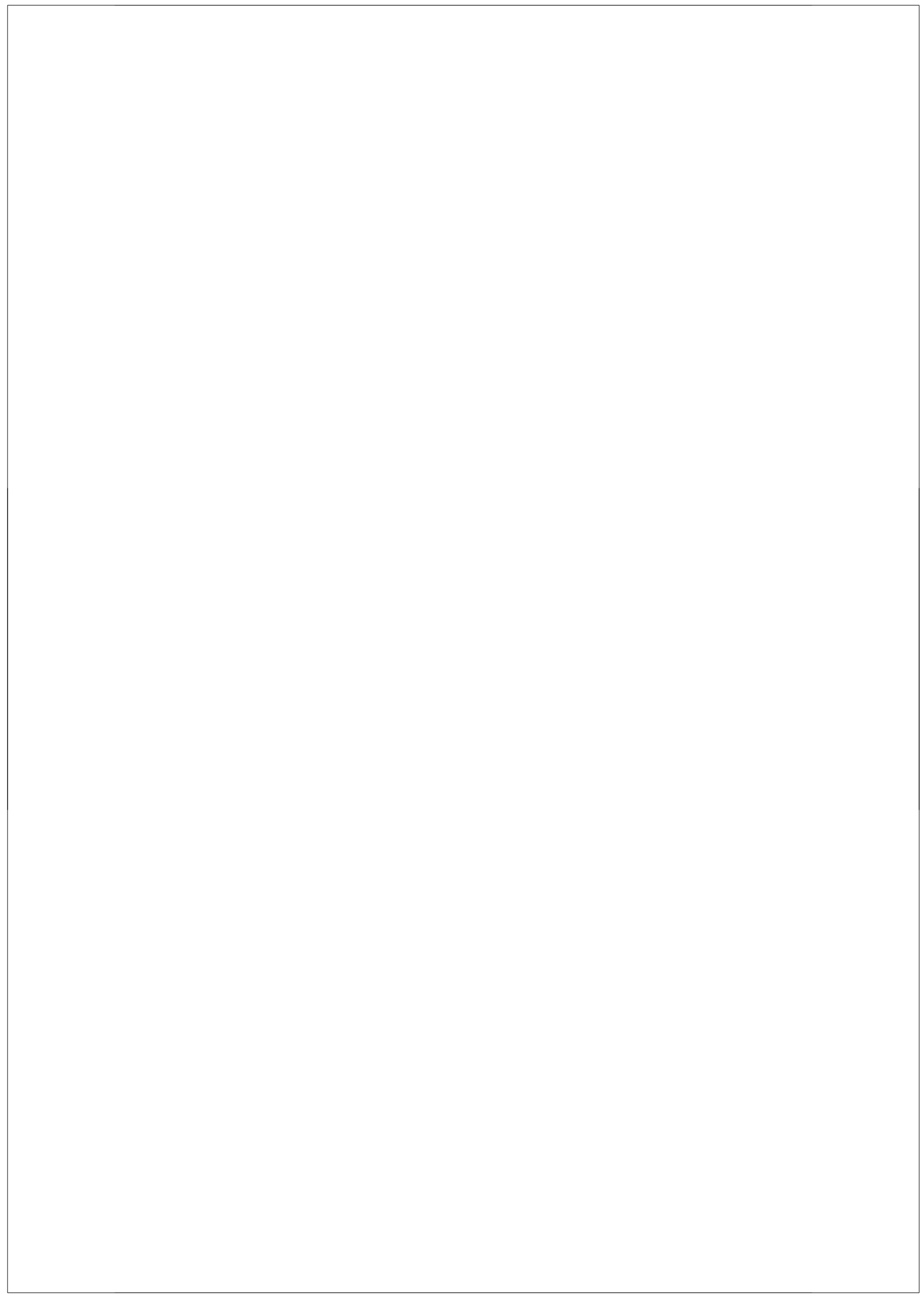

